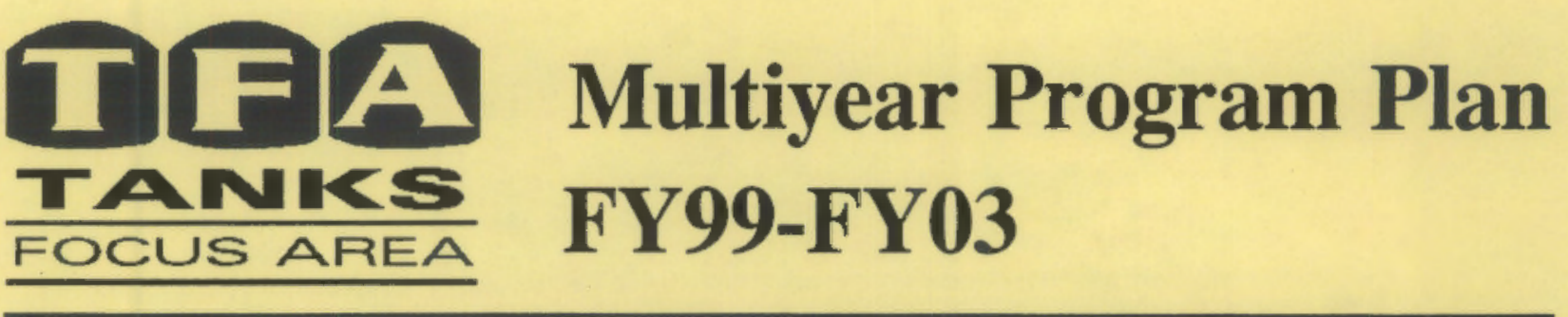




\title{
DISCLAIMER
}

This report was prepared as an account of work sponsored by an agency of the United States Government. Neither the United States Government nor any agency thereof, nor Battelle Memorial Institute, nor any of their employees, makes any warranty, express or implied, or assumes any legal liability or responsibility for the accuracy, completeness, or usefulness of any information, apparatus, product, or process disclosed, or represents that its use would not infringe privately owned rights. Reference herein to any specific cornmercial product, process, or service by trade name, trademark, manufacturer, or otherwise does not necessarily constitute or imply its endorsement, recommendation, or favoring by the United States Government or any agency thereof, or Battelle Memorial Institute. The views and opinions of authors expressed herein do not necessarily state or reflect those of the United States Government or any agency thereof.

\author{
PACIFIC NORTHWEST NATIONAL LABORATORY \\ operated by \\ BATTELLE \\ for the \\ UNITED STATES DEPARTMENT OF ENERGY \\ under Contract DE-ACO6-76RLO 1830
}

\author{
Printed in the United States of America \\ Available to DOE and DOE contractors from the \\ Office of Scientific and Technical Information, P.O. Box 62, Oak Ridge, TN 37831; \\ prices available from (615) 576-8401.
}

Available to the public from the National Technical Information Service, U.S. Department of Commerce, 5285 Port Royal Rd., Springfield, VA 22161

83 This document was printed on recycled paper. 


\section{TFA Multiyear Program Plan FY99-FY03}

September 1998

Prepared for

the U.S. Department of Energy

under Contract DE-AC06-76RLO 1830

Pacific Northwest National Laboratory

Richland, Washington 99352 



\section{Contents}

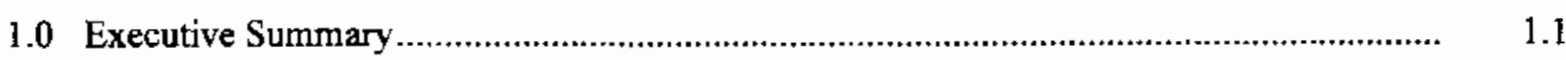

2.0 Program Backgound and Problem Description .................................................... 2.1

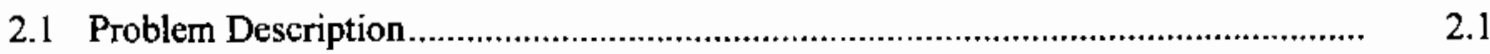

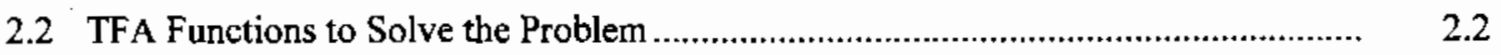

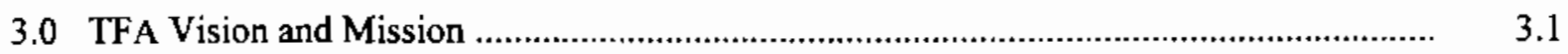

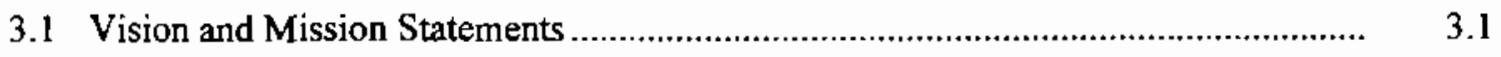

3.2 TFA's Relation to the Focus Area Centered Approach...........................................

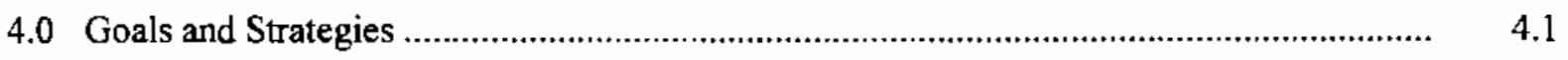

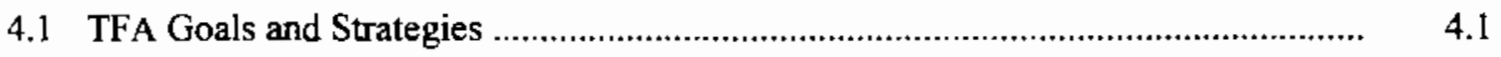

4.2 TFA's Support to EM's Major Science and Technology Thrusts .............................. 4.2

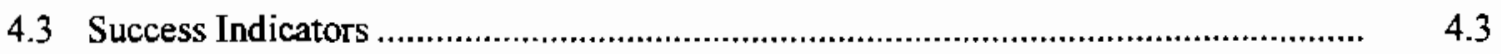

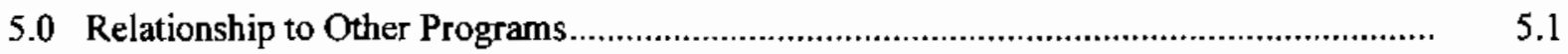

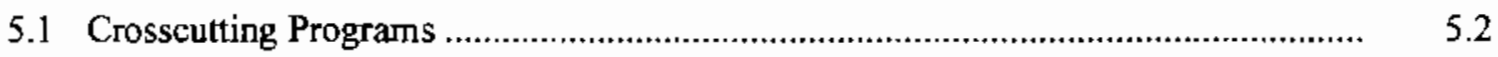

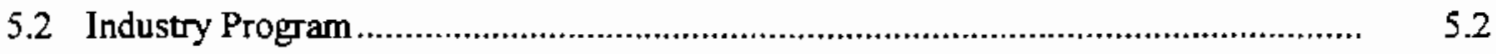

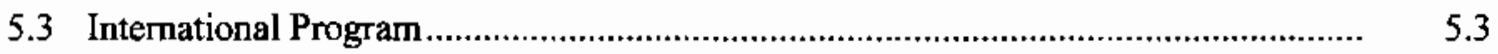

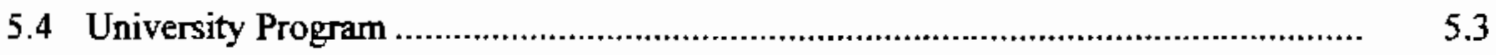

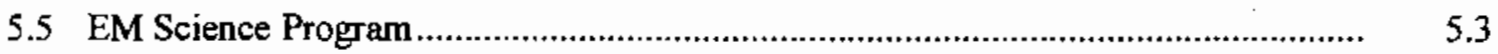

5.6 Accelerated Site Technology Deployment Program .............................................. 5.4

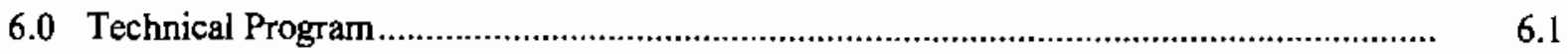

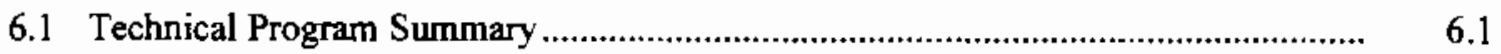

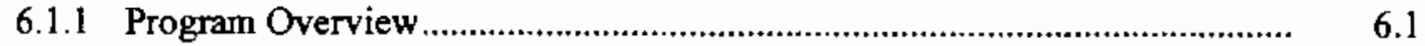

6.1.2 Technical Program Structure ....................................................................... 6.2

6.1.3 Technical Strategies and Investments...................................................... $\quad 6.2$ 
Problem Elements

1.1.1.1 Monitor Tank Integrity/Avoid Corrosion ..................................................... 6.17

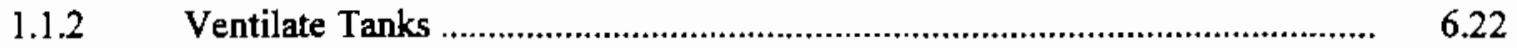

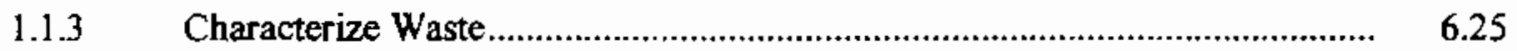

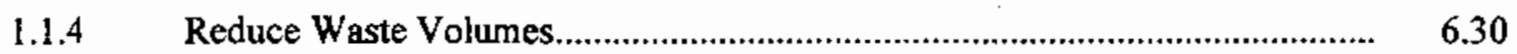

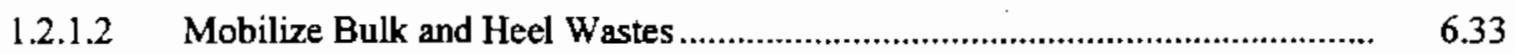

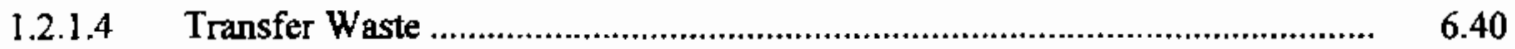

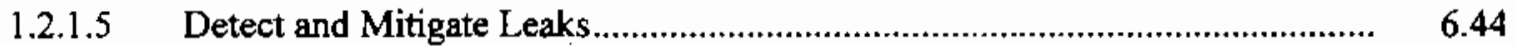

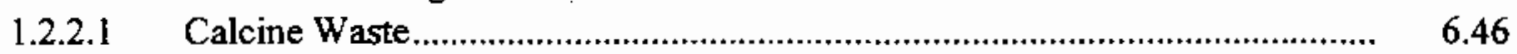

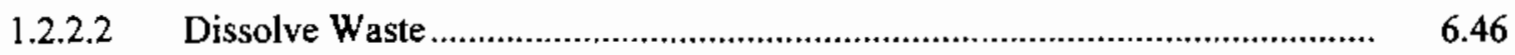

1.2.2.3 Prepare Retrieved Waste for Transfer and Pretreatment ................................. 6.49

1.2.2.4 Clarify Liquid Stream............................................................................ 6.51

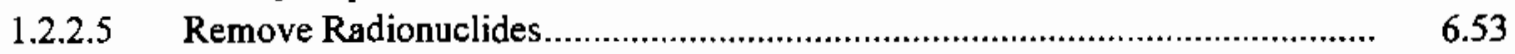

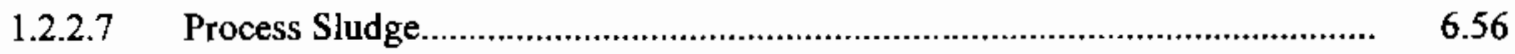

1.2.2.8 Prepare Pretreated Waste for Immobilization …................................................. 6.59

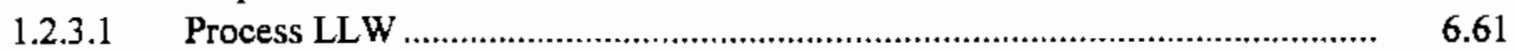

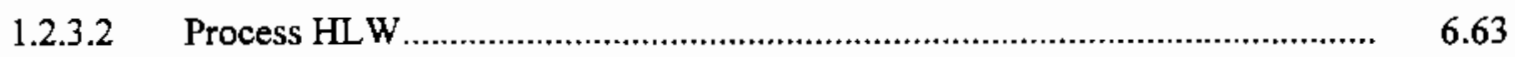

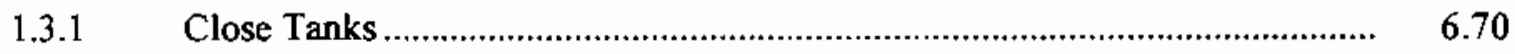

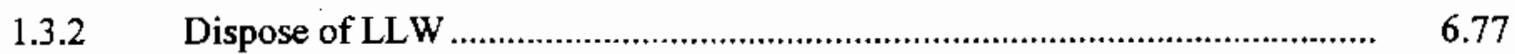

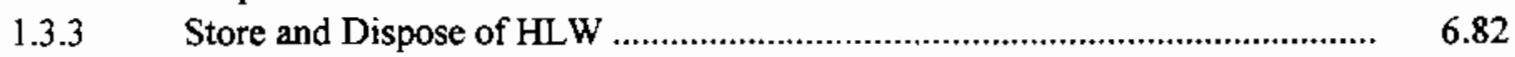

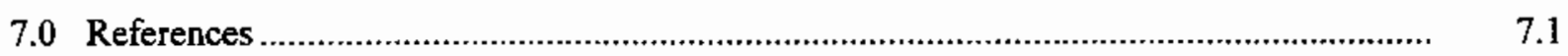

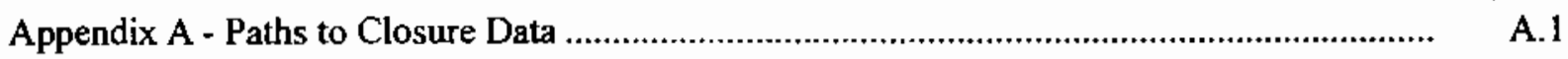

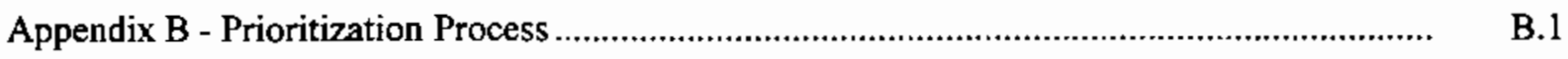

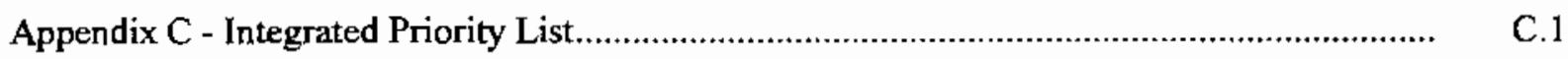

Appendix D - Gantt Charts of Major TFA Milestones .................................................... D.1

Appendix E - Tanks Focus Area Otganization ........................................................... E.1

Appendix F - Crosswalk of Work Packages to Budget Formulation Product Lines .................. F. F.1

Appendix G - Description of DOE's System for Remediating Tank Waste (not provided) ....... G.1

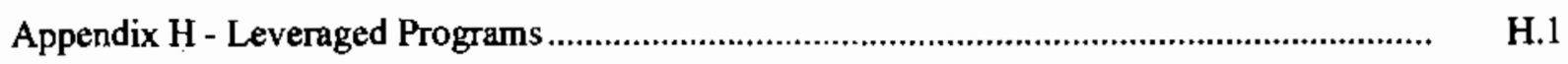




\section{Figures}

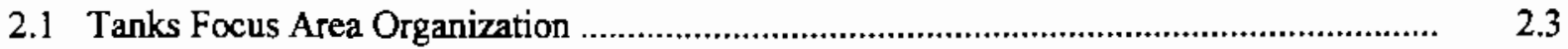

5.1 Tanks Focus Area Conceptual Strategy Model .....................................................

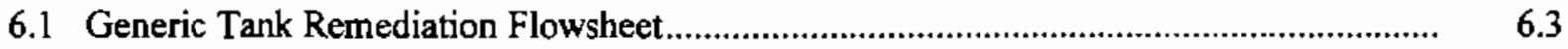

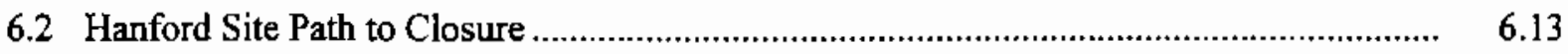

6.3 Idaho National Engineering and Engineering Laboratory Path to Closure ........................

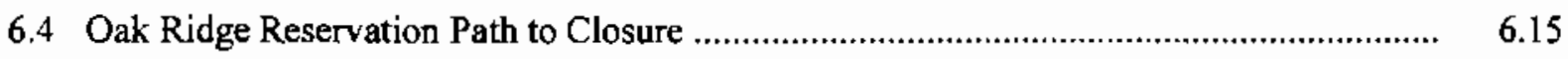

6.5 Savannah River Site Path to Closure .............................................................................

\section{Tables}

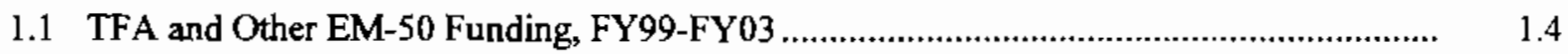

2.1 Summary of Paths to Closure Data on High-Level Waste Mission................................. 2.2

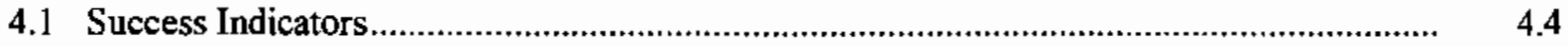

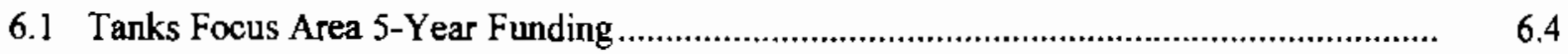





\section{Acronyms and Abbreviations}

\begin{tabular}{|c|c|}
\hline AEAT & AEA Technology \\
\hline $\mathrm{AM}$ & assistant manager \\
\hline ASTD & Accelerated Site Technology Deployment \\
\hline BDAT & best demonstrated available technology \\
\hline BVEST & Bethel Valley Evaporator Service Tank \\
\hline CCD & countercurrent decantation \\
\hline CERCLA & Comprehensive Environmental Response, Compensation, and Liability Act \\
\hline CIF & Consolidated Incineration Facility \\
\hline CSEE & Confined Sluicing End-Effector \\
\hline CMST & Characterization, Monitoring, and Sensors Technology Crosscutting Program \\
\hline CPT & cone penetrometer \\
\hline CPU & compact processing unit \\
\hline CST & crystalline silicotitanate \\
\hline CUF & cells unit filter \\
\hline D\&D & decontamination and decommissioning \\
\hline DOE & U.S. Department of Energy \\
\hline DOE-HQ & U.S. Department of Energy-Headquarters \\
\hline $\mathrm{DSC}$ & differential scanning calorimeter \\
\hline DST & double-shell tank \\
\hline DWPF & Defense Waste Processing Facility \\
\hline EM & Office of Environmental Management (DOE) \\
\hline EM-30 & Office of Waste Management (DOE) \\
\hline EM-40 & Office of Environmental Restoration (DOE) \\
\hline EM-50 & Office of Science and Technology (DOE) \\
\hline EMSP & Environmental Management Science Program \\
\hline EN & electrochemical noise \\
\hline ESP & Efficient Separations and Processing Crosscutting Program \\
\hline ESW & enhanced sludge washing \\
\hline ETF & Effluent Treatment Facility \\
\hline FETC & Federal Energy Technology Center \\
\hline $\mathrm{F} \& \mathrm{R}$ & functions and requirements \\
\hline FY & fiscal year \\
\hline GAAT & Gunite and Associated Tanks \\
\hline HAW & high-activity waste \\
\hline $\mathrm{HCI}$ & Hanford Capsule Initiative \\
\hline HEPA & high-efficiency air particulate (filter) \\
\hline HL W & high-level waste \\
\hline HTI & Hanford Tanks Initiative \\
\hline ILAW & immobilized low-activity waste \\
\hline
\end{tabular}




\begin{tabular}{|c|c|}
\hline INEEL & $\begin{array}{l}\text { Idaho National Engineering and Environmental Laboratory } \\
\text { (Idaho Falls, Idaho) }\end{array}$ \\
\hline INTEC & Idaho Nuclear Technology and Engineering Center \\
\hline IRB & Internal Review Budget \\
\hline ITP & in-tank precipitation \\
\hline LAW & low-activity waste \\
\hline LDUA & Light-Duty Utility Arm \\
\hline LLW & low-level waste \\
\hline M\&I & manageınent \& integration \\
\hline MLDUA & Modified Light-Duty Utility Arm \\
\hline $\mathrm{M} \& \mathrm{O}$ & management and operation \\
\hline MVCIT & Melton Valley Capacity Increase Tank \\
\hline MVST & Melton Valley Storage Tank \\
\hline MYPP & multiyear program plan \\
\hline NDE & nondestructive examination \\
\hline NDT & nondestructive testing \\
\hline $\mathrm{OHF}$ & Old Hydrofracture Facility \\
\hline $\mathrm{O} \& \mathrm{M}$ & operations and maintenance \\
\hline ORNL & Oak Ridge National Laboratory \\
\hline ORR & Oak Ridge Reservation (Oak Ridge, Tennessee) \\
\hline OST & Office of Science and Technology (DOE) \\
\hline PBS & Program Baseline Summary \\
\hline PHMC & Project Hanford Management Contract \\
\hline PI & principal investigator \\
\hline RCRA & Resource Conservation and Recovery Act \\
\hline REDOX & reduction-oxidation \\
\hline RFP & request for proposal \\
\hline $\mathrm{RL}$ & Richland Operations Office (DOE) \\
\hline ROD & record of decision \\
\hline SBW & sodium-bearing waste \\
\hline SREX & strontium extraction \\
\hline SRS & Savannah River Site (Aiken, South Carolina) \\
\hline SST & single-shell tank \\
\hline STCG & Site Technology Coordination Group \\
\hline TAG & Technical Advisory Group \\
\hline TDI & Technology Deployment Institute \\
\hline TFA & Tanks Focus Area \\
\hline TPA & Hanford Federal Facility Agreement and Consent Order \\
\hline TRU & transuranic (waste) \\
\hline TRUEX & transuranic extraction \\
\hline TTP & technical task plan \\
\hline USG & User Steering Group \\
\hline
\end{tabular}


WAPS

waste acceptance product specification

WIPP

Waste Isolation Pilot Plant 



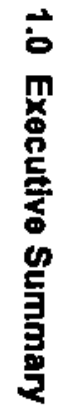




\section{Section 1 - Executive Summary}

The U.S. Department of Energy (DOE) continues to face a major radioactive waste tank remediation problem with hundreds of waste tanks containing hundreds of thousands of cubic meters of high-level waste $(\mathrm{HLW})$ and transuranic (TRU) waste across the DOE complex. Approximately 68 tanks are known or assumed to have leaked to the soil. Some of the tank contents have reacted to form flammable gases, introducing additional safety risks. These tanks must be maintained in a safe condition and eventually remediated to minimize the risk of waste migration and/or exposure to workers, the public, and the environment. However, programmatic drivers are more ambitious than baseline technologies and budgets will support. Science and technology development investments are required to reduce the technical and programmatic risks associated with the tank remediation baselines.

The Tanks Focus Area (TFA) was initiated in 1994 to serve as the DOE Office of Environmental Management's (EM's) national technology development program for radioactive waste tank remediation. The national program was formed to increase integration and realize greater benefits from DOE's technology development budget. The TFA is responsible for managing, coordinating, and leveraging technology development to support DOE's four major tank sites: Hanford Site (Washington), Idaho National Engineering and Environmental Laboratory (INEEL) (Idaho), Oak Ridge Reservation (ORR) (Tennessee), and Savannah River Site (SRS) (South Carolina). Its technical scope covers the major functions that coinpose a complete tank remediation system: waste retrieval, waste pretreatment, waste immobilization, tank closure, and characterization of both the waste and tank with safety integrated into all the functions. The TFA integrates program activities across EM organizations that fund tank technology development, including the Offices of Waste Management (EM-30), Environmental Restoration (EM-40), and Science and Technology (EM-50 or OST).

The TFA depends heavily upon site users to participate in the TFA's multiyear planning and execution. One of the key TFA organizational elements is the Management Team led by DOE's Richland Operations Office (RL) and composed of federal user representatives from each of the four sites plus DOE-Headquarters (DOE-HQ). The Management Team conducts weekly program updates, determines program policy, performs program prionitization, and performs program oversight. Through its DOE-HQ members, the TFA communicates with a HLW Steering Committee consisting of assistant managers from each of the four sites.

For technical issues, the Pacific Northwest National Laboratory leads the TFA Technical Team that includes six additional laboratory partners. A User Steering Group (USG) that consists of senior contractor user members provides additional user representation to the program. Through its own technical review body, the Technical Advisory Group (TAG), the TFA receives high-quality, quick reacting, independent technical reviews. 
Together, all the components of the TFA team execute a mission to deliver and work with users to implement technical solutions using an integrated approach to safely and efficiently accomplish tank waste remediation across the DOE complex. Inherent in the TFA mission, the TFA seeks to

- Provide technical solutions to enable and enhance remediation.

- Respond to the unique technical challenges inherent to the radioactive tank waste mission.

- Work with users and program partners throughout the remediation process, from problem identification to implementation of technical solutions.

- Focus on filling technical gaps, enabling progress, and making tangible progress toward solving key tank problems.

To accomplish this mission, the TFA's goals include working to increase the use of EM-50 funded results, reduce programmatic and technical risk, and direct a portion of the program to contingency or alternative technology approaches. Several strategies are required to support the TFA's mission and goals. Meeting users needs, building and nurturing user-producerdeveloper teams, developing and executing a leveraged program, and providing a balanced portfolio of near- and long-term investments are among the key supporting strategies.

This multiyear program plan (MYPP) reflects the TFA's plan for the next five fiscal years (FY99-FY03). Most of the planning emphasis is on FY99 and FY00. During this period, the TFA plans major work in six key areas:

1) Safe waste storage

2) Waste mobilization and retrieval

3) Conditioning, transfer, and retrieval-pretreatment integration

4) Waste pretreatment

5) Waste immobilization

6) Closure.

Safe Waste Storage: The sites require improvements in monitoring tank integrity, tank corrosion prevention, tank ventilation, and characterization of the waste within the tanks. Additionally, waste reduction technologies are needed to minimize the amount of waste entering the tank farms from source and recycle streams.

The TFA is investing in the development of monitors and sensors to better control the addition of inhibitor water, a technique used to avoid tank corrosion. Real-time tank wall inspection and corrosion monitoring technologies will permit a more proactive approach to monitoring the condition of the tanks. Other TFA investments include passive ventilation systems and regenerable high-efficiency particulate air (HEPA) filters that will reduce the costs and risks associated with safe waste storage.

Waste Mobilization and Retrieval: Improved or new methods to mobilize wastes and detect and mitigate leaks during waste retrieval operations constitute the TFA's major areas 
of emphasis in waste mobilization and retrieval. The TFA will continue its investigation of improved mixing and pumping technologies, to include potential developments available from the United Kingdom and Russia. The sites' concerns with waste leakage during retrieval operations are being addressed through a wide range of TFA activities that include improved control of water during retrieval, technologies for detecting leaks, and operational strategies in the event a leak is detected.

Conditioning, Transfer, and Retrieval-Pretreatment Integration: The sites face several problems between the time waste is retrieved and before pretreatment. The TFA will continue its investigation of waste re-precipitation, solids formation, waste transfer line plugging, and settling. This work includes monitors that report the condition of the waste and adapting and testing systems that unplug pipe blockages. Thermodynamic laboratory studies will increase the knowledge of waste performance between retrieval and pretreatment. These studies should produce results that have implications on both the retrieval and pretreatment operations.

Waste Pretreatment: The TFA has been successful in integrating pretreatment requirements with those of waste immobilization. This is important because immobilization operations follow pretreatment operations. The specific pretreatment operations conducted directly affect immobilization. For example, immobilization waste volumes depend upon the effectiveness of the pretreatment steps. Therefore, the TFA seeks to develop and implement technologies that more efficiently remove radionuclides from wastes and process sludges.

Waste Immobilization: The TFA will continue to support the sites' requirements for improvements to ongoing immobilization operations and the privatization of waste treatment. This wide-ranging work includes studies and tests on glass formulations, waste product performance, feed preparation, improved melter designs, and more efficient and productive melter operations. The TFA's work will assist DOE in measuring contractor performance and identifying expected waste performance characteristics that result from the contractors' immobilization operations.

Closure: The TFA will continue to assist sites in stabilizing and closing their tanks. Past success in grouting operations leads the TFA to invest in improved grout formulation and better develop bases for tank closure. Based on site needs, the TFA is investing in vadose zone contamination issues and those related to residual tank wastes. The TFA integrates a wide range of activities from other EM-50 programs directed at solving these problens. These activities include characterization, retrieval, out-of-tank processing, and in situ grouting systems.

To support all of the work summarized above, the TFA, in concert with the user community it serves, developed technical approaches to solve the problems and the supporting funding requirements. The funding requirements are based on users' needs submitted during FY98 and include all EM-50 funding sources (e.g., crosscutting programs) (see Table 1.1). 
Table 1.1. TFA and Other EM-50 Funding, FY99-FY03

\begin{tabular}{|c|c|c|c|c|c|}
\hline & FY99 & FY00 & FY01 & FY02 & FY03 \\
\hline \hline TFA & 28.9 & 44.0 & 49.4 & 51.5 & 51.7 \\
\hline Other EM-50 & 17.4 & 13.1 & 15.0 & 16.0 & 17.0 \\
\hline Total & $46.3 \mathrm{M}$ & $57.1 \mathrm{M}$ & $64.4 \mathrm{M}$ & $67.5 \mathrm{M}$ & $68.7 \mathrm{M}$ \\
\hline
\end{tabular}

The TFA formally updates its requirements with its users annually and routinely makes program adjustments as soon as new requirements are identified or when previous requirements become satisfied or no longer serve as a priority.

The TFA MYPP presents the recommended TFA technical program. The recommendation covers a 5-year funding outlook (FY99-FY03), with an emphasis on FY99 and FY00. The MYPP describes the tank waste remediation problem and TFA's role in solving it (Section 2), the TFA's mission and vision (Section 3), the goals and strategies required for TFA to succeed (Section 4), the relationships between the TFA and significant programs involved in deploying innovative technologies and providing critical data (Section 5), the TFA's technical program (Section 6), and references used in the work (Section 7).

As supporting material, this report contains paths to closure data (Appendix A), a description of the TFA's prioritization process (Appendix B), the Integrated Priority List (Appendix C), Gantt charts showing significant milestones (Appendix D), the TFA's organization (Appendix E), a crosswalk of work packages to budget formulation product lines (Appendix F), descriptions of the four major tank sites (Appendix $G$ ), and leveraged programs (Appendix H). 


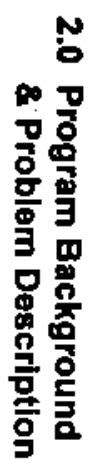




\section{Section 2 - Program Background and Problem Description}

\subsection{Problem Description}

Remediation of tanks containing highly radioactive waste is a major technical and programmatic challenge for the DOE (Stewart et al. 1997). The DOE system currently stores about 355 million liters of waste containing more than $730 \mathrm{MCi}$ in 271 tanks at four major sites. The 271 tanks are located at the Hanford Site near Richland, Washington, SRS near Aiken, South Carolina, INEEL near Idaho Falls, Idaho, and ORR near Oak Ridge, Tennessee. In addition to the 271 tanks within the TFA's purview, each site also contains miscellaneous tanks.

The wastes are chemically and physically heterogeneous between sites, between tanks on a given site, and in some cases, between the phases of waste within a single tank. The wastes at Hanford, SRS, and ORR are alkaline. At Hanford and SRS, these wastes resulted from chemical separations operations required to produce plutonium. Hanford used several different separations processes over the years of plutonium production and additional operations such as uranium, cesium, and strontium recovery. As a result, there are several different waste types at Hanford. The ORR wastes are similar in composition to some of the wastes at Hanford and SRS because during World War II this site piloted many of the chemical separations processes used at these sites. INEEL's waste type is unique within the DOE system in that it is stored in an acidic form. The majority of the INEEL waste has been calcined, which is considered an interim storage form by the state of Idaho that requires further processing to convert to a more durable long-term waste form. In addition, the INEEL has some tank heel waste remaining in a liquid form that must be addressed (see Appendix $\mathrm{G}$ for more details).

Based on the paths to closure document that outlines the activities, cost, and schedule for EM-40 and EM-30 cleanup, the HLW mission area can be described as long term with high cost and technical risk. The life-cycle cost for $\mathrm{HLW}$ remediation is estimated as $\$ 49 \mathrm{~B}$ over 30 years. The schedules for cleanup have been negotiated through federal facility agreements for each site. Cost, schedule, number of waste streams, and number of Program Baseline Summaries (PBSs) with urgent or high technical risk and high visibility are summarized for each site in Table 2.1 .

The tanks have limited access for in-tank sampling and characterization, tank inspection, and waste mobilization and retrieval activities. Moreover, the tank configuration, including internal structures that impact access and ability to clean tanks, also vary widely. 
Table 2.1. Summary of Paths to Closure Data on High-Level Waste Mission

\begin{tabular}{|l|c|c|c|c|c|}
\hline \multicolumn{1}{|c|}{ Site } & Cost, \$B & $\begin{array}{c}\text { Complete } \\
\text { Date }\end{array}$ & $\begin{array}{c}\text { Waste } \\
\text { Streams }\end{array}$ & $\begin{array}{c}\text { PBS Urgent/ } \\
\text { High Risk }\end{array}$ & $\begin{array}{c}\text { PBS High } \\
\text { Visibility }\end{array}$ \\
\hline Hanford Site & 28.5 & 2032 & 14 & 5 & 10 \\
\hline Savannah River Site & 11.5 & 2028 & 53 & 6 & 3 \\
\hline $\begin{array}{l}\text { Idaho National Engineering and } \\
\text { Environmental Laboratory }\end{array}$ & 5 & 2035 & 14 & 1 & 4 \\
\hline
\end{tabular}

Safe operations in the tank farms continue to be a key concern of the DOE and their stakeholders. To date, 68 tanks are known or assumed to have leaked to the surrounding soil, and safety issues have been frequently raised by the DOE, their stakeholders, and oversight groups. Finally, each of the four sites has a different set of regulatory requirements that impact tank closure definition and procedure. Tanks at SRS are closed under State Waste Water Regulations, Hanford and INEEL tanks are to be closed under the Resource Conservation and Recovery Act (RCRA), and ORR inactive tanks are being closed under Comprehensive Environmental Response, Compensation, and Liability Act (CERCLA). These different regulatory requirements can impact the acceptability of technical solutions from site-to-site. Soils at ORR, SRS, and INEEL are subject to CERCLA. All of these situations lead to technical challenges that have both common and site-specific requirements to which a national science and technology program must respond.

\subsection{TFA Functions to Solve the Problem}

Before FY95, responsibility for developing technical solutions to support tank remediation was spread across multiple EM organizations and sites. In January 1994, DOE issued an action plan establishing a new approach for solving complex remediation problems, including highly radioactive waste tank problems. On April 1, 1994, DOE issued a call for proposals on approaches for transitioning tank technology from a distributed to a focused national effort.

A team of seven contractors and national laboratories responded to and were awarded the responsibility to implement the focus area concept. This concept includes leadership through a partnership between RL and the Pacific Northwest National Laboratory. It also includes partnerships between users and technical experts to define and execute an integrated, focus area centered program.

This concept has been put into practice for the last four fiscal years. Renewal of the commitment for this approach has been received by the Office of Science and Technology (EM-50) in FY98. This commitment emphasizes: 
- Integration with the users

- Centers of excellence

- Focus area centered

- Technical assistance to users.

Integration with the users: The EM- 30 and $\mathrm{EM}-40$ users on both the $\mathrm{DOE}$ and the contractor sides are active members of the TFA. The TFA organization is shown in Figure 2.1, with details of membership in Appendix E. Both the TFA Management Team and the HLW Steering Committee represent the users. The TFA Management Team consists of DOE users from the four tank sites and DOE-HQ. Their role is to ensure needs are developed and submitted through the Site Technology Coordinating Groups at their sites, to prioritize the technical responses to those needs, and to help ensure site contractors are incentivized to include TFA technical solutions in their baselines. Additionally, the DOE user members of this team act as liaisons to their assistant managers (AMs) for EM-30 and EM-40 on specific TFA activities and products.

The AMs comprise the HLW Steering Committee, which is led by EM-30 DOE-HQ. This committee ensures complex-wide integration on policy and other issues including science and technology. The HLW Steering Committee, including the Acting Deputy Assistant Secretary for the EM-30, have been signatories on the TFA multiyear program plan starting

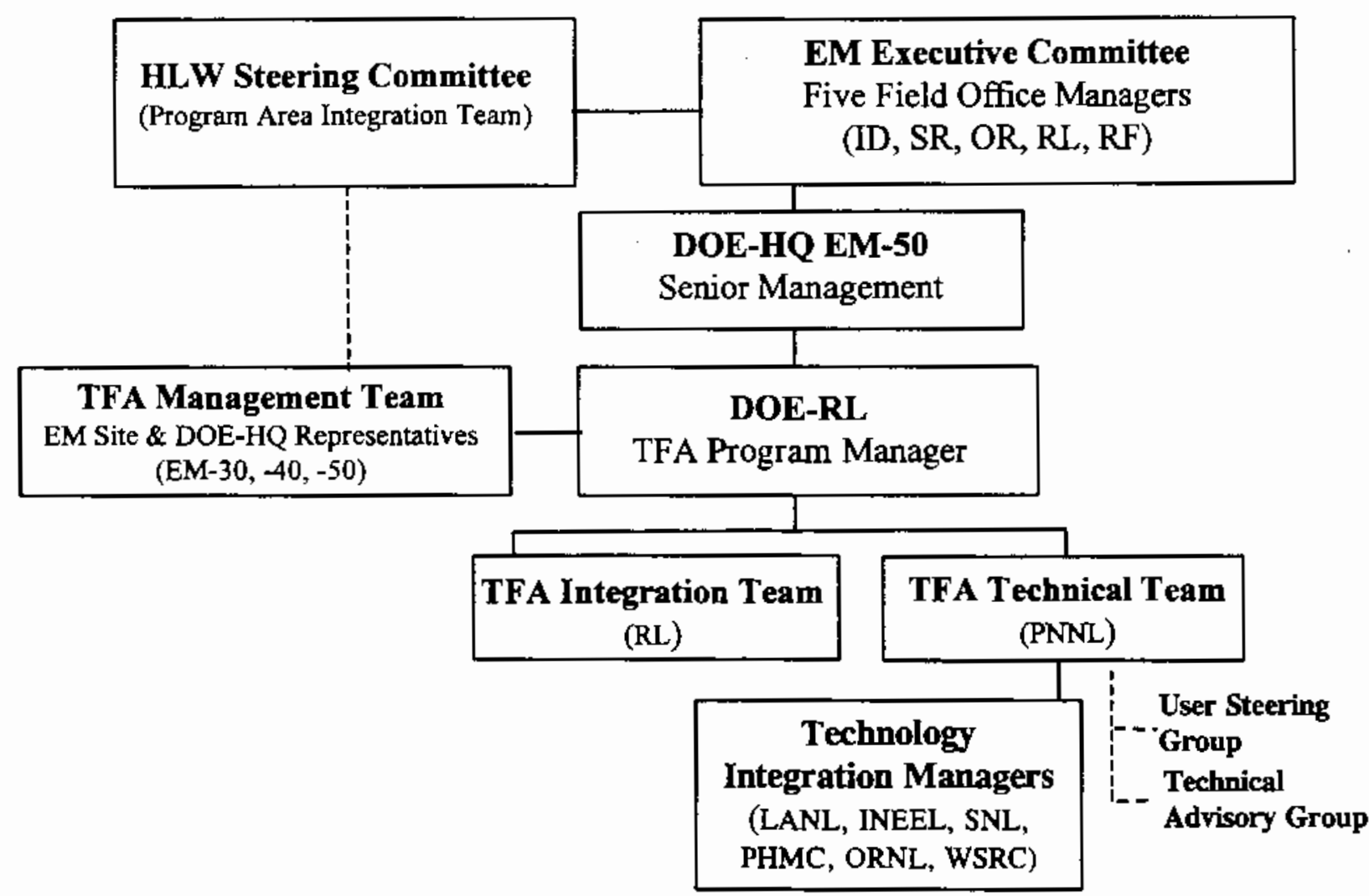

Figure 2.1. Tanks Focus Area Organization 
in FY97. The combination of the day-to-day management attention from the user program provided through the TFA Management Team and the endorsement of the HLW Steering Committee has allowed TFA to stay aligned with user needs and schedules. This helps lead the TFA to deploy and implement several key technical solutions that have resulted in significant progress by EM in resolving tank problems.

Integration with the users, however, also requires active participation with the implementing contractors at each of the sites. As a result, the USG participated in the TFA. The USG comprises managers from the four management and integration or management and operations organizations at each of the sites plus managers from the laboratories that participate on the TFA. This group ensures that the technical and programmatic details required to fully define the needs are provided. :hat barriers to deployment of technical solutions ar ${ }^{\star}$ mitigated within the contractor organization, and that site resources are provided to ensure implementation of technical solutions.

The result of integrating the TFA Management Team and the USG into site planning and resource allocation is delivery and implementation of technical solutions to solve users' key problems.

Centers of excellence: The TFA is constructed on a partnership between the DOE and the national laboratories to ensure technical excellence in both the translation of a need to a viable technical solution and the execution of the program in a technically sound manner. This partnership is illustrated in Figure 2.1. The Technical Tean is led by the Pacific Northwest National Laboratory and has six laboratory partners that are technical leaders in the key functional areas associated with tank waste remediation: Los Alamos National Laboratory provides safety leadership, INEEL provides characterization leadership, Numatec Hanford Corporation provides retrieval leadership, Oak Ridge National Laboratory (ORNL) provides pretreatment leadership, Westinghouse Savannah River Company provides immobilization leadership, and Sandia National Laboratories provides closure leadership. The Technical Team provides the technical expertise and deployment experience required to develop technical scope, maintain technical progress, and ensure delivery of technically responsive products to the user.

Focus area centered: The TFA encompasses 11 science and technology-related programs within EM that range from the applied research conducted by Environmental Management Science Program (EMSP) to the site programs that focus on site-specific issues. As needs are received, the TFA works to identify not only the appropriate technical response, but also the best qualified program to perform the work scope. The TFA then ensures integration and coordination of all of the products from these 11 programs in a way that leads to single-point delivery of technical solutions to the user programs. This approach clarifies and tracks the interfaces in a systematic manner, avoids duplication of technical investments, and enables deployment and implementation by providing the coordination required to deliver products.

Technical assistance to users: The network of users and technical experts provided by the TFA organization has also provided and will continue to provide technical assistance to the 
four tank sites plus the Fernald Environmental Management Project and the West Valley Demonstration Project. Frequent technical exchanges on key topics have occurred and are planned in the future to ensure rapid dissemination of lessons learned as technology has been deployed. This approach has increased the likelihood of multiple deployments. Moreover, the technical experts including those from the TFA's TAG, which serves to review many aspects of the TFA program, are providing technical assistance through consultation and reviews for key activities at each site as needed. Examples include privatization at Hanford, flowsheet development at INEEL, and alternatives for in-tank precipitation at SRS. 



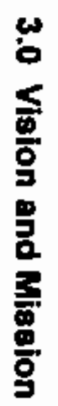

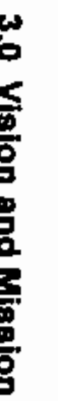


This section describes the TFA's mission and vision and places the TFA's mission within the context of the mission of EM-50. In addition, this section discusses the direct correlation between the four elements of the EM-50's focus area centered approach and the TFA's mission and operational approach.

\subsection{Vision and Mission Statements}

The vision of EM-50 (the principal force in creating and funding the focus areas) is to provide the scientific foundation, new approaches, and new technologies that contribute to significant reductions in risk, cost, and schedule for completion of the EM mission. Within EM-50's vision is the TFA's vision. The TFA's vision is to enable EM's goal of tank farm closure through the development and application of safe and efficient technologies. The mission of EM-50 is to manage and direct targeted basic research and focused, solutionoriented technology development programs to support EM.

Within this mission, the TFA's mission is to

Work with users to deliver, develop and implement technical solutions through an integrated approach - to safely and efficiently accomplish tank waste remediation at four major DOE sites: Hanford Site, Idaho National Engineering and Environmental Laboratory (INEEL), Oak Ridge Reservation (ORR), and Savannah River Site (SRS).

Inherent in the TFA's mission, the TFA seeks to

- Provide technical solutions to enable and enhance remediation.

- Respond to the unique technical challenges inherent in the program's mission.

- Work with the user and program partners through the entire process, from problem identification to implementation of technical solutions.

- Focus on filling technical gaps, enabling progress, and making tangible progress toward solving key tank problems.

\subsection{TFA's Relation to the Focus Area Centered Approach}

Under the focus area centered approach, the TFA leads the integration of EM-50's technology development that supports tank waste remediation. Four key elements distinguish the focus area centered concept. These four elements are presented below, including a short description of the TFA's support to them. 
1) Focus Area Centered Key Element \#1 - Integration. The TFA maintains continuous contact with other EM-50 programs in developing and executing technology development work supporting tank waste remediation. For the TFA, these programs include Crosscutting, Industry, International, and University Programs. The TFA maintains close relations with the EMSP, the TFA's link to supporting basic research. For each of these programs, the TFA strives to ensure planned and ongoing technology development work supports users' needs effectively, efficiently, and without duplication. (See Section 5.0 for more information on the partner programs).

2) Focus Area Centered Key Element \#2 - Expanding the Technical Assistance Role. The TFA seeks to be proactive in solving technical problems. Beginning with its analysis of users' technology development needs, the TFA maintains an interactive posture with each user. The TFA's goal is to not only ensure the TFA understands each need, but also to ensure that the user fully understands the ramifications of each need. During needs analysis, the TFA attempts to identify technology gaps that should be brought to the attention of the user. Exposure of these technology gaps provides the user with a broader understanding of the technical problem to be solved and potential solutions.

Throughout any year, the TFA seeks to lead technical exchanges between technical researchers and users. In the past, various TFA-led or TFA-sponsored workshops, such as the Immobilization-Pretreatment Integration Workshop and the Retrieval Workshop, provide complex-wide technical assistance.

3) Focus Area Centered Key Element \#3 - Maintaining the Highest Technical Capahility. The TFA consists of a network of the most highly qualified federal and contractor technical and program management experts. The TFA's technical core is drawn from seven contractors and national laboratories that regularly contribute to the program (see Appendix E). The TFA's USG, Technical Advisory Group, and independent peer reviews ensure that the performers work meets the users' needs and is of the highest quality. The TFA uses performer selection criteria to select top quality organizations and principal investigators to carry out the TFA's technical work.

4) Focus Area Centered Key Element \#4 - User Connection. The TFA is a consensusdriven program that formally includes users throughout program development and execution. The TFA's annual program cycle includes users throughout the process, including the annual kickoff meeting, technical response development to users' needs, the annual program prioritization meeting, midyear review, and Technical Task Plan review meeting. Weekly telephone conferences of the TFA's Management Team keep users abreast of key technical and programmatic developments. 


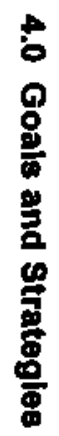




\section{Section 4-Goals and Strategies}

The objective of the TFA is to build a risk-driven, fully integrated, fully leveraged technology development program that is responsive to user and stakeholder needs to remediate radioactive waste tanks. The program strives to be consistent with the accelerated cleanup plan and enables EM to meet its goals for processing waste (e.g., number of canisters per year) and closing tanks (e.g., number of tanks closed per year).

This section presents the strategic intent of the program through an explanation of the program's goals and strategies.

\subsection{TFA Goals and Strategies}

The TFA uses three goals to guide program development and execution. These goals are under constant revision; however, the present set is a product of reflection on the TFA's past and present program and an assessment of future requirements, all developed and coordinated with site users.

\section{Goal \#1: Increase use of EM-50-funded results so that $70-90 \%$ of products are being} used. The key point of the goal is to increase the use of EM-50-funded technologies. While the percentage of increase may be debated, increasing the percentage is most important. To attain this goal, the TFA is committed to the following strategies:

- Deliver technology as defined on schedule.

- Construct and maintain a leveraged program.

- Emphasize user/producer/developer teams.

- Understand functions, requirements, and schedule.

- Bridge the gap between fundamental science and technology iinplementation.

- Identify and build user relationships.

Goal \#2: Reduce programmatic and tecbnical risk The TFA seeks to reduce risk for both the user and EM-50. Essential elements of this goal are the constant pursuit of multisite technology applications focused on high priority, high risk needs of the users; and the selection of the best technical performers available to address technical risk issues most effectively. To attain this goal, the TFA commits to the following strategies:

- Maximize multi-site benefits from technology investments and focus on activities with the greatest technical impact.

- Develop national laboratory-industry partnerships to respond to needs, ensure scientific and technical excellence, and deploy technologies.

- Manage budget, budget change process, and site prioritization influences to respond quickly to changes in sites' programmatic risks. 
Goal \#3: Direct up to $20 \%$ of the TFA program so that $10-20 \%$ of the funding is directed at contingency or alternative technology approaches. As a proactive technology development program, the TFA uses its technical expertise to anticipate problems and riskreducing technical solutions. With widespread support from its user community, the TFA pursues, within available funding, contingency or alternative technology approaches. To attain this goal, the TFA commits to the following strategies:

- Continue to define strategic goals to guide technology investments.

- Continue to develop a basis for initiating and maintaining a forward-thinking program that balances near- and long-term investments.

- Establish user and DOE-HQ advocacy for TFA strategic investments.

\subsection{TFA's Support to EM's Major Science and Technology Thrusts}

Strategies to attain each TFA goal directly support EM's four major thrusts for science and technology investment.

1) Accelerate technology deployment. To support this thrust, the TFA is committed to the following strategies:

- Deliver its solutions on time.

- Thoroughly understand users' needs.

- Seek multi-site benefits.

- Develop national laboratory/industry partnerships.

- Ensure goals and strategies reflect users' needs.

- Pursue strategic investments.

2) Reduce cost. To support this thrust, the TFA is committed to the following strategies:

- Leverage other technical tasks, whether TFA-funded or not.

- Build quality user/producer/developer teams.

- Deploy technologies at multiple sites or for multiple purposes.

- Skillfully manage the TFA budget.

- Ensure programmatic goals and strategies target user needs.

3) Meet high prionity needs. To support this thrust, the TFA is committed to the following strategies:

- Ensure complete communication between users, producers, and developers.

- Manage the gap between fundamental science and technology implementation.

- Continually build relationships with users.

- Nurture national laboratory-industry partnerships as a catalyst to more effectively and 'efficiently respond to users' needs.

- Manage the technical task prioritization process to ensure the highest priority needs receive available funding.

- Develop and maintain program goals and strategies that support high-priority needs.

- Provide a balanced portfolio of near- and long-term investments. 
4) Reduce EM's technological risk. To support this thrust, the TFA is committed to the following strategies:

- Consider all risk from fundamental science to technology implementation.

- Take advantage of successful technology implementations through lessons learned and practical multi-site or multi-use implementations.

- Develop powerful national laboratory-industry partnerships that can result in technology breakthroughs.

- Consider risk-based performer selection and task prioritization criteria.

- Maintain risk as a component of the TFA program goals.

- Be proactive in strategic investments and technical assistance.

\subsection{Success Indicators}

Delivery of solutions to address site needs is a critical measure of the TFA investments' success in solving EM problems. The nature of those problems and the technical solutions and schedules are discussed in Sections 2 and 6 . To monitor progress toward technical objectives and increase probability of success, key deliverables are identified from the overall list of program milestones that represent significant progress, accomplishments, or interim steps towards delivery of technical solutions. Progress toward delivery of solutions is measured in three areas:

- Delivery of data to support key decisions and to fill gaps in technical knowledge required to define the path to solution.

- Demonstration of technologies or concepts to support selection of technology alternatives or to demonstrate progress towards deployment of selected technologies.

- Deployment of technical solutions, including implementation of data in a baseline program and actual installation and operation of technologies in a tank, tank complex, or waste treatment facility.

Program guidance and technical task plans are developed including meaningful milestones to guide the evolution of the work and also to measure progress at appropriate points in the implementation of the workscope. From those overall program milestones, a subset of key deliverables is selected that represents critical activities, demonstrations, or deployments indicating significant progress toward or completion of delivering a technical solution. These key performance indicators and expected performance for each activity are defined in more detail in the annual performance plan. The annual performance plan is submitted at the start of the current execution year. Key activities and deliverables for FY99 through FY00 are summarized in Table 4.1. 
Table 4.1. Success Indicators

\begin{tabular}{|c|c|c|c|}
\hline $\begin{array}{l}\text { Problem } \\
\text { Element }\end{array}$ & Need Number & Key Deliverable Description - Site(s) Supported & FY \\
\hline 1.1.1.1 & ID-2.1.10 & Deploy LDUA \& NDE End Effector for Tank Wall Inspection - INEEL & 99 \\
\hline 1.1 .1 .1 & RL-WT04 & Deploy $3^{\text {cd }}$ Generation EN/MIT Corrosion Probe - Hanford & 99 \\
\hline 1.1 .1 .1 & SR-2918 & Hot Test Raman Probe for Corrosion Monitoring - SRS & 99 \\
\hline 1.1 .1 .1 & SR-2918 & Complete Cold Demonstration of Corrosion Species Probe - SRS & 99 \\
\hline 1.1 .1 .1 & SR-2018 & Deploy Corrosion Species and EN Probes - SRS & 00 \\
\hline 1.1 .2 & SR-2901 & Complete Vendor Testing/Issue Test Report on Metal Filters - SRS & 99 \\
\hline 1.1 .2 & SR-2901 & Demonstrate Metal Filters - SRS & 00 \\
\hline 1.1 .2 & SR-2901 & Deploy Metal Filters - SRS & $\overline{01}$ \\
\hline 1.1 .3 .2 & ID-2.1.10 & Complete LDUA Heel Sample Analysis Report - INEEL & 99 \\
\hline $1.1 . \overline{3.2}$ & RL-WT09 & Complete Vendor Testing, AEA Nested Sampler - Hanford & 99 \\
\hline 1.1 .3 .2 & RL-WT09 & Demonstrate Nested Sampler - Hanford & 00 \\
\hline 1.1 .3 .2 & RL-WT09 & Deploy Nested Sampler - Hanford & 01 \\
\hline 1.1 .3 .2 & RL-WT09 & Demonstrate At-Tank Analysis System - Hanford & 01 \\
\hline 1.1 .4 .2 & SR-2921 & Receive CIF Evaporator from Vendor - SRS & 99 \\
\hline 1.1 .4 .2 & SR-2921 & Demonstrate CIF Evaporator - SRS & 00 \\
\hline 1.1 .4 .2 & SR-2921 & Deploy CIF Evaporator - SRS & 01 \\
\hline 1.2 .1 .2 & TK-05 & Deploy Russian Pulsating Monitor - ORR & 99 \\
\hline 1.2 .1 .2 & RL-WT028 & Issue Recommendations for Extended Sludge Retrieval - Hanford/SRS & 99 \\
\hline 1.2 .1 .2 & SR-2902 & Issue Test Report on Criticality Mitigation for Salt Dissolution - SRS & 99 \\
\hline 1.2 .1 .2 & RL-WT013 & Select HTI C-106 Retrieval System Vendor - Hanford & 99 \\
\hline 1.2 .1 .2 & RL-WT013 & Begin Onsite Cold Testing of C-106 Retrieval System - Hanford & 00 \\
\hline 1.2 .1 .2 & SR-2911 & Deploy Tank 19 Heel Retrieval System - SRS & 99 \\
\hline 1.2 .1 .2 & SR-2911 & Issue Requirements/Specification for Type 1/II Tanks Retrieval - SRS & 00 \\
\hline 1.2 .1 .2 & 98069 & Demonstrate at Full-Scale Alternate Mixer System - Hanford/SRS & 00 \\
\hline 1.2 .1 .2 & 98054 & Deploy Salt Retrieval System in Tank 16 - SRS & 00 \\
\hline 1.2 .1 .2 & SR-2911 & Deploy Retrieval System in Type I/II Tank - SRS & 01 \\
\hline 1.2 .1 .2 & SR-2911 & Issue Recommendations for Mixer Pump Improvements - SRS & 01 \\
\hline 1.2 .1 .2 & SR-2911 & Issue Russian Chemical Cleaning Recommendations - SRS & 00 \\
\hline 1.2 .1 .2 & RL-WT028 & Issue Recommendations for Sludge Retrieval - Hanford & 00 \\
\hline 1.2 .1 .4 & TK-02 & Issue Performance Report on Slurty Monitor/Pulsair - ORR & 99 \\
\hline 1.2 .1 .4 & TK-02 & Deploy/Issue Performance Report on CPU Waste Conditioning - ORR & 00 \\
\hline 1.2 .1 .4 & RL-WT023 & Issue Recommendations for Control of Solid Formation - Hanford & 00 \\
\hline 1.2 .1 .4 & RL-WT023 & Demonstrate Saltcake Dissolution at Pilot-Scale - Hanford & 00 \\
\hline 1.2 .1 .4 & SR-2913 & Demonstrate Industry Pipe Unplugging Systems - SRS/ORR & 00 \\
\hline$\overline{1.2 .1 .4}$ & SR-2913 & Issue Recommendations for Transfer/Pipeline Unplugging - SRS/ORR & 01 \\
\hline 1.2 .1 .4 & SR-2913 & Demonstrate Industry Pipe Inspection Systems - SRS/ORR & 01 \\
\hline 1.2 .2 .4 & TK-05 & Deploy Solid Liquid Separation System - ORR & 99 \\
\hline 1.2 .2 .5 & SR-2908 & Issue Report on ITP Alternative Evaluation \& Recommendation - SRS & 99 \\
\hline 1.2 .2 .5 & SR-2908 & Issue Specification for Demonstration of ITP Alternative - SRS & 00 \\
\hline 1.2 .2 .5 & SR-2908 & Deploy ITP Alternative System - SRS & 02 \\
\hline 1.2 .2 .7 & TK-11 & Deploy Modular Evaporator/Cs Removal System - ORR & 99 \\
\hline 1.2 .3 .2 .4 & RL-WT06 & Issue Technical Report on Glass Liquidus Temperature - Hanford & 99 \\
\hline 1.2 .3 .2 .4 & RL-WT06 & Define Acceptable Composition Range for ILAW/IHAW - Hanford & 00 \\
\hline 1.2 .3 .2 .4 & ID-2.1.08 & Issue Summary Glass Formulation Report - INEEL & 99 \\
\hline 1.2 .3 .2 .4 & ID-2.1.08 & Issue Report on $1 / 4$ Scale Melter Test Runs - INEEL & 99 \\
\hline 1.2 .3 .2 .4 & ID-2.1.08 & Recommend Melter Technology for HAW - INEEL & 00 \\
\hline
\end{tabular}


Table 4.1. (contd)

\begin{tabular}{|c|c|c|c|}
\hline $\begin{array}{l}\text { Probler } \\
\text { Elemen }\end{array}$ & Need Number & Key Deliverable Description - Site(s) Supported & FY \\
\hline 1.2 .3 .2 .4 & ID-2.1.08 & Define Key Melter Design Parameters for HAW - INEEL & 01 \\
\hline 1.2 .3 .2 .4 & ID-2.1.08 & Demonstrate INEEL HAW Immobilization at Pilot Scale - INEEL & 01 \\
\hline 1.2 .3 .2 .4 & SR-2910 & Demonstrate Replacement of Melter Knife Edge - SRS & 99 \\
\hline 1.2 .3 .2 .4 & SR-2910 & Recommend Design for DWPF Melter Pour Spout/Riser Heaters - SRS & 00 \\
\hline $\overrightarrow{1.2 .3 .2 .4}$ & SR-2910 & Deploy Optimized Waste Loading in DWPF - SRS & 00 \\
\hline 1.2 .3 .2 .4 & SR-2910 & Recommend Design Requirements for Next Generation Melter - SRS & 01 \\
\hline 1.3 .1 .2 & RL-WT013 & Deploy LDUA for Sampling of AX-104 HTI - Hanford & 99 \\
\hline 1.3 .1 .3 & RL-WT013 & Deploy Cone Penetrometer in AX-104 Vadose Zone HTI - Hanford & 99 \\
\hline 1.3 .1 .3 & RL-WT013 & $\begin{array}{l}\text { Issue HTI Closure Alternatives Conclusions/Recommendations - } \\
\text { Hanford }\end{array}$ & 99 \\
\hline 1.3 .1 .3 & TK-09 & Complete Closure of FFA Tank - ORR & 00 \\
\hline 1.3.1.3 & RL-WT013 & Deploy C-106 Heel Retrieval System & 01 \\
\hline 1.3 .1 .7 & TK-09 & Issue Report on Grout Injection Technology Applications - ORR/SRS & 99 \\
\hline 1.3 .1 .7 & TK-09 & Issue Deployment Plan for Grouting of GAAT/FFA Tank - ORR & 99 \\
\hline 1.3 .1 .7 & TK-09 & Deploy Grout Injection Technology in ORR Tanks - ORR/SRS & 00 \\
\hline 1.3.1.7 & TK-10 & Deploy/Issue Performance Report on Pipe Capping System - ORR & 99 \\
\hline 1.3.1.7 & SR-3022 & Deploy Grout Injection/Close OBG Solvent Extraction Tank - SRS & 00 \\
\hline 1.3 .2 .1 & RL-WT010 & Issue Report on Round Robin Testing for LAW Acceptance - Hanford & 99 \\
\hline AEA & \multicolumn{3}{|l|}{ AEA Technology } \\
\hline $\begin{array}{l}\text { CIF } \\
\text { CPU }\end{array}$ & & compact processing unit \\
\hline DWPF & \multicolumn{3}{|c|}{ Defense Waste Processing Facility } \\
\hline EN & \multicolumn{3}{|c|}{ electrochemical noise } \\
\hline FFA & \multicolumn{3}{|c|}{ Federal Facility Agreement } \\
\hline GAAT & \multicolumn{3}{|c|}{ Gunite and Associated Tank } \\
\hline HAW & \multicolumn{3}{|c|}{ high-activity waste } \\
\hline HTI & \\
\hline IHAW & \multicolumn{3}{|c|}{ immobilized high-acrivity waste } \\
\hline ILAW & \multicolumn{3}{|c|}{ immobilized low-activity waste } \\
\hline INEEL & \multicolumn{3}{|c|}{ Idaho National Engineering and Environmental Laboratory } \\
\hline ITP & \multicolumn{3}{|c|}{ in-tank precipitation } \\
\hline LAW & \multicolumn{3}{|l|}{ low-activity waste } \\
\hline LDUA & \multicolumn{3}{|c|}{ Light-Duty Utility Arm } \\
\hline MIT & \multicolumn{3}{|c|}{ Multi-Function Instrument Tree } \\
\hline NDE & \multicolumn{3}{|c|}{ Nondestructive Examination } \\
\hline OBG & \multicolumn{3}{|c|}{ Old Radioactive Waste Burial Grounds } \\
\hline ORR & \multicolumn{3}{|c|}{ Oak Ridge Reservation } \\
\hline SRS & \multicolumn{3}{|l|}{ Savannah River Site } \\
\hline
\end{tabular}





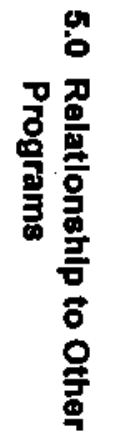




\section{Section 5 - Relationship to Other Programs}

The TFA maintains continuous working relationships with other EM-50 programs including: the crosscutting work (e.g., Robotics), Industry Programs, International Programs, University Programs, EMSP, and the Accelerated Site Technology Deployment (ASTD) Program. For each of these programs, the TFA strives, through its integration role, to ensure planned and ongoing technology development work supports users' needs effectively, efficiently, and without duplication. The only reason the TFA invests in technology development activities is to reduce the risks associated with tank waste remediation. The risks include environmental, safety, and health risks to workers and the public; ecological risk to the environment; cost and schedule risks; programmatic risks; and technical risks. The strategic intent of the TFA is to work closely with EM-50's Risk Program, the tank site user programs, and the Site Technology Coordination Groups (STCGs) to develop a risk-based prioritization of needs, and to make technology investments in response to those needs.

The strategic intent of the TFA is to leverage every available investment in science and technology made by DOE and in doing so, engage the entire intellectual capacity of the nation in solving this problem. In the model illustrated in Figure 5.1, each element in the technology maturation cycle is linked to the elements on either side and to the DOE's industrial and international outreach programs. Moreover, the "downstream" programs are the customers for the "upstream" programs. For example, the users are the customers for the focus areas, while the focus areas are the customers for the crosscutting programs. Needs flow upstream

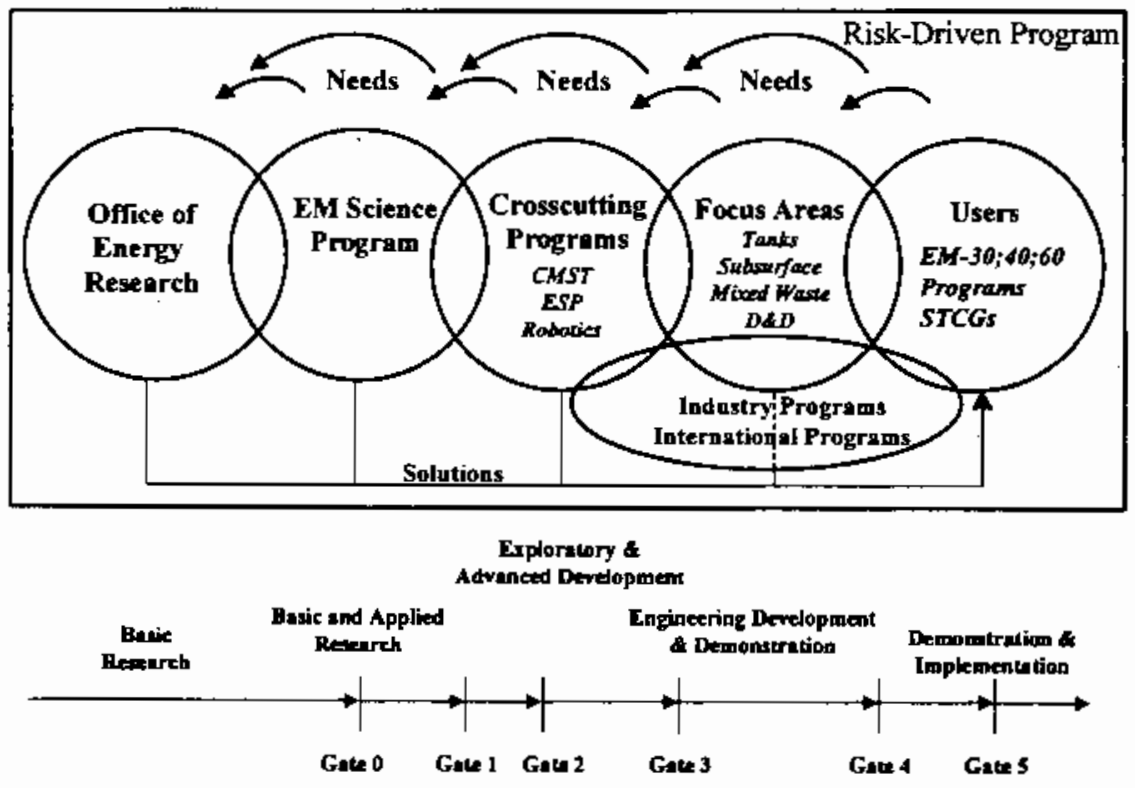

Figure 5.1. Tanks Focus Area Conceptual Strategy Model 
from the user, while science and technology solutions flow downstream to the user. However, users are the ultimate customer and can directly benefit from any "upstream" program. Deployment plans and memorandums of understanding will formalize the TFA's commitment to user, producer, and developer partnerships across sites regarding test variables and results that must be obtained to meet multi-site requirements and ensure technology implementation.

In FY99, the TFA envisions that it will be responsible for scope, schedule, and budget of EM-50's tanks program described in this MYPP. The TFA will coordinate tank-related work conducted by EM- 50 crosscutting programs, ASTD, EMSP, International and University Programs as well as related work being conducted by other focus areas and by each of the site's EM-30 or EM-40 programs. The TFA envisions greater management of a single focused program that crosses organizational boundaries with the TFA-managed scope covering tank technology work with potential multi-site applications. While site-specific technology will continue to be managed by each site, the TFA will be cognizant of all tank technology activities within EM to maximize beneficial coordination across sites, support site negotiations, and manage technical uncertainties with practical technical expertise.

\subsection{Crosscutting Programs}

As much as possible, the TFA remains cognizant of the activities in the other focus areas: Subsurface Contaminants; Mixed Waste; and Decontamination and Decommissioning. Furthermore, the TFA actively engages the EM- 50 crosscutting programs - Efficient Separations and Processing (ESP); Characterization, Monitoring, and Sensor Technology (CMST); and Robotics. The TFA is the customer for tank technologies developed in these programs and facilitates the technologies transition through the stage-gate framework from development to implementation. As such, the TFA requests support in areas consistent with its priority tasks (see Appendix $\mathrm{C}$ ) and actively works with these programs to review and transfer these technologies. This leveraging requires joint, timely planning, and Technical Team leadership by the TFA and other focus areas as well as crosscutting programs. To facilitate the cooperation, technical experts in each crosscutting program have been assigned to interface with the cognizant Technology Integration Manager within TFA. Annual meetings, technical seminars, workshops, and administrative planning are some of the means by which the integration is accomplished.

\subsection{Industry Program}

Industry's cooperation with TFA is secured through DOE internal contracts or DOE external competitively bid industrial contracts. The former process historically involved a DOE internal bid consisting of a consortium of entities, including industry, management and integration (M\&I) contractors, management and operations (M\&O) contractors, national laboratories, or universities with a DOE grant. Internal partnering has occurred when an existing DOE contractor solicits a partner for co-bidding a DOE project, or an industrial company approaches an existing DOE contractor to partner on an internal DOE solicitation for hids. The response to these calls must come from the DOE contractor who represents the consortium. Normally, 
these calls are limited to M\&Os, M\&Is, and national laboratories, universities with environmental research and development progtams that are recognized and supported by DOE.

Direct external contracts between TFA and industry are secured through a specific site procurement office (DOE or contractor) or through the DOE Federal Energy Technology Center (FETC) procurement office. The TFA does not directly request proposals nor do they accept unsolicited proposals either to their Management Team or any member of the technical staff. Rather, industrial partners are encouraged to communicate through FETC on all proposals, solicited or unsolicited. Responses or inquiries to requests for proposals (RFPs) solicited through an operating office or a support contractor should be directed to the issuer of the request. The DOE operations offices and DOE site contractors follow the Federal Acquisition Regulations and DOE Acquisition Regulations and have prescribed contractual procedures, which vary from site to site. Therefore, industry partners are encouraged to become familiar with the requirements of the site of interest before responding to RFPs.

\subsection{International Program}

The TFA's strategic intent for the International Program is the opportunistic leveraging and coordination of DOE's foreign investments in technology, performance data, and resources. This is accomplished through joint definition between the TFA and the user of the validated needs, negotiation of scope and deliverables with the international performers, and delivery and implementation of the final equipment to meet the users' schedules. Close cooperation between TFA and EM-50's International Technology Systems Applications Program has ensured that a suite of technology systems, ranging in maturity from developmental to final implementation, have been available and will continue to be available.

\subsection{University Program}

One means of identifying and fostering technology development is the nation's universities. The TFA's strategy for working with universities is to leverage resources available through the FETC University Program. Specifically, TFA works with those universities that have environmental research and development programs that are recognized by and supported by DOE in advancing science, technology development, and industrial relationships.

\subsection{EM Science Program}

Integrating science with technology programmatic assets is critical to the success of both TFA and EMSP. Acceleration of the technology development cycle through the integration of science can be achieved by maintaining multidisciplinary "technology fusion" teams that will deliver timely solutions to both short- and long-term environmental problems faced by DOE. The strategic intent of the TFA is to support strong programmatic and technical linkages between the EMSP, problem holders, and other EM programs. 
The success of the EMSP depends on the utility and application of its resuits. The science program must have mechanisms through which new information and discoveries can be communicated to the users, so that this new information can be deployed or employed to impact clean-up actions. The TFA will use numerous methods to foster communication such as annual workshops, special TFA seminars, and technical society symposia. The TFA has designated a single point of contact within the TFA Technical Team and the Management Team to be the EMSP representative. Additionally, technical highlights and reports generated by TFA will be distributed to the relevant EMSP principal investigators.

\subsection{Accelerated Site Technology Deployment Program}

The ASTD Program is chartered with accelerating the implementation of previously demonstrated technologies or processes in EM clean-up activities. Accomplishing this mission will require DOE complex-wide cooperation and coordination in identifying, verifying, implementing, and subsequently deploying the technologies. In FY99, the focus areas were more fully incorporated into ASTD to act as facilitators and integrators on ASTD projects. The TFA provides project coordination among all project participants keeping its partners, sponsors, customers, and stakeholders aware of project progress and issues, and the potential for application at other sites. 
$\mid$ 


\section{Section 6 - Technical Program}

\subsection{Technical Program Summary}

This section provides an overview of the technical program, including a brief discussion of assumptions and recommendations for a national science and technology program. In addition, this section summarizes TFA's technical strategies, planned accomplishments, and recommended program budget for addressing priority science and technology needs.

\subsubsection{Program Overview}

The TFA has continuously improved its program planning and development process since its inception in FY95, striving to meet and exceed the goals and strategies outlined in Section 4. In FY95, the TFA developed the organizational and technical basis for a nationally integrated technology program. During FY96, the TFA more fully developed an understanding of DOE complex-wide tank remediation issues. In FY97, the TFA established closer relationships with the users to improve the quality of the technical responses to site needs and to involve the users in program prioritization. This resulted in a consensus-based FY99 Internal Review Budget submission and construction of a multiyear program plan and final FY98 program that was approved by the HLW Steering Committee, representing the sites' AMs and the Deputy Assistant Secretary for the Office of Waste Management. In FY98, TFA further refined the process to 1) ensure technical responses to site needs meet the user requirements and are prioritized with the users, 2) ensure the program definition integrates all TFA activities and resources - including the core program, crosscutting programs, Industry Program, International Program, University Program, and ASTD - into a single, focus-area centered program to respond to the highest priority tank waste remediation needs, and 3) confirm user commitment to use the results of science and technology investments to meet their needs.

This document represents the cumulative and fully integrated science and technology program required to meet the priority needs of the tank waste remediation system at the four tank sites. Successful integration of all science and technology resources remains a challenge, and the TFA will continue to emphasize this as the key element of the focus-area centered concept. Constantly changing budget priorities and changing site needs demand constant and significant management and technical attention. With the force of the entire TFA team behind efforts to implement the focus-area-centered program, the next program development cycle should yield an even more responsive program for all EM tank investments. 


\subsubsection{Technical Program Structure}

The general process flowsheet for tank waste remediation is depicted in Figure 6.1. Each step in the process is further defined using a problem element structure (listed below each process step in Figure 6.1), which identifies discrete technical requirements and activities within the generic flowsheet. Tank waste remediation science and technology needs received from the sites are categorized within this structure. This structure provides a compact, understandable, and process- and systems-oriented foundation for managing program development and execution. The site needs assessment in FY98 (http://www.pnl.gov/tfa/needs/index.htm) resulted in technical responses to each site need that were organized within the problem element structure. These needs provided the basis for the multiyear program described in this document. The problem elements shown in bold are those for which site needs were received and for which TFA has developed technical responses and corresponding budgets in FY99 and beyond.

\subsubsection{Technical Strategies and Investments}

This section summarizes the technical basis and strategies for FY99 and beyond for each process step and corresponding problem element depicted in Figure 6.1. More detailed descriptions of the technical needs, strategies, and technical activities are provided in Section 6.2. Table 6.1 provides a summary of the budget requests to address top priority needs for FY99 and FY00 and all priority needs for FY01 and beyond. The requested budget is $\$ 39.8 \mathrm{M}$ and $\$ 50.3 \mathrm{M}$ for FY99 and FY00, respectively. The FY01-FY03 budget requests assume unconstrained funding levels but are based on current FY98 site need submittals. As these outyears approach, TFA anticipates that new issues and problems will give rise to additional, high-priority site needs that cannot be predicted at this time. Therefore, work activities planned for FY00 and beyond may be delayed or rescoped depending on the actual budget level authorized and changing needs and priorities of the sites. The TFA-managed program includes activities to ensure integration of complex-wide needs, timely delivery of responsive technical solutions, and leveraging of all available resources to address the national tank remediation priorities. These activities include technical strategy development, technology delivery, and overall program management. Therefore, budgets identified in Table 6.1 include costs for these activities.

\section{Safe Waste Storage}

Investments in safe waste storage are needed to fill technical gaps, reduce costs, and avoid costly problems while ensuring protection of the public and environment. Priority site needs are focused on science and technology to 1) improve tank integrity monitoring and corrosion prevention, 2) improve tank ventilation, 3) improve waste characterization, and 4) reduce the volume of waste entering the tank farm through source and recycle stream waste reduction.

Problem Element 1.1.1 is to "Extend Tank Life." The TFA's near-term goal to avoid tank corrosion is to improve upon methods for maintaining tank waste chemistry within site specifications by adapting commercial monitors for in-tank analysis of inhibitors and major species that control corrosion rate. The longer-term strategy for avoiding corrosion in tanks 


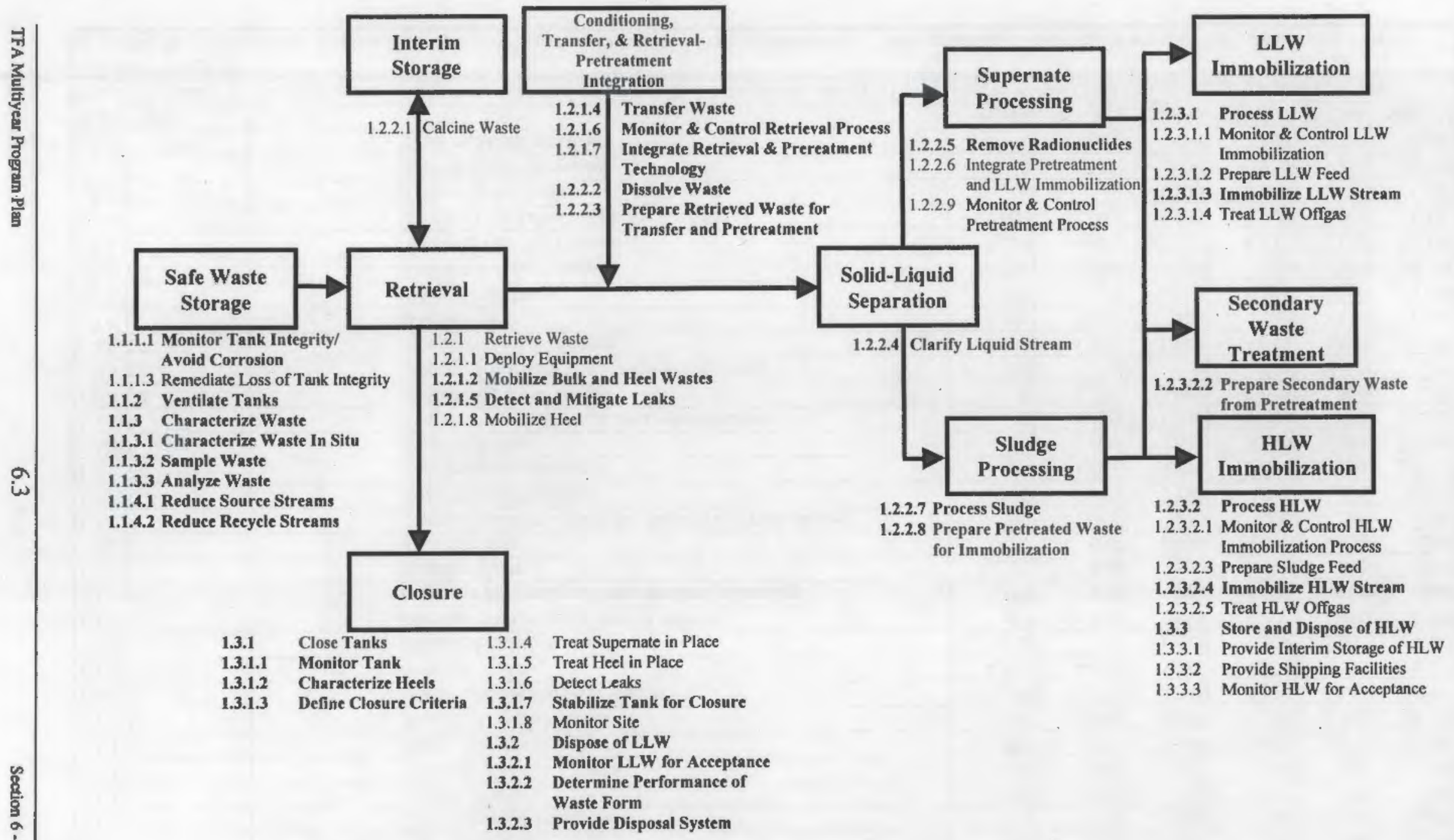

Figure 6.1. Generic Tank Remediation Flowsheet 
Table 6.1. Tanks Focus Area 5-Year Funding

\begin{tabular}{|c|c|c|c|c|c|c|c|c|}
\hline Problem Element \# & Need ID & Problem Element Title & $\overline{\text { FY99 }}$ & FY00 & FY01 & FY02 & FY03 & Total \\
\hline$\overline{1.1 .1 .1}$ & & Monitor Tank Integrity/Avoid Corrosion & 500 & 3,150 & 2,350 & 1,550 & 1,550 & $\overline{9,250}$ \\
\hline 1.1 .2 & & Ventilate Tanks & 495 & 625 & 450 & 100 & 100 & 1,770 \\
\hline 1.1 .3 .1 & & Characterize Waste In Situ & 0 & 0 & 600 & 500 & 500 & 1,600 \\
\hline 1.1 .3 .2 & & Sample Waste & 1,160 & 753 & 855 & 350 & 350 & 3,468 \\
\hline 1.1 .3 .3 & & Analyze Waste & 560 & 290 & 205 & 200 & 200 & 1,455 \\
\hline 1.1.4.1 & & Reduce Source Streams & 225 & 925 & 3,300 & 3,900 & 4,000 & 12,350 \\
\hline 1.1 .4 .2 & & Reduce Recycle Streams & 5,295 & 3,863 & 3,665 & 4,750 & 4,850 & 22,423 \\
\hline 1.2 .1 .2 & & Mobilize Bulk and Heel Wastes & 4,183 & 4,837 & 5,375 & 4,025 & 4,125 & 22,545 \\
\hline 1.2 .1 .4 & & Transfer Waste & 4,811 & 4,590 & 5,435 & 4,750 & 4,950 & 24,536 \\
\hline 1.2 .1 .5 & & Detect and Mitigate Leaks & 0 & 0 & 1,125 & 1,500 & 1,500 & 4,125 \\
\hline 1.2 .1 .6 & & Monitor and Control Retrieval Process & 559 & 615 & 1,555 & 1,400 & 1,450 & 5,579 \\
\hline 1.2 .1 .7 & & Integrate Retrieval and Pretreatment Technology & 573 & 465 & 210 & 200 & 200 & 1,648 \\
\hline 1.2 .2 .1 & & Calcine Waste & 0 & 400 & 500 & 500 & 500 & 1,900 \\
\hline 1.2 .2 .2 & & Dissolve Waste & 0 & 600 & 1,400 & 1,400 & 1,400 & 4,800 \\
\hline 1.2 .2 .3 & & Prepare Retrieved Waste for Transfer and Pretreatment & 572 & 465 & 210 & 200 & 200 & 1,647 \\
\hline 1.2.2.4 & & Clarify Liquid Stream & 990 & 500 & 750 & 800 & 850 & 3,890 \\
\hline 1.2 .2 .5 & & Remove Radionuclides & 3,829 & 5,709 & 5,850 & 6,050 & 6,250 & 27,688 \\
\hline 1.2 .2 .7 & & Process Sludge & 525 & 2,500 & 3,465 & 3,200 & 3,200 & 12,890 \\
\hline 1.2 .2 .8 & & Prepare Pretreated Waste for Immobilization & 0 & 1,400 & 1,000 & 1,200 & 1,200 & 4,800 \\
\hline 1.2 .3 .1 .3 & & Immobilize LLW Stream & 0 & 1,375 & 900 & 1,000 & 1,000 & 4,275 \\
\hline 1.2 .3 .2 .2 & & Prepare Secondary Waste from Pretreatment & 75 & 0 & 0 & 0 & 0 & 75 \\
\hline 1.2 .3 .2 .4 & & Immobilize HLW Stream & 3,150 & 4,450 & 5,040 & 4,840 & 4,890 & 22,370 \\
\hline 1.3 .1 .1 & & Monitor Tank & 956 & 463 & 250 & 150 & 150 & 1,969 \\
\hline 1.3 .1 .2 & & Characterize Heels & 200 & 108 & 1,050 & 1,250 & 1,300 & 3,908 \\
\hline 1.3 .1 .3 & & Define Closure Criteria & 8,000 & 9,008 & 800 & 950 & 950 & 19,708 \\
\hline 1.3 .1 .7 & & Stabilize Tank for Closure & 1,154 & 1,212 & 5,600 & 6,075 & 6,125 & 20,166 \\
\hline 1.3 .2 .1 & & Monitor Low Level Waste for Acceptance & 1,000 & 1,600 & 1,500 & 1,200 & 1,200 & 6,500 \\
\hline 1.3 .2 .2 & & Determine Performance of Waste Form & 0 & 0 & 1,100 & 1,400 & 1,400 & 3,900 \\
\hline 1.3 .2 .3 & & Provide Disposal System & 0 & 359 & 2,900 & 3,750 & 3,750 & 10,759 \\
\hline 1.3 .3 & & Store and Dispose HLW & 0 & 0 & 960 & 1,260 & 1,260 & 3,480 \\
\hline Grand Total & & & 39,812 & 50,262 & 58,400 & 58,500 & 59,500 & 266,474 \\
\hline
\end{tabular}

Note: 1) Includes TFA core program funding, plus dedicated funding to TFA activities by other OST programs, including Cross Cut, Industry, International, and University Programs.

2) All funding estimates are for planning purposes only and are not official funding information. These estimates do not include any required management costs. 
includes development and assessment of corrosion monitoring methods that provide more direct and real-time measurement of the corrosion potential within a tank than do corrosion coupons. The strategy for evaluating tank integrity also includes near- and longer-term approaches. Commercial NDE techniques will be deployed near term using an arm-based or crawler-based system to inspect tank walls. Longer-term efforts will integrate needs from multiple sites to define, develop, and test the specific systems needed to imspect tank floors, inspect surfaces below a liquid level, and assess a tank's integrity before reuse or waste retrieval. Specific technologies supported by the TFA to replace the baseline techniques include

- Develop an electrochemical noise corrosion monitor, which is deployed through a tank riser, for use at SRS and Hanford.

- Develop a Raman-based nitrate, nitrite, and hydroxide $\left(\mathrm{NO}_{2}^{-}{ }^{-} \mathrm{NO}_{3}{ }^{-} / \mathrm{OH}\right)$ in-tank sensor for corrosion inhibitor concentration monitoring at SRS.

- Develop NDE end effectors to be deployed by an LDUA or crawler-based platform.

Problem Element 1.1.2 is titled "Ventilate Tanks." The TFA's goal regarding this problem elenient is to reduce the cost of active ventilation. Specific activities include

- Explore and evaluate passive ventilation concepts for use in replacement of the active ventilation systems on specific waste tanks at SRS.

- Select and demonstrate regenerable filter systems to replace HEPA filters within the existing active ventilation system. A commercial system will be procured for demonstration.

Problem Element 1.1.3 is titled "Characterize Waste." The TFA's goal regarding this problem element is to invest in tools and methods to characterize waste in situ to support sludge and supernate processing at SRS and ORR. Specifically, the TFA will

- Develop and deliver a weight percent suspended solids monitor for SRS use in sludge settling and decanting operations to ensure continued feed to DWPF and process evaporators.

- Develop a sludge mapping system for ORR to determine the volumes and interface between supernate, sludge, and/or hard heel.

- Develop and deploy nested-array fluidic sampler and at-tank analysis system into Hanford waste tank to support feed staging for waste treatment.

Problem Element 1.1.4 is titled "Reduce Waste Volumes." The TFA's goal regarding this problem elenient is to implement technologies to reduce source and recycle streams at SRS and INEEL. Specifically, the TFA will

- Assemble a treatment train of commercially available technologies to meet the waste acceptance criteria for SRS's liquid effluent treatment plant. Specifically, the TFA will evaluate the use of a compact processing unit concept to avoid large capital expenditures on new facilities. The TFA will also evaluate options for reducing mercury concentration in this stream, which would reduce the complexity of the treatment train. 
- Design and evaluate the potential for direct waste stream immobilization and on- or offsite disposal as low-activity waste (LAW) to avoid a costly treatment process and avoid increased volumes of tank high-activity waste (HAW) requiring treatment at INEEL.

For more information on these problem elements, see Section 6.2.

\section{Retrieval}

Investments in waste mobilization and retrieval fill technical gaps and reduce costs while ensuring safe operations. Priority site needs are focused on science and technology to 1) mobilize and retrieve bulk and heel wastes including sludge and saltcake, and 2) detect and mitigate leaks during retrieval.

Problem Element 1.2.1.2 is titled "Mobilize Bulk and Heel Waste." The TFA's goals regarding this problem are to provide the following technologies and technical solutions:

- Pulsed air systems developed by industry (i.e., Pulsair ${ }^{\circledR}$ ) to suspend solids before transfer at ORR Gunite and Associated Tanks (GAATs) (also part of waste conditioning for transfer).

- Jet pump eductor improvements to extend operating life in support of GAAT retrieval at ORR.

- Fluidic systems developed and used in the United Kingdom (higher jet-velocity sluicing system) to suspend and transfer solids at ORR's Bethel Valley Evaporator Service Tanks (BVESTs).

- Salt dissolution and retrieval methods for removing salt from tanks and tank annulus at SRS.

- Modified density gradient techniques coupled with low flow rate pumps for bulk saltcake dissolution and removal at SRS without mixer pumps.

- Enhanced sluicing systems including enhanced nozzle and sweep designs for Hanford.

- Russian pulse-jet pump technology for slurry mobilization and transfer.

- Sludge mobilization and retrieval techniques for sludge heel retrieval at SRS.

- Improved operation of baseline mixers at SRS.

- Alternate mixer technology to enhance bulk retrieval at SRS and Hanford.

Problem Element 1.2.1.5 is titled "Detect and Mitigate Leaks." The TFA's goals relating to this problem are to provide retrieval methods that avoid leakage by controlling and minimizing water, provide leak detection devices that can rapidly output data to guide retrieval operations, and create strategies to mitigate leaks once detected during retrieval. To address this goal, the TFA will

- Emphasize industry support and technology to develop methods for leak detection and mitigation.

For more information on these problem elements, see Section 6.2. 


\section{Conditioning, Transfer, and Retrieval-Pretreatment Integration}

Retrieved wastes need to be transferred, and may require monitoring and conditioning to avoid problems with re-precipitation, solids formation, plugging of transfer lines, and settling or simply to enhance downstream processing. Investments are needed for data and technologies to ensure the interface between retrieval and pretreatment avoids unwanted problems.

Problem Element 1.2.1.4 is "Transfer Waste." The TFA's goals relating to this problem are to deliver data and systems to reduce the risk during waste retrieval and waste transfers. Specific activities include

- Evaluate the impacts of physical and chemical conditions on waste rheology and transfer for Hanford, ORR, and SRS waste types.

- Identify and test pipeline plug-locating technologies.

- Adapt and test commercial systems for pipeline unplugging with side-by-side testing to evaluate the merits of a variety of systems. Functions and requirements, primarily from Hanford and SRS, will be used to select and test industry technologies acquired through a joint program between TFA and Industry Programs.

- Develop and deploy a waste conditioning compact processing unit (CPU) for monitoring and conditioning for safe transfer of GAAT waste to Melton Valley Storage Tank (MVST).

Problem Element 1.2.1.6 is titled "Monitor and Control Retrieval Process." The TFA's goals regarding this work are

- Deploy on-line slurry monitor to support GAAT retrieval at ORR.

- Develop improved gas retention sensing system to avoid problems during retrieval of Hanford HLW tanks.

Problem Element 1.2.2.3 is to "Prepare Retrieved Waste for Transfer and Pretreatment." The TFA's goal regarding this problem is to ensure retrieved wastes are ready for downstream processing. Specific activities include

- Evaluate saltcake dissolution and concentrate re-precipitation phenomena in complex solutions using nonradioactive surrogates to upgrade thermodynamic models to support retrieval and storage operations at Hanford for privatization.

- Study dilution, leaching, and washing of Hanford sludge, in conjunction with Problem Element 1.2.2.7 to provide information on the solubility of components in complex solidliquid systems and identify the operating envelope required to minimize solids formation problems during pretreatment.

For more information on these problem elements, see Section 6.2.

\section{Interim Storage}

Interim storage includes those activities to enable storage of wastes as dry materials. Efforts are focused on calcination and dissolution of INEEL wastes and processing of Hanford's cesium and strontium capsules. 
Problem Element 1.2.2.1 is titled "Calcine Waste" and Problem Element 1.2.2.2 is titled "Dissolve Waste." The TFA's goals are to provide data and technology to enable waste processing at INEEL. Specific activities include

- Develop and pilot test an advanced calcination flowsheet that will handle the sodiumbearing wastes while minimizing the chemical additives, controlling volatilization and fines generation, and producing a calcine that is safe and effective to transport, retrieve, dissolve, and is compatible with immobilization.

- Evaluate the chemistry and dissolution behavior of existing calcine and bench-test preferred dissolution schemes to support flowsheet design decisions.

- Develop process for disassembling and processing Hanford's cesium and strontium capsules.

For more information on these problem elements, see Section 6.2.

\section{Pretreatment}

Investments in waste pretreatment must be fully integrated with waste immobilization, which receives feed from pretreatment processes, and waste retrieval, which provides feed to pretreatment. The pretreatment step is critical to reducing the volume of LLW and HLW products; this reduces disposal costs. Investments include clarifying liquid streams through solid-liquid separations, supernate processing to remove radionuclides, and sludge processing to remove excess chemical species that either increase the volume of HLW or adversely impact the performance of the HLW form. On Figure 6.1, pretreatment is shown as these three investments.

Problem Element 1.2.2.4 is titled "Clarify Liquid Streams." The TFA's goal regarding this activity is to deliver data and technologies to meet ORR, SRS, Hanford, and NEEL needs for process selection. Specific activities include

- Demonstrate operation of the cross-flow filtration system by treating Melton Valley Storage Tank (MVST) supernate.

Problem Element 1.2.2.5 is titled "Remove Radionuclides." This includes reducing the levels of cesium, technetium, strontium, or TRU to meet LLW disposal requirements onsite. The TFA's goal regarding radionuclide removal for alkaline wastes is to deliver improved cesium separations systems to reduce cost and technical risk at INEEL and SRS. Specific activities include

- Evaluate crystalline silicotitanate and other sorbents or extraction processes to develop an alternative processing system to ITP and provide cesium removal for the DWPF recycle stream (see problem element 1.1.4) for SRS.

- Deploy process monitor to detect and measure cesium in process effluents through the CMST. 
The TFA's goal for TRU, cesium, and strontium removal from acidic wastes is to provide performance and engineering data to INEEL users on solvent-extraction and ion-exchange processes to confirm their baseline process assumptions, support the record of decision, and support Title 1 design. The TFA's goals are

- Demonstrate TRU and strontium solvent-extraction processes at INTEC with actual wastes.

- Develop an integrated cesium solvent-extraction process through the Efficient Separations and Processing Crosscutting Program for consideration as part of the INEEL flowsheet.

- Test alternative cesium and strontium separations processes through the Efficient Separations and Processing Crosscutting Program to provide additional performance data to support flowsheet development and downselects.

Problem Element 1.2.2.7 is titled "Process Sludge." The TFA's goal relating to this work is to provide Hanford with baseline processing data to support phase II privatization. Specific activities include

- Evaluate chromium removal performance during sludge washing and identify methods (e.g., oxidative leaching and caustic leaching) to improve chromium removal to ensure a baseline exists that can reduce the impact of chromium on HLW glass volume and subsequent immobilization costs.

- Conduct a scale up and processing evaluation on settle-decant to ensure that combined washing and settling operations can be adequately designed and scaled to support Hanford phase II privatization.

Problem Element 1.2.2.8 is titled "Prepare Pretreated Waste for Immobilization." The TFA's goals relating to this work are to support INEEL, SRS, and Hanford with improved volume reduction processes to reduce waste immobilization costs and technical risks. Specific activities include

- Salt splitting and membrane separation for caustic recovery at SRS and Hanford. Evaluation of full-scale costs and process performance is needed to compliment previous laboratory- and bench-scale testing.

- Design and testing of appropriate evaporation technology to provide pretreatment of INTEC HAW and LAW at INEEL.

For more information on these problem elements, see Section 6.2.

\section{Waste Immobilization}

Waste immobilization includes LLW immobilization, secondary waste treatment, and HLW immobilization. Efforts are focused on reducing cost and enhancing the baseline at SRS, as well as filling technical gaps in the baseline for Hanford and INEEL.

Problem Element 1.2.3.1 is titled "Process LLW." The TFA's goals regarding immobilizing LLW are to establish baseline processes for INEEL LAW immobilization and support Hanford and ORR privatization. Specific activities include 
- Support INEEL with LAW stream pretreatment and immobilization development for the FY99 record of decision and Title 1 design for INEEL's unique waste streams.

- Provide technical support to ORR in their privatization efforts.

- Develop data and technical methods for Hanford to ensure, through in-process quality assurance and possible testing methods, that the privatization vendor products meet acceptance criteria.

Problem Element 1.2.3.2 is titled "Process HLW." The TFA's goals regarding HLW processing are to reduce costs of $\mathrm{HLW}$ processes at SRS and to reduce the technical risks of HLW processing at INEEL and Hanford through process definition. Specific activities relating to this goal include

- Optimize waste loading for components such as iron, aluminum, silicon, zirconium, and alkali cations in SRS and Hanford wastes, and determine solubilities in glass of

- Minor components such as chromium, phosphate, halides, technetium, and actinides to optimize waste loading of these components.

- Establish glass compositions for INEEL's sodium-bearing and calcined wastes to avoid highly corrosive environments and produce acceptable waste forms.

- Test melters for use at INEEL to ensure compatibility of wastes and materials of construction.

- Develop and demonstrate equipment improvements such as melter pour spout (Florida International University and Clemson University), improved melter designs, and improved remote operations for DWPF to reduce downtime and increase throughput.

Problem Element 1.3.2 is titled "Dispose of LLW." The TFA's goal for FY99 and beyond regarding LLW disposal is to ensure that data to support the design of LLW disposal systems are available. Specific activities include

- Integrate efforts with the Hanford Vadose Zone/Groundwater project.

- Integrate with LLW disposal efforts.

- Integrate with ongoing and past science and technology investments (including Subsurface Contaminants Focus Area and EM Science Program) to define and prioritize specific technical issues to be addressed to improve performance assessment and design data to support Hanford.

- Provide technical data relating glass composition and waste form durability to support product acceptance and performance assessment analyses.

Problem Element 1.3.3 is titled "Store and Dispose HLW." The TFA's goals for FY99 and beyond regarding storage and disposal of HLW are to ensure that methods and data are available to support the disposition of secondary wastes from HLW processing and to store and transfer HLW. Specific activities include

- Develop techniques for the disassembly of failed $\mathrm{HLW}$ processing equipment including glass melters.

For more information on these problem elements, see Section 6.2. 


\section{Closure}

Tank closure activities include sampling or characterization of tank residuals, defining the closure criteria (i.e., answering the question "how clean is clean?"), and stabilizing the tank for closure.

Problem Element 1.3.1 is titled "Close Tanks." Investments in tank closure include advancements in grout formulations and delivery methods to reduce costs and improve performance for immobilizing residual tank waste and stabilizing SRS and ORR tanks. In addition, all aspects of tank isolation and stabilization for ORR and establishment of a basis for closure at Hanford and INEEL are required to reduce mortgages and move forward with retrieval and final tank closure decisions. The TFA's goal for FY99 and beyond regarding closing tanks is to deliver the technologies and data to enable all four tank sites to proceed toward closure. Specific activities relating to this goal include

- Deploy the LDUA at INEEL to sample tank residuals, evaluate tank integrity, and support strategy development for accelerated tank closure (see problem element 1.1.1.1).

- Develop and demonstrate vadose zone characterization tools for deployment with the cone penetrometer to support tank farm closure performance evaluations and development of retrieval performance criteria within HTI.

- Develop retrieval performance objectives to support the determination of closure basis.

- Characterization, retrieval, out-of-tank processing of retrieved waste, process monitoring, and in situ grouting systems will be used at ORR at GAAT to close the North and South Tank Farms by FY02. Technology from Robotics, Industry, CMST, and TFA will be used (GAAT Treatability Study). TFA will develop and deploy tools using the LDUA to isolate and plug tank penetrations (e.g., piping) and develop, test, and deploy grout formulations and grouting techniques to stabilize a gunite tank. The TFA will build off of efforts at SRS in FY97 with Tanks 17 and 20 and provide performance data on grouting to support additional tank stabilization activities at SRS, Hanford, and INEEL.

- Grouting and closure of smaller tanks at ORR and SRS will be accomplished through testing and deployment of improved multipoint grout injection methods.

- The sampling and retrieval of wastes from ancillary equipment, such as a tank farm evaporator at SRS, will be accomplished to support closure of the remaining tanks and tank farm at SRS.

For more information on these problem elements, see Section 6.2.

\subsection{TFA Problem Elements}

The TFA problem elements are described on the following pages. Together, these problem elements form the core of the TFA program as depicted in Figure 6.1. Each problem element description includes the following sections: Title, Problem Element Description and Priority Site Needs, and Technical Tasks. The Problem Element Description and Priority Site Needs section includes a table with the site need number, the title of the need as submitted by the site, the Program Baseline Summary (PBS) number for each need, the title of the technical task addressing the need, and the OST technology need number. In several instances, a need statement submitted by a site may include several needs that are addressed in several problem 
elements. Each technical task description includes a title, a brief summary of the need being addressed, and a list of key activities and schedule to resolve the need. For those activities funded in FY99, Budget Profiles are provided that show the associated Technical Task Plan (TTP) numbers and budgets. In a few instances, it was not possible to clearly identify the funding split when a particular TTP task spanned two or more problem elements. Acronyms are called out in each problem element.

Figures 6.2 through 6.5 show the path to closure for the Hanford Site, INEEL, ORR, and SRS. For each, key TFA activities supporting the path to closure are identified. 
- Deploy EN/MIT Corrosion Probe - FY99

- Complete Vendor Testing, AEA Nested Sampler - FY99

- Deploy Cone Penetrometer in AX-104 Vadose Zone HTI - FY99

- Issue HTI Closure Alternatives/Conclusions/Recommendations - FY99

- Select HTI C-106 Retrieval System Vendor - FY99

- Demonstrate Nested Sampler - FY0O

- Deploy LDUA for Sampling of AX-104 HTI - FY0O

- Deploy C-106 Heel Retrieval System - FY0I

- Deploy Nested Sampler - FYOI

- Demonstrote At-Tank Analysis System - FY01

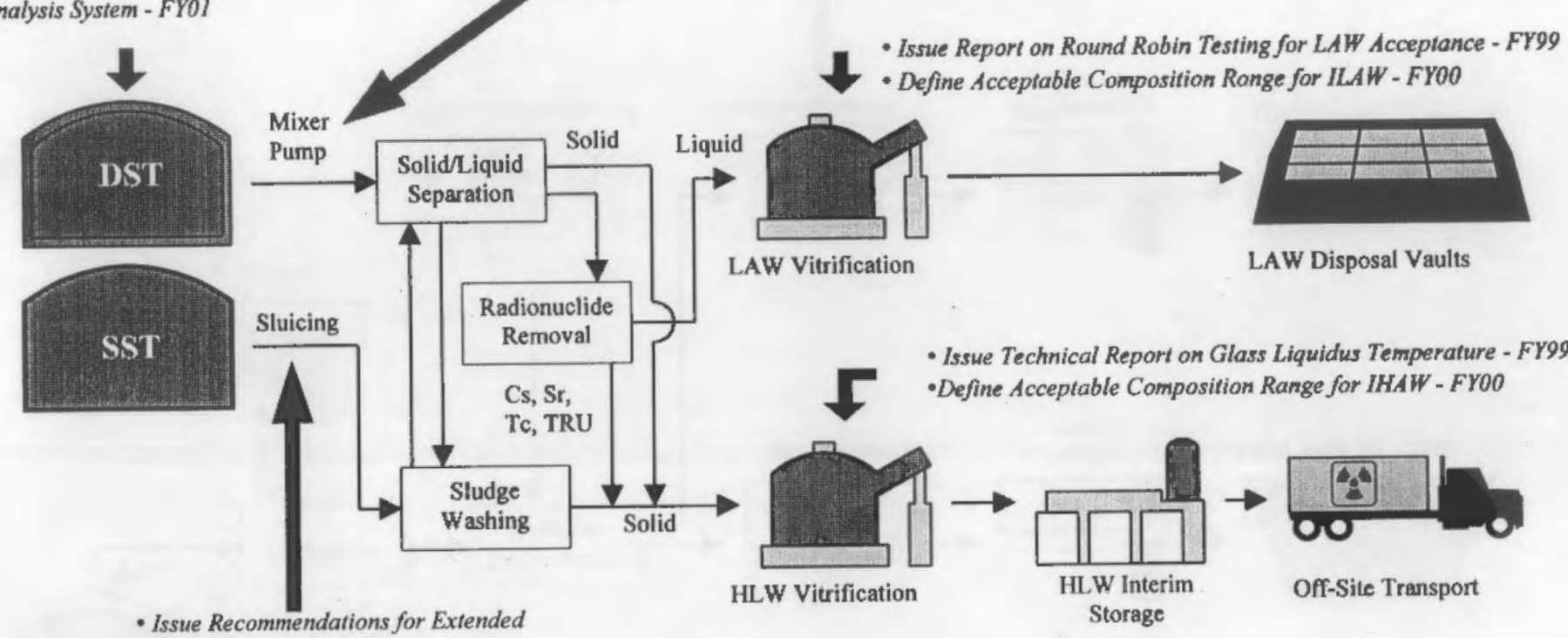

Sludge Retrieval - FY99

- Issue Recommendations for Sludge

Retrieval - FY0O

- Demonstrate Full-Scale Alternate Mixer System - FY00

- Issue Recommendations for Control of Solid Formation - FYOO

- Demonstrate Saltcake Dissolution at Pilot-Scale - FY0O

Figure 6.2. Hanford Site Path to Closure 
- Deploy LDUA \& NDE End Effector for Tank Wall Inspectian - FY99

- Complete LDUA Heel Sample Analysis Report - FY99

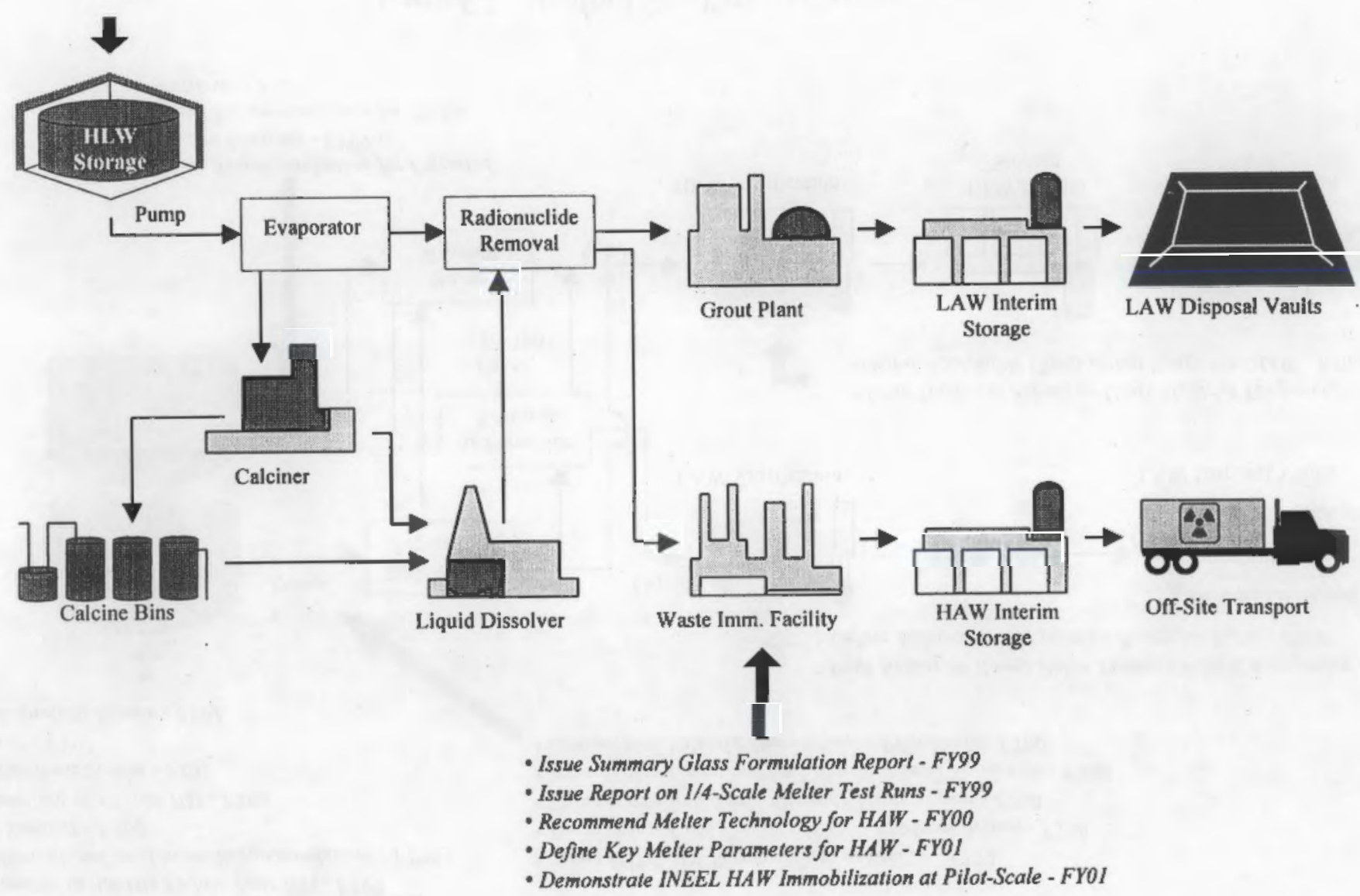

Figure 6.3. Idaho National Engineering and Engineering Laboratory Path to Closure 
- Issue Deployment Plan for Grouting of GAAT/FFA Tanks - FY99 - Deploy/lssue Performance Report on Pipe Capping System - FY99 - Deploy Grout Injection Technology in ORR Tanks - FY00

- Complete Closure of FFA Tank - FYOO

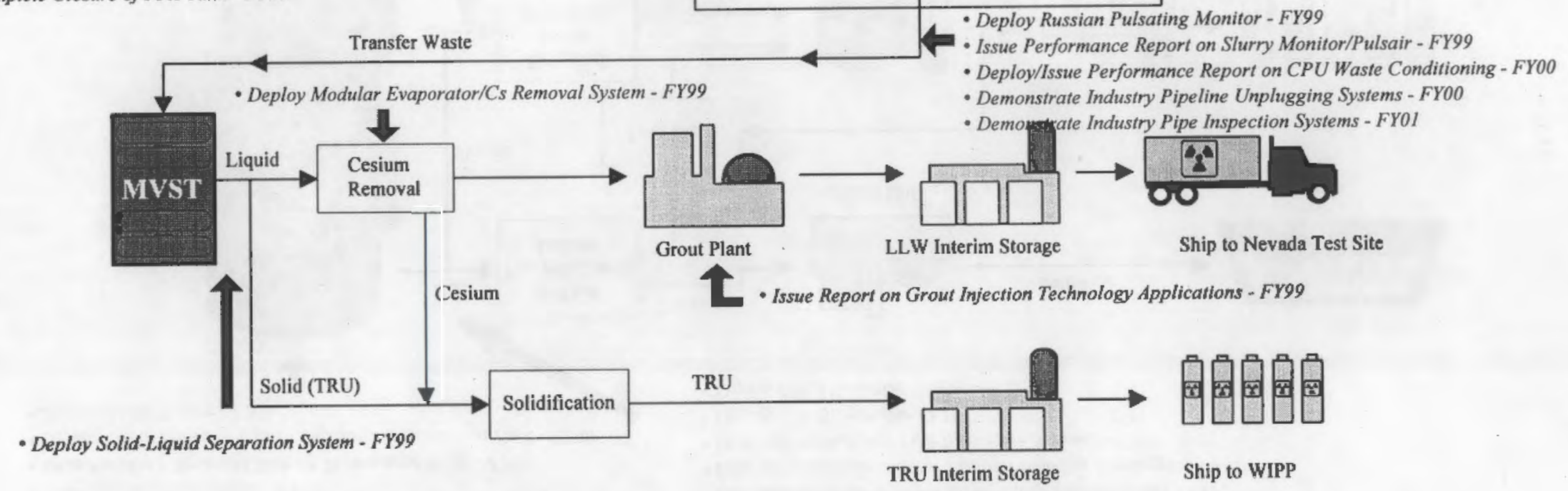

Figure 6.4. Oak Ridge Reservation Path to Closure 
- Issue Test Report on Criticality Mitigation for Solt Dissolution - FY99

- Deploy Tank 19 Heel Retrieval System - FY99

- Issue Report on ITP Alternative Evaluation \& Recommendation - FY99

- Receive CIF Evaporator from Vendor - FY99

- Issue Specification for Demonstration of ITP Alternotive - FY00

- Hot Test Raman Probe for Corrosion Monitoring - FY99

- Complete Cold Demonstration of Corrosion Species Probe - FY99

- Complete Vendor Testing/Issue Test Repart an Metal Filters - FY99

- Issue Report on Grout Injection Technology Applications - FY99

- Demonstrate CIF Evaporator - FY00

- Deploy Corrosion Species and EN Probes - FY00

- Demonstrate Metal Filters - FY00

- Issue Russian Chemical Cleaning Recommendations - FY0O

- Deploy Grout Injection/Close OBG Solwent Extraction Tank - FY00

- Deploy Metal Filfers - FYOI

- Demonstrate Full-Scale Alternate Mixer System - FY00

- Deploy Salt Retrieval System in Tank 16 - FY00

- Demonstrate Industry Pipeline Unplugging Systems - FY0O

- Deploy Retrievol System in Type I/II Tank - FY0I

- Issue Recommendations for Mixer Pump Improvements - FYOI

- Issue Recommendations for Transfer/Pipeline Unplugging - FY01

- Demonstrate Industry Pipe Inspection Systems - FY01

- Deploy CIF Evaporator - FYOI

- Deploy ITP Alternative System - FY02
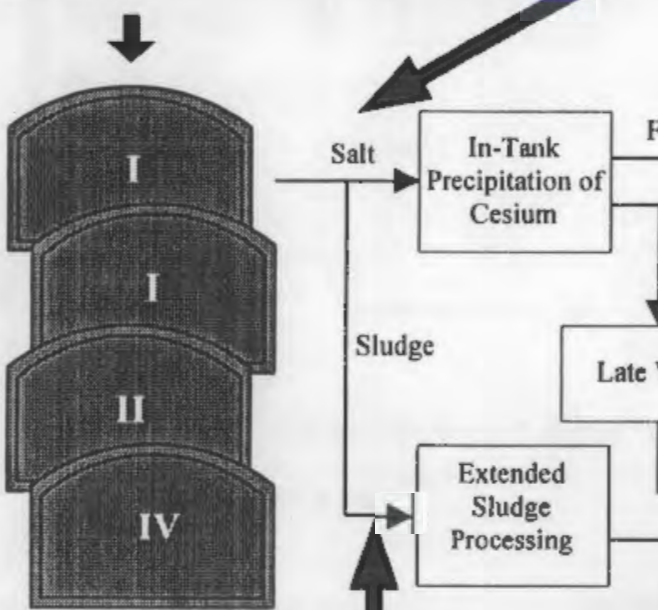

Itrate

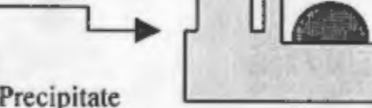

Saltstone

Grout Plant

Sludge

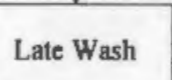

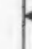

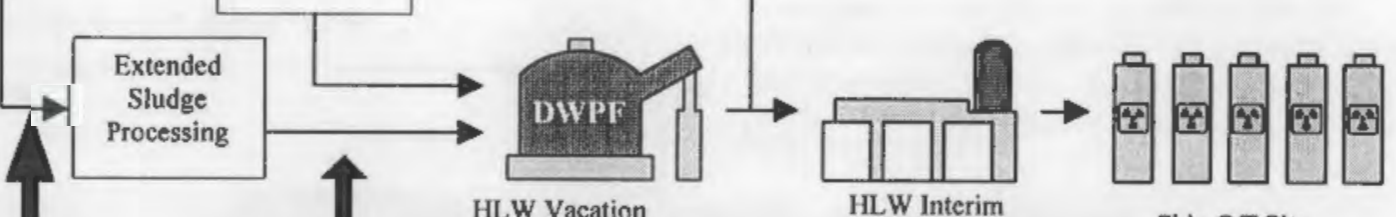

HLW Vacation

- Deploy Optimized Waste

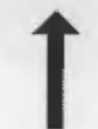

HLW Interim

Ship Off-Site

Loading in DWPF - FYOO

- Issue Recommendations for

Extended Sludge Retrieval - FY99
- Demonstrate Replacement of Melter Knije Edge - FY99

- Recommend Design for DWPF Melter Pour Spout/Riser Heaters - FYOO

- Recommend Design Requirements for Next Generation Melter - FYOI

Figure 6.5. Savannah River Site Path to Closure 


\section{Problem Element Description and Priority Site Needs}

Tank integrity and corrosion avoidance are critical issues during both long-term storage of radioactive tank wastes and during retrieval of tank wastes. Real-time corrosion inhibitor and corrosion monitoring methods are needed to provide early detection of potential problems that inay lead to leakage or structural failure. There is a need to perform nondestructive examination (NDE) of tank walls to determine structural integrity. Current methods are limited to contact examinations and usually require a cleaned surface and coupling between the head and structure being inspected. This problem element addresses methods to avoid corrosion of steel tanks and monitor the integrity of tanks to aid in early detection of tank problems that may lead to leakage, to minimize the potential for tank failure, and to reduce the costs of maintaining safe operating conditions. The site needs addressed in this problem element are identified below.

\begin{tabular}{|c|c|c|c|c|}
\hline \multicolumn{5}{|c|}{ Problem Element: 1.1.1.1 Monitor Tank Integrity/Avoid Corrosion } \\
\hline $\begin{array}{l}\text { STCG Need } \\
\text { Number }\end{array}$ & Need Title & $\begin{array}{c}\text { PBS } \\
\text { Number }\end{array}$ & Technical Task & $\begin{array}{c}\text { OST } \\
\text { Number }\end{array}$ \\
\hline RL-WT04 & DST Corrosion Monitoring & RL-TW03 & EN Corrosion Probe & 1985 \\
\hline SR-2919 & In-Tank Corrosion Probe Development & $\begin{array}{l}\text { SR-HL01, } \\
\text { SR-HL02, } \\
\text { SR-HL04 }\end{array}$ & EN Corrosion Probe & $\begin{array}{l}1985, \\
130, \\
1490\end{array}$ \\
\hline TK-01 & $\begin{array}{l}\text { ORNL Tank Waste Characterization } \\
\text { (Corrosion Monitor) }\end{array}$ & $\begin{array}{l}\text { OR-38112, } \\
\text { OR-38113, } \\
\text { OR-43201, } \\
\text { OR-43203 }\end{array}$ & EN Corrosion Probe & $\begin{array}{l}130 \\
1996\end{array}$ \\
\hline SR-2918 & $\begin{array}{l}\text { In Situ Methods for Characterization of } \\
\text { Tank Wastes }\end{array}$ & $\begin{array}{l}\text { SR-HL01, } \\
\text { SR-HL02 }\end{array}$ & $\begin{array}{l}\text { Corrosion Species } \\
\text { Monitor }\end{array}$ & 1985 \\
\hline RL-WT05 & $\begin{array}{l}\text { Remote Inspection of HLW Single-Shell } \\
\text { Tanks }\end{array}$ & RL-TW04 & $\begin{array}{l}\text { Nondestructive } \\
\text { Examination of Tanks }\end{array}$ & 1996 \\
\hline RL-WT022 & Tank Knuckle NDE & RL-TW03 & $\begin{array}{l}\text { Nondestructive } \\
\text { Examination of Tanks }\end{array}$ & 1996 \\
\hline SR-2909 & $\begin{array}{l}\text { Develop Advanced Techniques for Life } \\
\text { Extension of Tanks/Piping }\end{array}$ & $\begin{array}{l}\text { SR-HL01, } \\
\text { SR-HL02, } \\
\text { SR-HL04 }\end{array}$ & $\begin{array}{l}\text { Nondestructive } \\
\text { Examination of Tanks }\end{array}$ & N/A \\
\hline TK-01 & $\begin{array}{l}\text { ORNL Tank Waste Characterization } \\
\text { (Structural Integrity) }\end{array}$ & $\begin{array}{l}\text { OR-38112, } \\
\text { OR-38113, } \\
\text { OR-43201, } \\
\text { OR-43203 }\end{array}$ & $\begin{array}{l}\text { Nondestructive } \\
\text { Examination of Tanks }\end{array}$ & $\begin{array}{l}130 \\
1996\end{array}$ \\
\hline ID-2.1.10 & $\begin{array}{l}\text { Develop Technology to Characterize } \\
\text { Tank Farm Heel Residues (Tank } \\
\text { Inspection) }\end{array}$ & $\begin{array}{l}\text { ID-HLW- } \\
103\end{array}$ & $\begin{array}{l}\text { Nondestructive } \\
\text { Examination of Tanks }\end{array}$ & $\begin{array}{l}85,810 \\
890, \\
1996\end{array}$ \\
\hline
\end{tabular}

\section{Technical Tasks}

Electrochemical Noise (EN) Corrosion Probe

The Oak Ridge Reservation (ORR), Savannah River Site (SRS), and Hanford Site need improved real-time corrosion detection systems that can "fine tune" the amount of inhibitor needed and provide more rapid and less expensive methods to detect the corrosive characteristics of the tank wastes. A corrosion probe system that provides a real-time indication of 
corrosion potential in high-level waste (HLW) tanks at multiple levels or positions in the tank is needed to reduce the costs of chemical analysis and detection while providing data on tank conditions.

The EN probe is being developed as a corrosion-monitoring tool for HLW tanks. This technique can provide real-time, on-line measurements of the corrosion processes in the tank including the most probable processes of pitting and stress corrosion cracking. Development of the EN probe was initiated at Hanford and is being adapted for SRS. Future development of a stainless steel probe for application at ORR is anticipated. During FY98, Hanford designed and fabricated a second-generation EN prototype probe and SRS initiated work to evaluate signal response to waste compositions and to evaluate materials of construction.

Workscope to complete this task includes

- Design and deploy a third version of the EN probe using the Multi-Function Instrument Tree (MIT) approach (FY99, Hanford, RLO-8-WT-21).

- Collect data to support acceptance of EN corrosion probe as alternative for monitoring HLW tank corrosion (FY99, Hanford, RLO-8-WT-21, SRS, SRI-8-WT-21).

- Develop deployment plan for SRS corrosion probe (FY99, SRS, SRI-8-WT-21).

- Design and deploy fourth version of the EN probe including improved seal and improved data collection and analysis (FY00, Hanford).

- Deploy EN probe at SRS (FY00, SRS).

- Document final EN corrosion probe design (FY01, Hanford).

- Design and deploy stainless steel EN corrosion probe for application at ORR (TBD, Hanford, ORR).

\begin{tabular}{||l|c|c|c|c|c|c||}
\hline \multicolumn{7}{|c|}{ Budget Profile: EN Corrosion Probe } \\
\hline & TTP\# & FY 1999 & FY 2000 & FY 2001 & FY 2002 & FY 2003 \\
\hline \hline Hanford & RL08WT21 & 250 & 250 & 250 & TBD & TBD \\
\hline INEEL & & & & & TBD & TBD \\
\hline Oak Ridge & & & & & TBD & TBD \\
\hline SRS & SR18WR21 & 200 & 200 & 200 & TBD & TBD \\
\hline Total & & 450 & 450 & 450 & 0 & 0 \\
\hline
\end{tabular}

\section{Corrosion Species Monitor (Ion-Species Raman Probe)}

High-level liquid wastes at the SRS and Hanford Site are stored in carbon-steel tanks that are susceptible to nitrate ion-induced corrosion cracking. Monitoring and maintaining adequate nitrate, nitrite, and hydroxide ion levels prevents this degradation. Sensors that could monitor all three species would be optimal to reduce the costs of current baseline sampling and laboratory analysis methods, and to minimize the addition of inhibitor solution. Currently, inhibitor solution containing $\mathrm{NO}_{2}{ }_{2}$ and $\mathrm{OH}^{-}$is added in excess causing more liquid to be introduced into the tank, taking up much needed tank space and adding to the volume of waste that must eventually be retrieved and processed. Therefore, an increase in available 
tank space as well as a reduction in cost corresponding to the reduction in volume of waste requiring future processing would result if a $\mathrm{OH} / \mathrm{NO}_{3}{ }^{-} / \mathrm{NO}_{2}^{-}$monitor could be used to control the addition of inhibitor solution.

A corrosion species monitor is being developed by the Characterization, Monitoring, and Sensor Technology Crosscutting Program (CMST) as a technique for real-time, on-line monitoring of waste chemistry. A robust, in situ probe that uses Raman spectroscopy as the analysis technique is capable of measuring the nitrite/nitrate concentration and the hydroxide concentration. EIC Laboratories are developing the probe. Workscope to complete this task includes

- Complete design, fabrication, and cold acceptance testing on corrosion species monitor (FY99, SRS, SRI-8-WT-21, CMST).

- Demonstrate $\mathrm{NO}_{3}{ }^{-} / \mathrm{NO}_{2}{ }^{-} / \mathrm{OH}^{-}$chemistry probe in hot cell environment with tank waste samples (FY99, SRS, SRI-8-WT-21, CMST). Decision point for implementation.

- Deploy $\mathrm{NO}_{3}{ }^{-} \mathrm{NO}_{2}{ }^{-} / \mathrm{OH}^{-}$probe in selected waste tank at SRS (FY00, SRS).

\begin{tabular}{|c|c|c|c|c|c|c|}
\hline \multicolumn{7}{|c|}{ Budget Profile: Corrosion Species Monitor } \\
\hline & TTP\# & FY 1999 & FY 2000 & FY 2001 & FY 2002 & FY 2003 \\
\hline \multicolumn{7}{|l|}{ Hanford } \\
\hline \multicolumn{7}{|l|}{ INEEL } \\
\hline \multicolumn{7}{|l|}{ Oak Ridge } \\
\hline SRS & SR18WT21 & 50 & 250 & & & \\
\hline TFA Total & & 50 & 250 & 0 & 0 & 0 \\
\hline \multicolumn{7}{|l|}{ ASTD } \\
\hline CMST & NV08C231 & 120 & 400 & & & \\
\hline \multicolumn{7}{|l|}{ FETC } \\
\hline \multicolumn{7}{|l|}{ ESP } \\
\hline \multicolumn{7}{|l|}{ International } \\
\hline \multicolumn{7}{|l|}{ Robotics } \\
\hline EM-50 Total & & 170 & 650 & 0 & 0 & 0 \\
\hline
\end{tabular}

\section{Nondestructive Examination (NDE) of Tanks}

The need to perform NDE of tank walls and/or floors supports structural integrity determinations, tank life expectancy estimations, and retrieval strategy development. Current methods are limited to contact examinations and usually require a cleaned surface and coupling between the head and structure being inspected. This is very difficult in underground storage tanks, and improved methods that allow inspection to be performed without direct contact or through liquids are needed. The knuckle region of tanks where the walls and bottoms were joined by welding are believed to be primary sites for degradation and leakage to occur. This inspection must be performed remotely and provide the quantitative data on tank structure that is needed to ensure safety of current tank configurations and evaluate side loading limits. Hanford specifically needs an NDE system for both single- and double-shell tanks to support sluicing feasibility and life expectancy estimation. Systems that can be 
deployed using a remote device such as the Light-Duty Utility Arm (LDUA) or other similar robotic equipment are desired. Also, ORR, Idaho National Engineering and Environmental Laboratory (INEEL), and SRS have needs for tank inspection methods.

Work will be initiated in FY99 to identify and develop or adapt tank inspection technologies suitable to the harsh chemical and radiation environment of the waste tanks. Camera and NDE inspection systems mounted on a LDUA have the potential for addressing this need. INEEL will deploy its LDUA in a tank and use a weld inspection end effector and a camera to inspect walls. The T-SAFT technology may have application for inspection of tank knuckles. Work activities to support needs for tank integrity detection will include

\section{Visual Inspection}

- Develop, assemble, and acceptance test stereo-still photo system end effector (FY99, INEEL, ID7-7-WT-22).

- Demonstrate below-waste heel inspection tool for tank bottoms on surrogate waste heel (FY99, INEEL, ID7-7-WT-22).

- Deploy LDUA with SSTP and high-resolution stereo-video system to inspect tank integrity (FY99, INEEL, ID7-7-WT-22).

NDE

- Identify remote inspection technologies and deployment methods (FY00, SRS, INEEL, Hanford, ORR).

- Survey technologies available from the DOE complex, industry, and foreign companies.

- Develop specifications and selection criteria.

- Evaluate candidate technologies.

- Through an industry call, obtain NDE and deployment technologies.

- Prepare performance specifications.

- Perform acceptance testing after vendor fabrication.

- Deliver, cold test, and perform site qualification.

- Deploy NDE and deployment technologies.

- Develop decision logic to evaluate tank leakage potential from tank integrity data.

- Using data obtained from the NDE and camera along with data from other sources such as past leakage history, history of waste types in the tank, information from dry well around the tank, and records on corrosion inhibitor additions, develop a decision logic to evaluate potential for leakage in terms of tank integrity data (FY01, TFA, EM-30).

- Develop strategy for retrieval system selection based on potential for leakage. Reevaluate the selection method in terms of sensitivity to input information and redefine the analysis method if necessary. Document the method and ensure that technology issues are addressed, safety issues are resolved, and operational issues are addressed (FY01, TFA, EM-30). 
Problem Element Title: 1.1.1.1 Monitor Tank Integrity/Avoid Corrosion

\begin{tabular}{||l|c|c|c|c|c|c|}
\hline \multicolumn{7}{|c|}{ Budget Profile: Nondestructive Examination of Tanks } \\
\hline & TTP\# & FY 1999 & FY 2000 & FY 2001 & FY 2002 & FY 2003 \\
\hline \hline Hanford & & & & & & \\
\hline INEEL & ID77WT22 & 400 & & & & \\
\hline Oak Ridge & & & & & & \\
\hline SRS & & & & & & \\
\hline Total & & 400 & 0 & 0 & 0 & 0 \\
\hline
\end{tabular}




\section{Problem Element Description and Priority Site Needs}

Waste tank ventilation is necessary to maintain safe operating conditions within the tank farm. Ventilation systems prevent exposure of workers to highly radioactive aerosols and particulate that are generated within the waste tanks during waste decay, mixing, and transfer. Methods for active and passive waste ventilation and filtration are encompassed within this problem element. The site needs addressed in this problem element are addressed below.

\begin{tabular}{||c|l|l|l|l||}
\hline \multicolumn{5}{|c|}{ Problem Element: 1.1.2 Ventilate Tanks } \\
\hline $\begin{array}{c}\text { STCG Need } \\
\text { Number }\end{array}$ & \multicolumn{1}{|c|}{ Need Title } & $\begin{array}{c}\text { PBS } \\
\text { Number }\end{array}$ & \multicolumn{1}{c||}{ Technical Task } & $\begin{array}{c}\text { OST } \\
\text { Number }\end{array}$ \\
\hline \hline SR-2916 & $\begin{array}{l}\text { Develop Advanced Techniques to } \\
\text { Improve Safety Infrastructure } \\
\text { (Passive Ventilation) }\end{array}$ & $\begin{array}{l}\text { SR-HL01, } \\
\text { SR-HL02 }\end{array}$ & Passive Tank Ventilation & 1985 \\
\hline ID-2.1.13 & Washable Metal HEPA Filters & $\begin{array}{l}\text { ID-HLW- } \\
101\end{array}$ & $\begin{array}{l}\text { Alternative Air Filtration } \\
\text { Technology }\end{array}$ & 2091 \\
\hline SR-2901 & $\begin{array}{l}\text { Demonstrate Alternative Filtration } \\
\text { Technologies to Replace HEPA } \\
\text { Filters }\end{array}$ & $\begin{array}{l}\text { SR-HL01, } \\
\text { SR-HL02 }\end{array}$ & $\begin{array}{l}\text { Alternative Air Filtration } \\
\text { Technology }\end{array}$ & 2091 \\
\hline
\end{tabular}

\section{Tecbnical Tasks}

Passive Tank Ventilation

A primary cost of high-level waste (HLW) tank ventilation is operation and maintenance costs associated with the active ventilation system (i.e., blowers, condensers, demisters, heaters, and high-efficiency particulate air [HEPA] filters). In addition, upgrades to existing systems require significant capital investment. The Savannah River Site (SRS) is interested in alternatives to the active ventilation systems. For example, a passive device that ventilates the waste tank interior is needed. A tank top device is needed to purge the waste tank atmosphere of accumulated hydrogen gas and organic vapor. This type of system would need to provide a HEPA barrier between the tank atmosphere and the environment and provide an air exchange for a filled waste tank air space every 9 days (approximately $16,000 \mathrm{ft}^{3}$ volume).

Workscope to address the need for a passive ventilation system includes

- Procure passive ventilation system designs from industry.

- Develop performance specifications and issue an industrial request for proposal to solicit passive ventilation system designs (FY00, TFA, EM-30, FETC).

- Perform a technical evaluation and down-select to one or two designs for development of passive ventilation system prototypes for testing (FY00, TFA, EM-30, FETC).

- Test and demonstrate preferred prototype systems.

- Develop prototype passive ventilation systems, perform safety analysis, and develop operations requirements and installation procedures (FY00, TFA, EM-30, FETC).

- Construct and demonstrate the passive ventilation systems. Depending on safety requirements, cold test systems before hot testing in HLW tanks (FY00, TFA, EM-30, FETC). 
- Complete initial deployment of a passive ventilation system on selected HLW tank.

- Collect data and analyses to support necessary design changes for full-scale implementation (FY01, EM-30, TFA).

- Procure, construct, and deploy a final design unit (FY01, EM-30).

Alternative Air Filtration Technology

The HEPA filters are used to ensure that air emissions are free of radioactive particulates from tanks and waste processing operations. The glass fiber filters typically fail because of wetting. When the filters are replaced, personnel are exposed to radiation and the filters must be disposed of, increasing the cost of managing the tanks. Washable and recycleable HEPA filters will reduce personnel exposure and reduce the costs for processing and disposal of the filters.

Throughout the DOE complex, HEPA filters are used to ensure that air emissions to the environment are free of radioactive particulates. Filters are generally constructed of a 0.013-in.-thick glass fiber material and must meet the industry standard for $99.97 \%$ capture of $0.3-\mu \mathrm{m}$-diameter aerosol particles. The HEPA filters in service at SRS waste management (e.g., $\mathrm{H}$ and $\mathrm{F}$ Tank Farms) have a 2-year average life but are replaced when pressure drops or radiation levels become too high.

Water is the principal problem encountered with existing HEPA filters. Preheaters are installed in the air ducts upstream of most waste management HEPA filters in an effort to prevent condensation and subsequent damage to the HEPA filter. The need exists to eliminate costly failure problems associated with wetting of the filter, and provide an improved filter whose design includes permanently installed spray wash nozzles, which would be used to restore flow to a plugged or partially plugged filter. For example, use of a HEPA filter constructed of sintered stainless steel will provide filtration that is not subject to water damage and can be installed with built-in water jets, which will be used to wash the filter to reduce radiation and to eliminate dirt accumulation.

During FY98, two different cleanable sintered stainless steel filter technologies were identified and tested. A technical specification for development of a full-scale cleanable filtration system was prepared. Workscope to complete this task includes

- Evaluate plugging and feasibility of backwashing metal filters (FY99, TFA, SRS, SRI-8-WT-21).

- Design and fabricate prototype filtration system, select SRS tank(s) for initial testing and demonstration, and monitor and support technical progress on development of filtration system.

- Develop system designs and select final design for fabrication of prototype filtration system for testing at SRS (FY99, FETC).

- Review contractor-generated designs and support decision on final filtration system configuration (FY99, TFA, SRS, SRI-8-WT-21, EM-30).

- Develop testing plan and system acceptance testing procedures. Select tanks for demonstration and deployment of first filtration systems (FY00, TFA, EM-30). 
- Demonstrate and deploy filtration system on SRS high-level waste (HLW) tank.

- Deliver filtration system to SRS for acceptance testing (FY00, FETC).

- Complete verification and final hardware design and fabrication for tank interface (FY00, TFA, EM-30).

- Demonstrate and deploy filtration system on a SRS HLW tank and evaluate performance data (FY01, TFA, EM-30).

- Evaluate metal filters for high-temperature applications (FY00, TFA, FETC).

\begin{tabular}{|c|c|c|c|c|c|c|}
\hline \multicolumn{7}{|c|}{ Budget Profile: Alternative Air Filtration Technology } \\
\hline & TTP\# & FY 1999 & FY 2000 & FY 2001 & FY 2002 & FY 2003 \\
\hline Hanford & & & & & $\overline{\mathrm{TBD}}$ & TBD \\
\hline INEEL & & & & & TBD & TBD \\
\hline Oak Ridge & & & & & TBD & TBD \\
\hline SRS & SR18WT21 & 95 & 260 & 200 & TBD & TBD \\
\hline TFA Total & & 95 & 260 & 200 & 0 & 0 \\
\hline \multirow{2}{*}{\multicolumn{7}{|c|}{ ASTD }} \\
\hline \multirow{2}{*}{\multicolumn{7}{|c|}{ CMST }} \\
\hline & & & & & & \\
\hline FETC & & 400 & 300 & & & \\
\hline \multicolumn{7}{|l|}{ ESP } \\
\hline \multicolumn{7}{|l|}{ International } \\
\hline \multicolumn{7}{|l|}{ Robotics } \\
\hline University & & & & & & \\
\hline EM-50 Total & & 495 & 560 & 200 & 0 & 0 \\
\hline
\end{tabular}




\section{Problem Element Description and Priority Site Needs}

The baseline method for characterization of tank wastes is to collect waste samples and perform laboratory analyses in a hot cell. Improvements in sample collection methods, hot cell analytical methods, and in situ characterization methods are needed to expedite and reduce the costs of tank waste characterization. In situ characterization and at-tank sampling and characterization are highly desired as each could provide more rapid and cost-effective waste analysis. Characterizing the waste's physical, chemical, and radiochemical properties is required for planning and implementing tank safety, retrieval, pretreatment, immobilization, and closure processes. The site needs addressed in this problem element are identified below.

\begin{tabular}{|c|c|c|c|c|}
\hline \multicolumn{5}{|c|}{ Problem Element: 1.1.3 Characterize Waste } \\
\hline $\begin{array}{l}\text { STCG Need } \\
\text { Number }\end{array}$ & Need Title & $\begin{array}{c}\text { PBS } \\
\text { Number }\end{array}$ & Technical Task & $\begin{array}{c}\text { OST } \\
\text { Number }\end{array}$ \\
\hline TK-01 & $\begin{array}{l}\text { ORNL Tank Waste Characterization } \\
\text { (Sludge Mapping) }\end{array}$ & $\begin{array}{l}\text { OR-38112, } \\
\text { OR-38113, } \\
\text { OR-43201, } \\
\text { OR-43203 }\end{array}$ & In Situ Characterization & $\begin{array}{l}130, \\
1996\end{array}$ \\
\hline SR-2919 & $\begin{array}{l}\text { In-Tank Corrosion Probe } \\
\text { Development (Sludge Mapping and } \\
\text { Percent Solids) }\end{array}$ & $\begin{array}{l}\text { SR-HL01, } \\
\text { SR-HL02, } \\
\text { SR-HL04 }\end{array}$ & $\begin{array}{l}\text { Wt\% Suspended Solids } \\
\text { Monitor }\end{array}$ & $\begin{array}{l}130 \\
1490 \\
1985\end{array}$ \\
\hline RL-WT03 & $\begin{array}{l}\text { Large-Volume (3-5 Liter) Sludge and } \\
\text { Supernate Sampler }\end{array}$ & RL-TW05 & $\begin{array}{l}\text { Variable Depth Fluidic } \\
\text { Sampler }\end{array}$ & 2119 \\
\hline RL-WT09 & $\begin{array}{l}\text { Representative Sampling and } \\
\text { Associated Analysis to Support } \\
\text { Operations and Disposal }\end{array}$ & RL-TW04 & $\begin{array}{l}\text { Variable Depth Fluidic } \\
\text { Sampler, At-Tank } \\
\text { Analysis }\end{array}$ & 2119 \\
\hline ID-2.1.10 & $\begin{array}{l}\text { Develop Technology to Characterize } \\
\text { Tank Farm Heel Residues }\end{array}$ & $\begin{array}{l}\text { ID-HLW- } \\
103\end{array}$ & Tank Heel Analysis & $\begin{array}{l}85,810 \\
890 \\
1996\end{array}$ \\
\hline SR-2916 & $\begin{array}{l}\text { Develop Advanced Technology to } \\
\text { Improve Safety Infrastructure (Pot } \\
\text { Sampler) }\end{array}$ & $\begin{array}{l}\text { SR-HL01, } \\
\text { SR-HL02 }\end{array}$ & Fluid Sampler & $\begin{array}{l}2007 \\
1985\end{array}$ \\
\hline RL-WT025 & $\begin{array}{l}\text { Remote Sensing of Gas Retention in } \\
\text { HLW Slurries }\end{array}$ & RL-TW04 & $\begin{array}{l}\text { Entrapped Gas } \\
\text { Detection }\end{array}$ & N/A \\
\hline TK-04 & $\begin{array}{l}\text { ORNL Sludge Mixing and Slurry } \\
\text { Transport }\end{array}$ & $\begin{array}{l}\text { OR-38112, } \\
\text { OR-38113, } \\
\text { OR-43201, } \\
\text { OR-43203 }\end{array}$ & Slurry Monitors & 1547 \\
\hline
\end{tabular}

\section{Technical Tasks}

In Situ Characterization

In situ characterization methods are needed to support retrieval operations and waste pretreatment. Designing and deploying effective waste retrieval systems for tank wastes requires knowledge of the waste characteristics, such as the volumes and interface between supernate, sludge, and/or hard heel. Methods to map the sludge or heel level are needed for tanks where the bulk supernate remains, to allow for design of the retrieval system and retrieval strategy before supernate removal. Specifically, the Oak Ridge Reservation (ORR) needs a sludge mapping system to measure the volume of sludge under the supernate before and after removal to assess vendor performance. The Savannah River Site (SRS) has a similar need for sludge height mapping to verify that operations stay within safety constraints. 
Chemical characterization through in situ sensing is also needed to support pretreatment operations. For example, SRS needs in situ methods for monitoring sodium, potassium, strontium-90, cesium-137, uranium, and plutonium levels during cesium removal.

Sludge Mapping Tools - Work activities to support ORR's and SRS's need for sludge mapping tools include

- Define requirements and identify deployment method for sludge mapping.

- Define functions and requirements and identify deployment platform and mapping equipment for sludge mapping in ORR Melton Valley Storage Tank (MVST) and SRS tanks (FY00, TFA). Decision point for procurement and demonstration.

- Initiate procurement, fabrication of system components, and cold testing of components (FY00, TFA).

- Assemble components, test, and deploy system for sludge-level measurements.

- Complete mapping system assembly, calibration, and cold testing (FY01, TFA).

- Initiate in-tank deployment (FY01, TFA).

Sludge Washing Monitor - Activities to support SRS's and Hanford's need for process control monitoring during HLW sludge washing to remove soluble constituents include - Define specifications, functions, and requirements for in-tank process monitor.

- Define sensor concentration range, accuracy, precision, calibration procedure, service life, safety concerns, materials of construction, deployment platform, hardware, etc. to support procurement and comparison of sensors (FY99, CMST).

- Conduct feasibility evaluation of candidate analyzers best suited for application based on functions and requirements. Procure one or more sensors for laboratory testing. Conduct cold surrogate tests (FY99, CMST).

- Downselect sensor and deploy in the tank.

- Complete laboratory tests and downselect sensor. Procure new or modify existing sensor for deployment (FY00, CMST).

- Fabricate deployment platform and deploy sensor. Collect data to demonstrate performance in hot environment (FY00, CMST).

\begin{tabular}{|c|c|c|c|c|c|c|}
\hline \multicolumn{7}{|c|}{ Budget Profile: Sludge Washing Monitors } \\
\hline & TTP\# & FY 1999 & FY 2000 & FY 2001 & FY 2002 & FY 2003 \\
\hline \multicolumn{7}{|l|}{ Hanford } \\
\hline \multicolumn{7}{|l|}{ INEEL } \\
\hline \multicolumn{7}{|l|}{ Oak Ridge } \\
\hline \multicolumn{7}{|l|}{ SRS } \\
\hline TFA Total & & 0 & 0 & 0 & 0 & 0 \\
\hline \multirow{2}{*}{\multicolumn{7}{|c|}{ ASTD }} \\
\hline & & & & & & \\
\hline CMST & FT09C2?? & 469 & 350 & & & \\
\hline \multicolumn{7}{|l|}{ FETC } \\
\hline \multicolumn{7}{|l|}{ ESP } \\
\hline \multicolumn{7}{|l|}{ International } \\
\hline \multicolumn{7}{|l|}{ Robotics } \\
\hline EM-50 Total & & 469 & 350 & 0 & 0 & 0 \\
\hline
\end{tabular}


Waste Sampling and At-Tank Analysis

A sampling system capable of obtaining representative waste samples is needed to support ex situ waste characterization. The sampler should work with nonhomogeneous wastes, rapidly obtaining samples at multiple heights and during tank mixer operation.

AEA Technology has developed a prototype fixed-depth fluidic sampler that has been successfully deployed at SRS. A nested array, multi-point, fixed-depth sampling system based on this single-sample point design will be fabricated, cold tested, installed in a Hanford waste tank, and validated in operation. Workscope to complete this task includes

- Prepare definitive design based on prototype and user requirements (FY99, International Program, AEA).

- Fabricate nested array sampler and conduct acceptance testing (FY99, International Program, AEA).

- Demonstrate nested array sampler (FY00, TFA, CMST).

- Deploy nested array sampler (FY01, TFA, CMST).

For selected analytes, an at-tank analysis system to be used with the nested array sampler is needed to support waste transfer operations and for rapid waste feed characterization. During FY98, the analytes to be considered were identified and a conceptual design for the analysis system was developed by the Robotics Crosscutting Program. Workscope to complete this task includes

- Develop conceptual design for at-tank analysis system (FY99, CMST, Robotics).

- Conduct proof-of-principle testing of at-tank analysis system (FY00, CMST, Robotics).

- Design and fabricate at-tank analysis system (FY00, CMST).

- Conduct cold testing of at-tank analysis system (FY01, CMST).

- Deploy at-tank analysis system (FY02).

\begin{tabular}{||l|c|c|c|c|c|c||}
\hline \multicolumn{7}{|c|}{ Budget Profile: Waste Sampling and At-Tank Analysis } \\
\hline & TTP\# & FY 1999 & FY 2000 & FY 2001 & FY 2002 & FY 2003 \\
\hline Hanford & RL08WT22 & 530 & 270 & 300 & TBD & TBD \\
\hline INEEL & & & & & TBD & TBD \\
\hline Oak Ridge & & & & & TBD & TBD \\
\hline SRS & & & & & TBD & TBD \\
\hline TFA Total & & 530 & 270 & 300 & 0 & 0 \\
\hline & & & & & & \\
\hline ASTD & & & & & & \\
\hline CMST & FT09C2?? & 300 & 150 & 200 & & \\
\hline FETC & & & 600 & 1000 & & \\
\hline ESP & & & & & & \\
\hline International & HQ06PS11 & 500 & 300 & 400 & & \\
\hline Robotics & RL37C131 & 150 & 150 & & & \\
\hline EM-50 Total & & 1480 & 1620 & 1900 & & \\
\hline
\end{tabular}




\section{Physical Property Measurement}

The physical and chemical properties of the retrieved waste must meet certain operational requirements for retrieval and pretreatment operations to be successful. Transfer line pluggage is a concern for operations. Particle size, weight percent solids, and chemistry changes occurring during retrieval impact the efficiency of the downstream pretreatment operations. Sampling, analysis, and monitoring (e.g., sensors) that can provide this information are needed.

In-tank and pipeline monitors are needed to measure slurry density, viscosity, volume percent solids, particle size distribution, and flow rate before and during transport of retrieved tank wastes to ensure that the transport lines will not plug. The estimated cost to replace a plugged transport line at Hanford is $\$ 47 \mathrm{M}$. Crucial parameters for maintaining a turbulent slurry flow and avoiding plugging due to excessive solids are a Reynolds number $>22,000$, a specific gravity $<1.5$, a viscosity $<30 \mathrm{cP}$, a volume percent solids $<30$, particle sizes of $0.5-4000$ microns (with $95 \%$ of the total under 50 microns), and a design velocity of $6 \mathrm{ft} / \mathrm{s}$.

Retrieval and transfer activities in need of near-term slurry monitoring include the Gunite and Associated Tanks (GAATs) at ORR, and the Hanford tanks undergoing retrieval as part of the Hanford Tanks Initiative (HTI). For example, heel retrieval from Hanford Tank 241C-106 is planned in FY99 and the slurry will be transported a distance of more than $1,600 \mathrm{ft}$ in a pipeline. ORR plans to conduct a cross-site slurry transfer of about $145,000 \mathrm{gal}$ of low radioactivity tank waste in FY00 through a 2-in.-diameter transfer line. A downselect of the appropriate monitors, installment, and field testing of monitors is underway to provide validated on-line slurry monitoring.

Under a current Tank Waste Remediation System project (W211), commercial slurry monitors are being tested for their ability to measure slurry transport parameters in-line to avoid plugging. The TFA and Characterization, Monitoring, and Sensor Technology Crosscutting Program (CMST) have also sponsored the development and testing of slurry transport monitors. During FY98, slurry monitors were deployed at ORNL during GAAT retrieval and waste transfer operations.

Results of slurry monitoring testing at ORR will also be used to support Hanford's need within the HTI. Work activities will include

- Design, procure, and deploy a slurry monitoring system for Tank 241-C-106 slurry transfer.

- Establish requirements for monitoring of slurry transfers between Tank 241-C-106 and the double-shell receiver tank (FY99, TFA, EM-30).

- Acquire slurry monitoring technologies and integrate them into the transfer system (FY00, TFA, EM-30). Decision point for implementation.

\section{Entrapped Gas Detection Through Evaporation Monitoring}

During waste retrieval and transfer of solids, a potential exists for the creation of "slurry growth" conditions (i.e., entrapped gases) in the receiver tank with a subsequent gas release event similar to the behavior exhibited by Tank 241-SY-101. To monitor the waste for the 
presence of entrapped gases during a retrieval sequence, material balance calculations must account for the evaporative losses from the tank. This requires highly accurate psychrometric and flow measurement capabilities to detect the amount of entrapped gases.

Work activities to address Hanford's need for improved detection of entrapped gases will include - Development of a high-accuracy psychrometric and flow measurement system.

- Develop specifications for industrial call for proposals. Review information from the FY97 evaluations and past experience using high-accuracy psychrometric and flow measurement systems under tank farm conditions and ventilation systems. Evaluate the accuracy of psychrometric and flow measurement system testing that has been done by the laboratories and industry (FY00, TFA, EM-30).

- Solicit industry technology and select provider(s) for development and/or testing (FY00, TFA, EM-50 Industry Programs).

- Select Hanford tank for a preliminary ventilation system design to support improved psychrometric and flow measurement testing. Conduct testing of industry system(s) under simulated tank configurations to ensure performance requirements are met (FY01, TFA, EM-50 Industry Programs). Decision point for demonstration.

- Demonstrate improved psychrometric and flow measurement on selected Hanford tank to support retrieval operations (FY01, TFA, EM-30).

Tank Heel Analysis

The chemical characteristics of the heel with INEEL's pillar and panel tanks must be known to formulate a grout that will mix well, solidify, and remain stable. A heel sample has been obtained for analysis. Remaining work includes

- Analyze the WM-188 heel sample and issue analysis report (FY99, TFA, INEEL). 


\section{Problem Element Description and Priority Site Needs}

Secondary wastes such as contaminated water from off-gas treatment systems are generated during the processing of tank wastes. Some liquid streams are currently recycled to the tank farms due to their composition and lack of treatment trains that could allow release to liquid effluent treatment plants. Treatment of these waste streams would free tank storage space and reduce life-cycle cost by reducing the volume of waste re-entering process plants. Tank farms are still receiving wastes even though many major mission operations have ceased at most of the sites. Some of these wastes result from decontamination and decommissioning (D\&D) operations, from tank-to-tank transfers to solve waste storage problems, or from tank waste processing operations.

The site needs addressed by this problem element are identified below.

\begin{tabular}{||c|l|l|l|l||}
\hline \multicolumn{5}{|c|}{ Problem Element: 1.1.4 Reduce Waste Volumes } \\
\hline $\begin{array}{c}\text { STCG Need } \\
\text { Number }\end{array}$ & \multicolumn{1}{|c|}{ Need Title } & $\begin{array}{c}\text { PBS } \\
\text { Number }\end{array}$ & \multicolumn{1}{c||}{ Technical Task } & $\begin{array}{c}\text { OST } \\
\text { Number }\end{array}$ \\
\hline \hline ID-2.1.01 & $\begin{array}{l}\text { Technologies to Reduce Generation of } \\
\text { or Alternative Treatments for } \\
\text { Radioactive Liquid Waste at the ICPP }\end{array}$ & $\begin{array}{l}\text { ID-HLW- } \\
101\end{array}$ & $\begin{array}{l}\text { Laser Ablation } \\
\text { Decontamination } \\
\text { System }\end{array}$ & N/A \\
\hline SR-2907 & $\begin{array}{l}\text { Provide Alternative Processing and/or } \\
\text { Concentration Methods for DWPF } \\
\text { Recycle Aqueous Streams }\end{array}$ & SR-HL05 & $\begin{array}{l}\text { Cesium and Mercury } \\
\text { Removal from } \\
\text { DWPF Recycle }\end{array}$ & 21 \\
\hline SR-2921 & $\begin{array}{l}\text { Volume Reduction and Stabilization of } \\
\text { CIF Secondary Salt (NaCl) Liquid } \\
\text { Waste }\end{array}$ & SR-SW01 & CIF Evaporator & 20,2096 \\
\hline
\end{tabular}

\section{Technical Tasks}

Laser Ablation Decontamination System

At the Idaho National Engineering and Environmental Laboratory (INEEL), the Idaho Nuclear Technology and Engineering Center (INTEC), formerly known as Idaho Chemical Processing Plant, generates radioactive liquid waste from D\&D operations, which is routed to the tank farm. The liquid waste ranges from slightly contaminated water to highly radioactive waste containing many hazardous components. Current technologies used for D\&D include chemical cleaning, $\mathrm{CO}_{2}$ pellet blasting, liquid abrasive blasting, mechanical scabbling, and strippable coatings. Improved D\&D methods that reduce the volume of liquid waste generated are needed. Examples of improved methods include laser ablation and ultra-high liquid nitrogen. Workscope to complete this task includes

- Develop fieldable laser ablation decontamination system for INTEC testing.

- Develop a fieldable laser ablation decontamination system based on available laboratory model (FY00, TFA, EM-30).

- Develop functions and requirements for the needed performance of waste water/ decontamination systems (FY00, TFA, EM-30).

- Complete initial hot deployment and performance evaluation.

- Demonstrate laser ablation decontamination system on hot wastes at INEEL. Evaluate performance of system and issue recommendations based on systems analysis and generated functions and requirements (FY01, TFA, EM-30).

- Deploy decontamination system within INTEC for volume reduction (FY02, EM-30). 
Cesium and Mercury Removal from Defense Waste Processing Facility (DWPF) Recycle At the Savannah River Site (SRS), the recycle stream from the DWPF is adding to the volume of tank waste requiring subsequent treatment. Removal of dilute concentrations of problem constituents from this stream, such as cesium, solids, and mercury, could allow these wastes to be discharged rather than being recycled to the tank farms for subsequent costly processing. The DWPF recycle stream must be processed in such a manner that approximately $95 \%$ of the stream is decontaminated so that it can be processed by the Effluent Treatment Facility. The remaining 5\% would be transferred to the HLW tank farm. In FY98, tests were conducted to determine operational parameters and specifications for a procurement of an ion-exchange system composed of cesium removal, mercury removal, and filtration equipment. The Efficient Separations and Processing Crosscutting Program (ESP) is also developing technologies for cesium and mercury removal. Workscope to complete this task includes

- Complete laboratory studies of ESP-developed materials for removal of cesium and mercury from the DWPF recycle (FY99, ESP).

- Complete procurement, fabrication and delivery of ion-exchange systems for DWPF recycle (FY99, ASTD, TFA, EM-30, OR08SD11, SR08SD10).

- Document evaluation of mercury-loaded GT-73 ion-exchange resin for solid waste disposal (FY99, ASTD, TFA, EM-30, OR08SD11, SR08SD10).

- Complete laboratory testing and document evaluation of crystalline silicotitanates (CST) for cesium removal (FY99, ASTD, TFA, EM-30, OR08SD11, SR08SD10).

- Install and cold test ion-exchange systems for DWPF recycle (FY00, ASTD, TFA, EM-30).

- Startup and complete initial operation of ion-exchange systems for DWPF recycle (FY01, ASTD, TFA, EM-30).

\begin{tabular}{|c|c|c|c|c|c|c|}
\hline \multicolumn{7}{|c|}{ Budget Profile: Cesium and Mercury Removal for SRS DWPF Recycle } \\
\hline & TTP\# & FY 1999 & FY 2000 & FY 2001 & FY 2002 & FY 2003 \\
\hline Hanford & & & & & TBD & $\overline{T \text { TBD }}$ \\
\hline INEEL & & & & & TBD & TBD \\
\hline Oak Ridge & OR08SD11 & & & & TBD & TBD \\
\hline SRS & SR08SD10 & & & & TBD & TBD \\
\hline TFA Total & & 0 & 0 & 0 & 0 & 0 \\
\hline ASTD & $\begin{array}{l}\text { OR08SD11 } \\
\text { SR08SD10 }\end{array}$ & $\begin{array}{c}1320 \\
500\end{array}$ & $\begin{array}{l}250 \\
250\end{array}$ & $\begin{array}{l}200 \\
200\end{array}$ & & \\
\hline \multicolumn{7}{|l|}{ CMST } \\
\hline \multicolumn{7}{|l|}{ FETC } \\
\hline ESP & SR16C342 & 100 & & & & \\
\hline \multicolumn{7}{|l|}{ International } \\
\hline \multicolumn{7}{|l|}{ Robotics } \\
\hline \multicolumn{7}{|l|}{ University } \\
\hline EM-50 Total & & 1920 & 500 & 400 & 0 & 0 \\
\hline
\end{tabular}




\section{Consolidated Incinerator Facility (CIF) Evaporator}

Savannah River Site has a need for a modular evaporator system to reduce the volume of liquid waste generated by their Consolidated Incinerator Facility (CIF). The CIF incinerates mixed, low-level, and hazardous wastes. The off-gas treatment system for the CIF generates a high salt, high solids liquid waste stream that is subsequently stabilized in drummed cement waste forms. Reducing the volume of the liquid waste will reduce the volume of the stabilized waste forms. Development of technical specifications for procurement of an evaporator system was initiated in FY98. Testing was conducted to provide input regarding design and operating parameters for the evaporator. Workscope to complete this activity includes

- Complete procurement, fabrication, and delivery of CIF evaporator (FY99, ASTD, TFA, EM-30, OR08SD11, SR08SD10).

- Complete laboratory testing to evaluate volume reduction, composition, partitioning of hazardous components, and foaming (FY99, ASTD, TFA, EM-30, OR08SD11, SR08SD10).

- Install and cold test CIF evaporator (FY00, ASTD, TFA, EM-30).

- Startup and begin operation of CIF evaporator (FY00, ASTD, TFA, EM-30).

\begin{tabular}{|c|c|c|c|c|c|c|}
\hline \multicolumn{7}{|c|}{ Budget Profile: CIF Evaporator } \\
\hline & TTP\# & FY 1999 & FY 2000 & FY 2001 & FY 2002 & FY 2003 \\
\hline Hanford & & & & & TBD & TBD \\
\hline INEEL & & & & & TBD & TBD \\
\hline Oak Ridge & & & & & TBD & TBD \\
\hline SRS & & & & & TBD & TBD \\
\hline TFA Total & & 0 & 0 & 0 & 0 & 0 \\
\hline ASTD & $\begin{array}{l}\text { OR08SD11 } \\
\text { SR08SD10 }\end{array}$ & $\begin{array}{c}1310 \\
400\end{array}$ & $\begin{array}{l}200 \\
300 \\
\end{array}$ & $\begin{array}{l}150 \\
150 \\
\end{array}$ & & \\
\hline \multicolumn{7}{|l|}{ CMST } \\
\hline \multicolumn{7}{|l|}{ FETC } \\
\hline \multicolumn{7}{|l|}{ ESP } \\
\hline \multicolumn{7}{|l|}{ International } \\
\hline \multicolumn{7}{|l|}{ Robotics } \\
\hline \multicolumn{7}{|l|}{ University } \\
\hline EM-50 Total & & 1710 & 500 & 300 & 0 & 0 \\
\hline
\end{tabular}




\section{Problem Element Description and Priority Site Needs}

Mobilizing bulk and heel wastes within a tank is required to remove materials for tank closure, for treatment, and for ultimate immobilization and disposal of the hazardous waste components. Mobilizing dense sludge, saltcake, and dry/hardened materials is particularly challenging and important for retrieval operations. Baseline methods for waste mobilization are mixer pumps and long-range, high water volume sluicing. The site needs addressed by this problem element are identified below.

\begin{tabular}{|c|c|c|c|c|}
\hline \multicolumn{5}{|c|}{ Problem Element: 1.2.1.2 Mobilize Bulk and Heel Wastes } \\
\hline $\begin{array}{l}\text { STCG Need } \\
\text { Number }\end{array}$ & Need Title & $\begin{array}{c}\text { PBS } \\
\text { Number }\end{array}$ & Technical Task & $\begin{array}{c}\text { OST } \\
\text { Number }\end{array}$ \\
\hline RL-WT013 & $\begin{array}{l}\text { Establish Retrieval Performance } \\
\text { Evaluation Criteria (SST Retrieval } \\
\text { Enhancements) }\end{array}$ & RL-TW04 & $\begin{array}{l}\text { Mobile Manipulator for } \\
\text { Tank Waste Removal } \\
\text { (Tarzan) and Enhanced } \\
\text { Sluicing and Waste } \\
\text { Mobilization for Hanford }\end{array}$ & $\begin{array}{l}2198,127, \\
812,1490, \\
1547,2010, \\
2011,2012, \\
2117,2118\end{array}$ \\
\hline RL-WT014 & $\begin{array}{l}\text { Alternative to Baseline Tank } \\
\text { Waste Mixing System }\end{array}$ & RL-TW04 & $\begin{array}{l}\text { Enhanced Sluicing and } \\
\text { Waste Mobilization for } \\
\text { Hanford }\end{array}$ & 2119 \\
\hline RL-WT028 & Waste Mobilization Enhancement & RL-TW04 & $\begin{array}{l}\text { Enhanced Sluicing and } \\
\text { Waste Mobilization for } \\
\text { Hanford }\end{array}$ & 2097,2115 \\
\hline ID-2.1.09 & Remove and Transport Calcine & $\begin{array}{l}\text { ID-HLW- } \\
103\end{array}$ & & N/A \\
\hline TK-02 & ORNL Tank Solid Waste Retrieval & OR-43203 & $\begin{array}{l}\text { Sludge Mixing, } \\
\text { Mobilization, and } \\
\text { Retrieval for Oak Ridge }\end{array}$ & $\begin{array}{l}85,810 \\
890,1547 \\
2115 \\
\end{array}$ \\
\hline$\overline{\text { SR-2911 }}$ & $\begin{array}{l}\text { Tank Heel Removal/Closure } \\
\text { Technology }\end{array}$ & SR-HL03 & $\begin{array}{l}\text { Saltcake, Bulk Sludge, } \\
\text { Heel, and Debris } \\
\text { Retrieval for Savannah } \\
\text { River Site }\end{array}$ & 2097,2115 \\
\hline SR-2902 & $\begin{array}{l}\text { Alternate Waste Removal } \\
\text { Techniques }\end{array}$ & SR-HL03 & $\begin{array}{l}\text { Saltcake, Bulk Sludge, } \\
\text { Heel, and Debris } \\
\text { Retrieval for Savannah } \\
\text { River Site }\end{array}$ & 1989 \\
\hline SR-2918 & Alternate Mixer Pumps & SR-HL03 & $\begin{array}{l}\text { Saltcake, Bulk Sludge, } \\
\text { Heel, and Debris } \\
\text { Retrieval for Savannah } \\
\text { River Site }\end{array}$ & 1985 \\
\hline SR-2912 & $\begin{array}{l}\text { Evaporator Residual Waste } \\
\text { Removal and Closure (Heel } \\
\text { Removal) }\end{array}$ & $\begin{array}{l}\text { SR-HL01, } \\
\text { SR-HL02 }\end{array}$ & $\begin{array}{l}\text { Saltcake, Bulk Sludge, } \\
\text { Heel, and Debris } \\
\text { Retrieval for Savannah } \\
\text { River Site }\end{array}$ & $\begin{array}{l}2097,22, \\
1499,2115\end{array}$ \\
\hline TK-09 & ORNL Tank Closure & $\begin{array}{l}\text { OR-43201, } \\
\text { OR-43203 }\end{array}$ & $\begin{array}{l}\text { Sludge Mixing, } \\
\text { Mobilization, and } \\
\text { Retrieval for Oak Ridge }\end{array}$ & $\begin{array}{l}22,1499 \\
2093,2115\end{array}$ \\
\hline
\end{tabular}




\section{Tecbnical Tasks}

\section{Mobile Manipulator for Tank Waste Removal (Tarzan)}

Tarzan is a remote tool delivery system being developed for application at the West Valley Demonstration Project. The system will be used to deploy end effectors to mechanically clean and inspect the tanks. The Federal Energy Technology Center (FETC) is funding the development of Tarzan; the TFA is following its development and deployment for application to TFA needs.

\section{Enhanced Sluicing and Waste Mobilization for Hanford}

Performance and cost data comparing alternate and enhanced retrieval methods to the performance baseline of past-practice sluicing are needed for Hanford's single-shell tanks (SSTs). Data will be applied to the selection of retrieval systems for 1) Tank 241-C-106 Heel Removal (part of Hanford Tanks Initiative [HTT]), 2) management and integration (M\&I) retrieval of SSTs during privatization phase I (e.g., Tank 241-C-106 sluicing campaign) and initial single-shell tank retrieval system, 3) concept design technical input to the privatization phase II specification (Hanford Federal Facility Agreement and Consent Order Milestone M-45-04A), and 4) performance assessment for SST closure. Improvements to the baseline past-practice sluicing are of immediate interest to support the Tank 241-C-106 bulk waste removal campaign and heel retrieval as part of HTI.

In addition to SSTs, retrieval of double-shell tank (DST) using the baseline of two mixer pumps is expected to leave a considerable amount of hard, heavy, and/or cohesive sludge heel. While this is adequate for initial high-level waste (HLW) feed, the program needs assurance that if the effective cleaning radius of the mixers proves insufficient, that a backup method can be deployed to mobilize enough residual waste to complete the mission. Further effort in predicting the effective cleaning radius by characterizing the shear strength, or resistance to mobilization, of the sludge is needed to plan for use of a backup method. Alternative or supplementary methods are needed to better mobilize sludge from DSTs containing HLW feed for phase I privatization. Other DSTs may contain hard heels and sludges and other waste types, waste that mixer pumps will not adequately mobilize.

Work activities to support Hanford's needs for enhanced sluicing and waste mobilization include

Enhanced Sluicing: In FY98, TFA funded work in conjunction with Hanford Project W-320 to assess enhancements to the sluicing strategy and sluicing systems. Although sluicing of Tank 241-C-106 will continue into FY99, additional TFA-funded work in this area fell below the available funding and no further work is planned in FY99 or beyond.

Heel Retrieval for HTI (241-C-106):

- Procure industrial system for SST heel retrieval to support HTI and Hanford privatization.

- In FY98, contracts were awarded to two contractors to define retrieval systems for Tank 241-C-106 heel removal. Both contractors are developing the technical baseline, cost, and schedule to use their respective vehicle-based (as opposed to armbased) systems to retrieve waste from Tank 241-C-106. 
- Complete detailed design of equipment and testing of critical components for industry retrieval systems (FY99, TFA, EM-30). Decision point for downselect to one vendor for Tank 241-C-106 retrieval.

- Fabricate and cold test retrieval system for heel retrieval (FY99, TFA, EM-30).

- Demonstrate and deploy heel retrieval from Tank 241-C-106.

- Complete initial site upgrades to support vendor retrieval, and conduct qualification and mock-up/training tests of vendor and retrieval system (FY01, TFA, EM-30).

- Demonstrate heel retrieval using vendor system and operations (FY01, TFA, EM-30). Decision point for implementation.

Enhanced Mobilization of DST Wastes:

- Test and evaluate system to enhance retrieval of DSTs.

- Complete testing and evaluate performance of the system for enhancement to mixer pumps as well as to other technologies. Support EM-30 DST retrieval program at Hanford (FY99, TFA, EM-30).

- Deploy the system during DST mixer pump operations to evaluate system for improved tank cleaning and retrieval (FY00, TFA, EM-30).

\begin{tabular}{||l|c|c|c|c|c|c||}
\hline \multicolumn{7}{|c|}{ Budget Profile: Enhanced Sluicing and Waste Mobilization } \\
\hline & TTP\# & FY 1999 & FY 2000 & FY 2001 & FY 2002 & FY 2003 \\
\hline \hline Hanford & RL36WT51 & 225 & 240 & 115 & TBD & TBD \\
& RL09WT52 & 50 & 225 & 725 & & \\
& RL07WT61 & TBD & TBD & TBD & & \\
\hline INEEL & & & & & TBD & TBD \\
\hline Oak Ridge & & & & & TBD & TBD \\
\hline SRS & & & & & TBD & TBD \\
\hline TFA Total & & 275 & 465 & 840 & 0 & 0 \\
\hline
\end{tabular}

Sludge Mixing, Mobilization, and Retrieval for Oak Ridge Reservation (ORR) Sludge and heel retrieval from ORR's horizontal steel tanks and vertical concrete (i.e., gunite) tanks is required for tank remediation and closure. Dislodging, mobilization, transfer, and waste conditioning systems (also see problem elements 1.2.1.4, "Transfer Waste," and 1.2.2.3, "Prepare Retrieved Waste for Transfer and Pretreatment") are needed to remove bulk quantities of sludge from the tanks.

ORR has horizontal 50,000-gal stainless steel underground storage tanks, which have limited access and internal obstructions (Bethel Valley Evaporator Service Tanks [BVESTs]) and horizontal 13,000- to 25,000-gal carbon steel tanks (Old Hydrofracture Facility [OHF]). The BVESTs will remain in service and the OHF tanks will be remediated after the sludges are retrieved for treatment and disposal.

ORR also has 50-year-old vertical concrete tanks. The first tanks to be remediated are unlined gunite tanks. These tanks contain transuranic (TRU) and non-TRU wastes. The 
sludge ranges from very soft silt texture to hard chunks; debris, hardware, spalled concrete, and chunks of concrete inside the tanks also need to be retrieved.

Work activities to support ORR's needs for sludge mixing, mobilization, and retrieval include

Gunite and Associated Tanks (GAATs) Retrieval:

- Develop and deploy improved jet pump to support GAAT retrieval.

- Complete specifications for improved jet pump to reduce wear and optimize performance for both two- and three-phase flow regimes. Fabricate jet pump (completed FY98).

- Verify improved jet pump performance and deliver to ORR for deployment during GAAT retrieval campaign (completed FY98).

- Deploy improved jet pump and HOUDINI II remotely operated vehicle to support GAAT retrieval (FY99, TFA, Robotics, ASTD, EM-40).

- Deploy pulsed air system to maintain sludge suspension for transfer.

- Deliver pulsed air system designed for ORR Tank W-9 application (completed FY98).

- Demonstrate pulsed air system performance in Tank W-9 to support continued operation and deployment (FY99, TFA, ASTD, EM-40). Decision point for implementation.

- Evaluate alternative mobilization systems to mobilize, mix, and retrieve sludge waste.

- Complete procurement of alternative waste mobilization system (Flygt mixers, Russian pulsating monitors) (FY99, TFA, FETC).

- Conduct cold testing of alternative waste mobilization system (FY99, TFA, EM-30).

- Deploy alternative waste mobilization system (FY99, TFA, EM-30).

- Document results of alternative waste mobilization system (FY00, TFA, EM-30).

- Deploy floor cleaning system to retrieve residual waste after completion of bulk waste retrieval.

- Procure floor cleaning system (FY99, TFA).

- Conduct cold testing of floor cleaning system (FY00, TFA).

- Deploy floor cleaning system (FY00, TFA).

OHF Tanks Sludge Retrieval:

- Test and demonstrate Borehole Miner for sludge mobilization in OHF tanks.

- Complete cold test of extendible nozzle Borehole Miner, evaluate performance, and identify deficiencies and readiness to deploy (completed FY98).

- Complete initial hot demonstration of extendible nozzle Borehole Miner and evaluate performance on waste mobilization and transport of the system to subsequent tanks (completed FY98).

- Complete deployment of extendible nozzle at OHF tanks (completed FY98).

- Deploy remotely operated vehicle (Scarab IIa) in conjunction with borehole miner (completed FY98).

- Provide performance assessment data to support future site applications (FY99, ASTD, Robotics, EM-30). 
Bulk Sludge Retrieval from Large Horizontal Tanks (BVEST/Melton Valley Capacity Increase Tanks [MVCIT]):

- Deploy fluidic pulse jet mixing system in BVESTs and MVCITs (FY99, ASTD).

- Evaluate fluidic pulse jet mixing system for application to other DOE facilities (FY00, ASTD).

\begin{tabular}{|c|c|c|c|c|c|c|}
\hline \multicolumn{7}{|c|}{ Budget Profile: Sludge Mixing, Mobilization, and Retrieval for ORR } \\
\hline & TTP\# & FY 1999 & FY 2000 & FY 2001 & FY 2002 & FY 2003 \\
\hline Hanford & RL36WT51 & 440 & 80 & & TBD & TBD \\
\hline INEEL & & & & & TBD & TBD \\
\hline Oak Ridge & OR16WT51 & 850 & 750 & & TBD & TBD \\
\hline SRS & & & & & TBD & $\overline{T B D}$ \\
\hline TFA Total & & 1290 & 830 & 0 & 0 & 0 \\
\hline ASTD & OR08SD10 & 925 & 255 & & & \\
\hline \multicolumn{7}{|l|}{ CMST } \\
\hline \multicolumn{7}{|l|}{ FETC } \\
\hline \multicolumn{7}{|l|}{ ESP } \\
\hline \multicolumn{7}{|l|}{ International } \\
\hline Robotics & OR17C132 & 250 & & & & \\
\hline \multicolumn{7}{|l|}{ University } \\
\hline EM-50 Total & & 2465 & 1085 & 0 & 0 & 0 \\
\hline
\end{tabular}

Saltcake, Bulk Sludge, Heel, and Debris Retrieval for SRS

Saltcake is formed through successive evaporation cycles of alkali waste. Traditional salt and bulk sludge removal involves installing large slurry pumps into the tank to vigorously mix the contents into solution. However, it costs approximately $\$ 6-10 \mathrm{M} /$ tank to perform salt or sludge removal using the slurry pump method. Less expensive and invasive methods to re-dissolve the salt and to retrieve bulk solids, such as modified density gradient or water jets, are desired.

Residual heels of sludge and debris remain on the bottoms of the tanks after bulk waste removal is performed. The types of debris and residual waste include the following: hardened sludge; heavy, possible cohesive sludge deposits; zeolite; silica; reel tapes; and clinkers. Conventional waste removal techniques utilizing slurry pumps and transfer jets/ pumps do not suspend and remove these types of waste. As much as $40,000 \mathrm{gal}$ of residue can remain after a conventional waste removal campaign. Methods must be explored and developed to successfully remove these heels. Tank closure is not possible unless much of this residue is removed. For example, Tank 19 is scheduled for retrieval during FY99; 25,000 gal (estimated) residual zeolite heel remains which prevents immediate closure activities. In addition to residual heels, the Type I, II, and III waste storage tanks are also equipped with an annular space between the primary containment wall and the secondary containment wall. Waste has leaked in the tank annulus on several of these waste tanks. 
Before closing the tank for final disposition, waste from the annulus must be removed and the space cleaned. No proven methods of removing highly radioactive waste from this type of geometry exist.

SRS is entering into an intensive sludge retrieval campaign to produce feed for the Defense Waste Processing Facility (DWPF) melter. Long-shaft mixer pumps are the baseline technology. Tank 8 is scheduled for retrieval in FY99. Operational techniques to maximize the performance of the baseline system are needed.

The use of oxalic acid is the standby method for removal of residual sludge deposits for final tank cleaning. Under some conditions, oxalic acid preferentially dissolves iron compounds rather than plutonium and uranium, putting the process outside of the criticality safety specifications. Russian chemists are seeking and oxalic acid formulation that will be acceptable for use at SRS.

Work activities to support SRS's needs for saltcake, annulus salt, heel and clinker retrieval, and chemical cleaning include

Saltcake Retrieval:

- Adapt and demonstrate salt retrieval device for salt dissolution.

- Assemble, cold test, and complete initial hot testing of salt retrieval device (FY99, TFA, EM-30).

- Demonstrate retrieval device in Tank 16 annulus at SRS (FY00, TFA, EM-30). Decision point for implementation.

- Demonstrate modified density gradient technique for salt retrieval.

- Evaluate mixing to support salt retrieval (FY99, TFA).

- Develop test plan and schedule integrating salt retrieval demonstration into site baseline schedule (timing depends on in-tank precipitation alternative decision, TFA, EM-30).

- Initiate demonstration and deployment of density gradient salt retrieval for Tank 25 or 41 (timing depends on in-tank precipitation alternative decision, TFA, EM-30). Decision point for implementation.

- Initiate deployment of density gradient salt retrieval for Tank 29 (timing depends on in-tank precipitation alternative decision, EM-30).

- Evaluate Flygt mixer for criticality safety during salt retrieval.

Heel Retrieval:

- Develop and demonstrate technology for heel retrieval from Type IV tanks.

- Develop functional requirements and plan for heel retrieval from Type IV tanks (FY98, TFA, EM-30).

- Procure, assemble, and test heel retrieval equipment (FY98/99, TFA, EM-30). Decision point for implementation. 
- Procure and demonstrate heel retrieval from Type I and II tanks.

- Develop functional requirements for heel retrieval from Type I and II tanks (FY99, TFA, EM-30).

- Procure, assemble, and test heel retrieval equipment (FY99, TFA, EM-30). Decision point for implementation.

- Complete demonstration and evaluation of commercial system for Type I and II tank heel retrieval (FY00, TFA, EM-30).

Bulk Sludge Retrieval:

- Provide recommendations on how to optimize performance of baseline mixer system (FY99, TFA).

- Evaluate mixer system performance during Tank 8 retrieval (FY01, TFA).

Floor-Cleaning System:

- Complete prototype system demonstration (FY99, Robotics).

- Complete cold testing of floor-cleaning system (FY00, Robotics).

- Document floor-cleaning system (FY01, Robotics).

Chemical Cleaning:

- Test and demonstrate Russian chemical tank cleaning methods for application to SRS HLW tanks to support tank closure.

- Assess Russian chemical tank cleaning methods and evaluate options for U.S. application (FY99, TFA).

- Develop and test chemical cleaning methods for SRS application and downselect for cold testing (FY00, TFA).

- Conduct cold verification testing of chemical cleaning methods (FY00, TFA, EM-30).

- Complete initial hot demonstration of chemical cleaning to evaluate performance and support tank closure (FY01, TFA, EM-30). Decision point for implementation.

\begin{tabular}{|c|c|c|c|c|c|c|}
\hline \multicolumn{7}{|c|}{ Budget Profile: Saltcake, Bulk Sludge, Heel and Debris Retrieval for SRS } \\
\hline & TTP\# & FY 1999 & FY 2000 & FY 2001 & FY 2002 & FY 2003 \\
\hline Hanford & $\begin{array}{l}\text { RL36WT51 } \\
\text { RL09WT51 }\end{array}$ & $\begin{array}{l}850 \\
100\end{array}$ & $\begin{array}{l}560 \\
100\end{array}$ & 310 & TBD & TBD \\
\hline INEEL & & & & & TBD & TBD \\
\hline Oak Ridge & & & & & TBD & TBD \\
\hline SRS & SR16WT51 & 1525 & 1475 & 775 & TBD & TBD \\
\hline TFA Total & & 2475 & 2135 & 1085 & 0 & 0 \\
\hline \multicolumn{7}{|l|}{ ASTD } \\
\hline \multicolumn{7}{|l|}{ CMST } \\
\hline \multicolumn{7}{|l|}{ FETC } \\
\hline \multicolumn{7}{|l|}{ ESP } \\
\hline \multicolumn{7}{|l|}{ International } \\
\hline Robotics & OR17C132 & 300 & 600 & & & \\
\hline \multicolumn{7}{|l|}{ University } \\
\hline EM-50 Total & & 2775 & 2735 & 1085 & 0 & 0 \\
\hline
\end{tabular}




\section{Problem Element Description and Priority Site Needs}

Waste transfer operations are required after retrieval to move the waste to storage, to provide supernate for use in a retrieval operation, or staging of wastes for subsequent blending or pretreatment. Transfers may occur from tank-to-tank or tank to processing facility and can cover a distance of several miles. During transfers, pipeline plugging has occurred at most sites and can result in very costly delays and intensive efforts to mitigate the plugging. Methods are needed to prevent plugging and to mitigate plugged lines if it cannot be avoided. The site needs addressed in this problem element are identified below.

\begin{tabular}{|c|c|c|c|c|}
\hline \multicolumn{5}{|c|}{ Problem Element: 1.2.1.4 Transfer Waste } \\
\hline $\begin{array}{l}\text { STCG Need } \\
\text { Number }\end{array}$ & Need Title & $\begin{array}{c}\text { PBS } \\
\text { Number }\end{array}$ & Technical Task & $\begin{array}{c}\text { OST } \\
\text { Number }\end{array}$ \\
\hline RL-WT013 & $\begin{array}{l}\text { Establish Retrieval Performance } \\
\text { Evaluation Criteria (Waste } \\
\text { Conditioning for Heel Transfer) }\end{array}$ & RL-TW04 & $\begin{array}{l}\text { Waste Conditioning } \\
\text { for Transfer and } \\
\text { Pipeline Unplugging }\end{array}$ & $\begin{array}{l}127,812, \\
1490,1547, \\
2010,2011, \\
2117,2118\end{array}$ \\
\hline RL-WT020 & $\begin{array}{l}\text { Service Integrity Testing of High-Level } \\
\text { Waste Tanks and Piping (Plugging) }\end{array}$ & RL-TW03 & Pipeline Unplugging & 196 \\
\hline TK-02 & $\begin{array}{l}\text { ORNL Tank Solid Waste Retrieval } \\
\text { (Waste Conditioning) }\end{array}$ & OR-43203 & $\begin{array}{l}\text { Waste Conditioning } \\
\text { for Transfer }\end{array}$ & $\begin{array}{l}1510,85 \\
810,890 \\
1547,2115\end{array}$ \\
\hline SR-2913 & $\begin{array}{l}\text { Methods to Unplug Waste Transfer } \\
\text { Lines }\end{array}$ & $\begin{array}{l}\text { SR-HL01, } \\
\text { SR-HL02, } \\
\text { SR-HL04 }\end{array}$ & Pipeline Unplugging & N/A \\
\hline SR-2909 & $\begin{array}{l}\text { Develop Advanced Techniques for Life } \\
\text { Extension of Tanks/Piping (Piping } \\
\text { Inspection) }\end{array}$ & $\begin{array}{l}\text { SR-HL01, } \\
\text { SR-HL02, } \\
\text { SR-HL04 }\end{array}$ & Pipeline Unplugging & N/A \\
\hline
\end{tabular}

\section{Technical Tasks}

Waste Conditioning for Transfer

At Hanford, Savannah River Site (SRS), and Oak Ridge Reservation (ORR), the sludge and hard heel retrieval rates, which are influenced by the chemistry/speciation of sludges, may be too slow for the proposed processing schedule. Furthermore, the chemistry of the slurry from the sludge retrieval process may need to be adjusted to prevent plugging of transfer lines and other operational problems. In addition, the mixing of the heel from one tank (e.g., Tank 241-C-106) with the slurry or heel of another tank must be done so that the mixture is compatible. The influence of the retrieval and transfer processes on downstream waste pretreatment operations, such as enhanced sludge washing at Hanford, must be understood to avoid adverse impacts on operations and performance. Information is needed on conditioning requirements, speciation, and design envelopes of acceptable compositions for processing and mixing. In addition to chemistry/speciation of the materials, physical properties of the sludge may impact waste transfer. Tank waste has aged for several decades, and solids of various sizes have formed that must be retrieved and treated. How the solids are mobilized, reduced in size, transferred, and treated will have an impact on the overall cost and viability of the retrieval and downstream pretreatment processes. There is a need to investigate the impact of large particle transport, develop performance 
specifications for acceptable sludge properties, and conduct an engineering evaluation on potential in-tank or near-tank size reduction and/or conditioning techniques before transport for these dry/hardened sludges. Assistance to the retrieval team in preventing or solving problems with retrieval and transport is also needed.

Work activities to address ORR and Hanford needs for waste conditioming for transfer, and to support SRS's need for pipeline unplugging techniques are focused on both near-term processing equipment for ORR Gunite and Associated Tank (GAAT) and longer term bench-scale investigations to better understand solution rheology and plugging phenomena to identify waste conditioning requirements for Hanford and SRS. Efforts will include

Waste Conditioning Compact Process Unit (CPU) for ORR GAAT - Work activities to support ORR's need for conditioning GAAT sludges for transfer integrate 1) Characterization, Monitoring, and Sensor Technology Crosscutting Program (CMST) monitoring technologies, 2) Robotics Crosscutting Program recommendations for remote maintenance design features, and 3) commercial segregation and grinding equipment. In FY98, the Pulsair mixing system and pipeline slurry monitoring were deployed. Work to complete this activity includes

- Add grinder to waste conditioning CPU (FY99, ASTD).

- Deploy integrated waste conditioning CPU (FY99, ASTD, EM-40).

- Document performance of waste conditioning CPU (FY00, TFA, ASTD).

\begin{tabular}{|c|c|c|c|c|c|c|}
\hline \multicolumn{7}{|c|}{ Budget Profile: Waste Conditioning } \\
\hline & TTP\# & FY 1999 & FY 2000 & FY 2001 & FY 2002 & FY 2003 \\
\hline Hanford & RL36WT51 & 25 & & & TBD & TBD \\
\hline INEEL & & & & & TBD & TBD \\
\hline Oak Ridge & OR16WT51 & 325 & & & TBD & TBD \\
\hline SRS & & & & & TBD & TBD \\
\hline TFA Total & & 350 & 0 & 0 & 0 & 0 \\
\hline ASTD & OR08SD10 & 100 & 200 & & & \\
\hline CMST & OR17C231 & 50 & & & & \\
\hline \multicolumn{7}{|l|}{ FETC } \\
\hline \multicolumn{7}{|l|}{ ESP } \\
\hline \multicolumn{7}{|l|}{ International } \\
\hline Robotics & OR17C131 & 350 & & & & \\
\hline \multicolumn{7}{|l|}{ University } \\
\hline EM-50 Total & & 850 & 200 & 0 & 0 & 0 \\
\hline
\end{tabular}

Prevention of Pipeline Plugging-Waste Conditioning Requirements - Work activities to support Hanford and SRS's needs for understanding and preventing transfer line plugging will include

- Identify chemical and physical parameters that influence pipeline plugging.

- Develop or adapt a test system to evaluate potential for settling, plugging, and erosion/corrosion of transport lines based upon pipeline geometries and measured waste properties (FY00, TFA, EM-50 University Programs). 
- Develop test plan and initiate investigation of both physical and chemical (gelation) plugging and settling mechanisms (FY00, TFA, EM-50 University Programs).

- Complete tests to determine minimum settling velocity for particles, erosion factors, and the potential for precipitation and adherence of waste to pipe walls during transport. Incorporate instrumentation that will develop correlations between measurements and system performance (FY00, TFA, EM-50 University Programs).

- Establish waste conditioning functional requirements.

- Provide operational recommendations to quantify desired pressure drops and flow rates for pumps to achieve adequate safety factors for safe transport (FY01, TFA, EM-50 University Programs). Decision point for demonstration.

- Analyze Hanford Tank 241-C-106 heel to identify waste-specific issues and develop waste conditioning specifications.

- Complete analysis of tests on Hanford Tank 241-C-106 heel to determine compatibility with double-shell tank (DST) receiver tank wastes (FY00, TFA, EM-30). Decision point on waste conditioning requirements for Hanford Tanks Initiative.

\section{Pipeline Unplugging}

As the tank clean-out and decommissioning program becomes active at SRS, there is an increasing potential that the transfer lines that are in place will become plugged. In fact, the DWPF recycle evaporator drain line plugged in August 1997. Transfer systems will potentially become plugged if the solids concentration of the material being transferred increases beyond the capacity of the prime mover, which could be a jet or a pump. This can happen due to the solids settling out within the pipe as well as chemical precipitation/ crystallization. Safe and cost-effective pipeline unplugging systems are needed to mitigate future problems.

There are three key issues that should be examined with regard to transfer line blockages. First, there needs to be an understanding of what factors contribute to line blockage. Identifying these factors will enable the implementation of programs and processes to help preclude the formation of blockages. Second, once a blockage has occurred there must be a method to locate and evaluate the blockage. Third, once the blockage is located and evaluated, there must be a method of unplugging the line without causing damage. Pipeline plugging is important to SRS, Hanford, and ORR. Related activities will be conducted to develop waste conditioning methods and procedures to reduce the potential for pipeline plugging (problem element 1.2.2.3). Work activities to support SRS's need for pipeline unplugging will include

- Develop blockage prevention methods.

- Develop and implement models to predict formation of pipeline blockages (FY98, EM-50 University Programs).

- Design and fabricate a test bed to study blockage phenomena and validate the blockage models and provide a facility that would be available for the testing of blockage location and removal tools (FY99, EM-50 University Programs).

- Demonstrate blockage location tools.

- Develop specifications and solicit industry for technology to locate blockages in transfer lines (FY99, TFA, EM-50 University Programs). 
- Select industrial partners to provide and demonstrate tools to locate and/or evaluate transfer line blockages (FY00, TFA, EM-50 Industry Programs).

- Develop and test transfer line blockage location tools (FY00, TFA, EM-50 Industry Programs).

- Demonstrate industry technologies for locating blockage and evaluate performance using simulants (FY01, TFA, EM-50 Industry Programs, EM-50 University Programs). Decision point for demonstration.

- Demonstrate blockage removal tools.

- Develop specifications and solicit industry for technology to remove blockages in transfer lines (FY99, TFA, EM-50 University Programs).

- Select industrial partners to provide and demonstrate tools to remove blockages from transfer lines (FY00, TFA, EM-50 Industry Programs).

- Develop and test transfer line blockage removal tools (FY00, TFA, EM-50 Industry Programs).

- Demonstrate industry technologies for removing pipeline blockages and evaluate performance using simulants (FY01, TFA, EM-50 Industry Programs, EM-50 University Programs). Decision point for demonstration.

- Demonstrate pipeline inspection tools using FIU test bed.

- Develop specifications and solicit industry for technology inspect transfer lines (FY00, TFA, EM-50 Industry and University Programs).

- Select industrial partners to provide and demonstrate tools to inspect transfer lines (FY00, TFA, EM-50 Industry and University Programs).

- Test pipeline inspection tools (FY01, TFA, EM-50 Industry and University Programs).

\begin{tabular}{|c|c|c|c|c|c|c|}
\hline \multicolumn{7}{|c|}{ "Budget Profile: Pipeline Unplugging } \\
\hline & TTP\# & FY 1999 & FY 2000 & FY 2001 & FY 2002 & FY 2003 \\
\hline Hanford & $\begin{array}{l}\text { RL36WT51 } \\
\text { RL09WT51 }\end{array}$ & $\begin{array}{l}175 \\
475\end{array}$ & $\begin{array}{l}225 \\
600\end{array}$ & $\begin{array}{l}125 \\
550\end{array}$ & $\overline{\mathrm{TBD}}$ & TBD \\
\hline INEEL & & & & & TBD & TBD \\
\hline Oak Ridge & & & & & TBD & TBD \\
\hline SRS & SR16WT51 & 50 & 250 & 150 & TBD & TBD \\
\hline TFA Total & & 700 & 1075 & 825 & 0 & 0 \\
\hline \multicolumn{7}{|l|}{ ASTD } \\
\hline \multicolumn{7}{|l|}{ CMST } \\
\hline FETC & $\begin{array}{l}\text { RL09WT51 } \\
\text { FT09IP?? }\end{array}$ & $\begin{array}{l}205 \\
324\end{array}$ & 900 & & & \\
\hline \multicolumn{7}{|l|}{ ESP } \\
\hline \multicolumn{7}{|l|}{ International } \\
\hline \multicolumn{7}{|l|}{ Robotics } \\
\hline University & & 150 & & & & \\
\hline EM-50 Total & & 1379 & 1975 & 825 & 0 & 0 \\
\hline
\end{tabular}




\section{Problem Element Description and Priority Site Needs}

Tank leakage is a critical concern during long- and short-term waste storage, as well as during retrieval operations. This problem element covers the detection of leaks from storage tanks and the mitigation or repair of those leaks to prevent widespread contaminant migration. Baseline leak detection includes the use of drywells, radiation sensors below tanks, and tank liquid level measurement. No baseline methods exist for leak repair or leak mitigation. Subsurface barrier technologies are an example of the types of mitigation methods that would fit within this problem element. The site needs addressed in this problem element are identified below.

\begin{tabular}{|c|c|c|c|c|}
\hline \multicolumn{5}{|c|}{ Problem Element: 1.2.1.5 Detect and Mitigate Leaks } \\
\hline $\begin{array}{l}\text { STCG Need } \\
\text { Number }\end{array}$ & Need Title & $\begin{array}{c}\text { PBS } \\
\text { Number }\end{array}$ & Technical Task & $\begin{array}{c}\text { OST } \\
\text { Number }\end{array}$ \\
\hline RL-WT020 & $\begin{array}{l}\text { Service Integrity Testing of High-Level } \\
\text { Waste Tanks and Piping (Leak } \\
\text { Detection) }\end{array}$ & RL-TW03 & $\begin{array}{l}\text { Leak Detection, } \\
\text { Mitigation, and Repair }\end{array}$ & 1996 \\
\hline RL-WT026 & $\begin{array}{l}\text { Tank Leak Detection Systems for } \\
\text { Underground Single-Shell Storage } \\
\text { Tanks }\end{array}$ & RL-TW04 & $\begin{array}{l}\text { Leak Detection, } \\
\text { Mitigation, and Repair }\end{array}$ & 2118 \\
\hline RL-WT027 & Tank Leak Mitigation Systems & RL-TW04 & $\begin{array}{l}\text { Leak Detection, } \\
\text { Mitigation, and Repair }\end{array}$ & N/A \\
\hline SR-2909 & $\begin{array}{l}\text { Develop Advanced Techniques for Life } \\
\text { Extension of Tanks/Piping (Repair } \\
\text { Technologies) }\end{array}$ & $\begin{array}{l}\text { SR-HL01, } \\
\text { SR-HL02, } \\
\text { SR-HL04 }\end{array}$ & $\begin{array}{l}\text { Leak Detection, } \\
\text { Mitigation, and Repair }\end{array}$ & N/A \\
\hline
\end{tabular}

\section{Technical Tasks}

\section{Leak Detection, Mitigation, and Repair}

The use of past-practice sluicing for removing waste from Hanford Site single-shell tanks (SSTs) involves adding liquid to tanks and therefore increases the potential for waste leakage to the environment. Leakage mitigation applies to all SST retrieval, including retrieval during privatization phase I and preparation of the phase II specification. Mitigating systems that improve on the capabilities of the current baseline approach are needed. The objective is to prevent, curb, or eliminate the possibility or extent of liquid waste leakage from underground storage tanks into the surrounding soils. If cost-benefit, risk-reduction, and alternative evaluations of new mitigating technologies determine that deployment, implementation, and operation are feasible, then further evaluation should be pursued. Such evaluations may include demonstrations and testing. Example concepts that could be evaluated include retrieval methods that minimize the potential for leakage, leak point and potential leak point location, "seek-and-seal" devices and methods, administrative approaches that maximize the use and coordination of currently available tools and methods, sheet barriers, close-coupled grout injection barriers, and dry-air containment barriers.

The TFA, in conjunction with the Characterization, Monitoring, and Sensor Technology Crosscutting Program (CMST), made investments in leak detection technology and adapted 
a subsurface plume remediation monitoring technology (electrical resistance tomography) to leak detection for radioactive waste storage tanks. By combining the electrical resistance tomography technique with the push-mode cone penetrometer technology, rapid and lowcost deployment of leak detection systems was demonstrated. This approach is now ready for field demonstration and deployment.

Work activities to support Hanford's need for tank leak mitigation and repair will include a two-phase industrial procurement approach.

- Assessment of tank leak detection and mitigation technology.

- Develop specifications for an industry solicitation to perform an assessment of current leak detection and mitigation technology (FY00, TFA).

- Solicit industry and select performer to assess the state of the art in industry and within the DOE complex for leak detection and mitigation. Identify requirements for adapting detection and mitigation techniques for tank remediation needs (FY00, TFA, EM-30, EM-50 Industry Programs).

- Complete assessment and recommendations on detection and mitigation approaches. Develop industry solicitation to support phase II of the tank leak detection and mitigation procurement (FY01, TFA, EM-30, EM-50 Industry Programs). Decision point for phase II procurement.

- Develop and demonstrate tank leak detection and mitigation systems.

- Solicit and select industry performer(s) for tank leak detection and mitigation development and testing. Select multiple performers for future downselection (FY01, TFA, EM-50 Industry Programs).

- Develop and cold test leak detection and mitigation systems. Evaluate performance of systems (FY02, TFA, EM-50 Industry Programs). Decision point for demonstration (optional phase III of procurement).

- Downselect leak detection and mitigation systems for hot demonstration and deployment (FY02, TFA, EM-30, EM-50 Industry Programs).

- Demonstrate leak detection and mitigation in selected Hanford tank to support retrieval operations (FY03, EM-30). 


\section{Problem Elements Description and Priority Site Needs}

Calcination is the baseline technology at Idaho National Engineering and Environmental Laboratory (INEEL) for solidifying liquid high-level waste (HLW) and storing it as a granular solid in underground stainless steel bins within concrete vaults. This problem element addresses technology development to modify the calcination operating parameters to make them compatible for calcining radioactive liquid waste high in sodium. It also addresses development of methods to dissolve currently stored calcine to support future radionuclide separations that are part of the baseline plan for waste processing at the INEEL. This problem element also addresses the disassembly and processing of Hanford's cesium and strontium capsules. The site needs addressed in this problem element are shown below.

\begin{tabular}{||c|l|l|l|l||}
\hline \multicolumn{5}{|c|}{ Problem Elements: 1.2.2.1 Calcine Waste and 1.2.2.2 Dissolve Waste } \\
\hline $\begin{array}{c}\text { STCG Need } \\
\text { Number }\end{array}$ & \multicolumn{1}{|c|}{ Need Title } & $\begin{array}{c}\text { PBS } \\
\text { Number }\end{array}$ & \multicolumn{1}{|c|}{ Technical Task } & $\begin{array}{c}\text { OST } \\
\text { Number }\end{array}$ \\
\hline \hline ID-2.1.02 & $\begin{array}{l}\text { Process Flowsheet to Calcine } \\
\text { Sodium Bearing Waste }\end{array}$ & $\begin{array}{l}\text { ID-HLW- } \\
101\end{array}$ & Advanced Calcination & 881, \\
\hline ID-2.1.05 & Dissolution of ICCP Calcines & $\begin{array}{l}\text { ID-HLW- } \\
103\end{array}$ & Calcine Dissolution & 2095 \\
\hline RL-WT07 & $\begin{array}{l}\text { Hanford Capsule Initiative } \\
\text { (HCI): A Processing }\end{array}$ & RL-TW09 & Hanford Capsule Initiative & 2009 \\
& Demonstration of Cs/Sr \\
& Capsules for Final Disposition & & & \\
\hline
\end{tabular}

\section{Technical Tasks}

Advanced Calcination

Radioactive liquid waste containing large quantities of sodium has accumulated over the years and is stored in the Idaho Nuclear Technology and Engineering Center (INTEC) tank farm at INEEL. This waste is referred to as sodium-bearing waste (SBW) and was generated as a result of extraction system solvent cleanup and decontamination efforts. Sodium nitrate and potassium nitrate are major components of the SBW. The SBW is difficult to calcine due to agglomeration and caking of molten sodium nitrate and potassium nitrate that persist in the calcine product. The thermal decomposition of the nitrates is not fully achieved by calcination at $500^{\circ} \mathrm{C}$ (the normal operating temperature of the facility) due to mass transfer and kinetic limitations and due to the formation of eutectic phases during drying. INEEL's Settlement Agreement with the state of Idaho requires that the SBW be calcined by 2012. This commitment cannot be met using the established SBW flowsheet due to the copious quantity of aluminum nitrate that is required. Therefore, to meet the objectives of increased throughput, reduced waste volumes, and reduced cost, alternative calcination schemes must be investigated. 
Work activities to support INEEL's need for advanced calcination of their SBW will include

- Develop a process flowsheet, specifications for process equipment, and test prototype components for thermal denitration.

- Complete initial laboratory-scale (10-cm pilot plant) tests with simulated lowactivity waste to establish optimum temperature and additives for the hightemperature flowsheets (FY00, TFA, EM-30).

- Identify the acceptable operating envelope using a wide range of feed compositions (FY00, TFA, EM-30).

- Perform demonstration testing based on the FY00 results to support the full-scale design with engineering performance and cost data (FY01, TFA, EM-30).

- Demonstrate advanced calcination using 15-cm pilot plant and unique waste compositions (FY01, TFA, EM-30).

- Test alternative process configurations such as rotary kiln and auger-driven moving bed to compare calcination performance. Complete performance specifications for full-scale thermal denitration based on pilot-scale testing (FY01, TFA, EM-30). Decision point for demonstration.

\section{Calcine Dissolution}

The waste processing baseline plan for INEEL includes a separations flowsheet option and requires dissolution of calcine before radionuclide separation. Calcine must be dissolved to put it in a form that is compatible with radionuclide separation technologies. Parameters affecting dissolution efficiency must be defined and scale-up and design of a calcine dissolver must be completed to support Title 1 design.

Work activities to support INEEL's need for calcine dissolution will include

- Develop dissolution rate and kinetic expressions for calcine dissolution.

- Complete laboratory tests to determine rate and kinetic expressions for calcine dissolution using surrogate waste (FY00, TFA, EM-30).

- Evaluate dissolver equipment designs and test preferred concepts at a bench-scale.

- Complete conceptual design of pilot plant dissolver based on laboratory kinetics experiments.

- Demonstrate calcine dissolution at the bench-scale using surrogate wastes and pilotplant design. Validate design and scale-up relationships from laboratory scale (FY01, TFA, EM-30). Decision point for demonstration.

\section{Hanford Capsule Initiative}

Cesium chloride and strontium fluoride capsules are currently stored at the Waste Encapsulation Storage Facility at the Hanford Site awaiting processing and immobilization as HLW. A concept needs to be developed for disassembling and processing the cesium and strontium capsules that will condition the halide salts for blending with other HLW feeds before vitrification. A proven concept is needed as a risk reduction activity to incorporate the capsule processing activity as part of a privately operated HLW vitrification facility at Hanford. The processes to be included in the concept are to 1) remotely and with minimum contamination disassemble the capsule, 2) remove the capsule contents, 3) pulverize the. 
strontium fluoride and transport as a slurry to a holding tank, and 4) dissolve the cesium chloride and remove the chloride. The work to support this activity includes

- Identify and evaluate alternatives for disassembling capsules and removing contents (FY01, TFA, EM-30).

- Assess impact of cesium and strontium salts on HLW vitrification (FY01, TFA, EM-30).

- Demonstrate processing of capsules using nonradioactive surrogates (FY02, TFA, EM-30).

- Demonstrate processing of actual cesium and strontium capsules (FY03, TFA, EM-30). 


\section{Problem Element Description and Priority Site Needs}

Waste pretreatment facilities will require feed streams that are compatible (e.g., density, solids content, rheology, particle size, blending reactions, chemistry) with pretreatment unit operations. Physical and chemical properties of tank waste can impact the efficiency of pretreatment. Various chemical combinations can lead to gelation or precipitation, which will adversely impact processing. A better understanding of sludge and saltcake chemistry and its impact on dissolution rates, pipeline transfers, and mixing operations is needed. This "interface" with retrieval and transfer focuses on understanding the effects of properties on waste transfer and pretreatment process efficiency to ensure selection of appropriate performance requirements during retrieval, conditioning, transfer, and storage of wastes. The site needs addressed in this problem element are identified below.

\begin{tabular}{||c|l|l|l|l||}
\hline \multicolumn{3}{|c|}{ Problem Element: 1.2.2.3 Prepare Retrieved Waste for Transfer and Pretreatment } \\
\hline $\begin{array}{c}\text { STCG Need } \\
\text { Number }\end{array}$ & \multicolumn{1}{|c|}{ Need Title } & $\begin{array}{c}\text { PBS } \\
\text { Number }\end{array}$ & \multicolumn{1}{|c||}{ Technical Task } & $\begin{array}{c}\text { OST } \\
\text { Number }\end{array}$ \\
\hline \hline RL-WT023 & $\begin{array}{l}\text { Prediction of Solid Phase Formation in } \\
\text { Hanford Tank Waste Solutions }\end{array}$ & RL-TW04 & $\begin{array}{l}\text { Prevention of Solids } \\
\text { Formation and } \\
\text { Saltcake Dissolution }\end{array}$ & $\begin{array}{l}233, \\
2096\end{array}$ \\
\hline
\end{tabular}

\section{Technical Tasks}

Prevention of Solids Formation and Saltcake Dissolution

Solids and gels are known to form in the Hanford tank wastes when the solution ionic strength is decreased. Transfer lines have been plugged when solids or gels inadvertently formed. Knowledge of the solubility envelope for the waste is necessary to avoid unwanted precipitation or gel formation in supernate. The immediate need is for information on solubility envelopes for the double-shell tank (DST) supernate and saltcake to support phase I privatization at Hanford. The mid-term need is to support phase II privatization developments to improve prediction of solubility envelopes for sludge washing, leaching, and saltcake dissolution solutions.

During phase I of privatization at Hanford, the Tank Waste Remediation System will be retrieving DST supernate/saltcake. The current plan is to dissolve the saltcake/precipitated salts by the addition of water. While these precipitated salts are expected to go back into solution, this has not been verified with actual wastes. If solids remain, they can cause operational difficulties during transfer and can result in the transferred stream being greater than $5 \%$ solids, which is the allowable maximum specified in the privatization contracts. In addition, the chemistry of these concentrated supernates is quite complex, and the dilution itself may cause additional precipitation. While dilution may aid in the dissolution of sodium nitrate, it may also cause gibbsite (aluminum hydroxide) to precipitate. Therefore, understanding the conditions that avoid precipitation in supernate and saltcake solutions is important to the DST retrieval operations for phase I of privatization. Thermodynamic models, which help predict the occurrence of this precipitation, must be verified. 
Sludge washing and leaching performance and saltcake dissolution evaluations are currently based on empirical data extrapolated from individual tanks to groups of tanks based on waste types. Improvements in processing efficiency are expected if the wash, leach, and dissolution processes are based on an understanding of the dissolution thermodynamics and kinetics rather than just empirical data. Water usage and makeup chemical addition can also be reduced, which together with the improvement in efficiency, can reduce the amount of the final waste form (i.e., glass) produced.

During FY98, testing and thermodynamic calculations were conducted to identify conditions to control or avoid precipitation or gel formation during sludge processing. Laboratoryscale tests were initiated to identify optimum conditions for saltcake dissolution.

Work activities to support Hanford's need for confirmation and improvement of thermodynamic predications of waste solubility and reaction kinetics to support processing and transfer operations will include

- Verification of operating envelope for sludges, supernate, and saltcake.

- Prepare test plan to address identified gaps and improve model performance (FY99, TFA, AEA, EM-50 University Programs).

- Complete follow-on testing with sludge samples, saltcake samples, and surrogates to address issues from FY98 testing. Validate surrogate test data and model predictions (FY99, TFA, EM-30, AEA, EM-50 University Programs).

- Incorporate improved thermodynamic data into Hanford models and transfer to the Tank Waste Remediation System organization for use in establishing appropriate operating envelopes (FY99, TFA, EM-30, AEA, EM-50 University Programs). Decision point for demonstration.

- Issue recommendations for control of solids formation (FY00, TFA, EM-30, EM-50 University Programs).

- Demonstrate saltcake dissolution at pilot scale (FY00, TFA, EM-30, EM-50 University Programs).

- Provide laboratory support to scale-up testing (FY01, TFA).

\begin{tabular}{|c|c|c|c|c|c|c|}
\hline \multicolumn{7}{|c|}{ Budget Profile: Prevention of Solids Formation and Saltcake Dissolution } \\
\hline & TTP\# & FY 1999 & FY 2000 & FY 2001 & FY 2002 & FY 2003 \\
\hline Hanford & $\begin{array}{l}\text { RL08WT41 } \\
\text { RL09WT41 }\end{array}$ & $\begin{array}{l}275 \\
100\end{array}$ & 100 & & TBD & TBD \\
\hline INEEL & & & & & TBD & TBD \\
\hline Oak Ridge & OR16WT41 & 675 & 675 & 600 & TBD & TBD \\
\hline SRS & & & & & TBD & TBD \\
\hline TFA Total & & 1050 & 775 & 600 & 0 & 0 \\
\hline ASTD & & & & & & \\
\hline CMST & & & & & & \\
\hline FETC & & & & & & \\
\hline ESP & & & & & & \\
\hline International & HQ06PS11 & 150 & 45 & & & \\
\hline Robotics & & & & & & \\
\hline University & & 100 & 0 & & & \\
\hline EM-50 Total & & 1300 & 820 & 600 & 0 & 0 \\
\hline
\end{tabular}




\section{Problem Element Description and Priority Site Needs}

Liquid wastes retrieved from storage tanks require clarification (i.e., filtration, centrifugation, decanting) to remove suspended solids such as sludges or precipitates that may interfere with downstream processing. The site needs addressed by this problem element are addressed below.

\begin{tabular}{||c|l|l|l|l||}
\hline \hline \multicolumn{2}{|c|}{ Problem Element: } & 1.2.2.4 Clarify Liquid Stream \\
\hline $\begin{array}{c}\text { STCG Need } \\
\text { Number }\end{array}$ & \multicolumn{1}{|c|}{ Need Title } & $\begin{array}{c}\text { PBS } \\
\text { Number }\end{array}$ & \multicolumn{1}{c|}{ Technical Task } & \multicolumn{1}{c|}{$\begin{array}{c}\text { OST } \\
\text { Number }\end{array}$} \\
\hline \hline TK-05 & $\begin{array}{l}\text { ORNL Tank Sludge and } \\
\text { Supernatant Separations }\end{array}$ & $\begin{array}{l}\text { OR-38112, } \\
\text { OR-38113, } \\
\text { OR-43201, } \\
\text { OR-43203 }\end{array}$ & Cross-Flow Filtration & 350, \\
& & & & 2096 \\
\hline SR-2904 & $\begin{array}{l}\text { ITP Feed Solution Pretreatment } \\
\text { (Solids Separation) }\end{array}$ & SR-HL04 & Cross-Flow Filtration & 350 \\
\hline
\end{tabular}

\section{Technical Tasks}

Cross-Flow Filtration

The Savannah River Site (SRS) has a decade of experience designing, testing, and operating solid-liquid separation for in-tank precipitation; however, this technology is not directly applicable to all of the solid-liquid separation problems at the four sites. For example, at the Oak Ridge Reservation (ORR), treatability studies indicate that standard clarification/ filtration equipment will not be adequate. Testing of alternative filter systems is required to support the separation of the late wash precipitate at SRS; various liquid low-level waste (LLW) streams at ORR including transuranic (TRU) sludges; and strontium/TRU-bearing retrieval solutions, supernates, and wash solutions for phase I privatization at Hanford. Separation of fine solids and colloidal particles from Hanford supernates is required to ensure that the LLW stream will have acceptably low concentrations of insoluble radioactive material, principally strontium and TRU radioisotopes. At ORR, solid-liquid separation will be needed during the Gunite and Associated Tank retrieval demonstration to treat excess sluice water for disposal, to concentrate tank sludges for feed to a treatment process, or reduce volume of retrieved sludges before transfer to interim storage tanks in the ORR active waste system.

Small-scale, single-element tests with surrogates and selected samples of actual waste indicate that cross-flow filtration should be effective for removing suspended solids from ORR tank waste supernatant liquids. Full-scale testing is needed to evaluate the effectiveness of backpulsing, the cumulative effects of fouling, and the effectiveness of chemical cleaning techniques. The cross-flow filtration system has been designed and is being fabricated. Workscope to complete this activity includes

- Complete installation of cross-flow filtration system (FY99, EM-30, TFA, ASTD, OR16WT41).

- Demonstrate operation of the cross-flow filtration system by treating Melton Valley Storage Tank supernate (FY99, EM-30, TFA, ASTD, OR16WT41). 
- Evaluate and document first deployment of cross-flow filtration system at treating Melton Valley Storage Tank (FY99, EM-30, TFA, OR16WT41).

\begin{tabular}{|c|c|c|c|c|c|c|}
\hline \multicolumn{7}{|c|}{ Budget Profile: Cross-Flow Filtration } \\
\hline & TTP\# & FY 1999 & FY 2000 & FY 2001 & FY 2002 & FY 2003 \\
\hline Hanford & & & & & TBD & $\overline{\mathrm{TBD}}$ \\
\hline INEEL & & & & & TBD & TBD \\
\hline Oak Ridge & OR16WT41 & 240 & & & TBD & TBD \\
\hline SRS & & & & & TBD & TBD \\
\hline TFA Total & & 240 & 0 & 0 & 0 & 0 \\
\hline & & & & & & \\
\hline ASTD & OR08SD10 & 750 & 150 & & & \\
\hline \multicolumn{7}{|l|}{ CMST } \\
\hline \multicolumn{7}{|l|}{ FETC } \\
\hline \multicolumn{7}{|l|}{ ESP } \\
\hline \multicolumn{7}{|l|}{ International } \\
\hline \multicolumn{7}{|l|}{ Robotics } \\
\hline \multicolumn{7}{|l|}{ University } \\
\hline EM-50 Total & & 990 & 150 & 0 & 0 & 0 \\
\hline
\end{tabular}




\section{Problem Element Description and Priority Site Needs}

Radionuclide removal from tank waste supernate is a primary requirement at all of the DOE waste tank sites because the presence of radionuclides directly impacts the waste immobilization decisions and the volume and cost of low-level and high-level wastes generated. The primary radionuclides of concern are cesium, strontium, technetium, and transuranic elements (TRUs). Removal processes for these radionuclides include in-tank, at-tank (compact processing), and out-of-tank (processing facility unit operations), which separate and concentrate the radionuclides of concem. The site needs addressed in this problem element are identified below.

\begin{tabular}{||c|l|l|l|l||}
\hline \multicolumn{5}{|c|}{ Problem Element: 1.2.2.5 Remove Radionuclides } \\
\hline $\begin{array}{c}\text { STCG Need } \\
\text { Number }\end{array}$ & \multicolumn{1}{|c|}{ Need Title } & $\begin{array}{l}\text { PBS } \\
\text { Number }\end{array}$ & \multicolumn{1}{c||}{ Technical Task } & \multicolumn{1}{c|}{$\begin{array}{c}\text { OST } \\
\text { Number }\end{array}$} \\
\hline ID-2.1.06 & $\begin{array}{l}\text { Solvent Extraction and Ion- } \\
\text { Exchange to Remove TRU, Sr, Tc, } \\
\text { and Cs from ICPP Tank Farm }\end{array}$ & $\begin{array}{l}\text { ID-HLW- } \\
103\end{array}$ & $\begin{array}{l}\text { TRUEX/, SREX, } \\
\text { Technetium for Idaho } \\
\text { Pretreatment }\end{array}$ & $\begin{array}{l}347,241, \\
2096\end{array}$ \\
\hline SR-2908 & $\begin{array}{l}\text { Second Generation Salt Feed } \\
\text { Preparation }\end{array}$ & SR-HL04 & $\begin{array}{l}\text { Alternatives to In-Tank } \\
\text { Precipitation }\end{array}$ & 21,2006 \\
\hline SR-2904 & ITP Feed Solution Pretreatment & SR-HL04 & $\begin{array}{l}\text { Alternatives to In-Tank } \\
\text { Precipitation }\end{array}$ & 2096 \\
\hline
\end{tabular}

\section{Technical Tasks}

Transuranic Extraction (TRUEX), Strontium Extraction (SREX), Technetium for Idaho Pretreatment

The TFA has supported the processing of tank waste by demonstrating the satisfactory removal of TRUs in FY96 and strontium and technetium in FY97. The successful removal of cesium from dissolved calcine solutions was demonstrated in FY98. Due to a shift in the emphasis of the separation processes to the dissolved calcine solutions, countercurrent flowsheets are needed to remove TRUs and strontium and technetium to U.S. Nuclear Regulatory Commission Class A low-level waste (LLW) levels. The successful flowsheets demonstrated with tank waste will form the basis for flowsheet development with dissolved calcine; however, the chemistry of the dissolved calcine is significantly different from the tank waste (higher zirconium, calcium, and fluorine). The countercurrent flowsheets are needed so that feed compositions to downstream unit operations in the Idaho National Engineering and Environmental Laboratory (INEEL) processing scheme (vitrification, grout, and denitration) can be determined. These flowsheets will form the basis for all waste immobilization development activities and will be used to determine sequencing of unit operations for integrated testing.

Cesium, strontium, and TRUs comprise less than one percent of the total INEEL radioactive waste volume. If these elements can be removed from the bulk (inert) elements in the waste, a significant reduction in the volume of high-level waste (HLW) would be realized. 
Workscope to support INEEL radionuclide separations from dissolved calcines includes

- Develop countercurrent TRUEX and SREX flowsheets for removal of TRUs, strontium, and technetium from dissolved INEEL calcine (FY01, TFA, ESP, EM-30).

- Demonstrate TRUEX and SREX flowsheets with actual dissolved calcine (FY01, TFA, ESP, EM-30).

- Develop integrated process flowsheet to remove TRUs, strontium, technetium, and cesium from dissolved calcine (FY01, TFA, ESP, EM-30).

- Demonstrate integrated process flowsheet with actual dissolved calcine (FY02, TFA, ESP, EM-30).

In addition, the Efficient Separations and Processing Crosscutting Program (ESP) is funding work to support INEEL's need including bench-scale testing of separation technologies for INEEL; development and testing of spheroidal, inorganic sorbents; and chemical separations work at Russia's Institute of Physical Chemistry and Khlopin Radium Institute.

\begin{tabular}{|c|c|c|c|c|c|c|}
\hline \multicolumn{7}{|c|}{ Budget Profile: TRUEX, SREX, and Technetium for Idaho Pretreatment } \\
\hline & TTP\# & FY 1999 & FY 2000 & FY 2001 & FY 2002 & FY 2003 \\
\hline Hanford & & & & & TBD & $\overline{\text { TBD }}$ \\
\hline INEEL & ID76WT41 & & & 500 & TBD & TBD \\
\hline Oak Ridge & & & & & TBD & TBD \\
\hline SRS & & & & & TBD & TBD \\
\hline TFA Total & & 0 & 0 & 500 & 0 & 0 \\
\hline \multicolumn{7}{|l|}{ ASTD } \\
\hline \multicolumn{7}{|l|}{ CMST } \\
\hline \multicolumn{7}{|l|}{ FETC } \\
\hline ESP & $\begin{array}{l}\text { HQ08C311 } \\
\text { ID76C311 } \\
\text { OR16C342 } \\
\text { RL37C344 }\end{array}$ & $\begin{array}{c}230 \\
100 \\
50 \\
50 \\
\end{array}$ & $\begin{array}{c}250 \\
250 \\
400 \\
50\end{array}$ & & & \\
\hline \multicolumn{7}{|l|}{ International } \\
\hline \multicolumn{7}{|l|}{ Robotics } \\
\hline \multicolumn{7}{|l|}{ University } \\
\hline EM-50 Total & & 430 & 950 & 500 & 0 & 0 \\
\hline
\end{tabular}

\section{Alternatives to In-Tank Precipitation}

In FY98, DOE decided to abandon the in-tank precipitation (ITP) process using tetraphenyl borate for removal of cesium from tank wastes and has embarked on a downselection process for a cesium removal technology. The downselection is to be completed in October 1998. The TFA has developed technologies being considered in the downselection process and is providing technical assistance to the process. Following the downselection, the 
TFA will provide technical information necessary to fully implement the selected cesium removal process. That workscope will be defined after the selection. Work activities to support this activity include

- Conduct workshop to define in detail TFA support to implementation of the selected cesium removal technology (FY99, TFA, EM-30).

- Issue report on ITP alternative evaluation and recommendations (FY99, TFA, EM-30).

- Issue specification for demonstration of ITP alternative (FY00, SRS).

- Deploy ITP altemative system (FY01, SRS).

In addition to these TFA-funded activities, ESP is funding work to support the evaluation and selection of alternatives to the ITP process. Work at the Oak Ridge Reservation is focused on developing a solvent extraction flowsheet to remove cesium, strontium, and technetium from alkaline waste solutions in a single integrated process. Similarly, the Savannah River Site is funded by ESP to conduct tests of ESP-developed technologies including crystalline silicotitanates and alkaline solvent extraction as replacements to the ITP process.

\begin{tabular}{|c|c|c|c|c|c|c|}
\hline \multicolumn{7}{|c|}{ Budget Profile: Alternatives to In-Tank Precipitation } \\
\hline & TTP\# & FY 1999 & FY 2000 & FY 2001 & FX 2002 & FY 2003 \\
\hline Hanford & TBD & TBD & $\overline{\text { TBD }}$ & TBD & $\overline{\text { TBD }}$ & $\overline{\mathrm{TBD}}$ \\
\hline INEEL & TBD & TBD & TBD & TBD & TBD & TBD \\
\hline Oak Ridge & TBD & TBD & TBD & TBD & TBD & TBD \\
\hline SRS & TBD & TBD & TBD & TBD & TBD & TBD \\
\hline TFA Total & & 500 & 0 & 0 & 0 & 0 \\
\hline \multicolumn{7}{|l|}{ ASTD } \\
\hline \multicolumn{7}{|l|}{ CMST } \\
\hline \multicolumn{7}{|l|}{ FETC } \\
\hline ESP & $\begin{array}{l}\text { OR16C341 } \\
\text { SR16C342 }\end{array}$ & $\begin{array}{l}275 \\
234\end{array}$ & $\begin{array}{l}\text { TBD } \\
\text { TBD }\end{array}$ & & & \\
\hline \multicolumn{7}{|l|}{ International } \\
\hline \multicolumn{7}{|l|}{ Robotics } \\
\hline \multicolumn{7}{|l|}{ University } \\
\hline EM-50 Total & & 1009 & 0 & 0 & 0 & 0 \\
\hline
\end{tabular}




\section{Problem Element Description and Priority Site Needs}

Retrieved sludge from tank waste requires processing to remove entrained radionuclides for downstream separation and processing, and to remove salts and minerals that may impact downstream vitrification. Sludges at Savannah River Site (SRS), Hanford, and Oak Ridge Reservation (ORR) will require processing to remove nonradioactive constituents that either add to the volume of the resulting high-level waste (HLW) (e.g., aluminum) or impact immobilization processing (e.g., chromium, technetium, or phosphate). Processing of sludges primarily involves washing and separations. The site needs addressed in this problem element are identified below.

\begin{tabular}{|c|c|c|c|c|}
\hline \multicolumn{5}{|c|}{ Problem Element: 1.2.2.7 Process Sludge } \\
\hline $\begin{array}{l}\text { STCG Need } \\
\text { Number }\end{array}$ & Need Title & $\begin{array}{c}\text { PBS } \\
\text { Number }\end{array}$ & Technical Task & $\begin{array}{l}\text { OST } \\
\text { Number }\end{array}$ \\
\hline RL-WT024 & $\begin{array}{l}\text { Enhanced Sludge Washing } \\
\text { Process Data }\end{array}$ & RL-TW05 & $\begin{array}{l}\text { Enhanced Sludge Washing } \\
\text { Process Data and Chromium } \\
\text { Removal }\end{array}$ & $\begin{array}{l}233,350, \\
2096\end{array}$ \\
\hline TK-11 & $\begin{array}{l}\text { ORNL Tank Sludge and } \\
\text { Supernatant Pretreatment }\end{array}$ & $\begin{array}{l}\text { OR-38112, } \\
\text { OR-38113, } \\
\text { OR-43201, } \\
\text { OR-43203 }\end{array}$ & TBD & 20,2096 \\
\hline SR-2920 & Improved Sludge Processing & $\begin{array}{l}\text { SR-HL01, } \\
\text { SR-HL025 }\end{array}$ & $\begin{array}{l}\text { Sludge Processing Scale-Up } \\
\text { and Process Improvement }\end{array}$ & $\begin{array}{l}229,350 \\
2096\end{array}$ \\
\hline
\end{tabular}

\section{Tecbnical Tasks}

\section{Enhanced Sludge Washing Process Data}

The current baseline pretreatment option for Hanford tank sludges is enhanced sludge washing (ESW) -- caustic leaching followed by washing with dilute sodium hydroxide. Testing of the baseline pretreatment process with actual tank sludges is required to confirm (or amend) the assumptions made in the development of the process flowsheet. Process data on ESW are needed to prepare enough feed to satisfy the maximum order quantity for phase I, preparation of the phase II privatization request for proposal (RFP), and for bid evaluation of vendors' proposals. Currently, only about 70 to 80 percent of the maximum order quantity for phase I sludge washing has been identified. Additional feeds must be identified that can satisfy Envelope D after pretreatment to ensure that the private contractors will be able to operate through 2011. In addition to phase I, information is necessary to craft the phase II RFP and to provide enough definitive information for a fair cost estimate for bid evaluation purposes. Sludge washing data is also needed to identify technical risks for wastes that are part of phase II. Early data is needed to determine whether current processing concepts are adequate to handle more problematic wastes in phase II. Additional data on the effect of varying temperature and caustic concentration on leach performance is inportant. In FY98, TFA-supported data was used as the basis for the Hanford Federal Facility Agreement and Consent Order milestone (M-50-03) decision that enhanced sludge washing produces a reasonable number of $\mathrm{HLW}$ camisters. 
Work activities to address baseline ESW performance as a function of temperature and caustic concentration will include

- Parametric studies of ESW to support improved dissolution.

- Complete parametric tests of two Hanford sludges to evaluate temperature and caustic concentration dependence. Support M-50-03 milestone with two additional sludge types. Evaluate dilute hydroxide and caustic leaching performance (completed FY98).

- Complete final parametric tests of caustic leaching with two additional Hanford sludges to support phase II RFP development (FY00, TFA, EM-30). Decision point for engineering development.

\section{Chromium Removal}

A high emphasis needs to be placed on obtaining inforination on the chromium chemistry in the sludges and saltcakes. Testing of wastes with high chromium levels indicates insufficient chromium removal. Chromium removal is needed to reduce the impact on the HLW glass volume.

Work activities to support resolution of Hanford's chromium removal issues will include

- Alternative alkaline washes for chromium removal evaluation.

- Develop test plan for chromium-oxidation studies and conduct laboratory-scale chromium leaching tests on three Hanford tank sludges (completed FY98).

- Conduct final two laboratory-scale chromium-leaching tests on Hanford tank sludges (FY00, TFA, EM-30). Decision point for engineering development.

- Define functions and requirements for a bench-scale chromium leaching unit; design and procure system (FY00, TFA, EM-30).

- Complete bench-scale chromium-leaching tests on two Hanford sludges, and report on performance of system (FY01, TFA, EM-30). Decision point for demonstration.

\section{Sludge Processing Scale-Up and Process Improvement}

At Hanford, current sludge wash laboratory data to support delivery of feed for HLW immobilization in privatization phase IB are limited to that work done by the TFA for the HLW project. This small-scale laboratory work is at the 5-gram/test level. Data are needed to support scaling the process up to full scale; an intermediate-scale test (large bench-scale, small pilot-scale) involving about a 15-gal-sized vessel and a few hundred gallons of actual waste would provide the appropriate scale-up information. Information is needed about the effects of temperature on such process steps as dilution and perhaps re-precipitation of solids, washing efficiency, leaching efficiency, and quantity of caustic needed. The various privatization phase I sludges need to be tested to support the full-scale processing planned for Tanks 241-AZ-101, 241-AZ-102, and 241-AY-102 (including material retrieved from Tank 241-C-106). Oxidation states of some of the chemical species (e.g., chromiunı) may need to be altered to ensure dissolution to support overall project objectives.

Baseline flowsheets for SRS and Hanford are based on batch-wise sludge processing in large vessels or in-tank. Although batch processes offer some advantages, e.g., simplicity, 
they also present potential problems, especially when applied on a large scale. Potential drawbacks include poor efficiency because of heterogeneity and poor mixing as well as less ability to control mixing, mass transfer, heat transfer, and chemical kinetics. Continuous processing, on the other hand, trades some additional complexity for significant benefits. Because the continuous process can be designed to maximize rate-limiting processes, equipment sized to process an equivalent amount of waste in the same time can be processed in much smaller equipment than the corresponding batch vessels. Smaller equipment may result in reduced capital costs, less risk, better control, faster start-ups and shutdowns, and less impact and faster recovery from process upsets. However, continuous processing of sludge has not been adequately developed or tested. Continuous processing of Hanford and SRS sludges may provide significant benefits; however, scale-up, demonstration, and evaluation of cost benefit is needed to fully evaluate the merits over the current batchprocessing baseline.

Work activities to support scale-up of sludge processing at Hanford and continuous sludge processing at SRS will include

- Settle-decant testing to support Hanford phase I privatization. The scope of the settledecant work will be evaluated in light of the Tank Waste Remediation System privatization contract and will be refocused on supporting retrieval operations. This work will be started in FY99.

- Countercurrent decantation (CCD) for improved SRS sludge processing.

- Complete cost savings evaluation and initiate vendor manufacture and testing of a full-scale ( $7 \mathrm{ft} \mathrm{diameter)} \mathrm{single} \mathrm{settling} \mathrm{CCD} \mathrm{unit.} \mathrm{Develop} \mathrm{initial} \mathrm{design} \mathrm{concept}$ for future deployment at SRS (FY01, TFA, EM-30, EM-50 Industry Programs).

- Conduct necessary settling studies on actual waste to support scale. Develop plans for siting the unit within the SRS tank farm (FY01, TFA, EM-30, EM-50 Industry Programs). Decision point for demonstration.

- Develop design specifications for procurement of a multi-stage CCD system. Initiate procurement and site preparation for demonstration (FY02, TFA, EM-30, EM-50 Industry Programs).

- Fabricate and cold test CCD system. Install system within tank farm for hot operations. Initiate demonstration of multi-stage CCD sludge processing system (FY02, EM-30, EM-50 Industry Programs).

\begin{tabular}{||l|c|c|c|c|c|c||}
\hline \multicolumn{7}{|c|}{ Budget Profile: Sludge Processing Scale-Up and Process Improvement } \\
\hline & TTP\# & FY 1999 & FY 2000 & FY 2001 & FY 2002 & FY 2003 \\
\hline \hline Hanford & TBD & TBD & TBD & TBD & TBD & TBD \\
\hline INEEL & TBD & TBD & TBD & TBD & TBD & TBD \\
\hline Oak Ridge & TBD & TBD & TBD & TBD & TBD & TBD \\
\hline SRS & TBD & TBD & TBD & TBD & TBD & TBD \\
\hline TFA Total & & 500 & 0 & 0 & 0 & 0 \\
\hline
\end{tabular}




\section{Problem Element Description and Priority Site Needs}

Following pretreatment operations, supernate and sludge waste streams are transferred to high- and low-level waste (LLW) immobilization operations. A processing step may be required immediately following the radionuclide separation or sludge processing operations to ensure that the waste streams are acceptable for the immobilization unit operations. Processing may include additional volume reduction such as recycling, evaporation, or concentration to produce a stream more amenable to immobilization or of reduced volume to decrease the quantity of waste requiring immobilization. The site needs addressed in this problem element are identified below.

\begin{tabular}{|c|c|c|c|c|}
\hline \multicolumn{5}{|c|}{ Problem Element: 1.2.2.8 Prepare Pretreated Waste for Immobilization } \\
\hline $\begin{array}{l}\text { STCG Need } \\
\text { Number }\end{array}$ & Need Title & $\begin{array}{c}\text { PBS } \\
\text { Number }\end{array}$ & Technical Task & $\begin{array}{c}\text { OST } \\
\text { Number }\end{array}$ \\
\hline RL-WT08 & $\begin{array}{l}\text { Advanced Methods for Achieving } \\
\text { LLW Volume Minimization }\end{array}$ & RL-TW05 & Caustic Recycle & 885 \\
\hline ID-2.1.12 & $\begin{array}{l}\text { Denitrate and Solidify High-Activity } \\
\text { Waste for Transport (Waste } \\
\text { Partitioning) }\end{array}$ & $\begin{array}{l}\text { ID-HLW- } \\
103\end{array}$ & Caustic Recycle & 885 \\
\hline ID-2.1.14 & $\begin{array}{l}\text { Develop Technology for } \\
\text { Preconditioning ICPP High-Activity } \\
\text { and Low-Activity Wastes }\end{array}$ & $\begin{array}{l}\text { ID-HLW- } \\
103\end{array}$ & Out-of-Tank Evaporator & 20 \\
\hline SR-2923 & Caustic Recovery and Recycle & SR-HL08 & Caustic Recycle & 885 \\
\hline
\end{tabular}

\section{Technical Tasks}

Caustic Recycle

Pretreated alkaline supernate containing large volumes of sodium nitrate and sodium hydroxide is sent to LLW immobilization processes. Nitrate concentration impacts the volume of $L L W$, because it is one of the chemical species driving waste form performance requirements. In addition, sodium hydroxide levels increase volume and could be reduced through recycle back to the processing facilities. At the Savannah River Site (SRS), large quantities of chemicals (chiefly sodium salts of nitrate, nitrite, hydroxide, and aluminate) are present in the liquid phase of high-level waste (HLW). Greater than $99.9 \%$ of the soluble salts will be disposed in saltstone after removal of radioactive species. Recovery of sodium hydroxide (caustic) from the salt solution could significantly reduce the volume of waste disposed in saltstone. Recycling caustic also reduces the quantity of new chemicals added to the HLW system at the SRS. The recovered caustic could be used to neutralize fresh waste from the separations canyons, Defense Waste Processing Facility (DWPF), and the Effluent Treatment Facility, used as a corrosion inhibitor in the tank farm, and used to dissolve alumina in Extended Sludge Processing.

At Hanford, the volume of tank waste is so large that enormous quantities of immobilized low-activity waste will be generated and require appropriate LLW disposal. By removal of essentially nonradioactive constituents from the waste through innovative chemical processes, the volume of LLW requiring disposal could be significantly reduced. Like SRS, 
recovery of sodium hydroxide from the Hanford salt solutions and Idaho National Engineering and Environmental Laboratory's sodium-bearing waste could significantly reduce the volume of LLW produced.

Work activities to address SRS and Hanford needs for LLW minimization through caustic or salt recovery will include

- Demonstrate and deploy caustic recovery system for SRS and Hanford LLW minimization.

- Develop performance requirements for an industry solicitation to develop, demonstrate, and evaluate caustic recovery for DOE applications (FY00, TFA, EM-30).

- Solicit industry and select vendor for phase I cold demonstration and evaluation (FY00, TFA, EM-30, EM-50 Industry Programs).

- Complete cold simulant demonstration and evaluate economics for application of caustic recovery to SRS or Hanford LLW streams (FY01, TFA, EM-30, EM-50 Industry Programs). Decision point for demonstration.

- Initiate phase II fabrication and hot demonstration contract. Construct pilot-scale caustic recovery system (FY02, TFA, EM-30, EM-50 Industry Programs).

- Demonstrate caustic recovery at SRS or Hanford for LLW minimization. Complete performance evaluation (FY03, TFA, EM-30, EM-50 Industry Programs). Decision point for implementation.

\section{Out-of-Tank Evaporator}

INEEL has identified a need for evaporator systems to reduce the size and duty of the highactivity waste melter and to reduce the volume of low-activity liquid waste to be grouted. For both LLW and HLW, excess water in the waste can increase waste treatment costs and increase the volume of cementitious waste forms. Volume reduction through evaporation can reduce these costs. TFA work to develop and demonstrate evaporators is described in problem element 1.1.4, "Reduce Waste Volumes." 


\section{Problem Element Description and Priority Site Needs}

The low-level waste (LLW) streams produced during pretreatment separation operations at each of the tank waste sites will require immobilization to produce an acceptable waste form for disposal. Each of the DOE tank waste sites are considering different immobilization and disposal options for LLW, ranging from grout to glass, and from onsite to offsite disposal. The site needs addressed in this problem element are identified below.

\begin{tabular}{||c|l|l|l|l||}
\hline \multicolumn{5}{|c|}{ Problem Element: 1.2 .3 .1 Process LLW } \\
\hline $\begin{array}{c}\text { STCG Need } \\
\text { Number }\end{array}$ & \multicolumn{1}{|c|}{ Need Title } & \multicolumn{1}{c|}{$\begin{array}{c}\text { PBS } \\
\text { Number }\end{array}$} & \multicolumn{1}{|c||}{ Technical Task } & \multicolumn{1}{c|}{$\begin{array}{c}\text { OST } \\
\text { Number }\end{array}$} \\
\hline \hline ID-2.1.07 & $\begin{array}{l}\text { Develop Technology to } \\
\text { Stabilize/Solidify ICPP Low- } \\
\text { Activity Waste }\end{array}$ & $\begin{array}{l}\text { ID-HLW- } \\
102\end{array}$ & Low-Activity Waste Forms & 82 \\
\hline
\end{tabular}

\section{Tecbnical Tasks}

The current baseline for LLW immobilization at Savannah River Site (SRS), Oak Ridge Reservation (ORR), and Idaho National Engineering and Environmental Laboratory (INEEL) is grouting. The baseline for Hanford is being established based on performance requirements set forth in the Tank Waste Remediation System (TWRS) privatization contract. Glass waste forms are being considered for Hanford and for M Area sludges at SRS. At INEEL, high nitrate levels in LLW feed require development of an appropriate LLW grout formulation and/or denitration process to pretreat the LLW feed. A sound basis for selecting LLW forms and the data needed to make this selection would help DOE evaluate privatization proposals, support design decisions, and would provide stakeholders with better information for considering waste form options.

At the INEEL, LLW from the separations process will be acidic and high in nitrates, both of which are detrimental to grout chemistry. The LLW at other DOE sites is basic; therefore, their grout formulations are not applicable to INEEL LLW from tanks. Because of the high acidity and nitrates in the waste, waste conditioning is necessary before grouting. Grout formulation consists of blending and proportioning the waste with cements such as ordinary portland cement, blast furnace slag, and coal power plant fly ash. Once the grout formulation is developed for a specific LLW stream, extensive waste form qualification is required to document grout stability and leach resistance. Waste form qualification includes compressive strength after initial curing, immersing, and thermal cycling and leach tests for radionuclides and hazardous components. This is an iterative research process between waste conditioning, grout formulation, and waste form qualification. Equipment is needed to condition the simulated waste, mix grout, prepare full-size waste forms, core drill waste form, and conduct thermal cycle tests.

Current research utilizes thermal calcination to solidify the waste and destroy the nitrates. This denitration process produces significant amounts of off-gas, which must be handled. Denitration equipment must be specified, procured, and tested. The corrosive nature of the off-gas must be investigated and materials of construction determined. 
In addition to these needs for immobilization technology development and evaluation, Hanford and ORR also require waste acceptance criteria and testing methods for the selected LLW form. Problem element 1.3.2 (Dispose of LLW) describes these related monitoring and control needs and their respective paths to solution.

Work activities within the TFA are intended to provide processing data and product data (short-term acceptance testing and long-term performance testing) to allow the tank sites to reach well-thought out decisions on waste forms.

Low-Activity Waste Forms (INEEL) - Work activities to support INEEL's need to develop process data to support Title 1 design of their immobilization process for low-activity waste (LAW) will include

- Development and testing of thermal denitration for LAW.

- Determine optimum conditions for thermal denitration through laboratory studies (FY00, TFA, EM-30).

- Develop energy and material balances for LLW denitration to support flowsheet development and system design. Develop chemistry models and Chem CAD process plant simulator model (FY00, TFA, EM-30).

- Evaluation of process equipment and recommendation of a preferred system for LAW demitration.

- Determine suitable materials of construction through corrosion testing (FY00, TFA, EM-30).

- Evaluate commercial systems for thermal denitration, including moving bed, fluidized bed, and rotary kiln calciners. Recommend preferred thermal denitration process for INEEL LAW (FY00, TFA, EM-30). Decision point for procurement of pilot-scale equipment.

- Demonstrate thermal denitration processing at the pilot scale.

- Procure commercial equipment for pilot-plant thermal denitration system (FY01, TFA, EM-30).

- Complete pilot-plant installation at the Idaho Nuclear Technology and Engineering Center (INTEC) (FY01, TFA, EM-30).

- Test thermal denitration of INEEL LAW at the pilot-scale to confirm processability. Report on performance to support Title 1 design (FY01, TFA, EM-30). Decision point for demonstration.

- Develop grout formulation for immobilizing INEEL LAW.

- Develop grout formulation for INEEL LAW and demonstrate that the resulting "product" meets specifications (FY99, FY00, TFA, EM-50 International Programs, EM-30).

- Demonstrate grout formulation in pilot-scale test (FY01, TFA, EM-30).

\begin{tabular}{|l|c|c|c|c|c|c||}
\hline \multicolumn{7}{|c|}{ Budget Profile: Low-Activity Waste Forms (INEL) } \\
\hline & TTP\# & FY 1999 & FY 2000 & FY 2001 & FY 2002 & FY 2003 \\
\hline \hline Hanford & RL09WT31 & 225 & & & TBD & TBD \\
\hline INEEL & & & & & TBD & TBD \\
\hline Oak Ridge & & & & & TBD & TBD \\
\hline SRS & & & & & TBD & TBD \\
\hline TFA Total & & 225 & 0 & 0 & 0 & 0 \\
\hline
\end{tabular}




\section{Problem Element Description and Priority Site Needs}

Immobilization of the high-level waste (HLW) streams at Idaho National Engineering and Environmental Laboratory (INEEL), Savannah River Site (SRS), and Hanford is required to produce an acceptable HLW form for final disposal. Calcine immobilization and vitrification are the baseline methods for HLW immobilization. In addition to the calcination and vitrification immobilization processes, this problem element addresses melter feed preparation, process monitoring, and process control methods to produce acceptable waste forms.

The baseline technology for HLW processing is vitrification at all of the tank sites with this process being operational at SRS and West Valley, New York. At SRS, methods that can reduce the cost of operation are being identified and evaluated. Cost reduction can occur through optimization of waste loading that reduces the number of glass canisters produced, improvements in process equipment and materials of construction that reduce maintenance and downtime by reducing corrosion or other material failure problems. At the Hanford Site, optimized waste loading and melter selection are considerations for developing the baseline to support phase II privatization, especially with regard to concerns about high chromium wastes and their compatibility with current melter designs and waste formulations. At INEEL, waste formulation for sodium-bearing waste and calcined wastes followed by melter testing is needed to meet an accelerated schedule for the record of decision (ROD) and the FY00 Title 1 design schedule. Corrosion of melter materials from the acidic wastes at the INEEL is a key issue that must be addressed with both formulation and materials development and testing. The site needs addressed in this problem element are identified below.

\begin{tabular}{|c|c|c|c|c|}
\hline \multicolumn{5}{|c|}{ Problem Element: 1.2.3.2 Process HLW } \\
\hline $\begin{array}{l}\text { STCG Need } \\
\text { Number }\end{array}$ & Need Title & $\begin{array}{c}\text { PBS } \\
\text { Number }\end{array}$ & Technical Task & $\begin{array}{c}\text { OST } \\
\text { Number }\end{array}$ \\
\hline RL-WT06 & $\begin{array}{l}\text { Identification and Management of } \\
\text { Problem Constituents for HLW } \\
\text { Vitrification }\end{array}$ & RL-TW05 & $\begin{array}{l}\text { Optimize Waste Loading for } \\
\text { Hanford and SRS }\end{array}$ & 2009 \\
\hline RL-WT07 & $\begin{array}{l}\text { Hanford Capsule Initiative (HCI): } \\
\text { A Processing Demonstration of } \\
\text { Cs/Sr Capsules for Final } \\
\text { Disposition (Immobilization) }\end{array}$ & R1-TW09 & $\begin{array}{l}\text { Optimize Waste Loading for } \\
\text { Hanford and SRS }\end{array}$ & 2009 \\
\hline ID-2.1.08 & $\begin{array}{l}\text { Develop Technology/Process for } \\
\text { the Immobilization of High- } \\
\text { Activity Waste }\end{array}$ & $\begin{array}{l}\text { ID-HLW- } \\
102\end{array}$ & $\begin{array}{l}\text { Optimize Waste Loading for } \\
\text { Hanford and SRS }\end{array}$ & 2009 \\
\hline ID-2.1.12 & $\begin{array}{l}\text { Denitrate and Solidify High- } \\
\text { Activity Waste for Transport } \\
\text { (Immobilization) }\end{array}$ & $\begin{array}{l}\text { ID-HLW- } \\
103\end{array}$ & $\begin{array}{l}\text { Optimize Waste Loading for } \\
\text { Hanford and SRS and INEEL } \\
\text { HLW Immobilization }\end{array}$ & 2009 \\
\hline SR-2906 & Optimize Melter Glass Chemistry & SR-HL05 & $\begin{array}{l}\text { Optimize Waste Loading for } \\
\text { Hanford and SRS }\end{array}$ & 2009 \\
\hline SR-2910 & $\begin{array}{l}\text { Develop Second Generation } \\
\text { DWPF Melter }\end{array}$ & SR-HL05 & $\begin{array}{l}\text { Melter Pour Spout and Process } \\
\text { Equipment Improvements for } \\
\text { SRS }\end{array}$ & $\begin{array}{l}2009 \\
2092\end{array}$ \\
\hline SR2917 & $\begin{array}{l}\text { Develop Remote Technology to } \\
\text { Improve DWPF Operations }\end{array}$ & SR-HL05 & $\begin{array}{l}\text { Develop Remote Technology } \\
\text { to Improve DWPF Operations }\end{array}$ & 1510 \\
\hline SR-2903 & $\begin{array}{l}\text { Alternative DWPF Canister } \\
\text { Decontamination Techniques }\end{array}$ & SR-HL05 & $\begin{array}{l}\text { Melter Pour Spout and Process } \\
\text { Equipment Improvements for } \\
\text { SRS }\end{array}$ & 2009 \\
\hline
\end{tabular}




\section{Technical Tasks}

Optimize Waste Loading for Hanford and SRS

The SRS's Defense Waste Processing Facility (DWPF) complies with Waste Acceptance Product Specifications (WAPS) and process control requirements by demonstrating, to a high confidence, that melter feed will produce glass meeting all quality and processing requirements. This method requires that uncertainties associated with sampling, sample analysis, and models used to estimate properties are determined and that sufficient allowance is made for these uncertainties when controlling feed composition.

The existing model for liquidus temperature has a large uncertainty associated with it, and its application has led to reduction in allowable waste loading. Some constraints on the application of the durability model can cause acceptable glasses to be rejected, because the durability is indeterminate (i.e., the applicability of the model is not certain). New or improved versions of existing property models for liquidus temperature and durability are needed. The model tolerances need to be identified. These models should be applicable to the entire range of plausible glass compositions.

In addition to liquidus issues at SRS, waste loading issues associated with chromium and glass phase separation have been identified at Hanford. Currently, HLW glasses are formulated to ensure that little or no insoluble phases exist in the HLW melter. Insoluble phases are caused by such problem constituents as chrome minerals, spinels, and noble metals. An alternative method for handling problem constituents in HLW glasses is needed. The volume of HLW glass that will be produced from the sludges at Hanford is dependent on the ability to solubilize or dilute problem constituents that make up a very small fraction of the overall waste. Minimizing the impact of the problem constituents is important for formulating a strategy and staging the wastes to be treated during the phase II privatization effort. Diluting the problem constituents usually involves blending of waste types and/or increasing the volume of glass waste forms. Both of these alternatives are expensive. An alternative for handling problem constituents is to allow them to remain insoluble in the glass matrix. This approach is acceptable as long as the insoluble phase does not adversely affect the processing of the waste or the quality of the waste form. Usually, the concentration of the insoluble constituents in the final waste form would be very low (less than $2 \%$ ). Information is needed on the technical viability of producing HLW glasses with insoluble phases.

Work activities to support SRS and Hanford needs for optimizing waste loading will include

- Development of liquidus, nepheline, spinel, and waste loading maximization data to support increased waste loading at SRS and Hanford.

- Investigate spinel and nepheline formation and multi-phase glasses and resulting impacts on HLW vitrification and durability of HLW glasses (FY99, TFA, EM-30).

- Issue technical report on glass liquids temperature (FY99, TFA, EM-30).

- Define acceptable composition range for immobilized high-activity waste (FY00, TFA, EM-30).

- Deploy optimized waste loading in DWPF (FY00, TFA, EM-30). 
- Complete evaluation of tools for waste loading maximization and provide performance data on tests conducted for Hanford and DWPF glasses (FY00, TFA, EM-30). Decision point for demonstration.

\begin{tabular}{|l|c|c|c|c|c|c|}
\hline \multicolumn{7}{|c|}{ Budget Profile: Optimize Waste Loading for Hanford and SRS } \\
\hline & TTP\# & FY 1999 & FY 2000 & FY 2001 & FY 2002 & FY 2003 \\
\hline Hanford & RL37WT31 & 700 & 900 & 600 & TBD & TBD \\
\hline INEEL & ID77WT31 & 400 & 600 & 500 & 600 & TBD \\
\hline Oak Ridge & & & & & TBD & TBD \\
\hline SRS & SR16WT31 & 700 & 900 & 600 & TBD & TBD \\
\hline TFA Total & & 1800 & 2400 & 1700 & 600 & 0 \\
\hline \hline
\end{tabular}

\section{Melter Pour Spout and Process Equipment Improvements for SRS}

Pour Spout: The DWPF melter pour spout accumulates glass and crystalline deposits in three areas. These deposits must be periodically removed from the pour spout to maintain melter operability. The deposits also result in further glass deposition and pluggage in the bellows assembly, which couples the glass-receiving canister to the melter. The causes of this accumulation and pluggage must be characterized as a part of the effort to eliminate the problem. Improved cleaning techniques are required to remove these deposits from the pour spout, the cause of the pluggage needs to be identified, and inserts or process improvements need to be developed to reduce or eliminate the problem for future melters. Suspected contributors to the problem include physical design, glass chemistry/redox, and melter/pour spout pressure control systems.

Melter Throughput and Equipment Cost: The DWPF melter has been unable to sustain glass production at the reference rate of $228 \mathrm{lb} / \mathrm{hr}\left(8 \mathrm{lb} / \mathrm{hr} \cdot \mathrm{ft}^{2}\right)$. It is important to produce glass at that rate or above to meet production goals and work off HLW inventories within the projected time frame. Besides pour spout problems limiting throughput, melt rate is also an issue. Experience to date indicates that "foaming" at the glass/feedstock interface is contributing to the melt rate problem by limiting heat transfer from the glass to the feed material. The redox state of the feed/glass may be a contributing cause. Viscosity of the glass and melting feed may also limit the melting rate.

In addition to throughput issues, the melter is one of the most expensive and most complicated components in the DWPF. In the future, it could also become the production ratelimiting component in the plant. A simpler, lower cost melter could result in significant lower life-cycle costs for the DWPF.

Work activities to support SRS needs in melter throughput will include

- Inprove pour spout performance for DWPF.

- Work to understand DWPF pour stream wicking was initiated in FY98. A fundamental study of pour wicking was initiated. Experimental test equipment including a full-scale pour test unit were installed and testing initiated. 
- Continue testing of pour spout design improvements and demonstrate pour spout insert and knife edge (FY99, TFA, EM-30, EM-50 University Programs).

- Provide recommended improvements to pour spout design and melter operations (FY00, TFA, EM-30, EM-50 University Programs).

- Evaluate commercial alternative heater materials and equipment. Downselect systems and demonstrate within the test system to evaluate performance and impact on pour spout flow characteristics (FY00, TFA, EM-30). Decision point for pour spout design and heater system modifications to DWPF melter design. Decision point for demonstration.

- Enhance melter throughput and reduce equipment costs.

- Identify alternative features needed to extend melter life and performance, including the melter, auxiliary support systems, and the off-gas system. Identify advanced materials needs (FY99, TFA, EM-30).

- Initiate collaborative development with industry, universities, and national laboratories to address priority features identified in FY99 (FY00, TFA, EM-30).

- Evaluate feature improvements for consideration in design of future melters for DWPF (FY01, TFA, EM-30). Decision point for demonstration.

DWPF Canister Decontamination: There is a potential problem that at near design production rates the DWPF canister decontamination operation could limit plant operating attainment to less than the design $75 \%$. Canister decontamination is a water-frit slurry blast technique that removes contamination and oxides from the entire canister exterior surface. The waste from this process is in two forms. An off-gas is routed to the facility vessel ventilation system and on to facility controlled ventilation exhaust. A water-frit slurry waste stream is pumped into the facility chemical process and fed into the vitrification process stream, to minimize liquid waste production. This coupling of canister decontamination with chemical processing is less than optimum and could limit production rates in the future. Technology development is desired in this area, with the objectives to

- Minimize actual decontamination time, as well as full cycle time between canister decontaminations

- Simplify decontamination system controls, regarding operations and maintenance functions

- Minimize gas and liquid waste

- Minimize cost

- Minimize or eliminate the couple between canister decontamination and chemical processing.

- Develop improved DWPF canister decontamination process.

- Develop functional performance requirements for the canister decontamination system. Solicit commercial solutions and evaluate concept proposals (FY00, TFA, EM-30).

- Select commercial vendor for development and adaptation of improved decontamination system for remote service (FY01, TFA, EM-30).

- Complete system adaptation and shakedown testing (FY01, TFA, EM-30). Decision point for demonstration. 
- Demonstrate improved decontamination system for DWPF canisters. Evaluate performance (FY02, EM-30).

\begin{tabular}{|c|c|c|c|c|c|c|}
\hline \multicolumn{7}{|c|}{ Budget Profile: Melter Pour Spout and Process Equipment Improvements for SRS } \\
\hline & TTP\# & FY 1999 & FY 2000 & FY 2001 & FY 2002 & FY 2003 \\
\hline Hanford & $\begin{array}{l}\text { RL37WT31 } \\
\text { RL09WT31 }\end{array}$ & $\begin{array}{l}125 \\
75\end{array}$ & $\overline{125}$ & 200 & 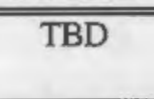 & $\overline{\text { TBD }}$ \\
\hline INEEL & ID77WT31 & 200 & 250 & 300 & TBD & TBD \\
\hline Oak Ridge & & & & & TBD & TBD \\
\hline SRS & SR16WT31 & 875 & 1125 & 950 & $\overline{T B D}$ & TBD \\
\hline TFA Total & & 1275 & 1500 & 1450 & 0 & 0 \\
\hline \multicolumn{7}{|l|}{ ASTD } \\
\hline \multicolumn{7}{|l|}{ CMST } \\
\hline \multicolumn{7}{|l|}{ FETC } \\
\hline \multicolumn{7}{|l|}{ ESP } \\
\hline \multicolumn{7}{|l|}{ International } \\
\hline \multicolumn{7}{|l|}{ Robotics } \\
\hline University & & 75 & 75 & & & \\
\hline EM-50 Total & & 1350 & 1575 & 1450 & 0 & 0 \\
\hline
\end{tabular}

INEEL HLW Immobilization

Technology is needed to develop a process that immobilizes the high-activity waste (HAW) fraction from INEEL's Idaho Nuclear Technology and Engineering Center (INTEC) calcine dissolution and radionuclide separation operations. Vitrification is considered the "Best Demonstrated Available Technology (BDAT)" for immobilizing highly radioactive wastes. Precedents are established for the use of a vitrification process to immobilize highly radioactive wastes by the operation of the DWPF at SRS and the West Valley Demonstration Plant in New York. Exact vitrification technologies from these sites cannot be transferred for use at the INEEL because of the unique composition of the HAWs. Thus variations in the vitrification process need to be incorporated to make the HAW "road ready" by year 2035 as required in Section E.6 of the Batt Settlement Agreement.

The initial major performance requirement for immobilization is to determine that the HAW composition can be vitrified. Thus vitrification formulation development must first be interfaced with separations development to demonstrate that the HAW product can be vitrified to a useful glass. This synergism may require not only alterations in the vitrification formulation, but also in the HAW product composition meaning consequent alteration of the separations process. Useful vitrification of the HAW product will be achieved when such a product meets all waste form performance specifications for repository storage as established in the EM WAPS. The next major performance requirement is that a process must be developed to produce the acceptable vitrified product on a production scale. The product of this process must also meet all the performance specifications established in the WAPS. These include specifications for waste forms, canisters, canistered waste forms, quality assurance, and documentation. 
Although vitrification of the INEEL's HAW is the BDAT, actual vitrification processing could take place either at the INTEC or at an off-site location. If vitrification is performed off-site, a means of preparing the waste for transport between locations is needed. Therefore, a safe and transportable interim waste form needs to be developed to support an offsite final vitrification option for INEEL.

In FY98, glass formulation activities focused on defining glass compositions to be processed in the INEEL quarter-scale melter and defining and extended test matrix encompassing INEEL HAW streams. The experimental glass composition region for each INEEL HAW stream was defined based on current flowsheet assumptions. Based on this information and the waste composition uncertainty regions, testing was initiated to define acceptable glass compositions.

Work activities to support HAW immobilization for INEEL will include

- Develop glass formulations and formulation correlations for INEEL wastes (FY99FY00, TFA, EM-30).

- Issue summary glass formulation report (FY99, TFA, EM-30, ID7-7-WT-31).

- Develop data, including corrosion rates, materials of construction, feed preparation and denitration, to support design of pilot-scale equipment (FY99-FY00, TFA, EM-30).

- Issue report on 1/4-scale melter test runs (FY99, TFA, EM-30, ID7-7-WT-31).

- Define key melter design parameters for HAW (FY01).

- Development and testing of an acceptable interim waste form for transport of HAW.

- Evaluate alternative technologies to solidify HAW for transport including Russian Silica Gel technology for INEEL HAW (FY99, TFA, EM-30, EM-50 Intemational Programs).

- Conduct laboratory-scale demonstration of up to two technologies for immobilization of partitioned radionuclides (FY00, TFA, EM-30, EM-50 International Programs). Decision point for engineering development.

- Conduct bench-scale testing to define process for solidification of HAW for transport (FY01, TFA, EM-30, EM-50 International Programs).

\section{Develop Remote Technology to Improve DWPF Operations}

The DWPF is limited in its ability to perform remote maintenance, inspection, and cleanup activities. The only access to the majority of the facility for maintenance is via overhead crane using hooks and an impact wrench. Viewing capability within the facility is limited to video cameras mounted on the Main Process Cell crane. The approach will be to develop remote equipment for the following needs: 1) Melt Cell equipment capable of retrieving glass shards and in-cell equipment as well as cleanup of in-cell equipment and the cell floor, 2) replacement of the Remote Equipment Decontamination Cell electromechanical manipulators with manipulators easier to operate and with greater range and reliability, and 3) a method to perform inspection, repair, decontaminate and decommission, and equipment recovery using a dual arm tele-robotic manipulator. 
Work activities to provide remote technologies to improve DWPF operations include

- Determine functions and requirements for each need and prepare procurement specifications (FY00, TFA, Robotics, EM-30).

- Procure advanced robotic equipment (FY00, FETC).

- Conduct mockup demonstration and vendor site(s) (FY01, TFA, Robotics, FETC, EM-30).

- Design and fabricate robotic systems for DWPF application (FY02, TFA, Robotics, FETC, EM-30).

- Deploy robotic systems (FY03, TFA, FETC, EM-30). 


\section{Problem Element Description and Priority Site Needs}

Closure of radioactive waste tanks requires sampling and/or characterization of waste tank residuals, definition of and compliance with closure criteria (i.e., "how clean is clean?"), and stabilization of the tank "potentially including barrier technology." Stabilization of the tanks and installation of surface or subsurface barriers may be required following retrieval and post-retrieval characterization, to prevent subsidence of a tank, collapse of the domed top, long-term migration of residual contaminants, or short-term release of residual waste contents due to catastrophic failure. Stabilization may encompass filling the tank with grout and stabilizing wastes, or a simple gravel fill to prevent tank dome collapse. Barrier technology may include engineered surface barriers to prevent water, plant, and animal intrusion, or subsurface barriers that prevent contaminants or moisture from migrating downward to the water table.

Closure of radioactive waste tanks has become a key element in the tank sites' baseline plans for reducing mortgage and accelerating cleanup. The Savannah River Site (SRS) is actively closing tanks, while the Oak Ridge Reservation (ORR) and the Hanford Site are preparing for future tank closure activities through the Gunite and Associated Tank (GAAT) Treatability Study and the Hanford Tanks Initiative (HTI), respectively. Idaho National Engineering and Environmental Laboratory (INEEL) is exploring an accelerated schedule for tank closure and will be sampling tank residuals to support future closure decisions. The site needs addressed in this problem element are identified below.

\begin{tabular}{|c|c|c|c|c|}
\hline \multicolumn{5}{|c|}{ Problem Element: 1.3.1 Close Tanks } \\
\hline $\begin{array}{l}\text { STCG Need } \\
\text { Number }\end{array}$ & Need Title & $\begin{array}{c}\text { PBS } \\
\text { Number }\end{array}$ & Technical Task & $\begin{array}{c}\text { OST } \\
\text { Number }\end{array}$ \\
\hline TK-09 & ORNL Tank Closure & $\begin{array}{l}\text { OR-43201, } \\
\text { OR-43203 }\end{array}$ & $\begin{array}{l}\text { Oak Ridge/SRS } \\
\text { Tank Closure }\end{array}$ & $\begin{array}{l}22,1499 \\
2093,2115\end{array}$ \\
\hline RL-WT030 & $\begin{array}{l}\text { Contaminant Mobility Beneath Tank } \\
\text { Farms }\end{array}$ & RL-TW03 & $\begin{array}{l}\text { Establish Closure } \\
\text { Basis }\end{array}$ & N/A \\
\hline RL-WT013 & $\begin{array}{l}\text { Establish Retrieval Performance } \\
\text { Evaluation Criteria }\end{array}$ & RL-TW04 & $\begin{array}{l}\text { Sample and } \\
\text { Characterize } \\
\text { Heels/Residual } \\
\text { Waste and Establish } \\
\text { Closure Basis }\end{array}$ & $\begin{array}{l}127,812, \\
1490,1547, \\
2010,2011, \\
2012,2117, \\
2118\end{array}$ \\
\hline SR-2912 & $\begin{array}{l}\text { Evaporator Residual Waste Removal } \\
\text { and Closure }\end{array}$ & $\begin{array}{l}\text { SR-HL01, } \\
\text { SR-HL.02 }\end{array}$ & $\begin{array}{l}\text { Oak Ridge/SRS } \\
\text { Tank Closure }\end{array}$ & $\begin{array}{l}22,1499 \\
2097,2115\end{array}$ \\
\hline RL-WT021 & $\begin{array}{l}\text { Cleaning and Decontamination of } \\
\text { Hanford Pits }\end{array}$ & RL-TW04 & $\begin{array}{l}\text { Tank Farm Pit } \\
\text { Decontamination }\end{array}$ & 85 \\
\hline TK-10 & $\begin{array}{l}\text { ORNL Remediated Tank Isolation } \\
\text { and Removal }\end{array}$ & $\begin{array}{l}\text { OR-43201, } \\
\text { OR-43203 }\end{array}$ & $\begin{array}{l}\text { GAAT Tank } \\
\text { Isolation }\end{array}$ & 2093 \\
\hline SR-3022 & $\begin{array}{l}\text { In Situ Grouting of Underground } \\
\text { Tanks (Formerly Used for the } \\
\text { Storage of Radioactive Solvents) }\end{array}$ & SR-ER02 & $\begin{array}{l}\text { Oak Ridge/SRS } \\
\text { Tank Closure }\end{array}$ & $\begin{array}{l}22,1499 \\
2115\end{array}$ \\
\hline
\end{tabular}




\section{Technical Tasks}

Oak Ridge/SRS Tank Closure

ORR, SRS, and other DOE facilities have waste storage tanks that will require either complete removal or in-place stabilization of sludge heels remaining after retrieval operations. In many cases, complete removal of the heels can be extremely costly with negligible resulting benefits to health or to the environment. Residual contamination in the tank walls and liners may also dictate tank closure. An in-situ grouting process is being developed to stabilize and close tanks with small amounts of residual heels and contamination. A multi-point, high-pressure grout injection technology was demonstrated on a cold basis in FY98. Activities to complete this work include

- Issue deployment plan for closure of a GAAT (FY99, TFA, EM-40, OR16WT51).

- Evaluate applicability of ORR tank closure technology to SRS and Hanford tanks (FY99, TFA, OR16WT51, SR16WT51).

- Demonstrate grout injection technology on a GAAT (FY00, ORNL, TFA, EM-40).

- Demonstrate grout injection technology on a SRS old burial grounds (OBG) tank (FY00, SRS, TFA).

- Demonstrate grout injection technology to close ORR Federal Facility Agreement (FFA) tank (FY00, ORNL, TFA).

\begin{tabular}{||l|c|c|c|c|c|c||}
\hline \multicolumn{7}{|c|}{ Budget Profile: Oak Ridge/SRS Tank Closure } \\
\hline & TTP\# & FY 1999 & FY 2000 & FY 2001 & FY 2002 & FY 2003 \\
\hline \hline Hanford & & & & & TBD & TBD \\
\hline INEEL & & & & & TBD & TBD \\
\hline Oak Ridge & OR16WT51 & 435 & 400 & & TBD & TBD \\
\hline SRS & SR16WT51 & 25 & 300 & & TBD & TBD \\
\hline TFA Total & & 460 & 700 & 0 & 0 & 0 \\
\hline
\end{tabular}

Establish Closure Basis

Retrieval Performance Criteria for Hanford (HTI): Other than the retrieval performance goal provided in the Hanford Federal Facility Agreement and Consent Order which is recognized by the Washington Department of Ecology and DOE in a memorandum of understanding as only an "interim" goal, no basis currently exists for defining retrieval performance objectives that address how much waste must be removed from SSTs and how much leakage during retrieval of single-shell tanks (SSTs) will be allowable. Several discrete technology needs must be satisfied to support decisions for tank closure alternatives. These needs include

- Improvements to equipment and methods for tank heel removal (described in problem element 1.2.1.2).

- Conditioning of wastes to slurries acceptable for transport (described in problem elements 1.2.1.4 and 1.2.2.3).

- Techniques to measure the residual waste volume following retrieval efforts

- Methods to capture samples of waste that are not directly below the riser (described in this problem element under "sample and characterize heels/residual waste").

- Methods to map contaminants in the vadose zone. 
Data addressing these needs must then be incorporated into performance evaluation modeling tools, evaluated, and discussed with stakeholders and regulators to define the performance criteria for tank waste retrieval and ultimate closure.

Parameters Influencing Performance Evaluations: To ensure adequate predictions of longterm performance of stabilized and closed tanks or immobilized low-level waste (LLW) (see problem element 1.3.2 "Dispose of LLW"), adequate modeling of fate and transport is required. A number of issues impact the accuracy of fate and transport modeling, especially in arid western environments such as Hanford. These issues revolve around the dependence of contaminant migration on the related parameters of vadose zone soil moisture content, hydraulic properties of the soil, and water recharge rates. Uncertainties exist in our current understanding and estimation of these parameters. Therefore, a number of related needs exist that, if addressed, would allow for improved performance evaluations to support tank closure and waste form disposal. Specifically, issues include

- Liquid and vapor flow in unsaturated soils: Moisture flow is the driving force for contamination release from waste and the transport of the contaminants. This flow is poorly understood under the arid conditions frequently found in western sites. In particular, for those sites where moisture barriers or diverters are, the theory and parameters describing liquid and vapor flow under very dry conditions need to be better understood.

- Recharge rates: Recharge water is the primary means for dissolution and release of contaminants from the buried waste and transport of those contaminants to the groundwater. Estimation of these rates is difficult under arid conditions because the rates are very low. In addition, significant questions exist about the adequacy of the estimated recharge rates given the heterogeneity of the environmental processes, the effect of facility features, the uncertainty of climate, and the influence of humans. Quantification of the distribution of recharge rates to enable sounder estimates of the mean and range of rates to be expected during the lifetime of the facilities are needed.

- Contaminant adsorption/retardation: Contaminants interaction with the soil can greatly delay and diminish the contaminant transport. For example, Hanford studies have shown a moisture dependency of uranium adsorption to soils. More recent research has shown that the degree of uranium adsorption may increase or decrease, depending on the soil type, as soil moisture increases. The relationship of the uranium adsorption to soil moisture content is needed to support performance assessment efforts.

- Accurate measurement of hydraulic properties: Assessments of waste disposal require the knowledge of hydraulic properties in the unsaturated sediments (vadose zone). Typically, these properties are inferred or estimated from small cores or particle size distributions obtained from a drilled borehole. Field measurements of hydraulic properties will eliminate the uncertainty when extrapolating small-scale laboratory measurements. 
Work activities to support Hanford's need for establishing retrieval performance criteria will include

- Establish retrieval performance evaluation criteria and evaluate retrieval and closure alternatives for Tank 241-AX-104.

- Adapt fate and transport models and integrate preliminary vadose zone characterization data to assess potential health risks. Conduct sensitivity analysis of model predictions as a function of parameters (FY99, TFA, EM-30).

- Update model with tank residual estimates, final vadose zone characterization data, and retrieval and closure engineering alternatives. Evaluate potential health risks for each alternative and compliance with federal and state requirements (FY99, TFA, EM-30).

- Evaluate alternatives and potential risks with stakeholders to identify retrieval and closure alternatives to continue to be pursued (FY99, TFA, EM-30).

- Issue final version of retrieval performance evaluation criteria assessment report (FY99, TFA, EM-30).

Tank Site Closure Technology for Hanford - Work activities to support Hanford's needs for improved data and understanding of vadose zone inoisture and contaminant transport will include

- Identification of the important parameters (such as hydraulic conductivity, diffusion coefficients, effective porosities, etc., by radionuclide species) for determining liquid and vapor phase moisture flow in arid conditions.

- Review state of understanding of moisture flow in arid soil. Evaluate existing simulation codes and select the baseline analysis tool (FY00, TFA, EM-30).

- Perform sensitivity analyses with this baseline tool to determine key flow parameters to be evaluated and measured. Develop program plan to guide priority testing/assessment efforts (FY00, TFA, EM-30).

- Measurement and simulation of parameters over a wide range of potential environments for a variety of potential closure materials such as sand, gravel, concrete, grout, etc.

- Evaluate the impact of flow parameters, through laboratory testing and simulation on retrieval performance criteria for HTI. Assess the uncertainty in these parameters and their impact on the HTI performance assessment efforts (FY00, TFA, EM-30).

- Performance of laboratory and field tests to verify simulations and key parameters.

- Establish field test plan and equipment to determine actual flow parameters for the Hanford vadose zones and compare with previous laboratory results (FY01, TFA, EM-30).

- Complete performance evaluations using both field and laboratory results to understand impact of test results on HTI closure activities (FY01, TFA, EM-30). Decision point on demonstration.

No budget table is provided because no work is being conducted by TFA in FY99. 


\section{Sample and Characterize Heels/Residual Waste}

Tank 241-AX-104 at Hanford (HTI): Methods are needed to sample the residual waste for use in establishing retrieval performance evaluation criteria. Conventional sampling methods for residual waste can prove ineffective due to little or no waste being located directly below the access riser. In addition, enough locations in the tank need to be sampled to show adequate characterization of residual waste for use in tank-specific performance assessment work. Sampling tools that can collect off-riser samples for analysis are needed. In addition, vadose zone sampling is required to quantify source term from leaked waste.

Idaho Nuclear Technology and Engineering Center (INTEC) Tanks at INEEL: When the INTEC high-activity tanks are emptied, a heel may remain. It is proposed to grout any such heel in place upon tank closure. Technology is required to characterize tank farm heel residuals to allow development of grout formulations as well as assess residual radionuclide activity. The heel characterization must take place in highly radioactive and limited access environments. Methodologies and platforms for deploying heel sample retrieval equipment are also needed for heel mixing, hose deployment, ventilation, shielding, containment, heel sampling, etc. Deployment of the LDUA at INEEL to address characterization of heels is discussed in problem element 1.1.3.

Work activities to support Hanford's need for characterizing the tank residuals in and around Tanks 241-AX-104 and 241-C-106 will include

- Conduct 241-AX-104 in-tank residual waste volume assessment and sampling to determine if residual wastes can meet retrieval performance objectives.

- Issue final 241-AX-104 auger sample leach test report (FY99, TFA, EM-30, RL07WT61).

- Deploy the LDUA in 241-AX-104 and collect off-riser waste residual samples (FY99, TFA, EM-30, RL07WT61).

- Complete waste volume estimation based on 241-AX-104 sampling and assessment efforts (FY99, TFA, EM-30).

- Conduct 241-C-106 waste volume measurement and assessment.

- Deploy LDUA in 241-C-106 and collect off-riser waste residual samples (FY01, TFA, EM-30).

- Complete waste volume estimation based on 241-C-106 sampling and assessment efforts (FY01, TFA, EM-30).

- Development and deployment of vadose zone characterization tools for the cone penetrometer to obtain data to support performance assessment efforts.

- Deploy the cone penetrometer sensor/sampler system at Tank 241-AX-104 to collect vadose zone characterization data to support retrieval performance criteria evaluations (FY99, TFA, EM-30, RL07WT61).

The budget for this work is included under "Hanford Tanks Initiative." 


\section{Tank Farm Pit Decontamination}

Waste retrieved from Hanford tanks must pass through a number of transfer pits before the wastes are received by the private contractor for treatment and immobilization. Many of these transfer pits must be modified before the waste can be transferred. Current methods for modifying, operating, cleaning, and decontaminating these pits are labor intensive, costly, and result in high doses to workers. This task will estabilish cost-effective robotics technologies for in-pit equipment and debris removal, cleaning, and decontamination.

Activities to complete this task include

- Develop conceptual design for a pit decontamination system based on refurbishing the 241-C-106 pit (FY99, Robotics).

- Complete final design for pit decontamination system (FY00, Robotics).

- Complete procurement of pit decontamination system (FY00, Robotics).

\begin{tabular}{|c|c|c|c|c|c|c|}
\hline \multicolumn{7}{|c|}{ Budget Profile: Tank Farm Pit Decontamination } \\
\hline & TTP\# & FY 1999 & FY 2000 & FY 2001 & FY 2002 & FY 2003 \\
\hline Hanford & & & & & TBD & TBD \\
\hline INEEL & & & & & TBD & TBD \\
\hline Oak Ridge & & & & & TBD & TBD \\
\hline SRS & & & & & TBD & TBD \\
\hline TFA Total & & 0 & 0 & 0 & 0 & 0 \\
\hline & & & & & & \\
\hline \multicolumn{7}{|l|}{ ASTD } \\
\hline \multicolumn{7}{|l|}{ CMST } \\
\hline \multicolumn{7}{|l|}{ FETC } \\
\hline \multicolumn{7}{|l|}{ ESP } \\
\hline \multicolumn{7}{|l|}{ International } \\
\hline Robotics & $\begin{array}{l}\text { RL39C132 } \\
\text { AL29C132 } \\
\text { OR17C132 }\end{array}$ & $\begin{array}{l}200 \\
300 \\
100\end{array}$ & 1000 & & & \\
\hline \multicolumn{7}{|l|}{ University } \\
\hline EM-50 Total & & 600 & 1000 & 0 & 0 & 0 \\
\hline
\end{tabular}

\section{GAAT Isolation}

ORR's GAATs have historically experienced undesirable leakage into the tanks via piping connected to the tanks. To avoid the expense and personnel exposures associated with externally locating and plugging each pipe connected to the GAATs, ORR desires to deploy a pipe plugging system within the tank. This system consists of a suite of remotely deployed tools to prepare and cap the pipes inside the tanks using primarily the Modified Light-Duty Utility Arm (MLDUA) and Houdini. An improved method for plugging pipelines from inside the tanks was developed in FY98 and a system was designed and fabricated. Refinement is needed to facilitate installation of pipe plugs and management of 
closely packed pipes. Improvements are also needed for better alignment of the pipe plugs and for better integration with the MLDUA and the Houdini used to place the plugs.

Activities to complete this work include

- Demonstrate the pipe plugging system for piping within two GAATs (FY99, TFA, EM-30, OR16WT51).

- Document deployment and the need for other pipe-plugging contingencies (FY99, TFA, EM-30, OR16WT51).

\begin{tabular}{||l|c|c|c|c|c|c||}
\hline \multicolumn{7}{|c|}{ Budget Profile: GAAT Tank Isolation } \\
\hline & TTP\# & FY 1999 & FY 2000 & FY 2001 & FY 2002 & FY 2003 \\
\hline \hline Hanford & & & & & & \\
\hline INEEL & & & & & & \\
\hline Oak Ridge & OR16WT51 & 200 & & & & \\
\hline SRS & & & & & & \\
\hline TFA Total & & 200 & 0 & 0 & 0 & 0 \\
\hline
\end{tabular}




\section{Problem Element Description and Priority Site Needs}

The immobilized low-activity or low-level waste (ILAW) from grouting operations at Savannah River Site (SRS), Oak Ridge Reservation (ORR), and possibly Idaho National Engineering and Environmental Laboratory (INEEL) or vitrification operations at the Hanford Site will require, in most cases, onsite disposal. To ensure the waste form meets disposal requirements, regardless of the specific waste form selected by the site for use, process monitoring and/or product assessment is required. In addition, low-level waste (LLW) disposal will require performance assessment (see related discussion in problem element 1.3.1 - Close Tanks) and consideration of surface and subsurface engineered barriers to ensure the immobilized LLW disposal site meets performance requirements. Barrier technology may include engineered surface barriers to prevent water, plant, and animal intrusion, or subsurface barriers that prevent contaminants or moisture from migrating downward to the water table.

This problem element addresses both ILAW product acceptance testing and ILAW disposal facility engineering. Needs exist for both product acceptance testing to ensure the LLW immobilization process produces an acceptable waste form, data collection to support performance assessment efforts, and evaluation of disposal site barrier technologies to ensure the final disposal of the ILAW meets requirements. The following needs are addressed in this problem element.

\begin{tabular}{|c|c|c|c|c|}
\hline \multicolumn{5}{|c|}{ Problem Element: 1.3.2 Dispose of LLW } \\
\hline $\begin{array}{l}\text { STCG Need } \\
\text { Number }\end{array}$ & Need Title & $\begin{array}{c}\text { PBS } \\
\text { Number }\end{array}$ & Technical Task & $\begin{array}{c}\text { OST } \\
\text { Number }\end{array}$ \\
\hline RL-WT010 & $\begin{array}{l}\text { ILAW Product Acceptance Inspection } \\
\text { and Test Methods }\end{array}$ & RL-TW06 & $\begin{array}{l}\text { Waste Form Product } \\
\text { Acceptance Testing }\end{array}$ & 2094,82 \\
\hline RL-WT-015 & $\begin{array}{l}\text { Standard Method for Determining } \\
\text { Waste Form Release Rate }\end{array}$ & RL-TW09 & $\begin{array}{l}\text { Waste Form Product } \\
\text { Acceptance Testing }\end{array}$ & 2094,82 \\
\hline RL-WT016 & Glass Monolith Surface Area & RL-TW09 & $\begin{array}{l}\text { Performance Assessment } \\
\text { of the ILAW }\end{array}$ & 2094 \\
\hline RL-WT017 & Long-Term Testing of Surface Barrier & RL-TW09 & $\begin{array}{l}\text { Barrier Technologies for } \\
\text { Hanford Closure }\end{array}$ & N/A \\
\hline RL-WT018 & $\begin{array}{l}\text { Testing of Sand-Gravel Capillary } \\
\text { Barrier }\end{array}$ & RL-TW09 & $\begin{array}{l}\text { Barrier Technologies for } \\
\text { Hanford Closure }\end{array}$ & N/A \\
\hline RL-WT019 & Getter Materials & RL-TW09 & $\begin{array}{l}\text { Barrier Technologies for } \\
\text { Hanford Closure }\end{array}$ & N/A \\
\hline RL-WT029 & $\begin{array}{l}\text { Data and Tools for Performance } \\
\text { Assessments (Tools) }\end{array}$ & RL-TW09 & $\begin{array}{l}\text { Barrier Technologies for } \\
\text { Hanford Closure }\end{array}$ & N/A \\
\hline RL-WT030 & $\begin{array}{l}\text { Contaminant Mobility Beneath Tank } \\
\text { Farms }\end{array}$ & RL-TW03 & & N/A \\
\hline SR-2916 & $\begin{array}{l}\text { Develop Advanced Techniques to } \\
\text { Improve Safety Infrastructure (Leaked } \\
\text { Waste) }\end{array}$ & $\begin{array}{l}\text { SR-HL01, } \\
\text { SR-HL02 }\end{array}$ & & 1985 \\
\hline TK-06 & $\begin{array}{l}\text { ORNL Tank Sludge and Supernatant } \\
\text { Immobilization }\end{array}$ & $\begin{array}{l}\text { OR-38112, } \\
\text { OR-38113, } \\
\text { OR-43201, } \\
\text { OR-43203 }\end{array}$ & $\begin{array}{l}\text { Waste Form Product } \\
\text { Acceptance Testing }\end{array}$ & 2094,82 \\
\hline
\end{tabular}




\section{Technical Tasks}

Waste Form Product Acceptance Testing

Product quality assurance is a necessary step in the LLW immobilization process. The baseline LLW immobilization technology for INEEL and SRS is grout and saltstone, respectively, while Hanford is pursuing a glass waste form as part of privatization. Grout and glass waste forms are being evaluated for ORR (see problem element 1.2.3.1.3). While product quality assurance is well established for the high-level waste (HLW) glass at SRS's Defense Waste Processing Facility (DWPF), and for the LLW saltstone at SRS, LLW glass for Hanford still requires product quality assurance methods and waste form performance testing to allow for LLW disposal preparations and receipt of LLW glass product from the privatization vendors. Specific needs include

- Reference glass for ILAW: A standard reference material for ILAW applications must be identified for use in inter- and intra-laboratory comparisons between the private contractor and DOE to verify the accuracy of reported results. The identification, development, and qualification of ILAW form reference materials are required. These materials must have appropriate compositions typical of expected ILAW forms so that the reference materials have utility for verifying ILAW compositional and durability specifications and comparing inter- and intra-laboratory test results.

- Product Acceptance Inspection and Test Methods: Under the privatization (phase I) efforts at Hanford, DOE will provide tank wastes to the private contractors who will treat and immobilize the wastes and then return the final products to DOE for storage and final disposal. DOE will pay the private contractors for each waste package received that meets the product specifications. Acceptance of the immobilized wastes will be based on a combination of private contractor activities to qualify, verify, document, and certify the product and DOE activities to audit, review, inspect, and test the processes and products. The DOE may conduct nondestructive testing of the sealed immobilized waste containers and destructive and nondestructive testing of the process and product samples. Specific parameters of interest may include chemical composition of the waste forms, fillers, and containers; phase composition; radiochemical composition; thermal history and surface temperature; waste form volume and void space; waste form and container weight; container dimensions including wall thickness; effectiveness of container closure or seal (leak tightness); presence of prohibited materials including free liquids and explosive, pyrophoric or combustible materials; dose rate; surface contamination; waste form homogeneity; and waste form release rates. Generally, the inspection and test methods should not require opening or otherwise breaching the seal of the waste form containers. Appropriate sampling and analysis strategies need to be developed to provide the basis for making statistically based statements with respect to the confidence with which the products meet specifications. Similarly, ORR has identified a need for nondestructive examination methods for immobilized tank waste destined for the Waste Isolation Pilot Plant (WIPP).

To provide a technical basis for accepting ILAW and immobilized HLW, glass composition regions yielding waste forms meeting the specifications of the privatization contract must be identified and documented. The information will be used as 1) an independent verification of the results of the private contractor's waste form qualification 
activities, 2) a tool to accept actual ILAW and IHLW based on measured and reported compositions, and 3) a technical basis for product specifications for phase II of the privatization effort.

Work activities to support Hanford's need for ILAW product acceptance will include

- Define need for inspection and testing of ILAW packages based on product acceptance strategy and regulatory and permitting drivers (FY00, EM-30).

- Define acceptable ILAW glass composition region for phase I wastes (FY99-FY00, TFA, EM-30, RL37WT31, SR16WT31).

- Develop and validate reference glass for ILAW and document results of round robin testing (FY99, TFA, CH27WT31).

\begin{tabular}{|c|c|c|c|c|c|c|}
\hline \multicolumn{7}{|c|}{ Budget Profile: Waste Form Product Acceptance Testing } \\
\hline Performer & TTP\# & FY 1999 & FY 2000 & FY 2001 & FY 2002 & FY 2003 \\
\hline Argonne & CH27WT31 & $\overline{50}$ & & & & \\
\hline Hanford & RL37WT31 & 475 & 500 & 300 & TBD & TBD \\
\hline INEEL & & & & & TBD & TBD \\
\hline Oak Ridge & & & & & TBD & TBD \\
\hline SRS & SR16WT31 & 475 & 500 & 300 & TBD & TBD \\
\hline TFA Total & & 1000 & 1000 & 600 & 0 & 0 \\
\hline \multicolumn{7}{|l|}{ ASTD } \\
\hline \multicolumn{7}{|l|}{ CMST } \\
\hline \multicolumn{7}{|l|}{ FETC } \\
\hline \multicolumn{7}{|l|}{ ESP } \\
\hline \multicolumn{7}{|l|}{ International } \\
\hline \multicolumn{7}{|l|}{ Robotics } \\
\hline University & & 10 & & & & \\
\hline EM-50 Total & & 1010 & 1000 & 600 & 0 & 0 \\
\hline
\end{tabular}

\section{Performance Assessment of the ILAW}

- Waste Form Release Test: The release of radionuclides from a waste form and package to the environment results from the interactions between the waste form and water in the disposal system. Waste forms are typically developed to minimize the rate of release as measured by a variety of test methods. Current ILAW product specifications require product consistency testing and American Nuclear Society 16.1 testing of the waste forms. These test methods may not be representative of the expected disposal system environment at Hanford. A release rate test method yielding results that can be related to the waste form release rate under expected service conditions is needed as a basis for phase II privatization ILAW product specifications and to support the performance assessment efforts need for ILAW disposal for phases I and II.

- Waste Glass Surface Area: The contaminant release rate from glasses is proportional to the surface area reachable by moving moisture. As glass cools it experiences internal stresses and strains, which may cause the glass to crack and hence increase the surface area on the glass. External stresses (e.g., those caused by earthquakes) could also 
increase surface area. In addition, cracks may expose imperfections in waste form (internal gas pockets, nucleation sites, de-vitrification regions) which may cause increased contaminant release rates. Relatively little is known about the long-term behavior of such cracks. Yet the total contaminant release must be known (or at least estimated) for thousands of years. Estimates of cracking and surface area are needed to support performance assessment efforts.

- In Situ Testing of Glass Release: Most testing of waste form performance is done under controlled laboratory conditions that differ from the field conditions actually expected to occur. A field experiment is needed to allow scale-up questions to be explored and enhanced confidence to be generated in the expected performance of the entire disposal system (facility and waste form).

- Develop, test, and validate waste form release test to support performance assessment efforts and aid in privatization phase II request for proposal development.

- Conduct independent technical review of the Hanford strategy and analyze long-term performance of ILAW glass in Hanford disposal system to ensure waste acceptance criteria and disposal facility performance assessment constraints are addressed (FY99, TFA, EM-30).

- Assemble, analyze, and relate the existing international long-term burial data to the Hanford ILAW performance requirements. Evaluate consistency between the performance strategy and existing performance data. Identify issues to still be addressed (FY99, TFA, EM-30).

- Complete resolution of issues identified in FY98. Validate pressurized unsaturated flow test method, and provide performance data and recommendations to Hanford for use in ILAW disposal performance assessment activities (FY00, TFA, EM-30).

- Estimate waste glass surface area for ILAW to support performance assessments.

- Produce waste forms of the expected variety of sizes, shapes, and fill representing possible Hanford LAW glasses based on privatization vendor input on possible product configurations (FY00, TFA, EM-30).

- Complete characterization of surface area and crack area of glass samples. Evaluate area reachable by moisture, and determine unsaturated hydraulic properties of the waste form (FY02, TFA, EM-30). Decision point for demonstration. Transfer of data to support performance assessment efforts.

- Conduct in situ testing of glass release to support performance assessment efforts.

- Initiate in situ testing using ILAW forms representing the products that will be delivered by the private vendors at Hanford. Develop or adapt existing lysimeters to simulate the entire disposal system (FY00, TFA, EM-30).

- Conduct lysimeter testing and performance evaluation for at least 5 years to obtain in situ glass release data to substantiate performance assessment predictions (FY04, EM-30).

The budget information for this work is covered under other workscopes.

Barrier Technologies for Hanford Closure

An integral consideration in disposal of ILAW is the benefits and/or requirements for permeable or impermeable surface and subsurface barriers. Water is the driving force behind 
releasing contaminants from waste forms and then carrying those contaminants to groundwater. At Hanford, barrier technology can reduce contaminant migration through limiting moisture flow, or in the case of engineered permeable barriers, even retard specific contaminants through the use of special "sorbents" in the barrier construction. Evaluation of the performance of surface barriers, capillary barriers, and the potential use of sorbents or "getter" materials is needed.

- Surface Barriers: Surface barriers are being used over many Hanford environmental restoration and waste management sites and more barriers are expected in the future. Such barriers are used to reduce moisture infiltration and plant and animal intrusion.

- Short-term testing of barriers has occurred under project-sponsored activities, but longterm studies remain a funding orphan. Because the design life of the barrier is 1,000 years, data is needed on barrier degradation to better understand the validity of the design life estimate.

- Capillary Barriers: A sand-gravel capillary barrier consists of a layer of fine material having high conductivity (such as sand) over a layer of coarse material having low conductivity (such as gravel). Unlike a surface barrier (which uses many of the same hydrologic principles), the capillary barrier diverts water away from the object underneath rather than storing the water until evaporation or plant transpiration removes the water. Thus the capillary barrier is expected to have a significantly longer life and be more effective than a surface barrier for moisture diversion. Although the principles of sand-gravel capillary barriers are well established, such barriers (especially the ones the size needed for DOE applications) have not been extensively tested. A large-scale sandgravel capillary barrier needs to be designed, constructed, and operated to obtain performance data to support closure and LLW disposal.

- Getter Materials: To meet the contaminant release specifications for the disposal of Hanford low-activity tank waste, radiocontaminants are physically trapped in glass. However, only a few of these radionuclides drive the performance assessment. If these key radionuclides could be chemically trapped after their release from glass, then the performance of the waste disposal system could be significantly improved. Hydraulic properties of getter materials (original, loaded, and discharged) need to be measured to fully understand waste disposal performance in the presence of getters. The use of getter materials in the SRS's disposal of the saltstone waste was an important consideration in the approval of that site's disposal of tank waste.

Work activities supporting Hanford's need for barrier technology have and are being performed through efforts within the Subsurface Contaminants Focus Area and EM-40 at Hanford. A full-scale surface barrier prototype has been installed and continued monitoring and performance evaluation is underway. Further efforts to address barrier technology needs, including the capillary barrier and getter materials, will be considered as part of efforts to establish a closure basis, described within problem element 1.3.1.

Budget tables are not included for this work because no work is being done by TFA. 


\section{Problem Element Description and Priority Site Needs}

The immobilized high-level waste (HLW) from tank waste treatment operations at Hanford, Savannah River Site (SRS), and Idaho National Engineering and Environmental Laboratory (INEEL) will be stored onsite before being shipped to a federal repository. To ensure the waste form meets disposal requirements, process monitoring, and/or product characterization is required. In addition, contaminated failed equipment including glass melters and processing equipment must be dispositioned. This problem element addresses the disposition of the HLW glass canisters and secondary wastes generated during waste processing operations. The following site needs are addressed in this problem element.

\begin{tabular}{||c|l|c|l|l||}
\hline \multicolumn{5}{|c|}{ Problem Element: 1.3.3 Store and Dispose HLW } \\
\hline $\begin{array}{c}\text { STCG Need } \\
\text { Number }\end{array}$ & \multicolumn{1}{|c|}{ Need Title } & $\begin{array}{c}\text { PBS } \\
\text { Number }\end{array}$ & \multicolumn{1}{c||}{ Technical Task } & $\begin{array}{c}\text { OST } \\
\text { Number }\end{array}$ \\
\hline \hline SR-2914 & $\begin{array}{l}\text { Demonstrate Remote Disassembly of } \\
\text { HLW Melters and Other Processing } \\
\text { Equipment }\end{array}$ & SR-HL05 & $\begin{array}{l}\text { Disassembly of Failed } \\
\text { Equipment }\end{array}$ & N/A \\
\hline RL-WT011 & $\begin{array}{l}\text { IHLW Product Acceptance Inspection } \\
\text { and Test Methods }\end{array}$ & RL-TW09 & $\begin{array}{l}\text { IHLW and Secondary } \\
\text { Waste Product } \\
\text { Acceptance }\end{array}$ & N/A \\
\hline RL-WT012 & $\begin{array}{l}\text { Secondary Products Acceptance } \\
\text { Inspection and Test Methods }\end{array}$ & RL-TW05 & $\begin{array}{l}\text { IHLW and Secondary } \\
\text { Waste Product } \\
\text { Acceptance }\end{array}$ & N/A \\
\hline
\end{tabular}

\section{Technical Tasks}

\section{Disassembly of Failed Equipment}

This need requires development and proof of techniques to address the unusual secondary waste issue of a full failed melter and to process HLW residual from all steps in the process from sludge to glass. The size and weight of the melter and the potential for having up to five canister volumes of HLW glass is the most challenging aspect of this task. The approach will be to develop techniques that are compatible with remote operations either in a large shielded cell or in a portion of a "canyon" building monitored by video. The first step will be to develop techniques suitable for removing the HLW glass compatible with either recycling into a process step, or if glass can be shown to be acceptable, loaded directly into a Defense Waste Processing Facility (DWPF) canister for encapsulation into freshly poured glass. The second step is to address the melter structure, separating the HLW as much as possible, and developing a disposal path for the non-HLW components. The third step will be to develop or identify a process for removing $\mathrm{HLW}$ from canyon equipment, jumpers, pumps, etc., that contain either residual sludge or glass. The fourth step is to adapt robotic technology to cut failed DWPF equipment into manageable pieces for removal and disposal. It is expected that both cleaning and disposal of the refractory materials and the intricacies of the off-gas components will be challenging from both handling and disposal of the generated wastes. 
Work activities to support the need to disassemble failed equipment will include

- Evaluate the potential techniques for equipment disassembly and decontamination (FY00, TFA, EM-30).

- Prepare specifications for a procurement to develop equipment for disassembly and decontamination (FY00, TFA, EM-30).

- Design and fabricate disassembly and decontamination equipment (FY01, TFA, FETC).

- Demonstrate disassembly and decontamination equipment (FY02, TFA, FETC, EM-30).

IHLW and Secondary Waste Product Acceptance

The need for product acceptance technologies will be addressed in more detail as the Tank Waste Remediation System privatization contract is approved and the regulatory and permitting requirements for product inspection are identified. 

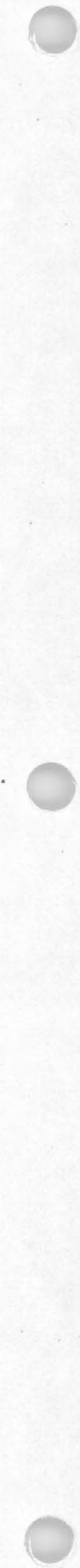


\section{Section 7 - References}

Stewart, TL, JA Frey, DW Geiser, and KL Manke. 1997. "Overview of U.S. Radioactive Tank Problem." Presented at the 1997 Annual American Chemical Society, Las Vegas, Nevada.

Tanks Focus Area. 1997. Tanks Focus Area multiyear program plan FY98-FY00. PNNL11622, Pacific Northwest National Laboratory, Richland, Washington.

Tanks Focus Area. 1998. Tanks Focus Area site needs assessment FY 1998. PNNL-11861, Pacific Northwest National Laboratory, Richland, Washington.

U.S. Department of Energy. 1998. Accelerating cleanup paths to closure. DOE/EM-0367, U.S. Department of Energy, Washington, D.C. 



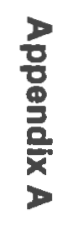




\section{Appendix A - Paths to Closure Data}

Tables A.1 through A.5 present data used to create the FY00 Internal Review Budget submission. These tables are extracted from the TFA's Attachment $\mathrm{E}$ as submitted for the FY00 Internal Review Budget. Additionally, this information was used in the national prioritization of the proposed program. 
Table A.1. WS 1 - Critical Closure Paths

\begin{tabular}{|c|c|c|c|}
\hline \multicolumn{4}{|c|}{ Worksheet 1 - Critical Closure Paths/Critical Events Impacted By WP } \\
\hline WP Number & WP Title & PBS ID \# & Short Activity Description \\
\hline TFA-1 & $\begin{array}{l}\text { Required Steps to Tank Closure at } \\
\text { Hanford, ORR, Idaho, and SRS }\end{array}$ & OR-43203 & $\begin{array}{l}\text { BV ROD for contaminated areas in } \\
\text { the BV Watershed }\end{array}$ \\
\hline TFA-1 & $\begin{array}{l}\text { Required Steps to Tank Closure at } \\
\text { Hanford, ORR, Idaho, and SRS }\end{array}$ & RL-TW03 & Single Shell Tanks interim stabilized \\
\hline TFA-1 & $\begin{array}{l}\text { Required Steps to Tank Closure at } \\
\text { Hanford, ORR, Idaho, and SRS }\end{array}$ & SR-HLO3 & $\begin{array}{l}\text { Removal of HLW form filled storage } \\
\text { tanks for further processing by HLW } \\
\text { system }\end{array}$ \\
\hline TFA-1 & $\begin{array}{l}\text { Required Steps to Tank Closure at } \\
\text { Hanford, ORR, Idaho, and SRS }\end{array}$ & SR-HL03 & $\begin{array}{l}\text { Decommissioning of remaining } \\
\text { HLW tanks and facilities }\end{array}$ \\
\hline TFA-1 & $\begin{array}{l}\text { Required Steps to Tank Closure at } \\
\text { Hanford, ORR, Idaho, and SRS }\end{array}$ & RL-TW04 & $\begin{array}{l}\text { Deploy \& Operate initial SST \& } \\
\text { DST waste retrieval systems for } \\
\text { privatization phase I }\end{array}$ \\
\hline TFA-1 & $\begin{array}{l}\text { Required Steps to Tank Closure at } \\
\text { Hanford, ORR, Idaho, and SRS }\end{array}$ & RL-TW04 & Complete tank farm closure \\
\hline TFA-1 & $\begin{array}{l}\text { Required Steps to Tank Closure at } \\
\text { Hanford, ORR, Idaho, and SRS }\end{array}$ & ID-HLW-03 & $\begin{array}{l}\text { Issue a Record of Decision for } \\
\text { treatment of calcine waste }\end{array}$ \\
\hline TFA-1 & $\begin{array}{l}\text { Required Steps to Tank Closure at } \\
\text { Hanford, ORR, Idaho, and SRS }\end{array}$ & ID-HLW-03 & $\begin{array}{l}\text { Convert pretreated waste to final } \\
\text { disposable form }\end{array}$ \\
\hline TFA-1 & $\begin{array}{l}\text { Required Steps to Tank Closure at } \\
\text { Hanford, ORR, Idaho, and SRS }\end{array}$ & ID-HLW-101 & Empty Tank Farm by calcination \\
\hline TFA-1 & $\begin{array}{l}\text { Required Steps to Tank Closure at } \\
\text { Hanford, ORR, Idaho, and SRS }\end{array}$ & OR-38112 & $\begin{array}{l}\text { Complete disposition of Legacy } \\
\text { Waste }\end{array}$ \\
\hline TFA-1 & $\begin{array}{l}\text { Required Steps to Tank Closure at } \\
\text { Hanford, ORR, Idaho, and SRS }\end{array}$ & OR-38113 & TRU steady state \\
\hline TFA-1 & $\begin{array}{l}\text { Required Steps to Tank Closure at } \\
\text { Hanford, ORR, Idaho, and SRS }\end{array}$ & OR-38902 & $\begin{array}{l}\text { RH-TRU Contract award for } \\
\text { collection, stabilization \& } \\
\text { containerization of ORNL RH-TRU } \\
\text { waste to meet WIPP WAC }\end{array}$ \\
\hline TFA-1 & $\begin{array}{l}\text { Required Steps to Tank Closure at } \\
\text { Hanford, ORR, Idaho, and SRS }\end{array}$ & SR-HLO4 & $\begin{array}{l}\text { Initial Operation of HLW treatment } \\
\text { facility }\end{array}$ \\
\hline TFA-1 & $\begin{array}{l}\text { Required Steps to Tank Closure at } \\
\text { Hanford, ORR, Idaho, and SRS }\end{array}$ & SR-HLO4 & $\begin{array}{l}3 \text { year delay in HLW program due to } \\
\text { funding shortfall in FY99 }\end{array}$ \\
\hline TFA-1 & $\begin{array}{l}\text { Required Steps to Tank Closure at } \\
\text { Hanford, ORR, Idaho, and SRS }\end{array}$ & SR-HLO4 & Completion of HLW treatment \\
\hline & 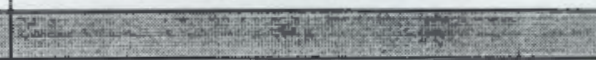 & द्या & 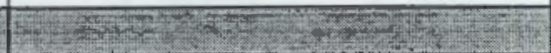 \\
\hline TFA-2 & $\begin{array}{l}\text { Waste Immobilization and Product } \\
\text { Acceptance Required to Meet DWPF } \\
\text { Schedule, Hanford Phase I and } 2 \\
\text { Privatization, and Idaho Title } 1 \text { Design }\end{array}$ & SR-HL05 & Completion of HLW Vitrification \\
\hline TFA-2 & $\begin{array}{l}\text { Waste Immobilization and Product } \\
\text { Acceptance Required to Meet DWPF } \\
\text { Schedule, Hanford Phase I and } 2 \\
\text { Privatization, and Idaho Title } 1 \text { Design }\end{array}$ & RL-TW06 & $\begin{array}{l}\text { Process LAW \& HLW, privatization } \\
\text { phase I }\end{array}$ \\
\hline
\end{tabular}


Table A.1. (contd)

\begin{tabular}{|c|c|c|c|}
\hline \multirow{2}{*}{ WP Number } & \multicolumn{3}{|c|}{ Worksheet 1 - Critical Closure PothatCritical Events Impacted By WP } \\
\hline & WP Title & $\mathrm{PBSID} \#$ & Short Activity Description \\
\hline & $\begin{array}{l}\text { Waste Immobilization and Product } \\
\text { Acceptance Required to Meet DWPF } \\
\text { Schedule, Hanford Phase I and } 2 \\
\text { Privatization, and Idaho Title } 1 \text { Design }\end{array}$ & $\overline{\text { RL-TW06 }}$ & Tank waste immobilization started \\
\hline TFA-2 & $\begin{array}{l}\text { Waste Immobilization and Product } \\
\text { Acceptance Required to Meet DWPF } \\
\text { Schedule, Hanford Phase I and } 2 \\
\text { Privatization, and Idaho Title } 1 \text { Design }\end{array}$ & RL-TW09 & $\begin{array}{l}\text { Complete HLW Disposition and } \\
\text { Storage Facility D\&D }\end{array}$ \\
\hline TFA-2 & $\begin{array}{l}\text { Waste Immobilization and Product } \\
\text { Acceptance Required to Meet DWPF } \\
\text { Schedule, Hanford Phase I and } 2 \\
\text { Privatization, and Idaho Title } 1 \text { Design }\end{array}$ & ID-HLW-103 & $\begin{array}{l}\text { Issue a Record of Decision for } \\
\text { treatment of calcine waste }\end{array}$ \\
\hline TFA-2 & $\begin{array}{l}\text { Waste Immobilization and Product } \\
\text { Acceptance Required to Meet DWPF } \\
\text { Schedule, Hanford Phase I and } 2 \\
\text { Privatization, and Idaho Title } 1 \text { Design }\end{array}$ & ID-HLW-103 & $\begin{array}{l}\text { Convert pretreated waste to final } \\
\text { disposable form }\end{array}$ \\
\hline & & & \\
\hline TFA-3 & $\begin{array}{l}\text { Alternative Paths to In-Tank } \\
\text { Precipitation at SRS }\end{array}$ & ID-HLW-101 & Empty Tank Farm by calcination \\
\hline TFA-3 & $\begin{array}{l}\text { Alternative Paths to In-Tank } \\
\text { Precipitation at SRS }\end{array}$ & OR-38112 & Complete disposition of legacy LLW \\
\hline TFA-3 & $\begin{array}{l}\text { Alternative Paths to In-Tank } \\
\text { Precipitation at SRS }\end{array}$ & OR-38113 & TRU steady state \\
\hline TFA-3 & $\begin{array}{l}\text { Alternative Paths to In-Tank } \\
\text { Precipitation at SRS }\end{array}$ & OR-43203 & $\begin{array}{l}\text { BV Rod for contaminated areas in } \\
\text { the BV Watershed }\end{array}$ \\
\hline TFA-3 & $\begin{array}{l}\text { Alternative Paths to In-Tank } \\
\text { Precipitation at SRS }\end{array}$ & SR-HL04 & $\begin{array}{l}\text { Initial Operation of HLW treatment } \\
\text { facility }\end{array}$ \\
\hline TFA-3 & $\begin{array}{l}\text { Alternative Paths to In-Tank } \\
\text { Precipitation at SRS }\end{array}$ & SR-HL04 & $\begin{array}{l}3 \text { year delay in HLW program due to } \\
\text { funding shortfall in FY99 }\end{array}$ \\
\hline TFA-3 & $\begin{array}{l}\text { Alternative Paths to In-Tank } \\
\text { Precipitation at SRS }\end{array}$ & SR-HL04 & Completion of HLW treatment \\
\hline TFA-3 & $\begin{array}{l}\text { Alternative Paths to In-Tank } \\
\text { Precipitation at SRS }\end{array}$ & SR-HL05 & Completion of HLW vitrification \\
\hline TFA-3 & $\begin{array}{l}\text { Alternative Paths to In-Tank } \\
\text { Precipitation at SRS }\end{array}$ & OR-38902 & $\begin{array}{l}\text { RH-TRU Contract award for } \\
\text { collection, stabilization \& } \\
\text { containerization of ORNL RH-TRU } \\
\text { waste to meet WIPP WAC }\end{array}$ \\
\hline & 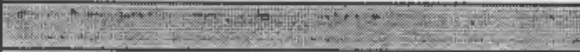 & & 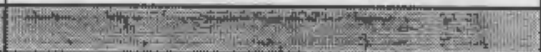 \\
\hline TFA-4 & $\begin{array}{l}\text { Slurry Preparation for Feed to HLW } \\
\text { Virtification at SRS and Hanford and } \\
\text { Radioactive Tank Waste Preparation at } \\
\text { ORR }\end{array}$ & OR-43203 & $\begin{array}{l}\text { BV ROD for contaminated areas in } \\
\text { the BV Watershed }\end{array}$ \\
\hline
\end{tabular}


Table A.1. (contd)

\begin{tabular}{|c|c|c|c|}
\hline \multicolumn{4}{|c|}{ Worksheet 1 - Critical Closure Paths/Critical Events Impacted By WP } \\
\hline WP Number & WP Title & PBSID \# & Short Activity Description \\
\hline TFA-4 & $\begin{array}{l}\text { Slurry Preparation for Feed to HLW } \\
\text { Vitrification at SRS and Hanford and } \\
\text { Radioactive Tank Waste Preparation at } \\
\text { ORR }\end{array}$ & OR-38112 & Complete disposition of legacy LLW \\
\hline TFA-4 & $\begin{array}{l}\text { Slurry Preparation for Feed to HLW } \\
\text { Vitrification at SRS and Hanford and } \\
\text { Radioactive Tank Waste Preparation at } \\
\text { ORR }\end{array}$ & OR-38113 & TRU steady state \\
\hline TFA-4 & $\begin{array}{l}\text { Slurry Preparation for Feed to HLW } \\
\text { Vitrification at SRS and Hanford and } \\
\text { Radioactive Tank Waste Preparation at } \\
\text { ORR }\end{array}$ & RL-TW06 & $\begin{array}{l}\text { Process LAW \& HLW, privatization } \\
\text { phase I }\end{array}$ \\
\hline TFA-4 & $\begin{array}{l}\text { Slurry Preparation for Feed to HLW } \\
\text { Vitrification at SRS and Hanford and } \\
\text { Radioactive Tank Waste Preparation at } \\
\text { ORR }\end{array}$ & SR-HL04 & $\begin{array}{l}\text { Initial Operation of HLW treatment } \\
\text { facility }\end{array}$ \\
\hline TFA-4 & $\begin{array}{l}\text { Slurry Preparation for Feed to HLW } \\
\text { Vitrification at SRS and Hanford and } \\
\text { Radioactive Tank Waste Preparation at } \\
\text { ORR }\end{array}$ & SR-HL04 & $\begin{array}{l}3 \text { year delay in HLW program due to } \\
\text { funding shortfall in FY99 }\end{array}$ \\
\hline TFA-4 & $\begin{array}{l}\text { Slurry Preparation for Feed to HLW } \\
\text { Vitrification at SRS and Hanford and } \\
\text { Radioactive Tank Waste Preparation at } \\
\text { ORR }\end{array}$ & SR-HLO4 & Completion of HLW treatment \\
\hline TFA-4 & $\begin{array}{l}\text { Slurry Preparation for Feed to HLW } \\
\text { Vitrification at SRS and Hanford and } \\
\text { Radioactive Tank Waste Preparation at } \\
\text { ORR }\end{array}$ & RL-TW04 & $\begin{array}{l}\text { Deploy \& Operate initial SST \& } \\
\text { DST waste retrieval systems for } \\
\text { privatization phase I }\end{array}$ \\
\hline TFA-4 & $\begin{array}{l}\text { Slurry Preparation for Feed to HLW } \\
\text { Vitrification at SRS and Hanford and } \\
\text { Radioactive Tank Waste Preparation at } \\
\text { ORR }\end{array}$ & OR-38902 & $\begin{array}{l}\text { RH-TRU Contract award for } \\
\text { collection, stabilization \& } \\
\text { containerization of ORNL RH-TRU } \\
\text { waste to meet WIPP WAC }\end{array}$ \\
\hline कांक्य & (5) & 5 & 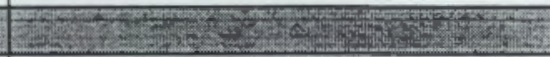 \\
\hline TFA-5 & Hanford Tanks Initiative & RL-TW04 & $\begin{array}{l}\text { Deploy \& Operate initial SST \& } \\
\text { DST waste retrieval systems for } \\
\text { privatization phase I }\end{array}$ \\
\hline TFA-5 & Hanford Tanks Initiative & RL-TW04 & Complete tank farm closure \\
\hline+4 & 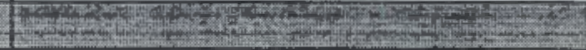 & 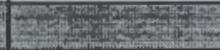 & 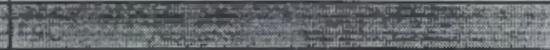 \\
\hline TFA-6 & $\begin{array}{l}\text { Pretreatment to Reduce Volume of } \\
\text { HLW and LLW Waste Forms at SRS, } \\
\text { Idaho, Hanford and Oak Ridge }\end{array}$ & ID-HLW-103 & $\begin{array}{l}\text { Issue a Record of Decision for } \\
\text { treatment of calcine waste }\end{array}$ \\
\hline TFA-6 & $\begin{array}{l}\text { Pretreatment to Reduce Volume of } \\
\text { HLW and LLW Waste Forms at SRS, } \\
\text { Idaho, Hanford and Oak Ridge }\end{array}$ & ID-HLW-103 & $\begin{array}{l}\text { Convert pretreated waste to final } \\
\text { disposable form }\end{array}$ \\
\hline
\end{tabular}


Table A.1. (contd)

\begin{tabular}{|c|c|c|c|}
\hline \multicolumn{4}{|c|}{ Worksheet 1 - Critical Closure Paths/Critical Events Impacted By MYP } \\
\hline WP Number & WP Title & PBS ID & Short Activity Description \\
\hline TFA-6 & $\begin{array}{l}\text { Pretreatment to Reduce Volume of } \\
\text { HLW and LLW Waste Forms at SRS, } \\
\text { Idaho, Hanford and Oak Ridge }\end{array}$ & RL-TW06 & $\begin{array}{l}\text { Process LAW \& HLW, privatization } \\
\text { phase I }\end{array}$ \\
\hline TFA-6 & $\begin{array}{l}\text { Pretreatment to Reduce Volume of } \\
\text { HLW and LLW Waste Forms at SRS, } \\
\text { Idaho, Hanford and Oak Ridge }\end{array}$ & RL-TW07 & $\begin{array}{l}\text { Deploy LAW \& HLW } \\
\text { immobilization facilities, } \\
\text { privatization phase II }\end{array}$ \\
\hline TFA-6 & $\begin{array}{l}\text { Pretreatment to Reduce Volume of } \\
\text { HLW and LLW Waste Forms at SRS, } \\
\text { Idaho, Hanford and Oak Ridge }\end{array}$ & OR-38112 & Complete disposition of legacy LLW \\
\hline TFA-6 & $\begin{array}{l}\text { Pretreatment to Reduce Volume of } \\
\text { HLW and LLW Waste Forms at SRS, } \\
\text { Idaho, Hanford and Oak Ridge }\end{array}$ & OR-38113 & TRU steady state \\
\hline TFA-6 & $\begin{array}{l}\text { Pretreatment to Reduce Volume of } \\
\text { HLW and LLW Waste Forms at SRS, } \\
\text { Idaho, Hanford and Oak Ridge }\end{array}$ & ID-HLW-101 & Empty tank farm by calcination \\
\hline TFA-6 & $\begin{array}{l}\text { Pretreatment to Reduce Volume of } \\
\text { HLW and LLW Waste Forms at SRS, } \\
\text { Idaho, Hanford and Oak Ridge }\end{array}$ & OR-38902 & $\begin{array}{l}\text { RH-TRU Contract award for } \\
\text { collection, stabilization \& } \\
\text { containerization of ORNL RH-TRU } \\
\text { waste to meet WIPP WAC }\end{array}$ \\
\hline TFA-6 & $\begin{array}{l}\text { Pretreatment to Reduce Volume of } \\
\text { HLW and LLW Waste Forms at SRS, } \\
\text { Idaho, Hanford and Oak Ridge }\end{array}$ & OR-43202 & $\begin{array}{l}\text { ROD for contaminated areas in the } \\
\text { ORNL MV within the MV } \\
\text { Watershed }\end{array}$ \\
\hline TFA-6 & $\begin{array}{l}\text { Pretreatment to Reduce Volume of } \\
\text { HLW and LLW Waste Forms at SRS, } \\
\text { Idaho, Hanford and Oak Ridge }\end{array}$ & OR-43203 & $\begin{array}{l}\text { BV ROD for contaminated areas in } \\
\text { the BV Watershed }\end{array}$ \\
\hline TFA-6 & $\begin{array}{l}\text { Pretreatment to Reduce Volume of } \\
\text { HLW and LLW Waste Forms at SRS, } \\
\text { Idaho, Hanford and Oak Ridge }\end{array}$ & SR-HLO4 & $\begin{array}{l}\text { Initial Operation of HLW treatment } \\
\text { facility }\end{array}$ \\
\hline TFA-6 & $\begin{array}{l}\text { Pretreatment to Reduce Volume of } \\
\text { HLW and LLW Waste Forns at SRS, } \\
\text { Idaho, Hanford and Oak Ridge }\end{array}$ & SR-HL04 & $\begin{array}{l}3 \text { year delay in HLW program due to } \\
\text { funding shortfall in FY99 }\end{array}$ \\
\hline TFA-6 & $\begin{array}{l}\text { Pretreatment to Reduce Volume of } \\
\text { HLW and LLW Waste Forms at SRS, } \\
\text { Idaho, Hanford and Oak Ridge }\end{array}$ & SR-HL04 & Completion of HLW treatment \\
\hline & 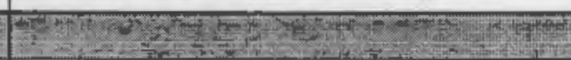 & Fingy & Expy \\
\hline TFA-7 & $\begin{array}{l}\text { Immobilization Process for Idaho } \\
\text { Supporting Title } 1 \text { Design; } \\
\text { Immobilization Evaluation for ORR } \\
\text { Privatization and Hanford Capsules }\end{array}$ & ID-HLW-103 & $\begin{array}{l}\text { Issue a Record of Decision for } \\
\text { treatment of calcine waste }\end{array}$ \\
\hline TFA-7 & $\begin{array}{l}\text { Immobilization Process for Idaho } \\
\text { Supporting Title } 1 \text { Design; } \\
\text { Immobilization Evaluation for ORR } \\
\text { Privatization and Hanford Capsules }\end{array}$ & ID-HLW-103 & $\begin{array}{l}\text { Convert pretreated waste to final } \\
\text { disposable form }\end{array}$ \\
\hline
\end{tabular}


Table A.1. (contd)

\begin{tabular}{|c|c|c|c|}
\hline \multicolumn{4}{|c|}{ 6. $=$ Work } \\
\hline WP Number & 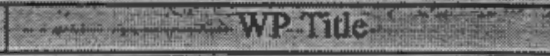 & PBS ID \# & Short Activity Description of \\
\hline TFA-7 & $\begin{array}{l}\text { Immobilization Process for Idaho } \\
\text { Supporting Title } 1 \text { Design; } \\
\text { Immobilization Evaluation for ORR } \\
\text { Privatization and Hanford Capsules }\end{array}$ & OR-38113 & TRU steady state \\
\hline TFA-7 & $\begin{array}{l}\text { Immobilization Process for Idaho } \\
\text { Supporting Title } 1 \text { Design; } \\
\text { Immobilization Evaluation for ORR } \\
\text { Privatization and Hanford Capsules }\end{array}$ & RL-TW04 & $\begin{array}{l}\text { Deploy \& Operate initial SST \& } \\
\text { DST waste retrieval systems for } \\
\text { privatization phase I }\end{array}$ \\
\hline TFA-7 & $\begin{array}{l}\text { Immobilization Process for Idaho } \\
\text { Supporting Title } 1 \text { Design; } \\
\text { Immobilization Evaluation for ORR } \\
\text { Privatization and Hanford Capsules }\end{array}$ & RL-TW04 & Complete tank farm closure \\
\hline TFA-7 & $\begin{array}{l}\text { Immobilization Process for Idaho } \\
\text { Supporting Title } 1 \text { Design; } \\
\text { Immobilization Evaluation for ORR } \\
\text { Privatization and Hanford Capsules }\end{array}$ & RL-TW09 & $\begin{array}{l}\text { Complete HLW Disposition and } \\
\text { Storage Facility D\&D }\end{array}$ \\
\hline TFA-7 & $\begin{array}{l}\text { Immobilization Process for Idaho } \\
\text { Supporting Title } 1 \text { Design; } \\
\text { Immobilization Evaluation for ORR } \\
\text { Privatization and Hanford Capsules }\end{array}$ & OR-38902 & $\begin{array}{l}\text { RH-TRU Contract award for } \\
\text { collection, stabilization \& } \\
\text { containerization of ORNL RH-TRU } \\
\text { waste to meet WIPP WAC }\end{array}$ \\
\hline TFA-7 & $\begin{array}{l}\text { Immobilization Process for Idaho } \\
\text { Supporting Title } 1 \text { Design; } \\
\text { Immobilization Evaluation for ORR } \\
\text { Privatization and Hanford Capsules }\end{array}$ & OR-43202 & $\begin{array}{l}\text { ROD for contaminated areas in the } \\
\text { ORNL MV within the MV } \\
\text { Watershed }\end{array}$ \\
\hline TFA-7 & $\begin{array}{l}\text { Immobilization Process for Idaho } \\
\text { Supporting Title } 1 \text { Design; } \\
\text { Immobilization Evaluation for ORR } \\
\text { Privatization and Hanford Capsules }\end{array}$ & OR-43203 & $\begin{array}{l}\text { BV ROD for contaminated areas in } \\
\text { the BV Watershed }\end{array}$ \\
\hline TFA-7 & $\begin{array}{l}\text { Immobilization Process for Idaho } \\
\text { Supporting Title } 1 \text { Design; } \\
\text { Immobilization Evaluation for ORR } \\
\text { Privatization and Hanford Capsules }\end{array}$ & OR-38112 & Complete disposition of legacy LLW \\
\hline
\end{tabular}


Table A.2. WS 2 - Disposition Map Waste Streams

\begin{tabular}{|c|c|c|c|}
\hline \multicolumn{4}{|c|}{ Worksheet 2 Disposition Map Waste Streams Impacted By WP } \\
\hline WP Number & WP Title & Waste Stream ID H & Waste Stream Name \\
\hline TFA-1 & $\begin{array}{l}\text { Required Steps to Tank Closure at } \\
\text { Hanford, ORR, Idaho, and SRS }\end{array}$ & 00759 & Tanks \\
\hline TFA-1 & $\begin{array}{l}\text { Required Steps to Tank Closure at } \\
\text { Hanford, ORR, Idaho, and SRS }\end{array}$ & 00761 & Filters \\
\hline TFA-1 & $\begin{array}{l}\text { Required Steps to Tank Closure at } \\
\text { Hanford, ORR, Idaho, and SRS }\end{array}$ & 01580 & Liquid LLW \\
\hline TFA-1 & $\begin{array}{l}\text { Required Steps to Tank Closure at } \\
\text { Hanford, ORR, Idaho, and SRS }\end{array}$ & 00428 & Remote-Handled TRU Sludges \\
\hline TFA-1 & $\begin{array}{l}\text { Required Steps to Tank Closure at } \\
\text { Hanford, ORR, Idaho, and SRS }\end{array}$ & 01593 & Remote Handled LLW \\
\hline TFA-1 & $\begin{array}{l}\text { Required Steps to Tank Closure at } \\
\text { Hanford, ORR, Idaho, and SRS }\end{array}$ & 02113 & Sludge, Salt, Liquid \\
\hline TFA-1 & $\begin{array}{l}\text { Required Steps to Tank Closure at } \\
\text { Hanford, ORR, Idaho, and SRS }\end{array}$ & 02120 & Tanks \\
\hline TFA-1 & $\begin{array}{l}\text { Required Steps to Tank Closure at } \\
\text { Hanford, ORR, Idaho, and SRS }\end{array}$ & 00496 & Sludge Feed to ESP \\
\hline TFA-1 & $\begin{array}{l}\text { Required Steps to Tank Closure at } \\
\text { Hanford, ORR, Idaho, and SRS }\end{array}$ & 00499 & Salt Feed to ITP \\
\hline TFA-1 & $\begin{array}{l}\text { Required Steps to Tank Closure at } \\
\text { Hanford, ORR, Idaho, and SRS }\end{array}$ & 00500 & $\begin{array}{l}\text { Salt/Sup. Feed to ITP - Tk } \\
\text { Wash }\end{array}$ \\
\hline TFA-1 & $\begin{array}{l}\text { Required Steps to Tank Closure at } \\
\text { Hanford, ORR, Idaho, and SRS }\end{array}$ & 00511 & Tank Stabilization Initiated \\
\hline TFA-1 & $\begin{array}{l}\text { Required Steps to Tank Closure at } \\
\text { Hanford, ORR, Idaho, and SRS }\end{array}$ & 00512 & Tanks Stabilized \\
\hline TFA-1 & $\begin{array}{l}\text { Required Steps to Tank Closure at } \\
\text { Hanford, ORR, Idaho, and SRS }\end{array}$ & 00510 & Tank Washing Initiatied \\
\hline \multicolumn{4}{|c|}{ 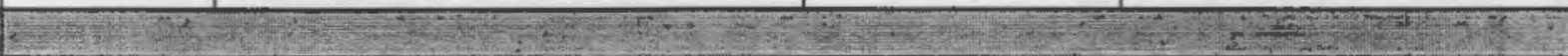 } \\
\hline TFA-2 & $\begin{array}{l}\text { Waste Immobilization and Product } \\
\text { Acceptance Required to Meet DWPF } \\
\text { Schedule, Hanford Phase I and } 2 \\
\text { Privatization, and Idaho Title } 1 \text { Design }\end{array}$ & 00513 & Failed Glass Melters \\
\hline TFA-2 & $\begin{array}{l}\text { Waste Immobilization and Product } \\
\text { Acceptance Required to Meet DWPF } \\
\text { Schedule, Hanford Phase I and } 2 \\
\text { Privatization, and Idaho Title } 1 \text { Design }\end{array}$ & 00503 & Washed Sludge to DWPF \\
\hline TFA-2 & $\begin{array}{l}\text { Waste Immobilization and Product } \\
\text { Acceptance Required to Meet DWPF } \\
\text { Schedule, Hanford Phase I and } 2 \\
\text { Privatization, and Idaho Title } 1 \text { Design }\end{array}$ & 00502 & ITP Precipitate to DWPF \\
\hline TFA-2 & $\begin{array}{l}\text { Waste Immobilization and Product } \\
\text { Acceptance Required to Meet DWPF } \\
\text { Schedule, Hanford Phase I and } 2 \\
\text { Privatization, and Idaho Title } 1 \text { Design }\end{array}$ & 00215 & High-Level Waste Soils \\
\hline
\end{tabular}


Table A.2. (contd)

\begin{tabular}{|c|c|c|c|}
\hline 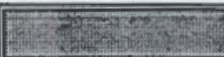 & Worksheet 2 Disposition Map & Woste Streams Impac & edBY $\mathrm{WP}$ \\
\hline WP Number & WP Title & Waste Stream ID : & Waste Stream Name \\
\hline TFA-2 & $\begin{array}{l}\text { Waste Immobilization and Product } \\
\text { Acceptance Required to Meet DWPF } \\
\text { Schedule, Hanford Phase I and } 2 \\
\text { Privatization, and Idaho Title } 1 \text { Design }\end{array}$ & 02113 & Sludge, Salt, Liquid \\
\hline TFA-2 & $\begin{array}{l}\text { Waste Immobilization and Product } \\
\text { Acceptance Required to Meet DWPF } \\
\text { Schedule, Hanford Phase I and } 2 \\
\text { Privatization, and Idaho Title } 1 \text { Design }\end{array}$ & 02114 & Washed Sludge \\
\hline TFA-2 & $\begin{array}{l}\text { Waste Immobilization and Product } \\
\text { Acceptance Required to Meet DWPF } \\
\text { Schedule, Hanford Phase I and } 2 \\
\text { Privatization, and Idaho Title } 1 \text { Design }\end{array}$ & 02115 & HLW Liquid w/Cs \\
\hline TFA-2 & $\begin{array}{l}\text { Waste Immobilization and Product } \\
\text { Acceptance Required to Meet DWPF } \\
\text { Schedule, Hanford Phase I and } 2 \\
\text { Privatization, and Idaho Title } 1 \text { Design }\end{array}$ & 02117 & HLW Glass \\
\hline TFA-2 & $\begin{array}{l}\text { Waste Immobilization and Product } \\
\text { Acceptance Required to Meet DWPF } \\
\text { Schedule, Hanford Phase I and } 2 \\
\text { Privatization, and Idaho Title } 1 \text { Design }\end{array}$ & 00757 & Vitrified HAW \\
\hline 5 & 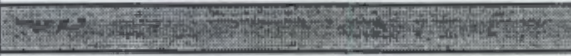 & 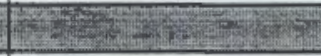 & \\
\hline TFA-3 & $\begin{array}{l}\text { Alternative Paths to In-Tank } \\
\text { Precipitation at SRS }\end{array}$ & 01286 & Radionuclide Separation \\
\hline TFA-3 & $\begin{array}{l}\text { Alternative Paths to In-Tank } \\
\text { Precipitation at SRS }\end{array}$ & 00754 & Liquid Feed to Separations \\
\hline TFA-3 & $\begin{array}{l}\text { Alternative Paths to In-Tank } \\
\text { Precipitation at SRS }\end{array}$ & 00428 & RH TRU Sludges \\
\hline TFA-3 & $\begin{array}{l}\text { Alternative Paths to In-Tank } \\
\text { Precipitation at SRS }\end{array}$ & 00501 & ITP Filtrate to Saltstone \\
\hline TFA-3 & $\begin{array}{l}\text { Alternative Paths to In-Tank } \\
\text { Precipitation at SRS }\end{array}$ & 00502 & ITP Precipitate to DWPF \\
\hline & 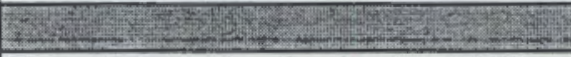 & 5 & \\
\hline TFA-4 & $\begin{array}{l}\text { Slurry Preparation for Feed to HLW } \\
\text { Vitrification at SRS and Hanford and } \\
\text { Radioactive Tank Waste Preparation at } \\
\text { ORR }\end{array}$ & 01580 & Liquid LLW \\
\hline TFA-4 & $\begin{array}{l}\text { Slurry Preparation for Feed to HLW } \\
\text { Vitrification at SRS and Hanford and } \\
\text { Radioactive Tank Waste Preparation at } \\
\text { ORR }\end{array}$ & 00428 & Remote-Handled TRU Sludges \\
\hline TFA-4 & $\begin{array}{l}\text { Slurry Preparation for Feed to HLW } \\
\text { Vitrification at SRS and Hanford and } \\
\text { Radioactive Tank Waste Preparation at } \\
\text { ORR }\end{array}$ & 02113 & Sludge, Salt, Liquid \\
\hline
\end{tabular}


Table A.2. (contd)

\begin{tabular}{|c|c|c|c|}
\hline \multicolumn{4}{|c|}{ Worksheet 2-Disposition Map Wraste Streams Tmpacted By WP } \\
\hline WP Number & W New WP Title & Waste Stream ID \# & Waste Stream Name \\
\hline TFA-4 & $\begin{array}{l}\text { Slurry Preparation for Feed to HLW } \\
\text { Vitrification at SRS and Hanford and } \\
\text { Radioactive Tank Waste Preparation at } \\
\text { ORR }\end{array}$ & 02115 & HLW Liquid w/Cs \\
\hline TFA-4 & $\begin{array}{l}\text { Slurry Preparation for Feed to HLW } \\
\text { Vitrification at SRS and Hanford and } \\
\text { Radioactive Tank Waste Preparation at } \\
\text { ORR }\end{array}$ & 00501 & ITP Filtrate to Saltstone \\
\hline TFA-4 & $\begin{array}{l}\text { Slurry Preparation for Feed to HLW } \\
\text { Vitrification at SRS and Hanford and } \\
\text { Radioactive Tank Waste Preparation at } \\
\text { ORR }\end{array}$ & 00502 & ITP Precipitate to DWPF \\
\hline TFA-4 & $\begin{array}{l}\text { Slurry Preparation for Feed to HLW } \\
\text { Vitrification at SRS and Hanford and } \\
\text { Radioactive Tank Waste Preparation at } \\
\text { ORR }\end{array}$ & 00503 & Washed Sludge to DWPF \\
\hline TFA-4 & $\begin{array}{l}\text { Slurry Preparation for Feed to HLW } \\
\text { Vitrification at SRS and Hanford and } \\
\text { Radioactive Tark Waste Preparation at } \\
\text { ORR }\end{array}$ & 00496 & Sludge Feed to ESP \\
\hline & & $x_{a x}^{2}$ & 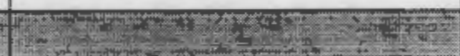 \\
\hline TFA-5 & Hanford Tanks Initiative & 02113 & Sludge, Salt, Liquid \\
\hline TFA-5 & Hanford Tanks Initiative & 02120 & Tanks \\
\hline$\sqrt{5 \sin }$ & 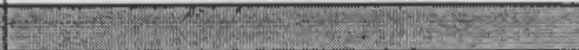 & $\sqrt{0^{\circ}}$ & 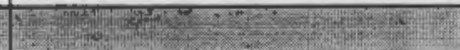 \\
\hline TFA-6 & $\begin{array}{l}\text { Pretreatment to Reduce Volume of } \\
\text { HLW and LLW Waste Forms at SRS, } \\
\text { Idaho, Hanford and Oak Ridge }\end{array}$ & 00747 & Liquid Waste \\
\hline TFA-6 & $\begin{array}{l}\text { Pretreatment to Reduce Volume of } \\
\text { HLW and LLW Waste Forms at SRS, } \\
\text { Idaho, Hanford and Oak Ridge }\end{array}$ & 00751 & Calcine Solids \\
\hline TFA-6 & $\begin{array}{l}\text { Pretreatment to Reduce Volume of } \\
\text { HLW and LLW Waste Forms at SRS, } \\
\text { Idaho, Hanford and Oak Ridge }\end{array}$ & 00749 & Liquid Feed to Separations \\
\hline TFA-6 & $\begin{array}{l}\text { Pretreatment to Reduce Volume of } \\
\text { HLW and LLW Waste Forms at SRS, } \\
\text { Idaho, Hanford and Oak Ridge }\end{array}$ & 00753 & Dissolved Calcine HLW \\
\hline TFA-6 & $\begin{array}{l}\text { Pretreatment to Reduce Volume of } \\
\text { HLW and LLW Waste Forms at SRS, } \\
\text { Idaho, Hanford and Oak Ridge }\end{array}$ & 00752 & Calcine to Dissolution \\
\hline TFA-6 & $\begin{array}{l}\text { Pretreatment to Reduce Volume of } \\
\text { HLW and LLW Waste Forms at SRS, } \\
\text { Idaho, Hanford and Oak Ridge }\end{array}$ & 00428 & Remote-Handled TRU Sludges \\
\hline TFA-6 & $\begin{array}{l}\text { Pretreatment to Reduce Volume of } \\
\text { HLW and LLW Waste Forms at SRS, } \\
\text { Idaho, Hanford and Oak Ridge }\end{array}$ & 02113 & Sludge, Salt, Liquid \\
\hline
\end{tabular}


Table A.2. (contd)

\begin{tabular}{|c|c|c|c|}
\hline \multicolumn{4}{|c|}{ Worksheet 2 - Disposition Map Waste Streams Impacted By WP } \\
\hline WP Number & 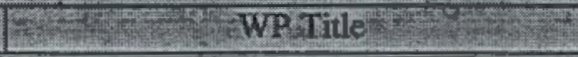 & Waste Stream ID \# & Waste Stream Name \\
\hline TFA-6 & $\begin{array}{l}\text { Pretreatment to Reduce Volume of } \\
\text { HLW and LLW Waste Forms at SRS, } \\
\text { Idaho, Hanford and Oak Ridge }\end{array}$ & 02114 & Washed Sludge \\
\hline TFA-6 & $\begin{array}{l}\text { Pretreatment to Reduce Volume of } \\
\text { HLW and LLW Waste Forms at SRS, } \\
\text { Idaho, Hanford and Oak Ridge }\end{array}$ & 02115 & HLW Liquid w/Cs \\
\hline TFA-6 & $\begin{array}{l}\text { Pretreatment to Reduce Volume of } \\
\text { HLW and LLW Waste Forms at SRS, } \\
\text { Idaho, Hanford and Oak Ridge }\end{array}$ & 00496 & Sludge Feed to ESP \\
\hline TFA-6 & $\begin{array}{l}\text { Pretreatment to Reduce Volume of } \\
\text { HLW and LLW Waste Forms at SRS, } \\
\text { Idaho, Hanford and Oak Ridge }\end{array}$ & 00499 & Salt/Sup. Feed to ITP \\
\hline 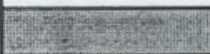 & 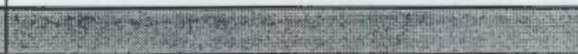 & & \\
\hline TFA-7 & $\begin{array}{l}\text { Immobilization Process for Idaho } \\
\text { Supporting Title } 1 \text { Design; } \\
\text { Immobilization Evaluation for ORR } \\
\text { Privatization and Hanford Capsules }\end{array}$ & 02113 & Sludge, Salt, Liquid \\
\hline TFA-7 & $\begin{array}{l}\text { Immobilization Process for Idaho } \\
\text { Supporting Title } 1 \text { Design; } \\
\text { Immobilization Evaluation for ORR } \\
\text { Privatization and Hanford Capsules }\end{array}$ & 02116 & Cs Concentrate \\
\hline TFA-7 & $\begin{array}{l}\text { Immobilization Process for Idaho } \\
\text { Supporting Title 1 Design; } \\
\text { Immobilization Evaluation for ORR } \\
\text { Privatization and Hanford Capsules }\end{array}$ & 02114 & Washed Sludge \\
\hline TFA-7 & $\begin{array}{l}\text { Immobilization Process for Idaho } \\
\text { Supporting Title } 1 \text { Design; } \\
\text { Immobilization Evaluation for ORR } \\
\text { Privatization and Hanford Capsules }\end{array}$ & 00754 & Liquid Feed to Separations \\
\hline TFA-7 & $\begin{array}{l}\text { Immobilization Process for Idaho } \\
\text { Supporting Title 1 Design; } \\
\text { Immobilization Evaluation for ORR } \\
\text { Privatization and Hanford Capsules }\end{array}$ & 00753 & Dissolved Calcine HLW \\
\hline TFA-7 & $\begin{array}{l}\text { Immobilization Process for Idaho } \\
\text { Supporting Title } 1 \text { Design; } \\
\text { Immobilization Evaluation for ORR } \\
\text { Privatization and Hanford Capsules }\end{array}$ & 00752 & Calcine to Dissolution \\
\hline TFA-7 & $\begin{array}{l}\text { Immobilization Process for Idaho } \\
\text { Supporting Title 1 Design; } \\
\text { Immobilization Evaluation for ORR } \\
\text { Privatization and Hanford Capsules }\end{array}$ & 00749 & Liquid Feed to Separations \\
\hline
\end{tabular}


Table A.2. (contd)

\begin{tabular}{||l|l|l|l||}
\hline WP Number & \multicolumn{1}{|c|}{ Worksheet 2 Disposition Map Waste Streams Impacted By WR } \\
\hline TFA-7 & $\begin{array}{l}\text { Immobilization Process for Idaho } \\
\text { Supporting Title 1 Design; } \\
\text { Immobilization Evaluation for ORR } \\
\text { Privatization and Hanford Capsules }\end{array}$ & 00750 & Calcine Solids to Storage \\
\hline TFA-7 & $\begin{array}{l}\text { Immobilization Process for Idaho } \\
\text { Supporting Title 1 Design; } \\
\text { Immobilization Evaluation for ORR } \\
\text { Privatization and Hanford Capsules }\end{array}$ & 00747 & Liquid Waste \\
\hline TFA-7 & $\begin{array}{l}\text { Immobilization Process for Idaho } \\
\text { Supporting Title 1 Design; } \\
\text { Immobilization Evaluation for ORR } \\
\text { Privatization and Hanford Capsules }\end{array}$ & 00751 & Calcine Solids \\
\hline TFA-7 & $\begin{array}{l}\text { Immobilization Process for Idaho } \\
\text { Supporting Title 1 Design; } \\
\text { Immobilization Evaluation for ORR } \\
\text { Privatization and Hanford Capsules }\end{array}$ & 00751 & Liquid LLW \\
\hline TFA-7 & $\begin{array}{l}\text { Immobilization Process for Idaho } \\
\text { Supporting Title 1 Design; } \\
\text { Immobilization Evaluation for ORR } \\
\text { Privatization and Hanford Capsules }\end{array}$ & 00428 & RH TRU Sludge \\
\hline
\end{tabular}


Table A.3. WS 3 - STCG Needs

\begin{tabular}{|c|c|c|c|}
\hline$=0$ & Worksheet $3-$ STCG & J/Needs Jmpacted & By WP \\
\hline WP Number & WP Tite & STCG Need D \# & STCG Need Title \\
\hline TFA-1 & $\begin{array}{l}\text { Required Steps to Tank Closure at } \\
\text { Hanford, ORR, Idaho, and SRS }\end{array}$ & ID-2.1.10 & $\begin{array}{l}\text { Develop Technology to Characterize } \\
\text { Tank Farm Heel Residues }\end{array}$ \\
\hline TFA-1 & $\begin{array}{l}\text { Required Steps to Tank Closure at } \\
\text { Hanford, ORR, Idaho, and SRS }\end{array}$ & ID-2.1.13 & Washable Metal HEPA Filters \\
\hline TFA-1 & $\begin{array}{l}\text { Required Steps to Tank Closure at } \\
\text { Hanford, ORR, Idaho, and SRS }\end{array}$ & RL-WT022 & Tank Knuckle NDE \\
\hline TFA-1 & $\begin{array}{l}\text { Required Steps to Tank Closure at } \\
\text { Hanford, ORR, Idaho, and SRS }\end{array}$ & RL-WT028 & Waste Mobilization Enhancement \\
\hline TFA-1 & $\begin{array}{l}\text { Required Steps to Tank Closure at } \\
\text { Hanford, ORR, Idaho, and SRS }\end{array}$ & RL-WT04 & DST Corrosion Monitoring \\
\hline TFA-1 & $\begin{array}{l}\text { Required Steps to Tank Closure at } \\
\text { Hanford, ORR, Idaho, and SRS }\end{array}$ & RL-WT05 & $\begin{array}{l}\text { Remote Inspection of High-Level Waste } \\
\text { Tanks }\end{array}$ \\
\hline TFA-1 & $\begin{array}{l}\text { Required Steps to Tank Closure at } \\
\text { Hanford, ORR, Idaho, and SRS }\end{array}$ & SR-2001 & Tank Heel Removal/Closure Techniques \\
\hline TFA-1 & $\begin{array}{l}\text { Required Steps to Tank Closure at } \\
\text { Hanford, ORR, Idaho, and SRS }\end{array}$ & SR-2002 & Alternative Waste Removal Techniques \\
\hline TFA-1 & $\begin{array}{l}\text { Required Steps to Tank Closure at } \\
\text { Hanford, ORR, Idaho, and SRS }\end{array}$ & SR-2003 & $\begin{array}{l}\text { In-situ Methods for Characterization of } \\
\text { Tank Wastes }\end{array}$ \\
\hline TFA-1 & $\begin{array}{l}\text { Required Steps to Tank Closure at } \\
\text { Hanford, ORR, Idaho, and SRS }\end{array}$ & SR-2004 & Methods to Unplug Waste Transfer Lines \\
\hline TFA-1 & $\begin{array}{l}\text { Required Steps to Tank Closure at } \\
\text { Hanford, ORR, Idaho, and SRS }\end{array}$ & SR-2009 & $\begin{array}{l}\text { Demonstrate Alternative Filtration } \\
\text { Technologies to Replace HEPA filters }\end{array}$ \\
\hline TFA-1 & $\begin{array}{l}\text { Required Steps to Tank Closure at } \\
\text { Hanford, ORR, Idaho, and SRS }\end{array}$ & SR-2015 & $\begin{array}{l}\text { Develop Advanced Techniques for Life } \\
\text { Extension of Tanks/Piping }\end{array}$ \\
\hline TFA-1 & $\begin{array}{l}\text { Required Steps to Tank Closure at } \\
\text { Hanford, ORR, Idaho, and SRS }\end{array}$ & SR-2017 & Alternative Mixer Pumps \\
\hline TFA-1 & $\begin{array}{l}\text { Required Steps to Tank Closure at } \\
\text { Hanford, ORR, Idaho, and SRS }\end{array}$ & SR-3022 & $\begin{array}{l}\text { In-situ grouting of underground tanks } \\
\text { formerly used for storage of radioactive } \\
\text { solvents }\end{array}$ \\
\hline TFA-1 & $\begin{array}{l}\text { Required Steps to Tank Closure at } \\
\text { Hanford, ORR, Idaho, and SRS }\end{array}$ & TK-01 & $\begin{array}{l}\text { Oak Ridge National Laboratory Tank } \\
\text { Waste Characterization }\end{array}$ \\
\hline TFA-1 & $\begin{array}{l}\text { Required Steps to Tank Closure at } \\
\text { Hanford, ORR, Idaho, and SRS }\end{array}$ & TK-02 & $\begin{array}{l}\text { Oak Ridge National Laboratory Solid } \\
\text { Waste Retrieval }\end{array}$ \\
\hline TFA-1 & $\begin{array}{l}\text { Required Steps to Tank Closure at } \\
\text { Hanford, ORR, Idaho, and SRS }\end{array}$ & TK-04 & $\begin{array}{l}\text { Oak Ridge National Laboratory Sludge } \\
\text { Mixing and Slurry Transport }\end{array}$ \\
\hline TFA-1 & $\begin{array}{l}\text { Required Steps to Tank Closure at } \\
\text { Hanford, ORR, Idaho, and SRS }\end{array}$ & TK-09 & $\begin{array}{l}\text { Oak Ridge National Laboratory Tank } \\
\text { Closure }\end{array}$ \\
\hline TFA-1 & $\begin{array}{l}\text { Required Steps to Tank Closure at } \\
\text { Hanford, ORR, Idaho, and SRS }\end{array}$ & TK-10 & $\begin{array}{l}\text { Oak Ridge National Laboratory } \\
\text { Remediated Tank Isolation and Removal }\end{array}$ \\
\hline & 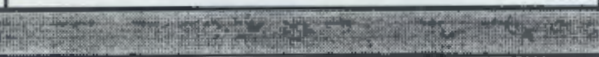 & 5 & the \\
\hline TFA-2 & $\begin{array}{l}\text { Waste Immobilization and Product } \\
\text { Acceptance Required to Meet DWPF } \\
\text { Schedule, Hanford Phase I and } 2 \\
\text { Privatization, and Idaho Title } 1 \text { Design }\end{array}$ & ID-2.1.08 & $\begin{array}{l}\text { Develop Technology/Process for the } \\
\text { Immobilization of High Activity Waste }\end{array}$ \\
\hline
\end{tabular}


Table A.3. (contd)

\begin{tabular}{|c|c|c|c|}
\hline \multicolumn{4}{|c|}{ Worksheet 3 -,STCGNeeds Impacted By WP } \\
\hline WP Number & WP Title & STCG Need ID \# & STCGNeed Title \\
\hline TFA-2 & $\begin{array}{l}\text { Waste Immobilization and Product } \\
\text { Acceptance Required to Meet DWPF } \\
\text { Schedule, Hanford Phase I and } 2 \\
\text { Privatization, and Idaho Title } 1 \text { Design }\end{array}$ & RL-WT010 & $\begin{array}{l}\text { ILAW Product Acceptance Inspection } \\
\text { and Test Methods }\end{array}$ \\
\hline TFA-2 & $\begin{array}{l}\text { Waste Immobilization and Product } \\
\text { Acceptance Required to Meet DWPF } \\
\text { Schedule, Hanford Phase } 1 \text { and } 2 \\
\text { Privatization, and Idaho Title } 1 \text { Design }\end{array}$ & RL-WT011 & $\begin{array}{l}\text { IHLW Product Acceptance Inspection } \\
\text { and Test Methods }\end{array}$ \\
\hline TFA-2 & $\begin{array}{l}\text { Waste Immobilization and Product } \\
\text { Acceptance Required to Meet DWPF } \\
\text { Schedule, Hanford Phase I and } 2 \\
\text { Privatization, and Idaho Title } 1 \text { Design }\end{array}$ & RL-WT015 & $\begin{array}{l}\text { Standard Method for Determining Waste } \\
\text { Form Release Rate }\end{array}$ \\
\hline TFA-2 & $\begin{array}{l}\text { Waste Immobilization and Product } \\
\text { Acceptance Required to Meet DWPF } \\
\text { Schedule, Hanford Phase I and } 2 \\
\text { Privatization, and Idaho Title } 1 \text { Design }\end{array}$ & RL-WT06 & $\begin{array}{l}\text { Identification and Management of } \\
\text { Chromium and Other Problem } \\
\text { Constituents for HLW Vitrification }\end{array}$ \\
\hline TFA-2 & $\begin{array}{l}\text { Waste Immobilization and Product } \\
\text { Acceptance Required to Meet DWPF } \\
\text { Schedule, Hanford Phase I and } 2 \\
\text { Privatization, and Idaho Title } 1 \text { Design }\end{array}$ & SR-2007 & Optimize Melter Glass Chemistry \\
\hline TFA-2 & $\begin{array}{l}\text { Waste Immobilization and Product } \\
\text { Acceptance Required to Meet DWPF } \\
\text { Schedule, Hanford Phase I and } 2 \\
\text { Privatization, and Idaho Title } 1 \text { Design }\end{array}$ & SR-2010 & $\begin{array}{l}\text { Develop Second Generation DWPF } \\
\text { Melter }\end{array}$ \\
\hline & 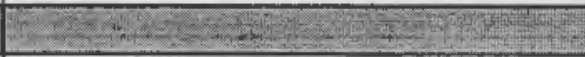 & & 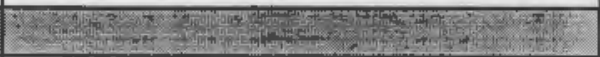 \\
\hline TFA-3 & $\begin{array}{l}\text { Alternative Paths to In-Tank } \\
\text { Precipitation at SRS }\end{array}$ & ID-2.1.01 & $\begin{array}{l}\text { Technologies to Reduce Generation of or } \\
\text { Alternative Treatments for Radioactive } \\
\text { Liquid Waste at the ICPP }\end{array}$ \\
\hline TFA-3 & $\begin{array}{l}\text { Alternative Paths to In-Tank } \\
\text { Precipitation at SRS }\end{array}$ & SR-2005 & Second Generation Salt Feed Program \\
\hline TFA-3 & $\begin{array}{l}\text { Alternative Paths to In-Tank } \\
\text { Precipitation at SRS }\end{array}$ & SR-2006 & $\begin{array}{l}\text { Provide Alternative Processing and /or } \\
\text { Concentration Methods for DWPF } \\
\text { Recycle Aqueous Streams }\end{array}$ \\
\hline TFA-3 & $\begin{array}{l}\text { Alternative Paths to In-Tank } \\
\text { Precipitation at SRS }\end{array}$ & SR-2008 & ITP Feed Solution Pretreatment \\
\hline TFA-3 & $\begin{array}{l}\text { Alternative Paths to In-Tank } \\
\text { Precipitation at SRS }\end{array}$ & TK-11 & $\begin{array}{l}\text { Oak Ridge National Laboratory Sludge } \\
\text { and Supernatant Pretreatment }\end{array}$ \\
\hline 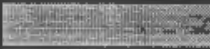 & 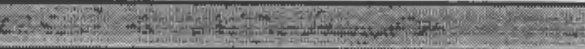 & 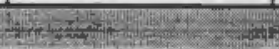 & 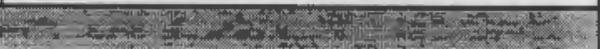 \\
\hline TFA-4 & $\begin{array}{l}\text { Slurry Preparation for Feed to HLW } \\
\text { Vitrification at SRS and Hanford and } \\
\text { Radioactive Tank Waste Preparation at } \\
\text { ORR }\end{array}$ & RL-WT023 & $\begin{array}{l}\text { Prediction of Solid Phase Formation in } \\
\text { Hanford Tank Waste Solutions }\end{array}$ \\
\hline
\end{tabular}


Table A.3. (contd)

\begin{tabular}{|c|c|c|c|}
\hline & Worksheet 3 STC & GNeeds Impacted & By WP \\
\hline WP Number & WP Tite & STCG Need ID \# & STCG Need Tide 2 ? \\
\hline TFA-4 & $\begin{array}{l}\text { Slurry Preparation for Feed to HLW } \\
\text { Vitrification at SRS and Hanford and } \\
\text { Radioactive Tank Waste Preparation at } \\
\text { ORR }\end{array}$ & RL-WT024 & Enhanced Sludge Washing Process Data \\
\hline TFA-4 & $\begin{array}{l}\text { Slurry Preparation for Feed to HLW } \\
\text { Vitrification at SRS and Hanford and } \\
\text { Radioactive Tank Waste Preparation at } \\
\text { ORR }\end{array}$ & RL-WT03 & $\begin{array}{l}\text { Large Volume (3-5 liter) Sludge and } \\
\text { Supernate Sampler }\end{array}$ \\
\hline TFA-4 & $\begin{array}{l}\text { Slurry Preparation for Feed to HLW } \\
\text { Vitrification at SRS and Hanford and } \\
\text { Radioactive Tank Waste Preparation at } \\
\text { ORR }\end{array}$ & RL-WT09 & $\begin{array}{l}\text { Representative Sampling and Associated } \\
\text { Analysis to Support Operations and } \\
\text { Disposal }\end{array}$ \\
\hline TFA-4 & $\begin{array}{l}\text { Slurry Preparation for Feed to HLW } \\
\text { Vitrification at SRS and Hanford and } \\
\text { Radioactive Tank Waste Preparation at } \\
\text { ORR }\end{array}$ & SR-1011 & $\begin{array}{l}\text { Volume Reduction and Stabilization of } \\
\text { CIF Secondary Salt ( } \mathrm{NaCl}) \text { Liquid Waste }\end{array}$ \\
\hline TFA-4 & $\begin{array}{l}\text { Slurry Preparation for Feed to HLW } \\
\text { Vitrification at SRS and Hanford and } \\
\text { Radioactive Tank Waste Preparation at } \\
\text { ORR }\end{array}$ & SR-2005 & Second Generation Salt Feed Program \\
\hline TFA-4 & $\begin{array}{l}\text { Slurry Preparation for Feed to HLW } \\
\text { Vitrification at SRS and Hanford and } \\
\text { Radioactive Tank Waste Preparation at } \\
\text { ORR }\end{array}$ & SR-2006 & Optimize Melter Glass Chemistry \\
\hline TFA-4 & $\begin{array}{l}\text { Slurry Preparation for Feed to HLW } \\
\text { Vitrification at SRS and Hanford and } \\
\text { Radioactive Tank Waste Preparation at } \\
\text { ORR }\end{array}$ & SR-2013 & Improved Sludge Processing \\
\hline TFA-4 & $\begin{array}{l}\text { Slurry Preparation for Feed to HLW } \\
\text { Vitrification at SRS and Hanford and } \\
\text { Radioactive Tank Waste Preparation at } \\
\text { ORR }\end{array}$ & TK-05 & $\begin{array}{l}\text { Oak Ridge National Laboratory Sludge } \\
\text { and Supernatant Separations }\end{array}$ \\
\hline TFA-4 & $\begin{array}{l}\text { Slurry Preparation for Feed to HLW } \\
\text { Vitrification at SRS and Hanford and } \\
\text { Radioactive Tank Waste Preparation at } \\
\text { ORR }\end{array}$ & TK-11 & $\begin{array}{l}\text { Oak Ridge National Laboratory Sludge } \\
\text { and Supernatant Pretreatment }\end{array}$ \\
\hline & foe & & 28y \\
\hline TFA-5 & Hanford Tanks Initiative & RL-WT013A & $\begin{array}{l}\text { Establish Retrieval Performance } \\
\text { Evaluation Criteria (Focus on Retrieval } \\
\text { Performance Evaluation/Closure } \\
\text { Criteria) }\end{array}$ \\
\hline TFA-5 & Hanford Tanks Initiative & RL-WT013B & \begin{tabular}{|l|} 
Establish Retrieval Performance \\
Evaluation Criteria (Characterization)
\end{tabular} \\
\hline TFA-5 & Hanford Tanks Initiative & RL-WT013C & $\begin{array}{l}\text { Establish Retrieval Performance } \\
\text { Evaluation Criteria (Heel Retrieval) }\end{array}$ \\
\hline
\end{tabular}


Table A.3. (contd)

\begin{tabular}{|c|c|c|c|}
\hline 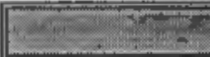 & Worksheet 3 STK & YNeeds Impacted & By WP \\
\hline WP Number: & WPTitle & STCG Need ID \# & STCG Need Titie \\
\hline TFA-5 & Hanford Tanks Initiative & RL-WT013D & $\begin{array}{l}\text { Establish Retrieval Performance } \\
\text { Evaluation Criteria (Waste Conditioning } \\
\text { for Heel Transfer) }\end{array}$ \\
\hline TFA-5 & Hanford Tanks Initiative & RL-WT013E & $\begin{array}{l}\text { Establish Retrieval Performance } \\
\text { Evaluation Criteria (SST Retrieval } \\
\text { Enhancements) }\end{array}$ \\
\hline-5 & 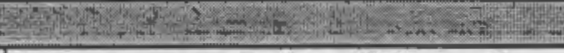 & $2 \div$ & 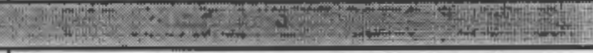 \\
\hline TFA-6 & $\begin{array}{l}\text { Pretreatment to Reduce Volume of } \\
\text { HLW and LLW Waste Forms at SRS, } \\
\text { Idaho, Hanford and Oak Ridge }\end{array}$ & ID-2.1.02 & $\begin{array}{l}\text { Process Flowsheet to Calcine Sodium- } \\
\text { Bearing Waste }\end{array}$ \\
\hline TFA-6 & $\begin{array}{l}\text { Pretreatment to Reduce Volume of } \\
\text { HLW and LLW Waste Forms at SRS, } \\
\text { Idaho, Hanford and Oak Ridge }\end{array}$ & ID-2.1.05 & Dissolution of ICPP Calcines \\
\hline TFA-6 & $\begin{array}{l}\text { Pretreatment to Reduce Volume of } \\
\text { HLW and LLW Waste Forms at SRS, } \\
\text { Idaho, Hanford and Oak Ridge }\end{array}$ & ID-2.1.06 & $\begin{array}{l}\text { Solvent Extraction and Ion-Exchange to } \\
\text { Remove TRU, Sr, Tc, and Cs from } \\
\text { ICPP Tank Farm }\end{array}$ \\
\hline TFA-6 & $\begin{array}{l}\text { Pretreatment to Reduce Volume of } \\
\text { HLW and LLW Waste Forms at SRS, } \\
\text { Idaho, Hanford and Oak Ridge }\end{array}$ & RL-WT019 & Getter Materials \\
\hline TFA-6 & $\begin{array}{l}\text { Pretreatment to Reduce Volume of } \\
\text { HLW and LLW Waste Forms at SRS, } \\
\text { Idaho, Hanford and Oak Ridge }\end{array}$ & RL-WT024 & Enhanced Sludge Washing Process Data \\
\hline TFA-6 & $\begin{array}{l}\text { Pretreatment to Reduce Volume of } \\
\text { HLW and LLW Waste Forms at SRS, } \\
\text { Idaho, Hanford and Oak Ridge }\end{array}$ & RL-WT08 & $\begin{array}{l}\text { Advanced Methods for Achieving LLW } \\
\text { Volume Minimization }\end{array}$ \\
\hline TFA-6 & $\begin{array}{l}\text { Pretreatment to Reduce Volume of } \\
\text { HLW and LLW Waste Forms at SRS, } \\
\text { Idaho, Hanford and Oak Ridge }\end{array}$ & SR-2003 & $\begin{array}{l}\text { In-situ Methods for Characterization of } \\
\text { Tank Wastes }\end{array}$ \\
\hline TFA-6 & $\begin{array}{l}\text { Pretreatment to Reduce Volume of } \\
\text { HLW and LLW Waste Forms at SRS, } \\
\text { Idaho, Hanford and Oak Ridge }\end{array}$ & SR-2011C & $\begin{array}{l}\text { Develop Advanced Techniques to } \\
\text { Improve Safety Infrastructure (Pot } \\
\text { Sampler) }\end{array}$ \\
\hline TFA-6 & $\begin{array}{l}\text { Pretreatment to Reduce Volume of } \\
\text { HLW and LLW Waste Forms at SRS, } \\
\text { Idaho, Hanford and Oak Ridge }\end{array}$ & SR-2023 & Caustic Recovery and Recycle \\
\hline TFA-6 & $\begin{array}{l}\text { Pretreatment to Reduce Volume of } \\
\text { HLW and LLW Waste Forms at SRS, } \\
\text { Idaho, Hanford and Oak Ridge }\end{array}$ & SR-2003 & $\begin{array}{l}\text { In-situ Methods for Characterization of } \\
\text { Tank Wastes }\end{array}$ \\
\hline TFA-6 & $\begin{array}{l}\text { Pretreatment to Reduce Volume of } \\
\text { HLW and LLW Waste Forms at SRS, } \\
\text { Idaho, Hanford and Oak Ridge }\end{array}$ & TK-01 & $\begin{array}{l}\text { Oak Ridge National Laboratory Tank } \\
\text { Waste Characterization }\end{array}$ \\
\hline TFA- 6 & $\begin{array}{l}\text { Pretreatment to Reduce Volume of } \\
\text { HLW and LLW Waste Forms at SRS, } \\
\text { Idaho, Hanford and Oak Ridge }\end{array}$ & TK-11 & $\begin{array}{l}\text { Oak Ridge National Laboratory Sludge } \\
\text { and Supernatant Pretreatment }\end{array}$ \\
\hline
\end{tabular}


Table A.3. (contd)

\begin{tabular}{||l|l|l|l|}
\hline \multicolumn{2}{|c|}{ Worksheet 3-STCG-Needs Impacted By WP } \\
\hline WP Number & \multicolumn{2}{|c|}{ WP Title } \\
\hline FFA-7 & $\begin{array}{l}\text { Immobilization Process for Idaho } \\
\text { Supporting Title 1 Design; } \\
\text { Immobilization Evaluation for ORR } \\
\text { Privatization and Hanford Capsules }\end{array}$ & ID-2.1.07 & $\begin{array}{l}\text { Develop Technology/Process for the } \\
\text { Immobilization of High Activity Waste }\end{array}$ \\
\hline TFA-7 & $\begin{array}{l}\text { Immobilization Process for Idaho } \\
\text { Supporting Title 1 Design; } \\
\text { Immobilization Evaluation for ORR } \\
\text { Privatization and Hanford Capsules }\end{array}$ & ID-2.1.14 & $\begin{array}{l}\text { Develop Technology for Preconditioning } \\
\text { ICPP High-Activity and Low-Activity } \\
\text { Wastes }\end{array}$ \\
\hline TFA-7 & $\begin{array}{l}\text { Immobilization Process for Idaho } \\
\text { Supporting Title 1 Design; } \\
\text { Immobilization Evaluation for ORR } \\
\text { Privatization and Hanford Capsules }\end{array}$ & RL-WT025 & $\begin{array}{l}\text { Remote Sensing of Gas Retention in } \\
\text { HLW Slurries }\end{array}$ \\
\hline TFA-7 & $\begin{array}{l}\text { Immobilization Process for Idaho } \\
\text { Supporting Title 1 Design; } \\
\text { Immobilization Evaluation for ORR } \\
\text { Privatization and Hanford Capsules }\end{array}$ & RL-WT07 & $\begin{array}{l}\text { Hanford Capsule Initiative (HCI): A } \\
\text { Processing Demonstration of CS/Sr } \\
\text { Capsules for Final Disposition }\end{array}$ \\
\hline TFA-7 & $\begin{array}{l}\text { Immobilization Process for Idaho } \\
\text { Supporting Title 1 Design; } \\
\text { Immobilization Evaluation for ORR } \\
\text { Privatization and Hanford Capsules }\end{array}$ & TK-06 & $\begin{array}{l}\text { Oak Ridge National Laboratory Tank } \\
\text { Sludge and Supernatant Immobilization }\end{array}$ \\
\hline
\end{tabular}


Table A.4. WS 4 - PBSs

\begin{tabular}{|c|c|c|c|}
\hline 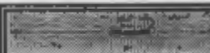 & Worksheet 4 4TES: & Timpacted By & WP \\
\hline WP Number & WP Title & PBSID $f$ & PBSTitlo: \\
\hline TFA-1 & $\begin{array}{l}\text { Required Steps to Tank Closure at } \\
\text { Hanford, ORR, Idaho, and SRS }\end{array}$ & ID-HLW-101 & High-Level Waste Pretreatment \\
\hline TFA-1 & $\begin{array}{l}\text { Required Steps to Tank Closure at } \\
\text { Hanford, ORR, Idaho, and SRS }\end{array}$ & ID-HLW-103 & HLW Treatment and Storage \\
\hline TFA-1 & $\begin{array}{l}\text { Required Steps to Tank Closure at } \\
\text { Hanford, ORR, Idaho, and SRS }\end{array}$ & OR-38112 & $\begin{array}{l}\text { Low Level Waste Storage, } \\
\text { Treatment, Disposal }\end{array}$ \\
\hline TFA-1 & $\begin{array}{l}\text { Required Steps to Tank Closure at } \\
\text { Hanford, ORR, Idaho, and SRS }\end{array}$ & OR-38113 & $\begin{array}{l}\text { Transuranic Waste Storage, } \\
\text { Treatment }\end{array}$ \\
\hline TFA-1 & $\begin{array}{l}\text { Required Steps to Tank Closure at } \\
\text { Hanford, ORR, Idaho, and SRS }\end{array}$ & OR-43201 & $\begin{array}{l}\text { ORNL Melton Valley Watershed } \\
\text { D\&D }\end{array}$ \\
\hline TFA-1 & $\begin{array}{l}\text { Required Steps to Tank Closure at } \\
\text { Hanford, ORR, Idaho, and SRS }\end{array}$ & OR-43203 & $\begin{array}{l}\text { ORNL Bethel Valley Remedial } \\
\text { Action }\end{array}$ \\
\hline TFA-1 & $\begin{array}{l}\text { Required Steps to Tank Closure at } \\
\text { Hanford, ORR, Idaho, and SRS }\end{array}$ & RL-TW03 & Tank Farms Operations \\
\hline TFA-1 & $\begin{array}{l}\text { Required Steps to Tank Closure at } \\
\text { Hanford, ORR, Idaho, and SRS }\end{array}$ & RL-TW04 & Retrieval Project \\
\hline TFA-1 & $\begin{array}{l}\text { Required Steps to Tank Closure at } \\
\text { Hanford, ORR, Idaho, and SRS }\end{array}$ & SR-HL01 & H-Tank Farm \\
\hline TFA-1 & $\begin{array}{l}\text { Required Steps to Tank Closure at } \\
\text { Hanford, ORR, Idaho, and SRS }\end{array}$ & SR-HLO2 & F-Tank Farm \\
\hline TFA-1 & $\begin{array}{l}\text { Required Steps to Tank Closure at } \\
\text { Hanford, ORR, Idaho, and SRS }\end{array}$ & SR-HL03 & Waste Removal Project \\
\hline TFA-1 & $\begin{array}{l}\text { Required Steps to Tank Closure at } \\
\text { Hanford, ORR, Idaho, and SRS }\end{array}$ & SR-HLO4 & ITP/ESP \\
\hline TFA-1 & $\begin{array}{l}\text { Required Steps to Tank Closure at } \\
\text { Hanford, ORR, Idaho, and SRS }\end{array}$ & SR-HL05 & High Level Waste System Upgrades \\
\hline TFA-1 & $\begin{array}{l}\text { Required Steps to Tank Closure at } \\
\text { Hanford, ORR, Idaho, and SRS }\end{array}$ & SR-ER02 & Four Mile Branch \\
\hline & $\sqrt{3+10}-5$ & & Fen syas \\
\hline TFA-2 & $\begin{array}{l}\text { Waste Immobilization and Product } \\
\text { Acceptance Required to Meet DWPF } \\
\text { Schedule, Hanford Phase I and } 2 \\
\text { Privatization, and Idaho Title } 1 \text { Design }\end{array}$ & ID-HLW-103 & HLW Immobilization Facility \\
\hline TFA-2 & $\begin{array}{l}\text { Waste Immobilization and Product } \\
\text { Acceptance Required to Meet DWPF } \\
\text { Schedule, Hanford Phase I and } 2 \\
\text { Privatization, and Idaho Title } 1 \text { Design }\end{array}$ & RL-TW05 & Process Waste Support \\
\hline TFA-2 & $\begin{array}{l}\text { Waste Immobilization and Product } \\
\text { Acceptance Required to Meet DWPF } \\
\text { Schedule, Hanford Phase I and } 2 \\
\text { Privatization, and Idaho Title } 1 \text { Design }\end{array}$ & RL-TW06 & Process Waste Privatization Phase I \\
\hline TFA-2 & $\begin{array}{l}\text { Waste Immobilization and Product } \\
\text { Acceptance Required to Meet DWPF } \\
\text { Schedule, Hanford Phase I and } 2 \\
\text { Privatization, and Idaho Title } 1 \text { Design }\end{array}$ & SR-HLO5 & Vitrification \\
\hline
\end{tabular}


Table A.4. (contd)

\begin{tabular}{|c|c|c|c|}
\hline \multicolumn{4}{|c|}{ Worksheet 4 PBSs Impacted By WP } \\
\hline WP Number & WP Title & PBS ID & PBSTitle \\
\hline TFA-2 & $\begin{array}{l}\text { Waste Immobilization and Product } \\
\text { Acceptance Required to Meet DWPF } \\
\text { Schedule, Hanford Phase I and } 2 \\
\text { Privatization, and Idaho Title } 1 \text { Design }\end{array}$ & RL-TW09 & $\begin{array}{l}\text { Immobilized Tank Waste Storage \& } \\
\text { Disposal Project }\end{array}$ \\
\hline & restentis & & atsict \\
\hline TFA-3 & $\begin{array}{l}\text { Alternative Paths to In-Tank } \\
\text { Precipitation at SRS }\end{array}$ & ID-HLW-101 & High-Level Waste Pretreatment \\
\hline TFA-3 & $\begin{array}{l}\text { Alternative Paths to In-Tank } \\
\text { Precipitation at SRS }\end{array}$ & OR-38112 & $\begin{array}{l}\text { Low Level Waste Storage, } \\
\text { Treatment, Disposal }\end{array}$ \\
\hline TFA-3 & $\begin{array}{l}\text { Alternative Paths to In-Tank } \\
\text { Precipitation at SRS }\end{array}$ & OR-38113 & $\begin{array}{l}\text { Transuranic Waste Storage, } \\
\text { Treatment }\end{array}$ \\
\hline TFA-3 & $\begin{array}{l}\text { Alternative Paths to In-Tank } \\
\text { Precipitation at SRS }\end{array}$ & OR-43201 & $\begin{array}{l}\text { ORNL Melton Valley Watershed } \\
\text { D\&D }\end{array}$ \\
\hline TFA-3 & $\begin{array}{l}\text { Alternative Paths to In-Tank } \\
\text { Precipitation at SRS }\end{array}$ & OR-43203 & $\begin{array}{l}\text { ORNL Bethel Valley Remedial } \\
\text { Action }\end{array}$ \\
\hline TFA-3 & $\begin{array}{l}\text { Alternative Paths to In-Tank } \\
\text { Precipitation at SRS }\end{array}$ & SR-HL04 & ITP/ESP \\
\hline TFA-3 & $\begin{array}{l}\text { Alternative Paths to In-Tank } \\
\text { Precipitation at SRS }\end{array}$ & SR-HL05 & Vitrification \\
\hline & & & \\
\hline TFA-4 & $\begin{array}{l}\text { Slurry Preparation for Feed to HLW } \\
\text { Vitrification at SRS and Hanford and } \\
\text { Radioactive Tank Waste Preparation at } \\
\text { ORR }\end{array}$ & OR-38112 & $\begin{array}{l}\text { Low Level Waste Storage, } \\
\text { Treatment, Disposal }\end{array}$ \\
\hline TFA-4 & $\begin{array}{l}\text { Slurry Preparation for Feed to HLW } \\
\text { Vitrification at SRS and Hanford and } \\
\text { Radioactive Tank Waste Preparation at } \\
\text { ORR }\end{array}$ & OR-38113 & $\begin{array}{l}\text { Transuranic Waste Storage, } \\
\text { Treatment }\end{array}$ \\
\hline TFA-4 & $\begin{array}{l}\text { Slurry Preparation for Feed to HLW } \\
\text { Vitrification at SRS and Hanford and } \\
\text { Radioactive Tank Waste Preparation at } \\
\text { ORR }\end{array}$ & OR-43201 & $\begin{array}{l}\text { ORNL Melton Valley Watershed } \\
\text { D\&D }\end{array}$ \\
\hline TFA-4 & $\begin{array}{l}\text { Slurry Preparation for Feed to HLW } \\
\text { Vitrification at SRS and Hanford and } \\
\text { Radioactive Tank Waste Preparation at } \\
\text { ORR }\end{array}$ & OR-43203 & $\begin{array}{l}\text { ORNL Bethel Valley Remedial } \\
\text { Action }\end{array}$ \\
\hline TFA-4 & $\begin{array}{l}\text { Slurry Preparation for Feed to HLW } \\
\text { Vitrification at SRS and Hanford and } \\
\text { Radioactive Tank Waste Preparation at } \\
\text { ORR }\end{array}$ & RL-TW04 & Retrieval Project \\
\hline TFA-4 & $\begin{array}{l}\text { Slurry Preparation for Feed to HLW } \\
\text { Vitrification at SRS and Hanford and } \\
\text { Radioactive Tank Waste Preparation at } \\
\text { ORR }\end{array}$ & RL-TW05 & Process Waste Support \\
\hline
\end{tabular}


Table A.4. (contd)

\begin{tabular}{|c|c|c|c|}
\hline & Worksheet 4-PBS & simpacted By & $\overline{\mathrm{WP}}$ \\
\hline WP Number & WP Titles Wh & PPBSID \# & PBS Tite \\
\hline TFA-4 & $\begin{array}{l}\text { Slurry Preparation for Feed to HLW } \\
\text { Vitrification at SRS and Hanford and } \\
\text { Radioactive Tank Waste Preparation at } \\
\text { ORR }\end{array}$ & SR-HL01 & H-Tank Farm \\
\hline TFA-4 & $\begin{array}{l}\text { Slurry Preparation for Feed to HLW } \\
\text { Vitrification at SRS and Hanford and } \\
\text { Radioactive Tank Waste Preparation at } \\
\text { ORR }\end{array}$ & SR-HL02 & F-Tank Farm \\
\hline TFA-4 & $\begin{array}{l}\text { Slurry Preparation for Feed to HLW } \\
\text { Vitrification at SRS and Hanford and } \\
\text { Radioactive Tank Waste Preparation at } \\
\text { ORR }\end{array}$ & SR-HL04 & ITP/ESP \\
\hline TFA-4 & $\begin{array}{l}\text { Slurry Preparation for Feed to HLW } \\
\text { Vitrification at SRS and Hanford and } \\
\text { Radioactive Tank Waste Preparation at } \\
\text { ORR }\end{array}$ & SR-SW01 & Consolidated Incineration Facility \\
\hline & 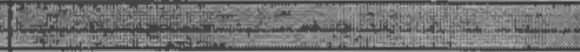 & & \\
\hline TFA-5 & Hanford Tanks Initiative & RL-TW04 & Retrieval Project \\
\hline & & & \\
\hline TFA-6 & $\begin{array}{l}\text { Pretreatment to Reduce Volume of } \\
\text { HLW and LLW Waste Forms at SRS, } \\
\text { Idaho, Hanford and Oak Ridge }\end{array}$ & ID-HLW-101 & High-Level Waste Pretreatment \\
\hline TFA-6 & $\begin{array}{l}\text { Pretreatment to Reduce Volume of } \\
\text { HLW and LLW Waste Forms at SRS, } \\
\text { Idaho, Hanford and Oak Ridge }\end{array}$ & ID-HLW-103 & HLW Treatment and Storage \\
\hline TFA-6 & $\begin{array}{l}\text { Pretreatment to Reduce Volume of } \\
\text { HLW and LLW Waste Forms at SRS, } \\
\text { Idaho, Hanford and Oak Ridge }\end{array}$ & OR-38112 & $\begin{array}{l}\text { Low Level Waste Storage, } \\
\text { Treatment, Disposal }\end{array}$ \\
\hline TFA-6 & $\begin{array}{l}\text { Pretreatment to Reduce Volume of } \\
\text { HLW and LLW Waste Forms at SRS, } \\
\text { Idaho, Hanford and Oak Ridge }\end{array}$ & OR-38113 & $\begin{array}{l}\text { Transuranic Waste Storage, } \\
\text { Treatment }\end{array}$ \\
\hline TFA-6 & $\begin{array}{l}\text { Pretreatment to Reduce Volume of } \\
\text { HLW and LLW Waste Forms at SRS, } \\
\text { Idaho, Hanford and Oak Ridge }\end{array}$ & OR-43201 & $\begin{array}{l}\text { ORNL Melton Valley Watershed } \\
\text { D\&D }\end{array}$ \\
\hline TFA-6 & $\begin{array}{l}\text { Pretreatment to Reduce Volume of } \\
\text { HLW and LLW Waste Forms at SRS, } \\
\text { Idaho, Hanford and Oak Ridge }\end{array}$ & OR-43203 & $\begin{array}{l}\text { ORNL Bethel Valley Remedial } \\
\text { Action }\end{array}$ \\
\hline TFA-6 & $\begin{array}{l}\text { Pretreatment to Reduce Volume of } \\
\text { HLW and LLW Waste Forms at SRS, } \\
\text { Idaho, Hanford and Oak Ridge }\end{array}$ & RL-TW05 & Process Waste Support \\
\hline TFA-6 & $\begin{array}{l}\text { Pretreatment to Reduce Volume of } \\
\text { HLW and LLW Waste Forms at SRS, } \\
\text { Idaho, Hanford and Oak Ridge }\end{array}$ & RL-TW06 & Process Waste Privatization Phase I \\
\hline
\end{tabular}


Table A.4. (contd)

\begin{tabular}{|c|c|c|c|}
\hline & Worksheet 4-PBS & Impacted By & $\overline{\mathrm{WP}}$ \\
\hline WP Number & D Sel WP Tite & PBSID \# & PBS Tite \\
\hline TFA-6 & $\begin{array}{l}\text { Pretreatment to Reduce Volume of } \\
\text { HLW and LLW Waste Forms at SRS, } \\
\text { Idaho, Hanford and Oak Ridge }\end{array}$ & RL-TW07 & Process Waste Privatization Phase II \\
\hline TFA-6 & $\begin{array}{l}\text { Pretreatment to Reduce Volume of } \\
\text { HLW and LLW Waste Forms at SRS, } \\
\text { Idaho, Hanford and Oak Ridge }\end{array}$ & SR-HL01 & H-Tank Farm \\
\hline TFA-6 & $\begin{array}{l}\text { Pretreatment to Reduce Volume of } \\
\text { HLW and LLW Waste Forms at SRS, } \\
\text { Idaho, Hanford and Oak Ridge }\end{array}$ & SR-HL02 & F-Tank Farm \\
\hline TFA-6 & $\begin{array}{l}\text { Pretreatment to Reduce Volume of } \\
\text { HLW and LLW Waste Forms at SRS, } \\
\text { Idaho, Hanford and Oak Ridge }\end{array}$ & SR-HL04 & ITP/ESP \\
\hline TFA-6 & $\begin{array}{l}\text { Pretreatment to Reduce Volume of } \\
\text { HLW and LLW Waste Forms at SRS, } \\
\text { Idaho, Hanford and Oak Ridge }\end{array}$ & SR-HL04 & Saltstone \\
\hline & & & \\
\hline TFA-7 & $\begin{array}{l}\text { Immobilization Process for Idaho } \\
\text { Supporting Title } 1 \text { Design; } \\
\text { Immobilization Evaluation for ORR } \\
\text { Privatization and Hanford Capsules }\end{array}$ & ID-HLW-103 & HLW Immobilization Facility \\
\hline TFA-7 & $\begin{array}{l}\text { Immobilization Process for Idaho } \\
\text { Supporting Title } 1 \text { Design; } \\
\text { Immobilization Evaluation for ORR } \\
\text { Privatization and Hanford Capsules }\end{array}$ & ID-HLW-103 & HLW Treatment and Storage \\
\hline TFA-7 & $\begin{array}{l}\text { Immobilization Process for Idaho } \\
\text { Supporting Title 1 Design; } \\
\text { Immobilization Evaluation for ORR } \\
\text { Privatization and Hanford Capsules }\end{array}$ & OR-38112 & $\begin{array}{l}\text { Low Level Waste Storage, } \\
\text { Treatment, Disposal }\end{array}$ \\
\hline TFA-7 & $\begin{array}{l}\text { Immobilization Process for Idaho } \\
\text { Supporting Title 1 Design; } \\
\text { Immobilization Evaluation for ORR } \\
\text { Privatization and Hanford Capsules }\end{array}$ & OR-38113 & $\begin{array}{l}\text { Transuranic Waste Storage, } \\
\text { Treatment }\end{array}$ \\
\hline TFA-7 & $\begin{array}{l}\text { Immobilization Process for Idaho } \\
\text { Supporting Title 1 Design; } \\
\text { Immobilization Evaluation for ORR } \\
\text { Privatization and Hanford Capsules }\end{array}$ & OR-43201 & $\begin{array}{l}\text { ORNL Melton Valley Watershed } \\
\text { D\&D }\end{array}$ \\
\hline TFA-7 & $\begin{array}{l}\text { Immobilization Process for Idaho } \\
\text { Supporting Title 1 Design; } \\
\text { Immobilization Evaluation for ORR } \\
\text { Privatization and Hanford Capsules }\end{array}$ & OR-43203 & $\begin{array}{l}\text { ORNL Bethel Valley Remedial } \\
\text { Action }\end{array}$ \\
\hline
\end{tabular}


Table A.4. (contd)

\begin{tabular}{|c|c|c|c|}
\hline \multicolumn{4}{|c|}{ Worksheet 4-PBSSi Impacted By WP } \\
\hline WP Number & WP Title & PBSID \# & PBS Title \\
\hline TFA-7 & $\begin{array}{l}\text { Immobilization Process for Idaho } \\
\text { Supporting Title 1 Design; } \\
\text { Immobilization Evaluation for ORR } \\
\text { Privatization and Hanford Capsules }\end{array}$ & RL-TW04 & Retrieval Project \\
\hline TFA-7 & $\begin{array}{l}\text { Immobilization Process for Idaho } \\
\text { Supporting Title } 1 \text { Design; } \\
\text { Immobilization Evaluation for ORR } \\
\text { Privatization and Hanford Capsules }\end{array}$ & RL-TW09 & $\begin{array}{l}\text { Immobilized Tank Waste Storage \& } \\
\text { Disposal Project }\end{array}$ \\
\hline
\end{tabular}


Table A.5. WS 5 - Technologies Supported by Work Package

\begin{tabular}{|c|c|c|c|c|}
\hline & Worksheet 5 - Tec & Inologies supported B & 5XMP & \\
\hline & & & OST Tech & \\
\hline WP Number & WP Tifle & Ops/Field Office & $\mathrm{ID} \pi$ & OST Tech Name \\
\hline TFA-1 & $\begin{array}{l}\text { Required Steps to Tank Closure at } \\
\text { Hanford, ORR, Idaho, and SRS }\end{array}$ & ORR & 22 & $\begin{array}{l}\text { In-Tank Grouting/Tank } \\
\text { Closure }\end{array}$ \\
\hline TFA-1 & $\begin{array}{l}\text { Required Steps to Tank Closure at } \\
\text { Hanford, ORR, Idaho, and SRS }\end{array}$ & Hanford, ORR, SRS & 1985 & Corrosion Probe \\
\hline TFA-1 & $\begin{array}{l}\text { Required Steps to Tank Closure at } \\
\text { Hanford, ORR, Idaho, and SRS }\end{array}$ & ORR, SRS, Hanford & 1996 & $\begin{array}{l}\text { Non-Destructive Examination } \\
\text { End-Effector }\end{array}$ \\
\hline TFA-1 & $\begin{array}{l}\text { Required Steps to Tank Closure at } \\
\text { Hanford, ORR, Idaho, and SRS }\end{array}$ & ORR & 1499 & Borehole Miner \\
\hline TFA-1 & $\begin{array}{l}\text { Required Steps to Tank Closure at } \\
\text { Hanford, ORR, Idaho, and SRS }\end{array}$ & Idaho, ORR & 85 & Light Duty Utility Arm \\
\hline TFA-1 & $\begin{array}{l}\text { Required Steps to Tank Closure at } \\
\text { Hanford, ORR, Idaho, and SRS }\end{array}$ & Idaho, ORR & 810 & $\begin{array}{l}\text { LDUA - Supervisory Data } \\
\text { Acquisition and Supervisory } \\
\text { Control System }\end{array}$ \\
\hline TFA-1 & $\begin{array}{l}\text { Required Steps to Tank Closure at } \\
\text { Hanford, ORR, Idaho, and SRS }\end{array}$ & ORR & 812 & $\begin{array}{l}\text { Confined Sluicing End } \\
\text { Effector }\end{array}$ \\
\hline TFA-1 & $\begin{array}{l}\text { Required Steps to Tank Closure at } \\
\text { Hanford, ORR, Idaho, and SRS }\end{array}$ & Idaho, SRS & 2091 & $\begin{array}{l}\text { Metal Filters for Waste Tank } \\
\text { Ventilation }\end{array}$ \\
\hline TFA-1 & $\begin{array}{l}\text { Required Steps to Tank Closure at } \\
\text { Hanford, ORR, Idaho, and SRS }\end{array}$ & ORR & 2093 & GAAT Tank Isolation \\
\hline TFA-1 & $\begin{array}{l}\text { Required Steps to Tank Closure at } \\
\text { Hanford, ORR, Idaho, and SRS }\end{array}$ & SRS, Hanford & 2097 & Heel Retrieval for SRS \\
\hline TFA-1 & $\begin{array}{l}\text { Required Steps to Tank Closure at } \\
\text { Hanford, ORR, Idaho, and SRS }\end{array}$ & Hanford, SRS & 1510 & Pulsed Air \\
\hline TFA-1 & $\begin{array}{l}\text { Required Steps to Tank Closure at } \\
\text { Hanford, ORR, Idaho, and SRS }\end{array}$ & SRS & 1989 & $\begin{array}{l}\text { Salt Dissolution/Density } \\
\text { Gradient }\end{array}$ \\
\hline TFA-1 & $\begin{array}{l}\text { Required Steps to Tank Closure at } \\
\text { Hanford, ORR, Idaho, and SRS }\end{array}$ & Idaho, ORR & 890 & $\begin{array}{l}\text { LDUA Stereo Viewing } \\
\text { System }\end{array}$ \\
\hline TFA-1 & $\begin{array}{l}\text { Required Steps to Tank Closure at } \\
\text { Hanford, ORR, Idaho, and SRS }\end{array}$ & ORR & 1511 & AEA Fluidic Pulse Jet Mixer \\
\hline TFA-1 & $\begin{array}{l}\text { Required Steps to Tank Closure at } \\
\text { Hanford, ORR, Idaho, and SRS }\end{array}$ & SRS & 2007 & AEA Fluidic Sampler \\
\hline$x$ & 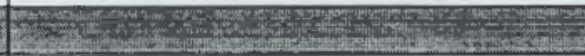 & & & 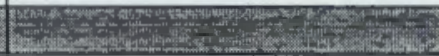 \\
\hline TFA-2 & $\begin{array}{l}\text { Waste Immobilization and Product } \\
\text { Acceptance Required to Meet DWPF } \\
\text { Schedule, Hanford Phase I and } 2 \\
\text { Privatization, and Idaho Title } 1 \text { Design }\end{array}$ & Idaho, Hanford, SRS & 2009 & $\begin{array}{l}\text { High Activity Waste Forms } \\
\text { and Processes }\end{array}$ \\
\hline TFA-2 & $\begin{array}{l}\text { Waste Immobilization and Product } \\
\text { Acceptance Required to Meet DWPF } \\
\text { Schedule, Hanford Phase I and } 2 \\
\text { Privatization, and Idaho Title } 1 \text { Design }\end{array}$ & SRS & 2092 & $\begin{array}{l}\text { DWPF Melter Pouring } \\
\text { Enhancements }\end{array}$ \\
\hline TFA-2 & $\begin{array}{l}\text { Waste Immobilization and Product } \\
\text { Acceptance Required to Meet DWPF } \\
\text { Schedule, Hanford Phase I and } 2 \\
\text { Privatization, and Idaho Title } 1 \text { Design }\end{array}$ & Hanford & 2094 & Product Acceptance Testing \\
\hline
\end{tabular}


Table A.5. (contd)

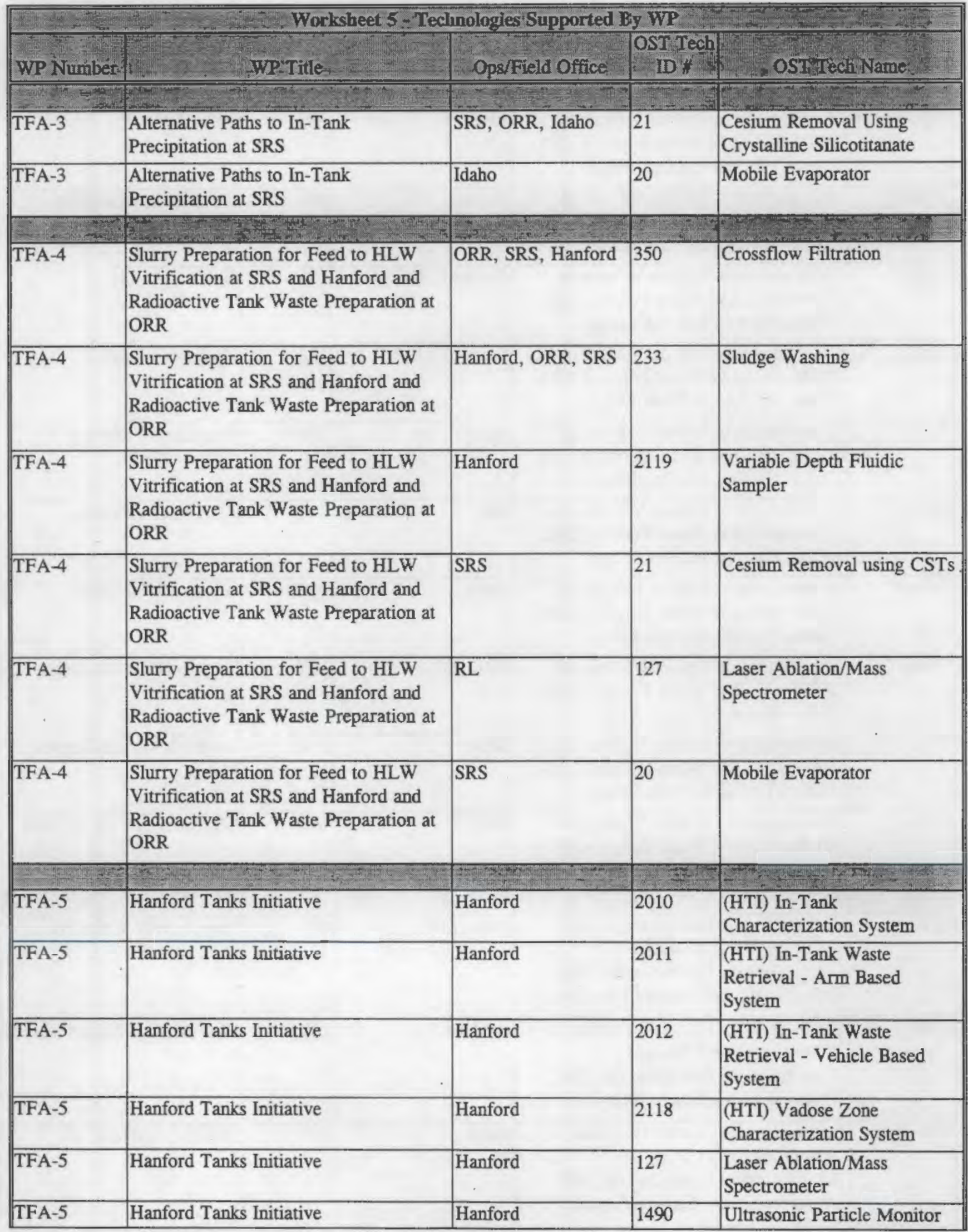


Table A.5. (contd)

\begin{tabular}{|c|c|c|c|c|}
\hline \multicolumn{5}{|c|}{ Worksheet 5-Teclinologies Supported By WP } \\
\hline WP Number & WP Tite & Ops/Field Office & $\begin{array}{c}\text { OST Tech } \\
\text { ID \# }\end{array}$ & OST Tech Name \\
\hline 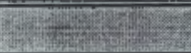 & 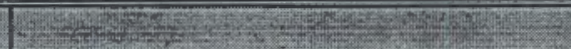 & $=x^{\prime}=$ & 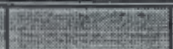 & \\
\hline TFA-6 & $\begin{array}{l}\text { Pretreatment to Reduce Volume of } \\
\text { HLW and LLW Waste Forms at SRS, } \\
\text { Idaho, Hanford and Oak Ridge }\end{array}$ & Idaho & 347 & TRUEX/SREX \\
\hline TFA-6 & $\begin{array}{l}\text { Pretreatment to Reduce Volume of } \\
\text { HLW and LLW Waste Forms at SRS, } \\
\text { Idaho, Hanford and Oak Ridge }\end{array}$ & Idaho & 881 & Calcination/Dissolution \\
\hline TFA-6 & $\begin{array}{l}\text { Pretreatment to Reduce Volume of } \\
\text { HLW and LLW Waste Forms at SRS, } \\
\text { Idaho, Hanford and Oak Ridge }\end{array}$ & Hanford, SRS & 885 & Caustic Recycle \\
\hline TFA-6 & $\begin{array}{l}\text { Pretreatment to Reduce Volume of } \\
\text { HLW and LLW Waste Forms at SRS, } \\
\text { Idaho, Hanford and Oak Ridge }\end{array}$ & Hanford, ORR & 233 & Sludge Washing \\
\hline TFA-6 & $\begin{array}{l}\text { Pretreatment to Reduce Volume of } \\
\text { HLW and LLW Waste Forms at SRS, } \\
\text { Idaho, Hanford and Oak Ridge }\end{array}$ & Idaho & 2096 & $\begin{array}{l}\text { Pretreatment Process } \\
\text { Analysis Tool }\end{array}$ \\
\hline TFA-6 & $\begin{array}{l}\text { Pretreatment to Reduce Volume of } \\
\text { HLW and LLW Waste Forms at SRS, } \\
\text { Idaho, Hanford and Oak Ridge }\end{array}$ & SRS & 2007 & AEA Fluidic Sampler \\
\hline TFA-6 & $\begin{array}{l}\text { Pretreatment to Reduce Volume of } \\
\text { HLW and LLW Waste Forms at SRS, } \\
\text { Idaho, Hanford and Oak Ridge }\end{array}$ & Idaho & 2095 & Advanced Calcination \\
\hline TFA-6 & $\begin{array}{l}\text { Pretreatment to Reduce Volume of } \\
\text { HLW and LLW Waste Forms at SRS, } \\
\text { Idaho, Hanford and Oak Ridge }\end{array}$ & ORR, SRS & 130 & $\begin{array}{l}\text { Topographical Mapping } \\
\text { System }\end{array}$ \\
\hline TFA- 6 & $\begin{array}{l}\text { Pretreatment to Reduce Volume of } \\
\text { HLW and LLW Waste Forms at SRS, } \\
\text { Idaho, Hanford and Oak Ridge }\end{array}$ & SRS & 2090 & $\begin{array}{l}\text { DWPF Level and Density } \\
\text { Meters }\end{array}$ \\
\hline TFA- 6 & $\begin{array}{l}\text { Pretreatment to Reduce Volume of } \\
\text { HLW and LLW Waste Forms at SRS, } \\
\text { Idaho, Hanford and Oak Ridge }\end{array}$ & SRS & 1490 & Ultrasonic Particle Monitor \\
\hline 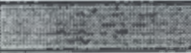 & 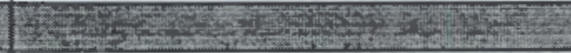 & & & \\
\hline TFA-7 & $\begin{array}{l}\text { Immobilization Process for Idaho } \\
\text { Supporting Title } 1 \text { Design; } \\
\text { Immobilization Evaluation for ORR } \\
\text { Privatization and Hanford Capsules }\end{array}$ & Idaho, ORR & 82 & Low Activity Waste Forms \\
\hline TFA-7 & $\begin{array}{l}\text { Immobilization Process for Idaho } \\
\text { Supporting Title } 1 \text { Design; } \\
\text { Immobilization Evaluation for ORR } \\
\text { Privatization and Hanford Capsules }\end{array}$ & Hanford & 2009 & High Activity Waste Forms \\
\hline TFA-7 & $\begin{array}{l}\text { Immobilization Process for Idaho } \\
\text { Supporting Title 1 Design; } \\
\text { Immobilization Evaluation for ORR } \\
\text { Privatization and Hanford Capsules }\end{array}$ & Idaho & 20 & Mobile Evaporator \\
\hline
\end{tabular}




\section{Appendix B - Prioritization Process}

Each fiscal year, the Tanks Focus Area (TFA) reviews its prioritization process and amends it according to any changes in programmatic requirements, such as changes in strategic and tactical approaches. Amendments to the prioritization process must be approved by the TFA's user community. Therefore, this appendix describes the process used im FY98. Modifications of this process may occur as the TFA works with its users to execute the program development activities scheduled in FY99.

\section{B.1 Program Development Process}

The TFA's prioritization process is but one component of the overall program development process. The entire program development process will be summarized here to provide a more comprehensive understanding of the prioritization process in a user-driven technology development program. The program development steps include (see Figure B.1)

- Site Technology Coordinating Group (STCG) Needs Submission and TFA Screen

- Needs Analysis

- Technology Gap Identification

- Technical Response Development

- Response Rating

- TFA Management Team Prioritization.

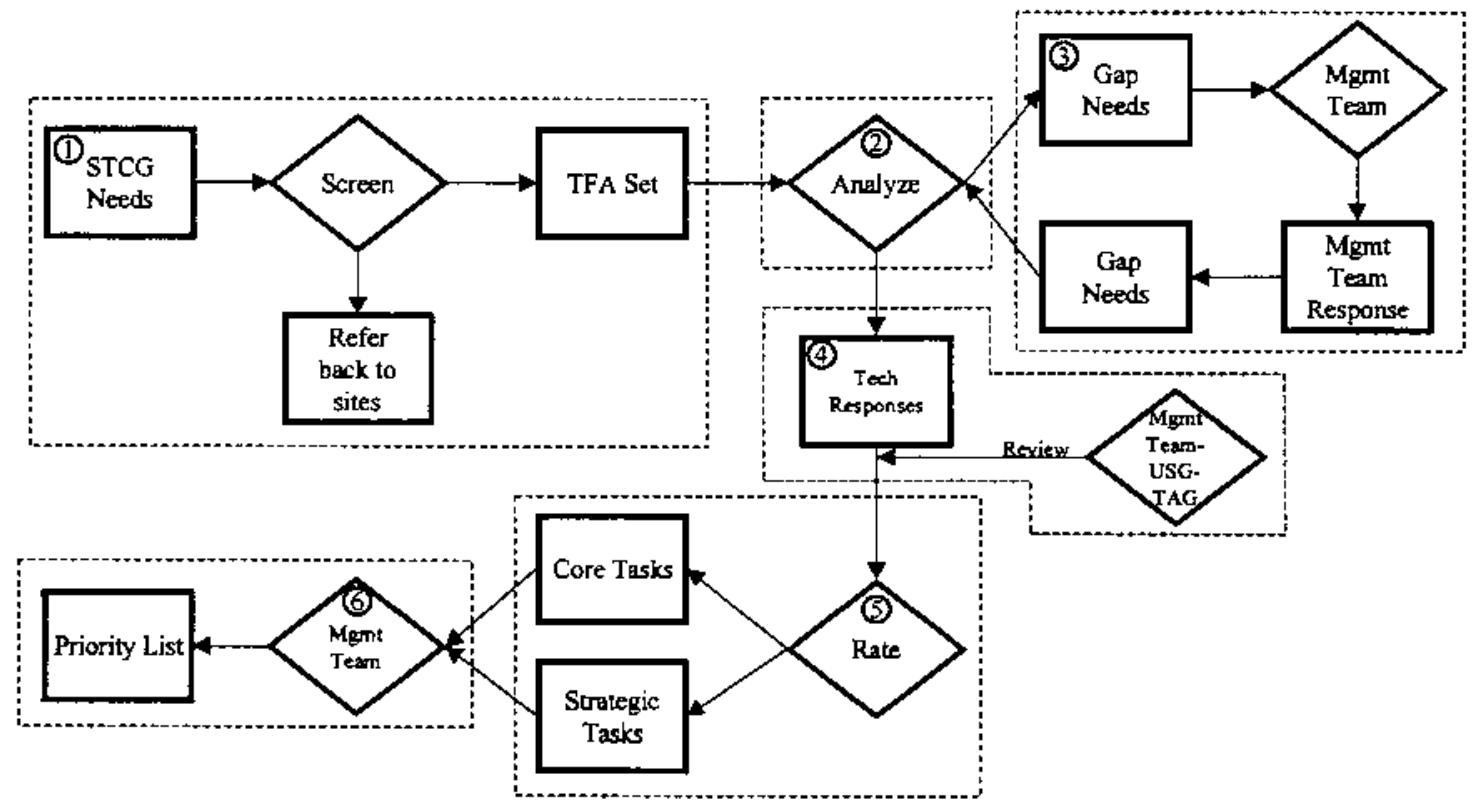

Figure B.1. Tanks Focus Area Technical Response Development Process 


\section{B.1.1 Needs Submission and TFA Screen}

Sites customarily submit their site needs during the end of the first quarter or beginning of the second quarter in the fiscal year. For FY99, the TFA requested site submittal of the needs to occur early in the first quarter of the fiscal year. Earlier needs submission will permit the TFA to construct and prioritize a comprehensive program, tightly bound to other U.S. Department of Energy (DOE) Office of Science and Technology (EM-50) resources. After needs submittal, the TFA screens the needs for relevance to the TFA program. The screening criteria identify site needs that fall outside of the TFA mission area, needs without a technology development component, or the unfeasibility of developing technical solutions within the time frame needed. The screening criteria are

a) Technology Development Component - The need must require technology development, first-time hot demonstration, or reengineering. Also, some needs may be satisfied through the use of technology already developed or may be candidates for resolution through the Technology Deployment Initiative (TDI). The TFA will not respond to needs that do not have a technology development requirement.

b) Technical Feasihility - Some needs may require a technical solution sooner than one can be developed by the TFA or may require investigation through the Environmental Management Science Program.

c) Consistent with TFA Goals - The TFA's goals include

- Provide systems or technologies necessary to support the closure of 16 radioactive waste storage tanks, including two tanks at each site by 2006 .

- Support tank farm closure activities by developing and deploying screening and sampling tools for residual tank waste and leaked waste inventory assessments.

- Provide data deliverables, performance specifications, and hardware supporting deployment of a heel retrieval system for single-shell tanks and a salt dissolution retrieval systen by 2001 ; improve baseline retrieval equipnent.

- Develop data and technologies to further the DOE's ability to oversee and monitor privatization of designated tank waste remediation functions.

- Develop and deploy by 2001 sensors to monitor 1) tank corrosion and support tank life extension requirements, 2) waste processing, 3) waste transfer and retrieval, and 4) waste and immobilized waste storage.

- Develop and deploy technologies to reduce the volumes, including water balancing techniques, of both high- and low-activity tank wastes.

- Improve waste loading for high-level vitrified waste at Savannah River Site (SRS) (up to $2 \%$ ) and Hanford by 2001 ; better understand melter glass chemistry.

- Develop a technical basis for immobilized waste product performance at Idaho National Engineering and Environmental Laboratory (INEEL) and Hanford by 2001.

- Develop and demonstrate lower cost solutions to support waste processing needs, such as low-cost mixers. 
- Identify issues and develop solutions to waste remediation technical voids that may exist between the imterfaces of retrieval, pretreatment, and immobilization processes, and the closure function and final waste state.

The TFA develops technical responses to all needs passing through the screening criteria. Those needs screened out are returned to the submitting site for further disposition. ${ }^{1}$

\section{B.1.2 Needs Analysis}

The TFA analyzes needs passing through the screening criteria. The analyses serve to familiarize the TFA with the general scope of site needs. The TFA works interactively with the sites to understand the problems to be solved, required performance specifications, tining of the technical solution, and integration of functional interfaces (e.g., between pretreatment and immobilization).

\section{B.1.3 Strategic Task Identification}

Focusing predominately on the analysis of site-submitted needs, the TFA identifies needs whose solutions may be strategic in nature to the TFA, as the TFA supports development of technical responses for both near-term and strategic purposes. Additionally, the TFA identifies any technology gaps that become apparent out of the needs analyses or that have been identified through other TFA processes, such as technology interface workshops. The TFA subnits for review to its Management Team a listing of potential strategic tasks and technology gaps. "Acceptance" of technology gap needs or strategic tasks by the TFA Management Team allows technical responses to be prepared for these needs, i.e., the TFA Management Team has no objection to the gap need being included within the TFA list of needs.

The following points define a TFA strategic task:

- Within a baseline, but not being addressed now. This need is longer term, not a multiple deployınent of existing technologies, and nay otherwise go unsatisfied due to budget limitations. The need may or may not have been submitted by a site. Successful response to the need may result in

- Accelerated schedule

- Risk reduction

- Establishment of a basis that drives near-term, related efforts.

- Critical issue not considered now. This need may be near or long term in nature and may or may not represent a baseline technology. This need may likely be identified by the TFA, rather than submitted by a site. Satisfaction of this need may result in

- Prevention of previously unforeseen problems

- Insurance

- Risk reduction.

I The TFA flags site needs potentially outside of the TFA mission area Technical responses that may be best initiaced within another EM-50 progran, such as another focus area or crosscutting program, will be identified for possibie Management Team action. The TFA formally interacts on these cases with the other programs and informs the submitting sile Site Technology Coordinating Group of any need identified as such in this process. 
- Effecting change to a baseline (alternative). The need could be near term and may require that the TFA leverage other programs. The need may or may not have been submitted by a site. Successful response to the need may result in

- Mortgage reduction

- Risk reduction.

\section{B.1.4 Technical Response Development}

The TFA prepares recommended technical responses for the needs. The responses are prepared by the Technical Team and submitted to the Technical Advisory Group (TAG), User Steering Group (USG), and TFA Management Team for review, comment, and adjustment. The responses for strategic tasks are very specific on incremental objectives and go/no-go decision points.

\section{B.1.5 Response Rating}

Final version technical responses are rated for use in funding decisions based on the task selection criteria (see Section B.2). Technical responses that rate above the anticipated funding line are known as "core" tasks. Selected technical responses falling below the funding line may be considered for TFA funding if they were previously identified as a strategic task. These strategic tasks are highlighted for Management Team review and prioritization with rationale describing the benefits of investments relative to the TFA's strategic intent.

\section{B.1.6 TFA Management Team Prioritization}

The TFA Management Team reviews, adjusts as necessary, and approves the task priority listing. The review ensures TFA-wide consensus on funding priorities, task acceptability, site user commitment, and initial performer selection bases as appropriate. Additionally, the TFA Management Team approves the inclusion of any strategic investments generated during the program development process. The importance of the deployment time frame (near or longer term) may be used by the Management Team to further differentiate tasks with identical ratings and at the core or strategic funding line.

The TFA rescores those tasks identified as strategic and that lie below the "core" funding line using a separate criteria weighting scheme that compensates for strategic tasks. The TFA's intention is to invest in the highest rated strategic tasks below the core funding line. In the prioritization of strategic tasks, the following "rules" apply.

- Tasks above the funding line, whether identified as strategic or not, retain their funding priority over any strategic task below the core funding line that has been selected for strategic funding.

- The TFA establishes a fixed percentage of the program to be dedicated to strategic tasks ( $3 \%$ for FY99, 10\% for FY00, and 20\% for FY01). At the conclusion of the prioritization process, strategic funding will be applied first to the highest rated strategic task below the 
core funding line, then down until strategic funding is exhausted. If there is insufficient funding for the last strategic task within the strategic funding zone, the Management Team may elect to fully fund the strategic task immediately before it and shift the remaining strategic funds to the core tasks.

Given no change in prioritization ratings, future funding reductions may be first taken from the lowest-rated funded strategic task. However, should funding reductions be severe enough to threaten elimination of all strategic tasks, the TFA may elect to absorb reductions proportionally among strategic and non-strategic tasks.

\section{B.2 Prioritization Criteria}

The TFA uses four prioritization criteria. They are summarized below.

a) Broad-Based Benefit - This criterion addresses the potential complex-wide benefit of a technical response. Weighting: Core Rating $=20 \%$; Strategic Rating $=30 \%$.

- 100 points. Two or more different site STCG-submitted needs with strong interest with a single, integrated response. Note: "Strong interest" means site interest is confirmed with the TFA Site Representative and USG member.

- 75 to 45 points:

- 75 points. One STCG-submitted need; two or more sites with strong interest where resulting hardware or data would directly benefit.

- 60 points. One STCG-submitted need; one site with strong interest where resulting hardware or data would directly benefit.

- 45 points. One STCG-submitted need; one site with strong interest where resulting hardware or data would indirectly benefit.

- 40 points. One STCG-submitted need that may be satisfied through deployment of a technology already deployed elsewhere, but still requiring technology development work.

- 25 points. One STCG-submitted need and one other potential benefiting site based on Technology Integration Manager (TIM) judgment.

- I point. One STCG-submitted need; site-specific.

b) User Commitment - The TFA values user commitment to the development and deployment of technical solutions. This criterion assesses the strength of the user commitment to share the burden of a technology's development and deployment. Weighting: Core Rating $=45 \%$; Strategic Rating $=20 \%$.

- 100 points.

- Site co-funds development and demonstration (or deployment).

- High commitment to deploy through out-year baseline, Program Baseline Summary (PBS), and budget request; memorandum of understanding (MOU) or other signed document for out-year deployment.

- Is in site baseline operational plan with MOU or other signed document committing to funding and plan for deployment in "subject" fiscal year. 
- Deployment within 1 to 2 years.

- Greater than or equal to 50/50 co-funding of development and demonstration for the year of prioritization and duration of the response.

- 90 points. Response results in data delivery for key DOE decisions, e.g., environmental impact statement or privatization decisions.

- Site co-funds data development and delivery.

- Data will be used within 1 to 2 years.

- High commitment to deploy through out-year baseline, PBS, and budget requist; MOU or other signed document for out-year deployment.

- Greater than or equal to 50/50 co-funding of development and delivery for the year of prioritization and duration of the response.

- 75 points. Approximately 50/50 co-funding to develop and demonstrate during time of the response. High commitment to deploy through out-year baseline, PBS, and budget request; TFA Site Representative commitment to obtain MOU or other signed document for out-year deployment or use of data.

- 50 points. Less than $10 \%$ co-funding; high commitment to deploy through out-year baseline, PBS, and budget request; TFA Site Representative commitment to obtain MOU or other signed document for out-year deployment or use of data.

- 25 points. Some co-funding (large percentage or small), but with no commitment to deploy or use data (not in out-year plan).

- 1 point. Little or no indication of site co-funding or commitment to deploy.

Note on Co-funding: Co-funding needs to be focused on support to the overall project TFA is funding. Co-funding may include direct support to principal investigator (PI), support to on-site operations staff to facilitate testing, sample collection/analysis/ shipping, design, and review. Example: Oak Ridge Reservation (ORR) Gunite and Associated Tanks cold testing support; SRS Tank 20 closure (application of TF A-funded grout test work).

c) PBS Risk - This criterion ties the technical response to the need, then to the PBS(s) the sites named for each need. Sites assigned risk factors ${ }^{2}$ to each PBS. The TFA rated the technical responses relevant to the assigned PBSs. Only two risk factor categories are possible, urgent or high. Weighting: Core Rating $=10 \%$.

- 100 points. The need is directly connected to a site PBS identified with urgent risk factors in the Path to Closure document.

- 50 points. The need is directly connected to a site PBS identified with high risk factors in the Path to Closure document.

- 0 points. The need has neither urgent nor high risk factors.

\footnotetext{
${ }^{2}$ Risk factors - rated by siles in constructing their PBSs. The DOE identified three risk factors; public safety and health, worker safety and health, and environmental health. The degree of jisk assigned to each depends on the probability that an cvent (i.e., exposure) occurs within a year leading to adverse impacts, or the proximity in time until the event (i.e., exposure) leading to adverse imparts is expected to occur. Urgent is the highest risk factor.
} 
d) Other Technology Impact - The objective of this criterion is to broadly assess the overall potential technology impact of a technical response. The TFA considers a response's impact on schedule, cost avoidance, and link to regulatory requirements to determine the impact. Weighting: Core Rating $=25 \%$.

- 100 points. The need meets one or more of the following criterion

- Technology required to meet the baseline assumption in the Path to Closure document.

- Documented high cost avoidance (over $\$ 250 \mathrm{M}$ ) to DOE's Office of Environmental Management (EM) (information must be provided to TFA by site with uncertainty analysis).

- Possesses high cost reduction potential (over $\$ 250 \mathrm{M}$ ).

- Technical response is required to meet firm regulatory requirements that could delay tank waste remediation schedules.

- 50 points. The need meets one or more of the following criterion:

- Technology required to meet enhancements or alternatives to baseline in the Path to Closure document.

- Documented moderate cost avoidance (between $\$ 250 \mathrm{M}$ and $\$ 50 \mathrm{M}$ ) to EM or general consensus on high cost avoidance (over $\$ 250 \mathrm{M}$ ) that cannot be documented due to lack of data, which will be developed if the task goes forward.

- Possesses moderate cost reduction potential.

- Technical response adds assurance that regulatory requirements are met or supports a regulatory requirement that the site may renegotiate.

- 1 point. The need meets one or more of the following criterion:

- Appears that technology could meet baseline or enhancement assumptions, but more information is needed, and will be provided explicitly if the task proceeds.

- General consensus that moderate cost avoidance (between $\$ 250 \mathrm{M}$ and $\$ 50 \mathrm{M}$ ) could be achieved, but cannot yet be documented.

- The technical response's link to regulatory requirements is not fully determined.

\section{B.3 Present Program Prioritization}

The prioritization process serves at least three purposes for the TFA. First, it fine-tunes the program scheduled for execution in the upcoming fiscal year. Second, it forms the basis for development of the Internal Review Budget (IRB) supporting the following year. Third, it adds shape to the program in the 3 years following the IRB year. The TFA's Integrated Priority Listing for FY99 appears in Appendix C. Section B.4 of this appendix describes the composition of the TFA program for the present IRB year, FY00.

\section{B.4 TFA Work Packages}

The TFA constructs its program around problem elements, which are used to create a functional rather than a fiscal programmatic structure. Preparing the program for fiscal purposes requires grouping similar work scopes into defendable work packages. Work package contents change from year to year, depending on users' needs submitted and the 
prioritization of potential tasks by the TFA's Management Team. For the FY00 program, the TFA developed 10 work packages to support users' needs. As a result of the OST prioritization process, funding was available to support seven work packages. These seven work packages are briefly explained below.

Work Package \#1, Technology Development to Support Tank Closure. Because the baseline plans for Hanford and SRS extend well past the year 2000, one of the top concerns at these sites is maintaining and ensuring tank integrity, as these tanks will be used for storage for up to 30 more years to meet Accelerated Cleanup goals. Tied closely with tank integrity needs is retrieval. All of the baseline plans call for bulk waste retrieval before closure; this means all four major tank sites must inspect tanks before initiating waste retrieval operations. For Hanford and SRS, sludge and saltcake retrieval must be performed at a rate that supports waste processing. Once the waste has been retrieved from ORR's GAATs, the next pressing need is to close tanks to meet CERCLA requirements.

This work package implements the following:

- Saltcake dissolution and retrieval techniques leading to tank closure for SRS and Hanford tanks.

- Sludge heel retrieval leading to closure of SRS tanks.

- Retrieval techniques for hard-to-access tanks at ORR (Federal Facility Agreement tanks) and SRS (solvent extraction tanks).

- Techniques for isolating, stabilizing, and closing GAATs at ORR.

- Technologies for maintaining safe storage conditions by monitoring corrosion in tanks at Hanford and SRS.

- Tank inspection to ensure tank integrity before waste retrieval and tank closure at INEEL, ORR, Hanford, and SRS.

This work package was rated 10 of 42 work packages by OST.

Work Package \#2, HLW Immobilization and Product Acceptance. Hanford, SRS, and INEEL all require baseline treatment process development and improvement to meet schedule requirements. Hanford must prepare for and deliver feed for privatization phase I, accept immobilized product from the private vendor, and develop the baseline data to support the phase II procurement package. SRS must maintain Defense Waste Processing Facility (DWPF) operations and improve throughput to meet canister production requirements. INEEL must continue baseline flowsheet development and testing to meet their Title 1 design schedule. This wotk package provides technology, data, and assistance to SRS, Hanford, and INEEL to enable baseline schedules to be met. This work package was rated 19 of 42 work packages by OST.

Work Package \#3, Alternative Paths to Salt Waste Treatment at SRS. This work package demonstrates and implements integrated processes that provide interim operation of DWPF on sludge-only feed, as well as provides new cesium removal process to allow future treatment of combined sludge and salt waste streams. Interim operation is enabled by 
implementing a DWPF recycle stream treatment process to avoid returning large volumes of this waste back to the high-level waste (HLW) tanks. After cesium, solids, and mercury removal, DWPF recycle can be processed through the Effluent Treatment Facility and discharged through a National Pollutant Discharge Elimination System. Development of a new cesium removal flowsheet, including cesium removal integrated with downstream feed preparation and immobilization, is required to replace in-tank precipitation. This work package was rated 29 of 42 work packages by OST.

Work Package \#4, Slurry Preparation for Feed to HLW Vitrification. This work package provides technical data required at SRS and Hanford to enable settle-decant operations that separate solids from liquids before pretreatment and vitrification of sludges. Increased effort at SRS is needed to support sludge-only processing until a replacement for in-tank precipitation can be defined and implemented. Hanford requires support for settledecant and feed stream preparation and confirmation to support phase I feed stream delivery and phase II strategy development and technical benchmarking. This work package was rated 23 of 42 work packages by OST.

Work Package \#5, Hanford Tanks Initiative. Hanford has 67 leaking or potentially leaking tanks from which the heel must be removed for closure. The Hanford Tanks Initiative is designed to investigate waste tank data needed to make tank/tank farm closure decisions at Hanford. These are key decision points and the data from this project is intended to support the environmental impact statement record of decision for closure. Coupled with the user program, the Hanford Tanks Initiative conducts performance assessment and characterization data analyses, provides infrastructure and operating costs to implement heel retrieval, and engages regulators and stakeholders in key decisions. This work package was rated 39 of 42 work packages by OST.

Work Package \#6, Pretreatment to Reduce High- and Low-Level Waste Forms. This work package provides technical data required to defme the integrated flowsheet at NEEL in support of Title 1 design, including advanced calcination, dissolution of calcine, and transuranic, cesium, and strontium removal. It provides technical data required for DWPF operations with sludge only and for phase II privatization to evaluate proposed sludge treatment to reduce the volume of HLW canisters produced at SRS and Hanford. It also demonstrates and implements caustic recycle to reduce the volume of low-level waste streams. This work package was rated 11 of 42 work packages by OST.

\section{Work Package \#7, INEEL and ORR Tank Waste Immobilization/Cesium and} Strontium Capsules. This work package provides testing and technical data that leads to Title 1 design of immobilization processes that stabilize/solidify low-activity waste from the Idaho Nuclear Technology and Engineering Center and conditioning processes for feed to the high-activity waste immobilization melters from tank sludge and dissolved calcine. This work package was rated 42 of 42 work packages by OST. 



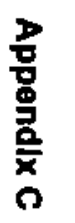

$\Gamma$ 


\section{Appendix C - Integrated Priority List}

Table C.1 shows the prioritization of TFA's technical responses to users' needs. Program prioritization is described in Appendix B. The results of the prioritization are shown in Table 3.1, including the TFA's funding priority, the needs submitted by the sites, DOE/ EM-50 technologies to be applied to the needs, and a 3-year funding profile of TFA core funding. 
Table C.1. Tanks Focus Area 5-Year Funding

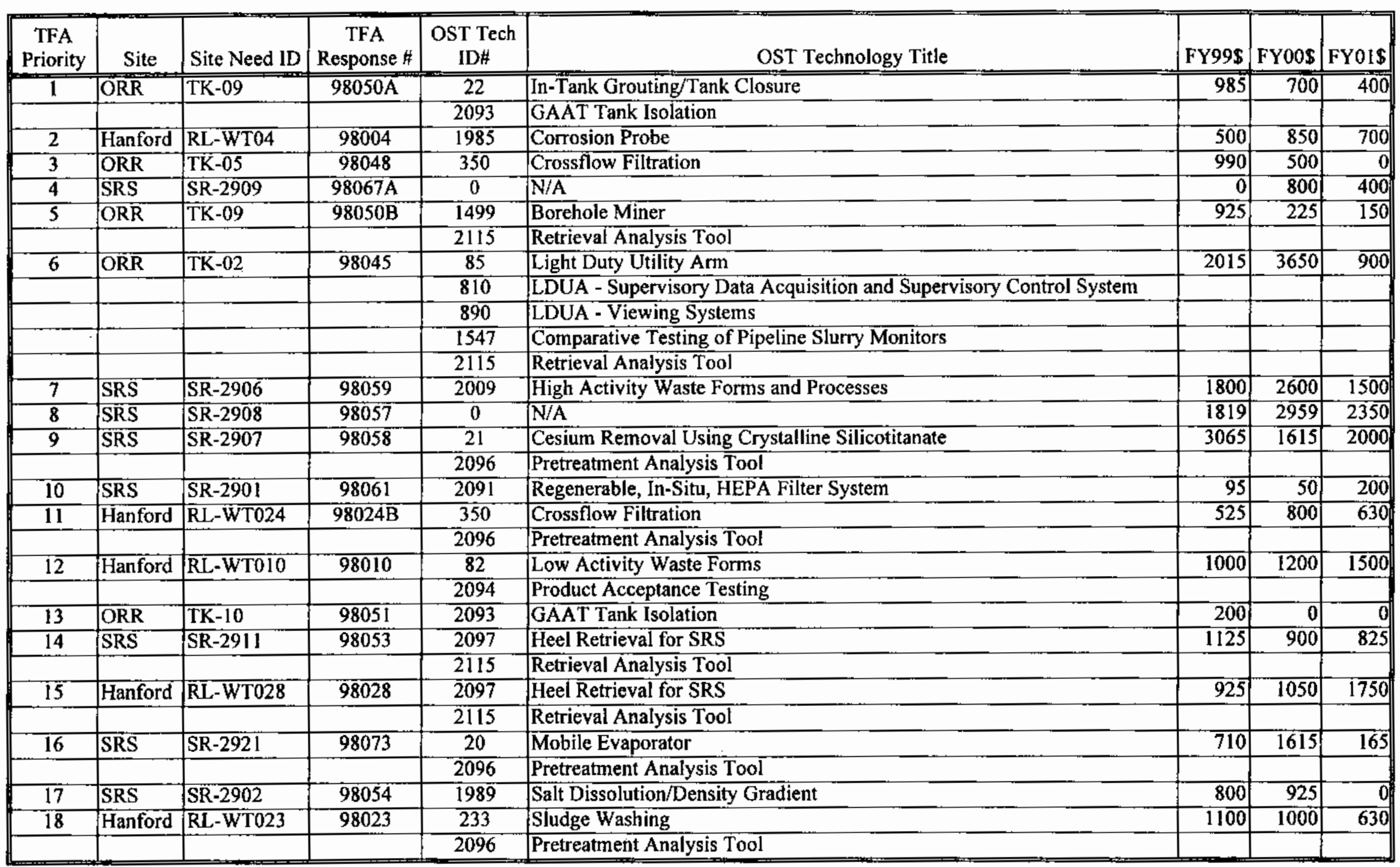


Table C.1. (contd)

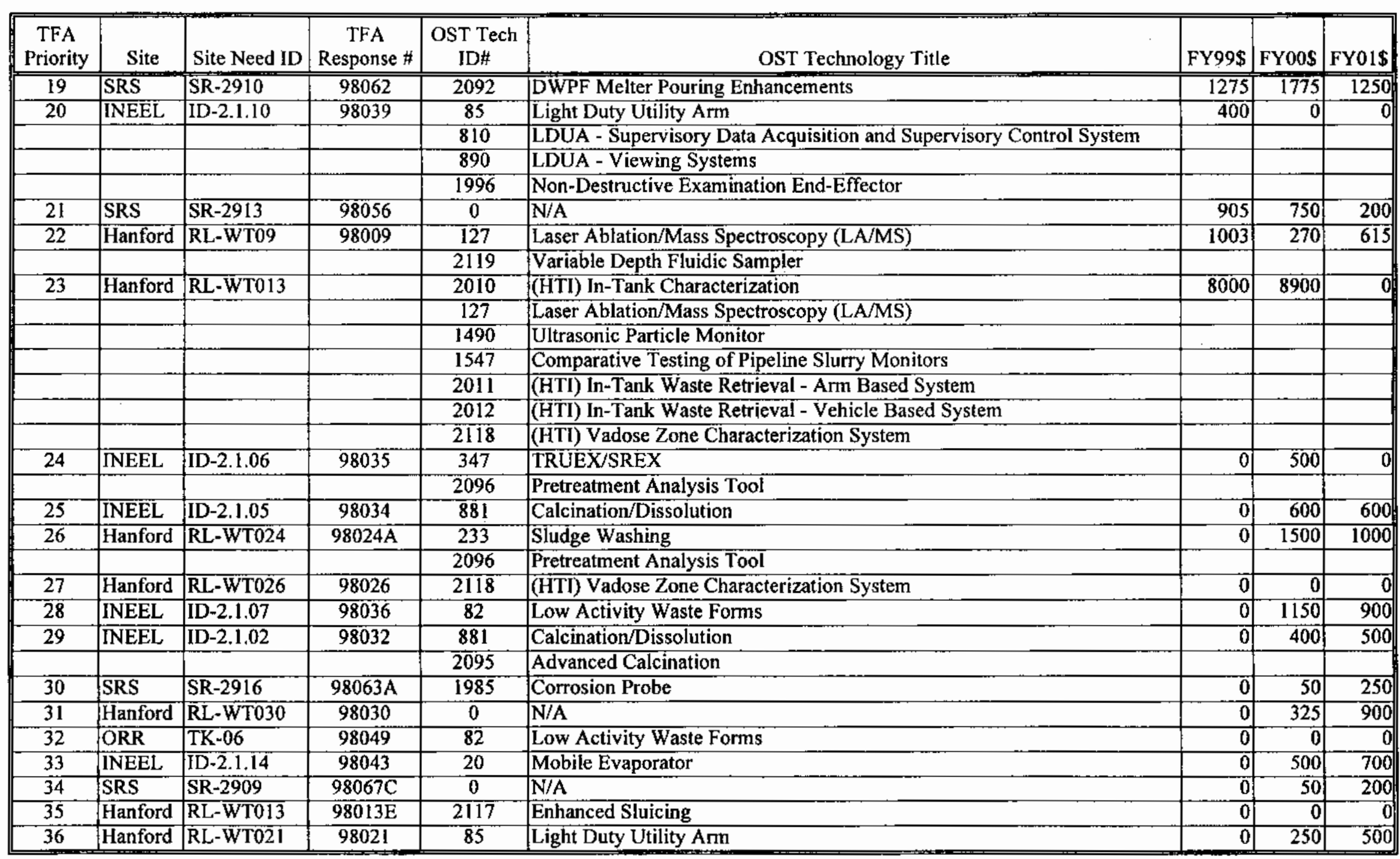


Table C.1. (contd)

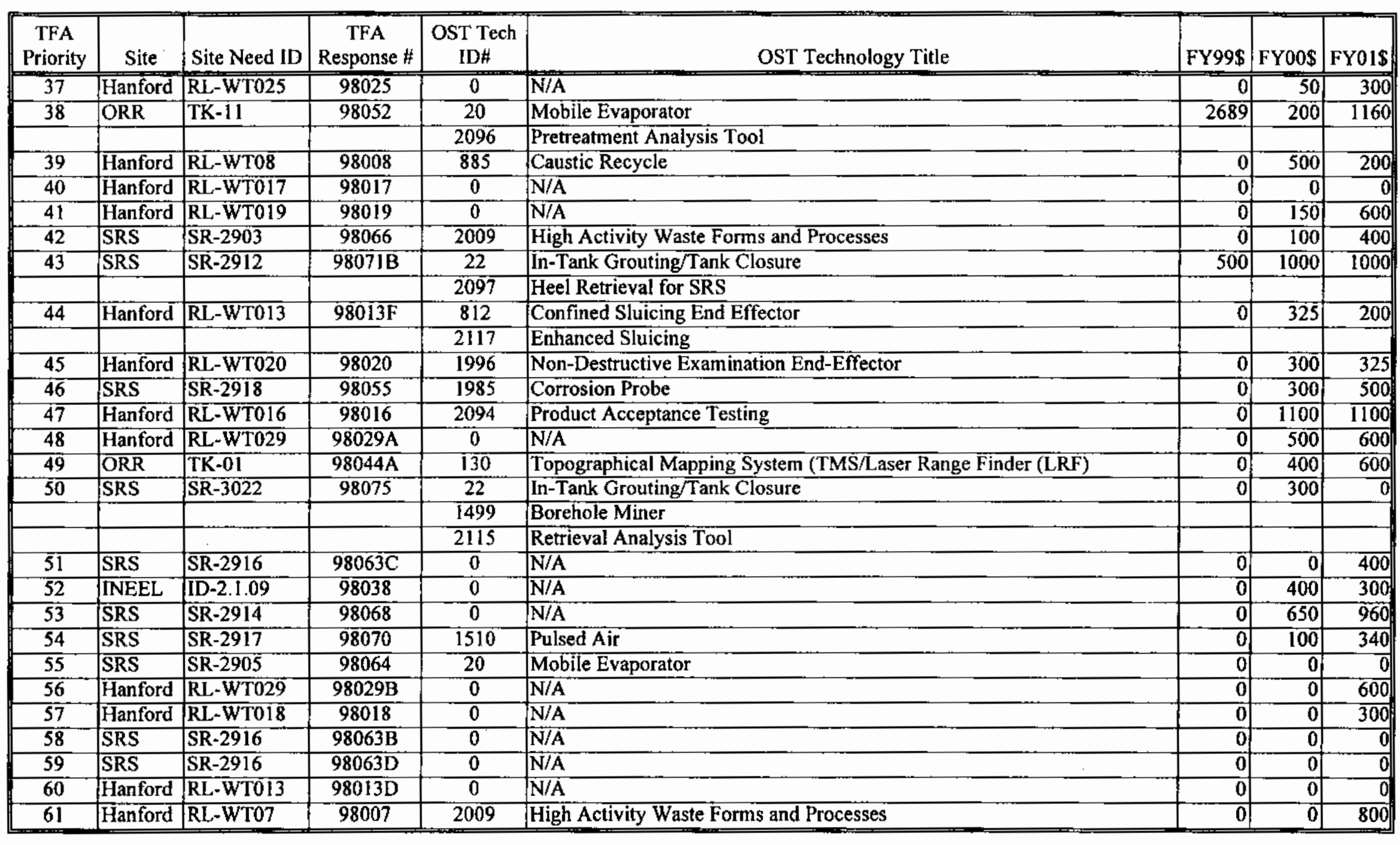


总 


\section{Appendix D - Gantt Charts of Major TFA Milestones}

The TFA constructed integrated schedules for each site and depicted them on Gantt charts. For each site (Hanford, Idaho National Engineering and Environmental Laboratory, Oak Ridge Reservation, and Savannah River Site), site needs are linked to appropriate Program Baseline Summaries (PBSs). The TFA's technical responses to these needs are shown, with key milestones and dates as well. 
TFA Integrated Schedule for Hanford Site

Finlsh 98 99/00

\begin{tabular}{|c|l|r|}
\hline 1 & RL-WM01 Conduct Spent Nuclear Fuels Project & $9 / 30 / 03$ \\
\hline 2 & RL-WM01 Conduct Spent Nuclear Fuels Project & $9 / 30 / 03$ \\
\hline 3 & AL-TW01 Conduct TWRS Characterlzation Project & $9 / 30 / 02$ \\
\hline 4 & RL-TW01 Conduct TWRS Characterization Project & $9 / 30 / 02$ \\
\hline 5 & RL-WT031-S Rapid Waste Characterization & $8 / 31 / 01$ \\
\hline 6 & RL-WT052-S Characterization of Organic Species in Feed to LAW and HLW Facilities & $1 / 1 / 00$ \\
\hline 7 & RL-TW02 Conduct TWAS Safety lssue Resolution Project & $9 / 28 / 01$ \\
\hline
\end{tabular}

\begin{tabular}{l|l|l|l|l|l|l|l}
01 & 02 & 03 & 04 & 05 & 06 \\
\hline
\end{tabular} \begin{tabular}{|l|l|l|l|l|l|l|l|}
\hline 07 & 08 & 09 & 10 & 11 & 12 & 13 \\
\hline
\end{tabular}

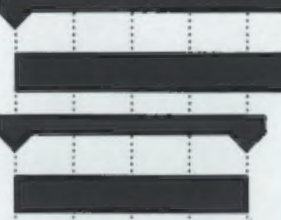

(†) $8 / 31$

(4) $1 / 1$

\begin{tabular}{|c|c|r|}
\hline B & RL-TW02 Conduct TWRS Safety Issue Resolution Project & $9 / 28 / 01$ \\
\hline 9 & RL-TW03 Conduct Tank Farm Operations Project & $9 / 28 / 01$ \\
\hline
\end{tabular}

\begin{tabular}{|c|c|r|}
\hline 9 & RL-TW03 Conduct Tank Farm Operations Project & $9 / 1 / 11$ \\
\hline 10 & RL-TW03 Conduct Tank Farm Operations Project & $6 / 30 / 05$ \\
\hline
\end{tabular}

\begin{tabular}{|c|l|r|}
\hline 11 & RL-WTO4 DST Corrosion Monitoring & $6 / 30 / 05$ \\
\hline 12 & 98004 - Hanford EN Corrosion Probe Development and Deployment & $9 / 28 / 01$ \\
\hline
\end{tabular}

\begin{tabular}{|r|l|r|}
\hline 13 & 98004 - Complete design of a version 3 EN probe & $9 / 26 / 99$ \\
\hline 14 & 98004 - Document deployment of the EN probe in the MIT design & $9 / 30 / 99$ \\
\hline
\end{tabular}

\begin{tabular}{|c|l|r|}
\hline 15 & 98004 - Document deployment of the EN probe in the MIT design & $9 / 30 / 99$ \\
\hline 16 & $98004 \cdot$ Document deployment of the EN probe in the MIT design & $9 / 30 / 99$ \\
\hline
\end{tabular}

\begin{tabular}{|c|c|r|}
\hline 16 & 98004 - Document deployment of the EN probe in the MIT design & $9 / 30 / 99$ \\
\hline 17 & 98004 - Complete development of an automated data analysis system & $9 / 30 / 99$ \\
\hline
\end{tabular}

\begin{tabular}{|c|c|c|}
\hline 18 & 98004 - Develop and Deploy Fourth Generation EN Probe & $9 / 28 / 00$ \\
\hline 19 & 98004 - Complete Final Design for EN Probe & $9 / 28 / 01$ \\
\hline 20 & RL-WTO5 Remote Inspection of High-Level Waste Tanks & $12 / 1 / 00$ \\
\hline 21 & RL-WT020 Service Integrity Testing of High-Level Waste Tanks and RL-WT022 Piping & $9 / 1 / 00$ \\
\hline 22 & 98020 - Service Integrity Testing of High-Level Waste Tanks and Piping & $9 / 28 / 01$ \\
\hline
\end{tabular}

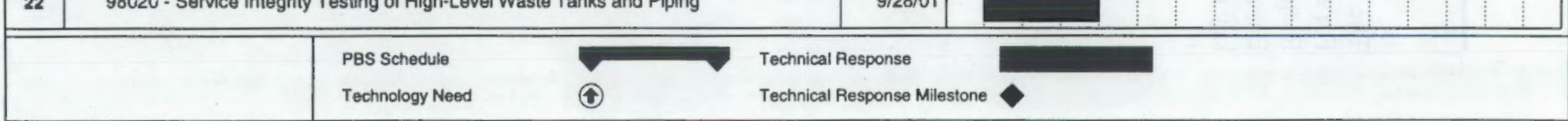




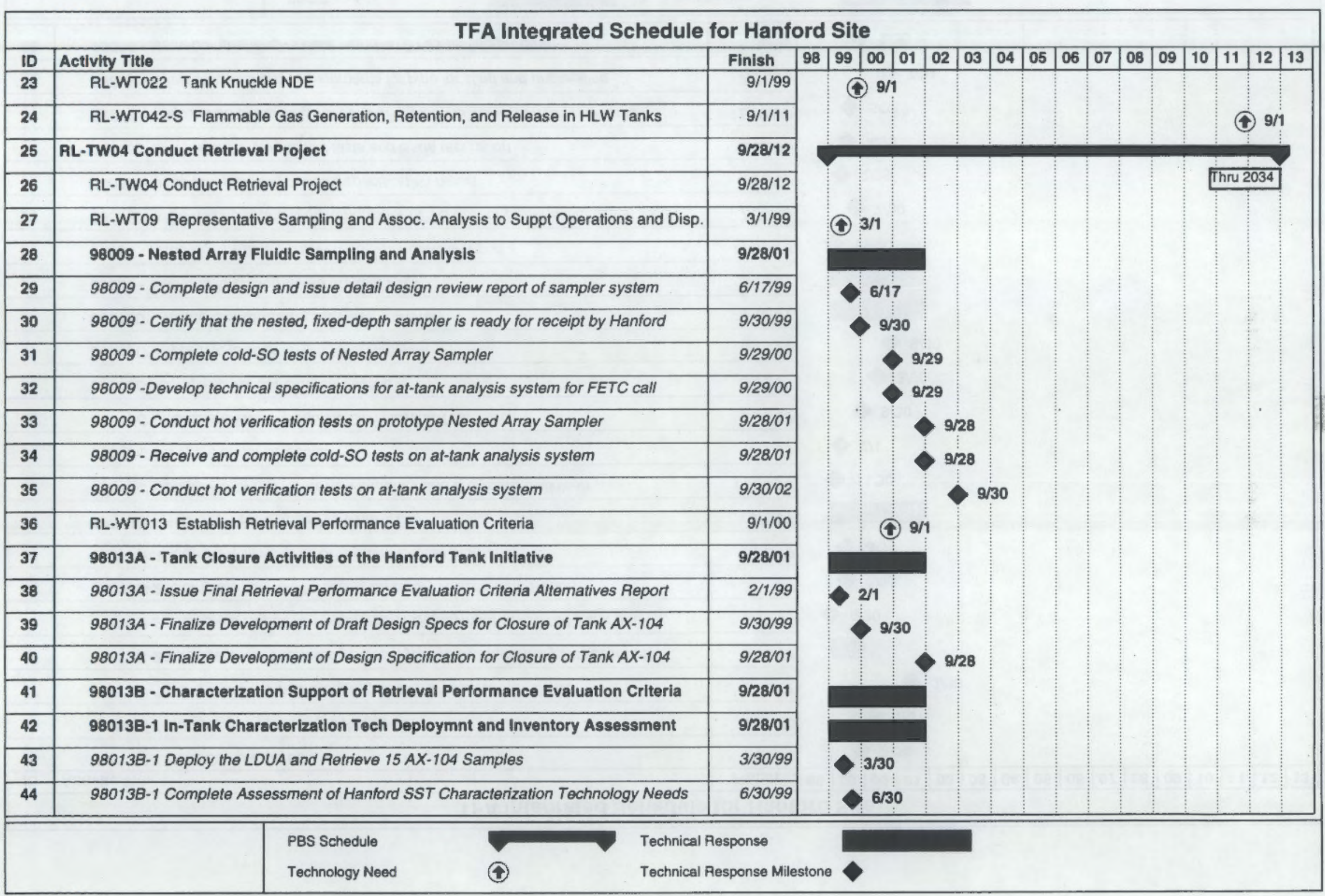




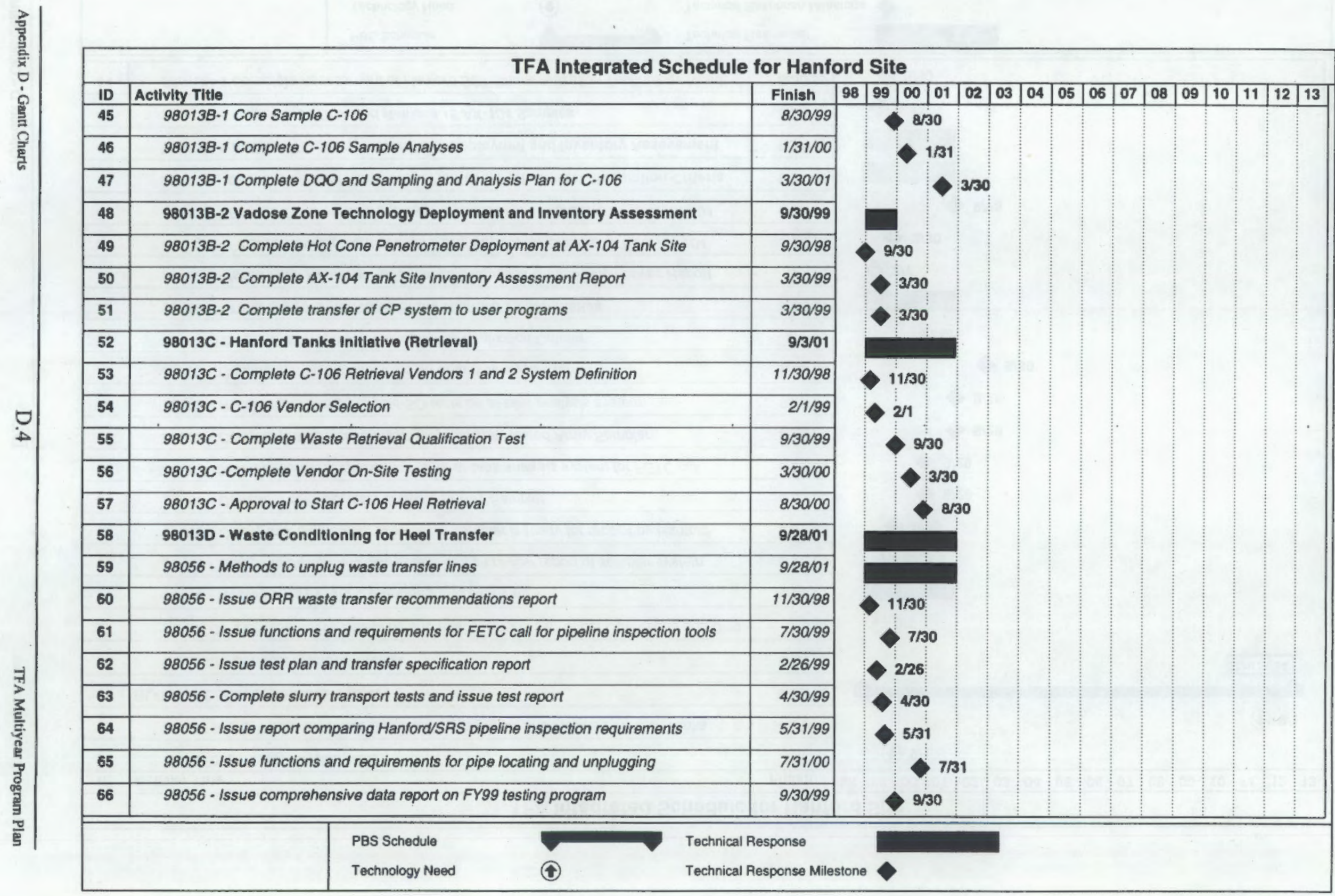




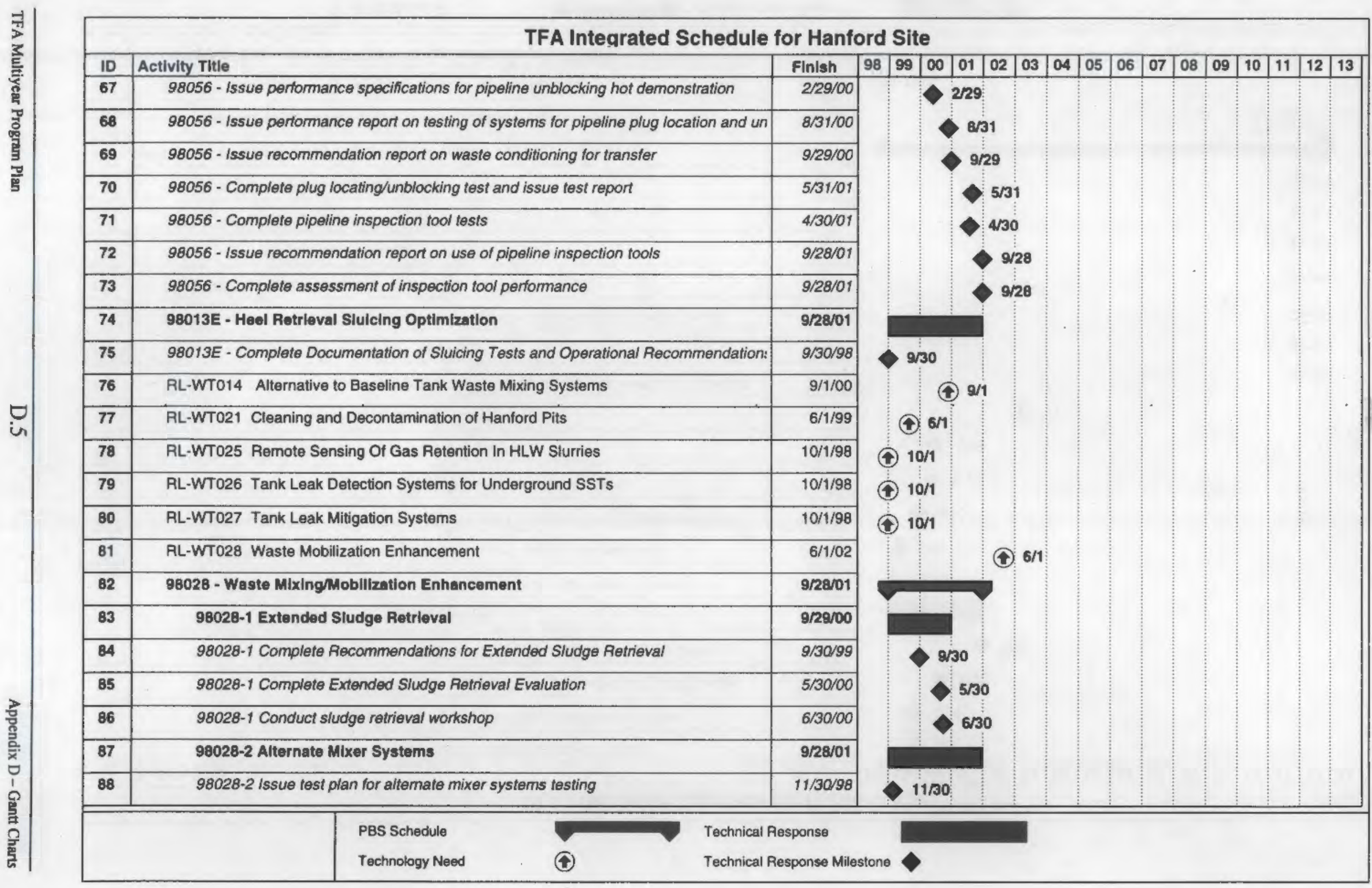




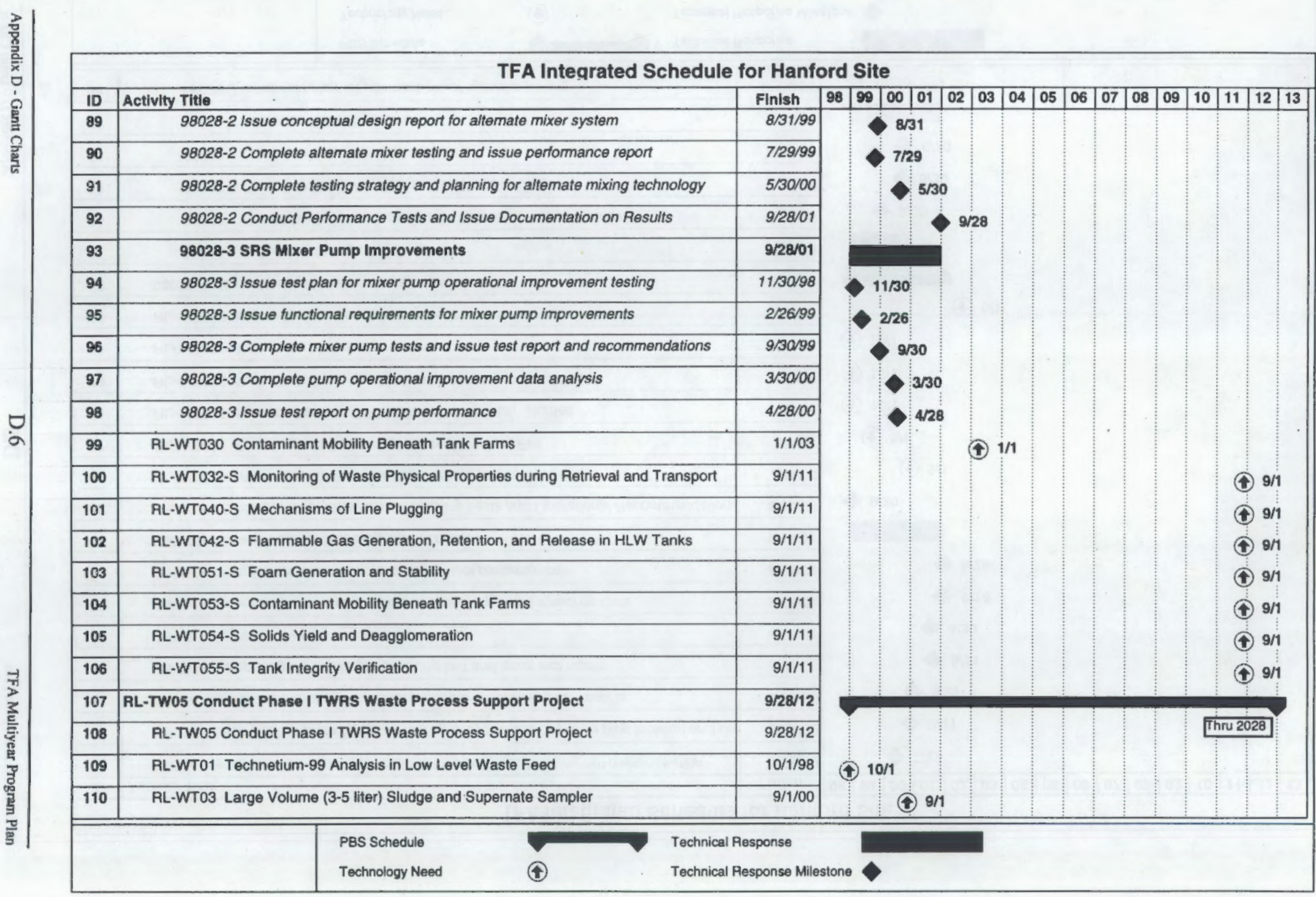




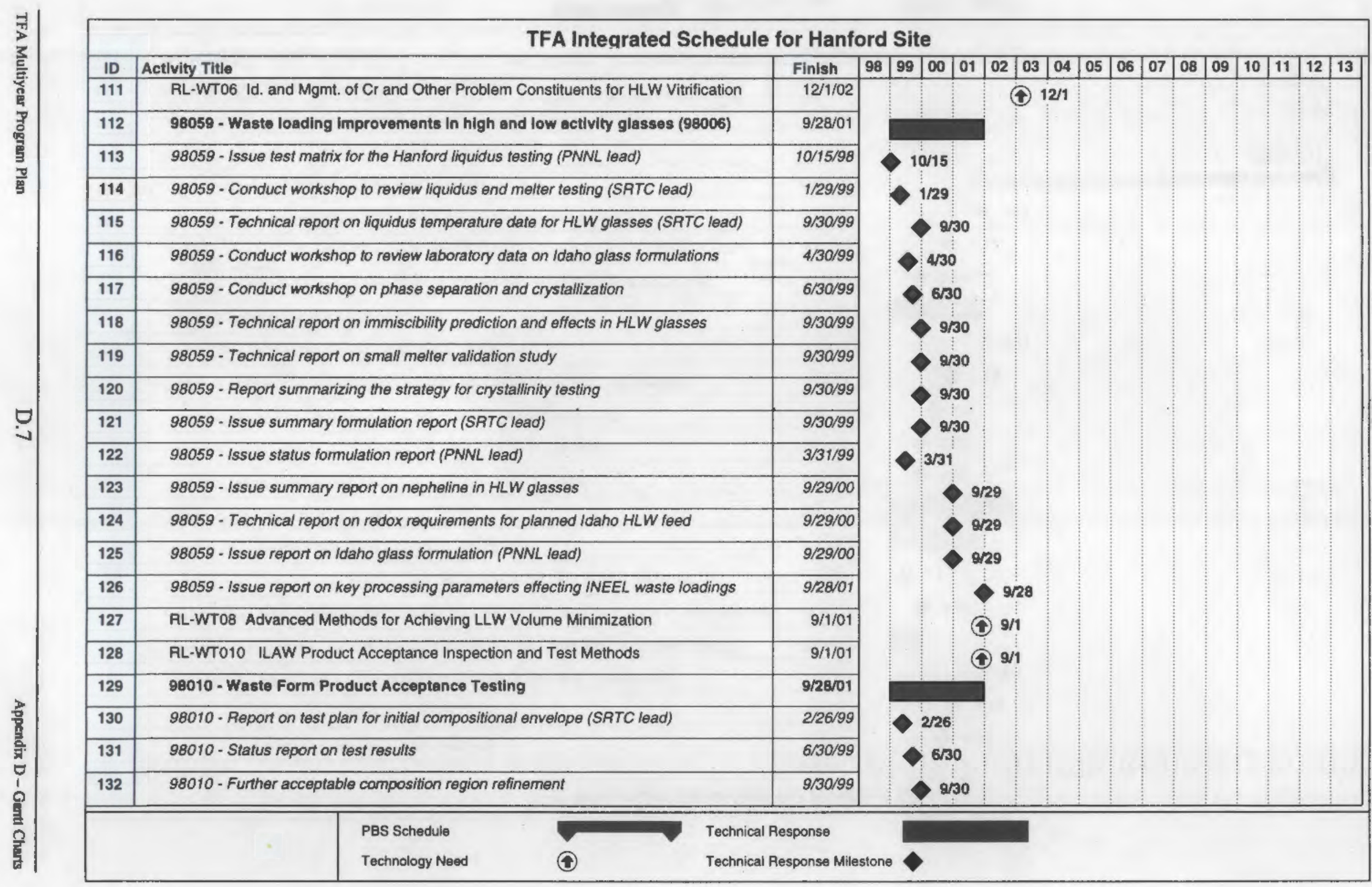




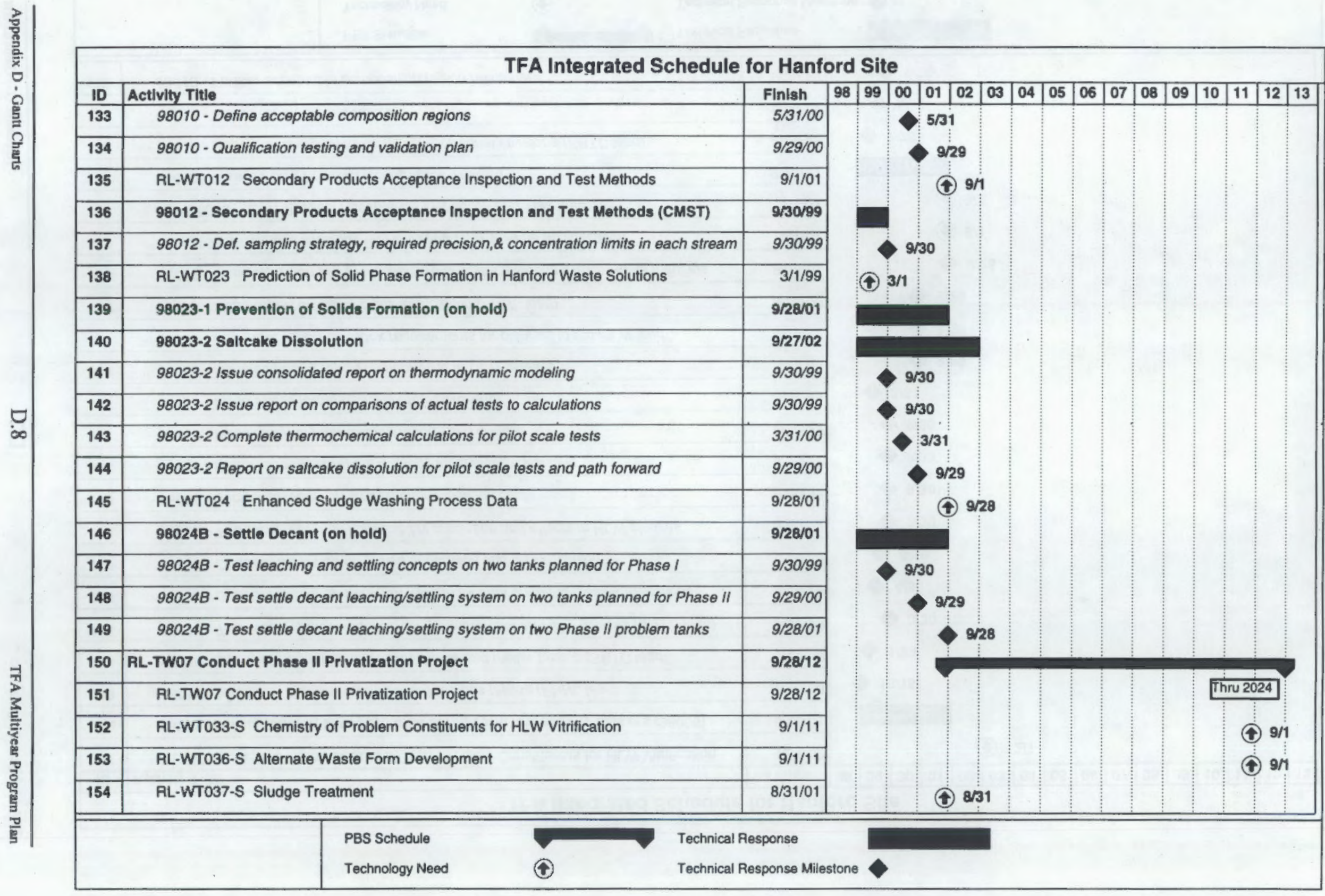




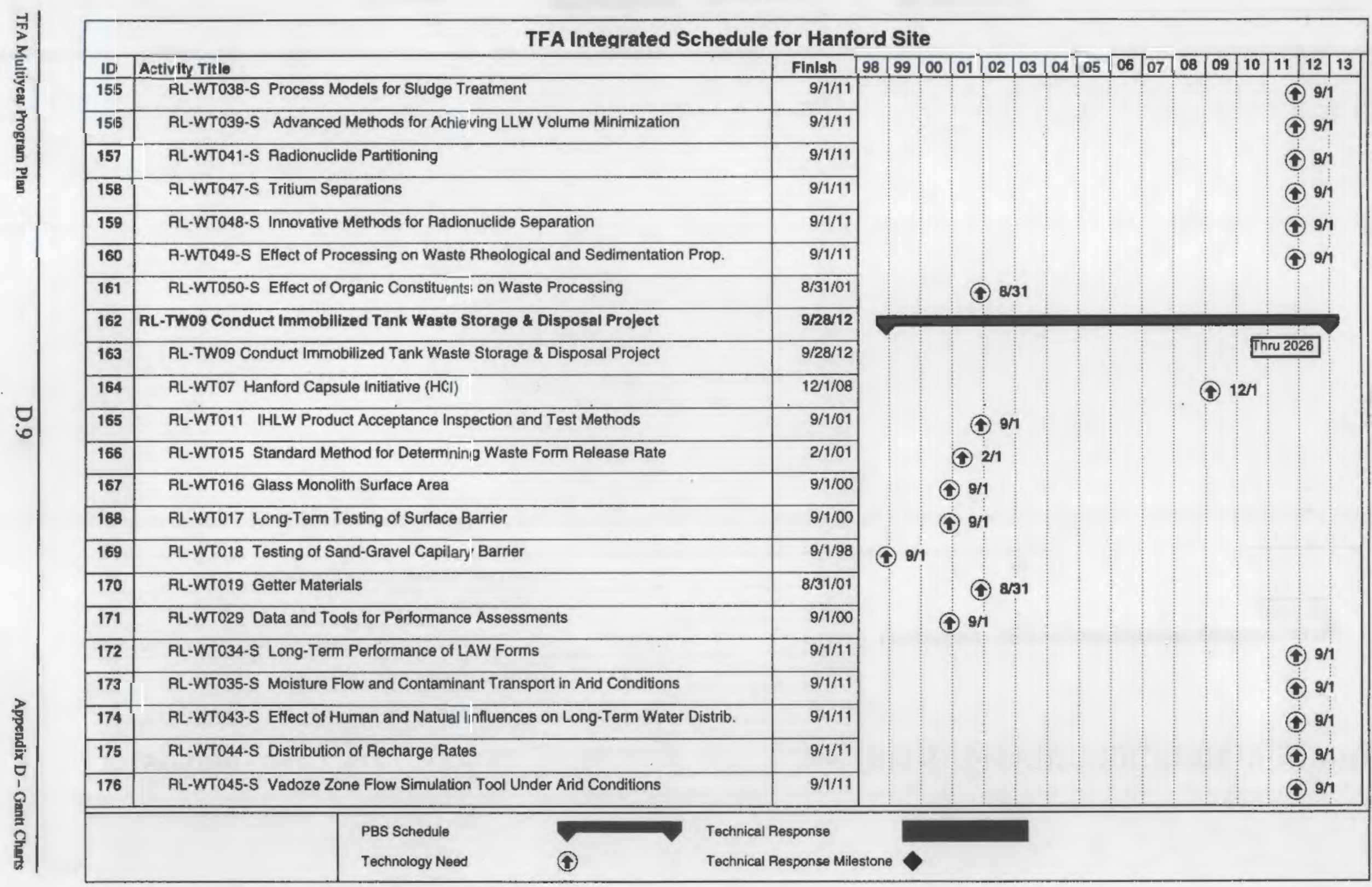




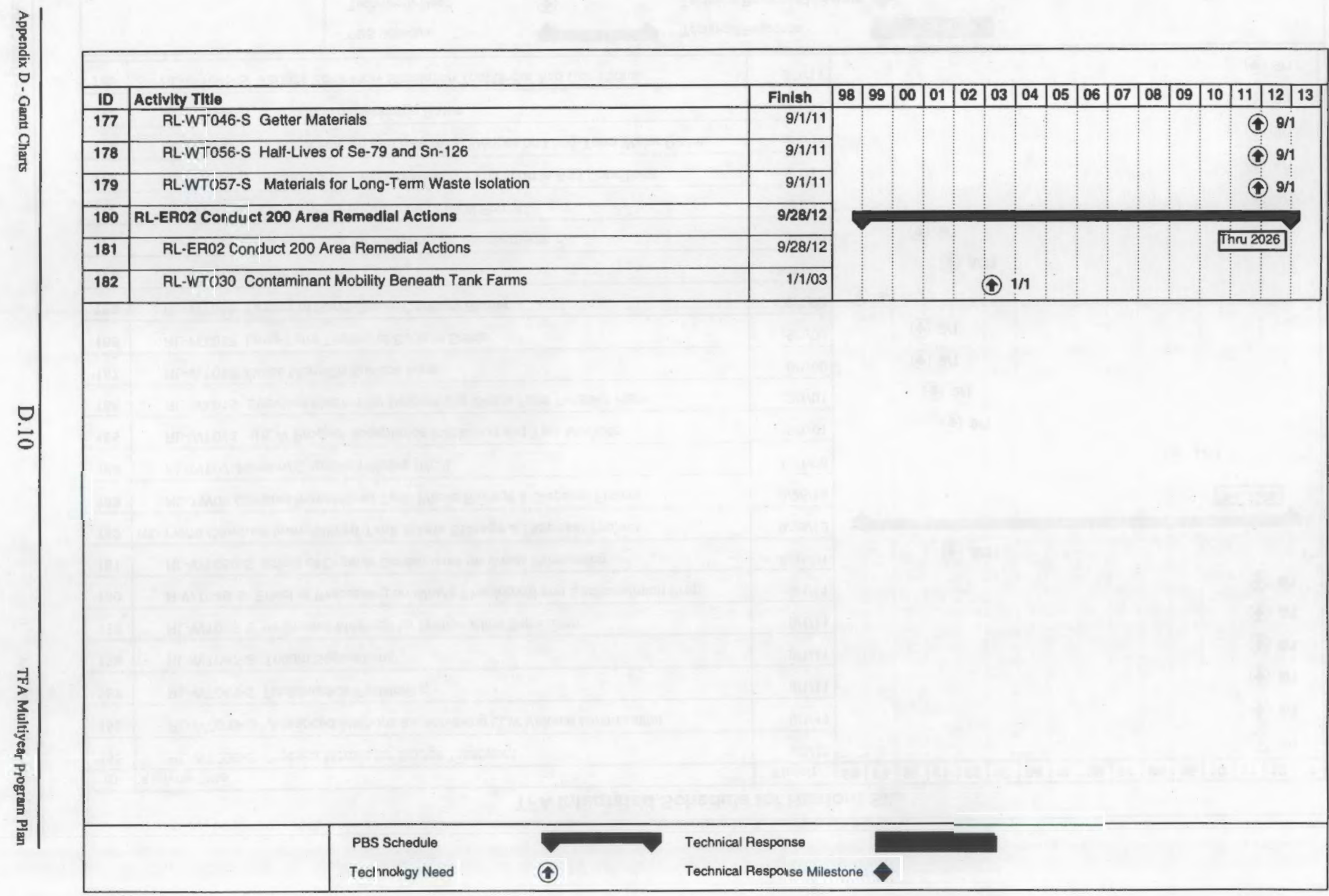




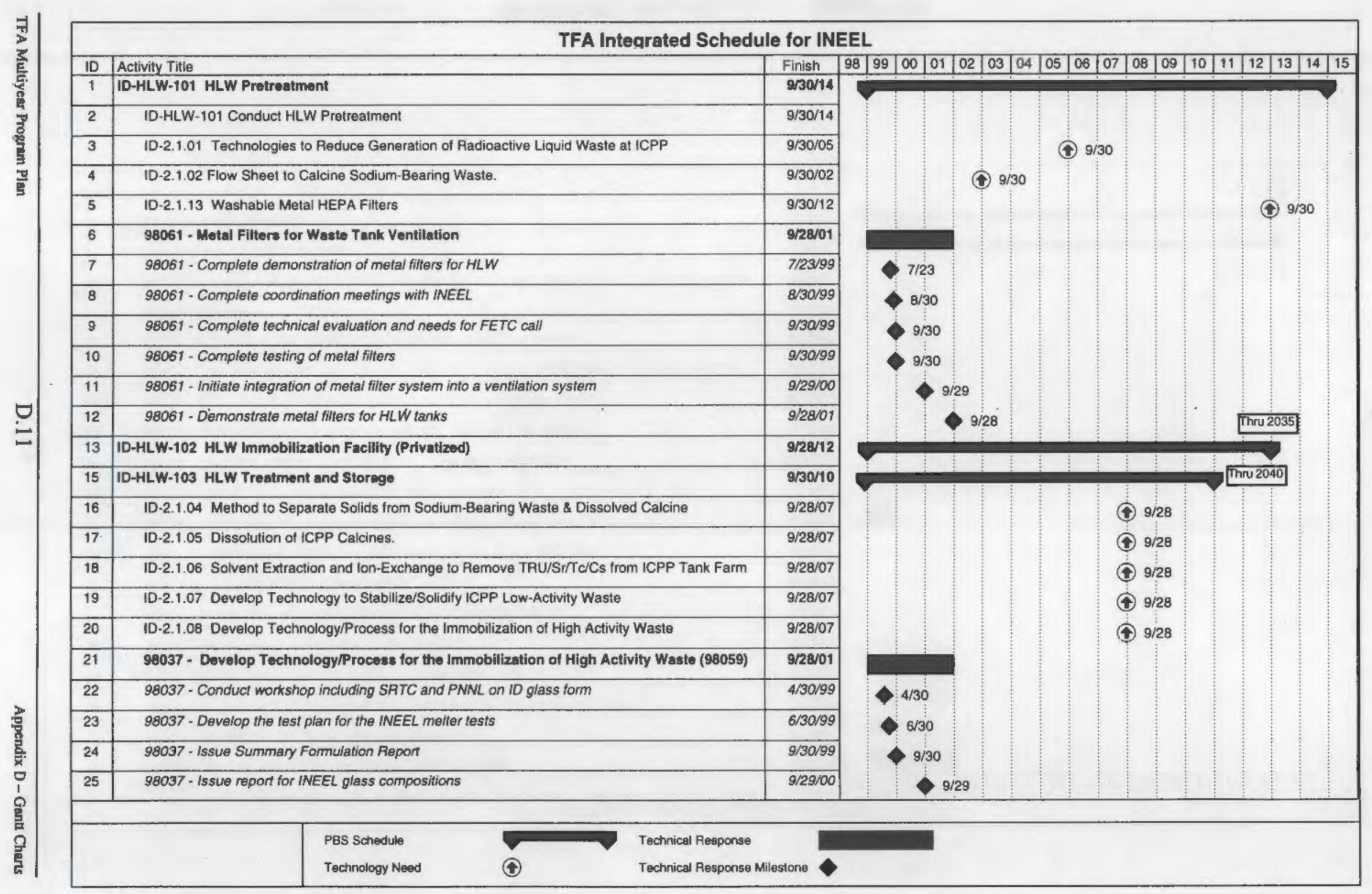




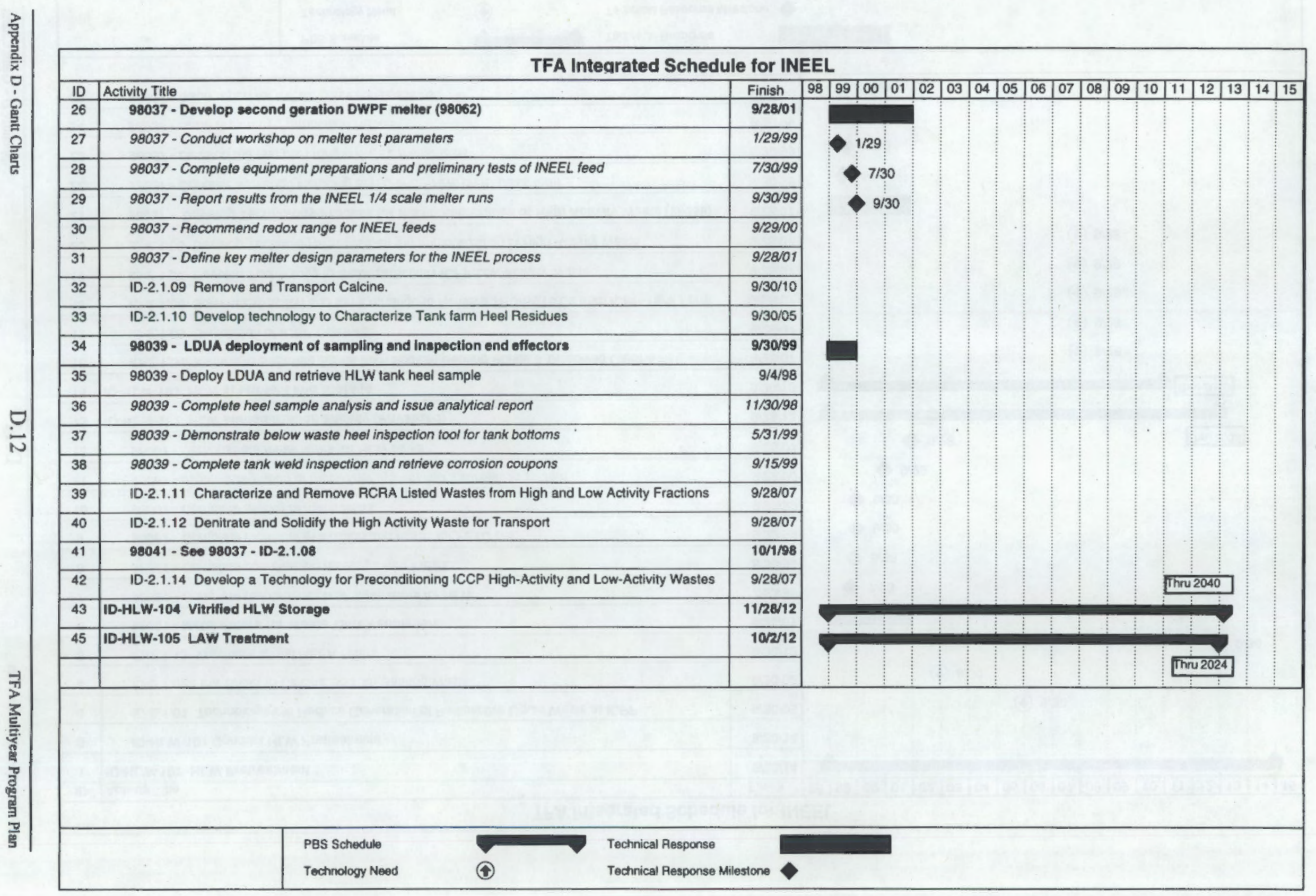




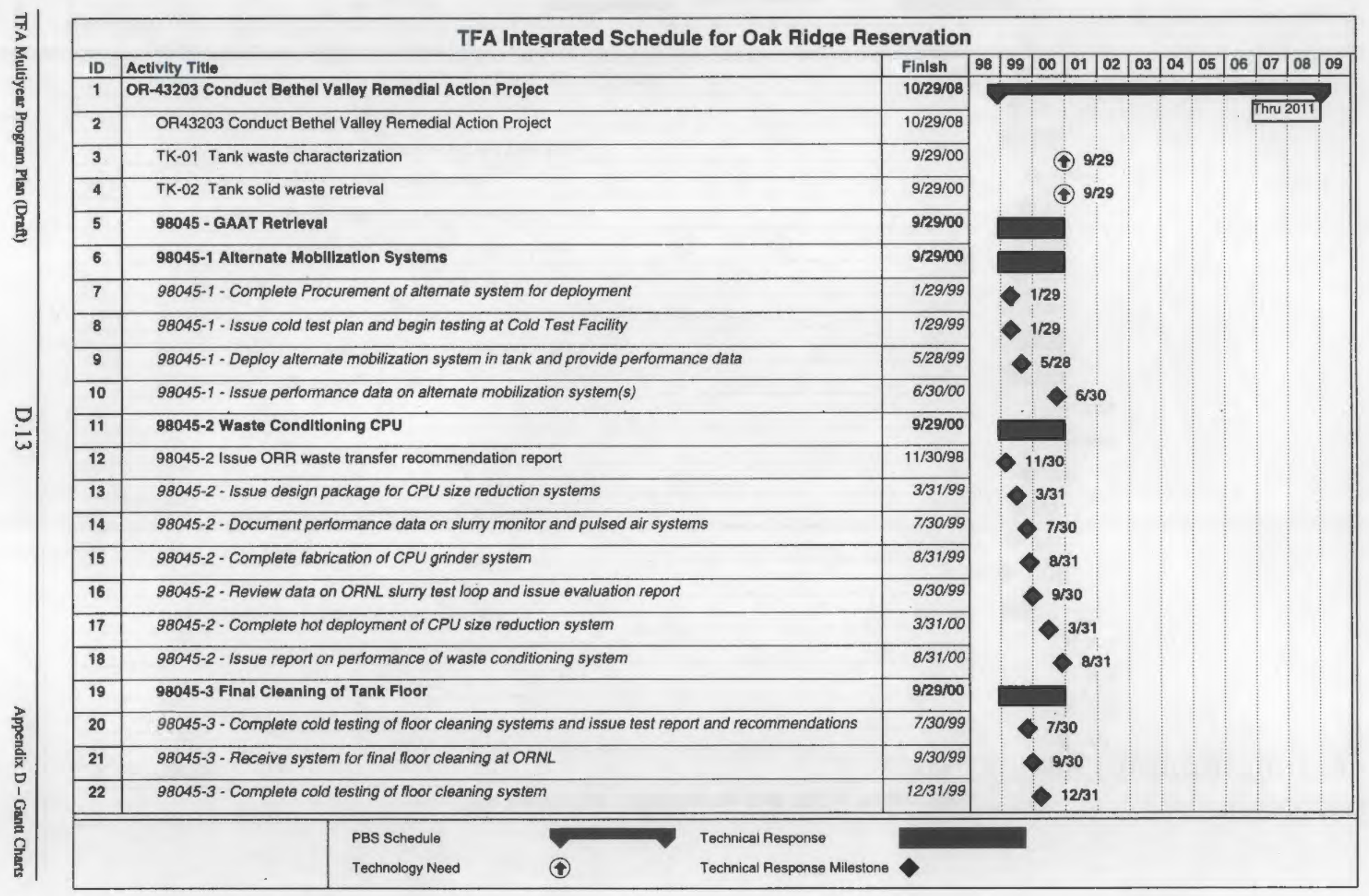




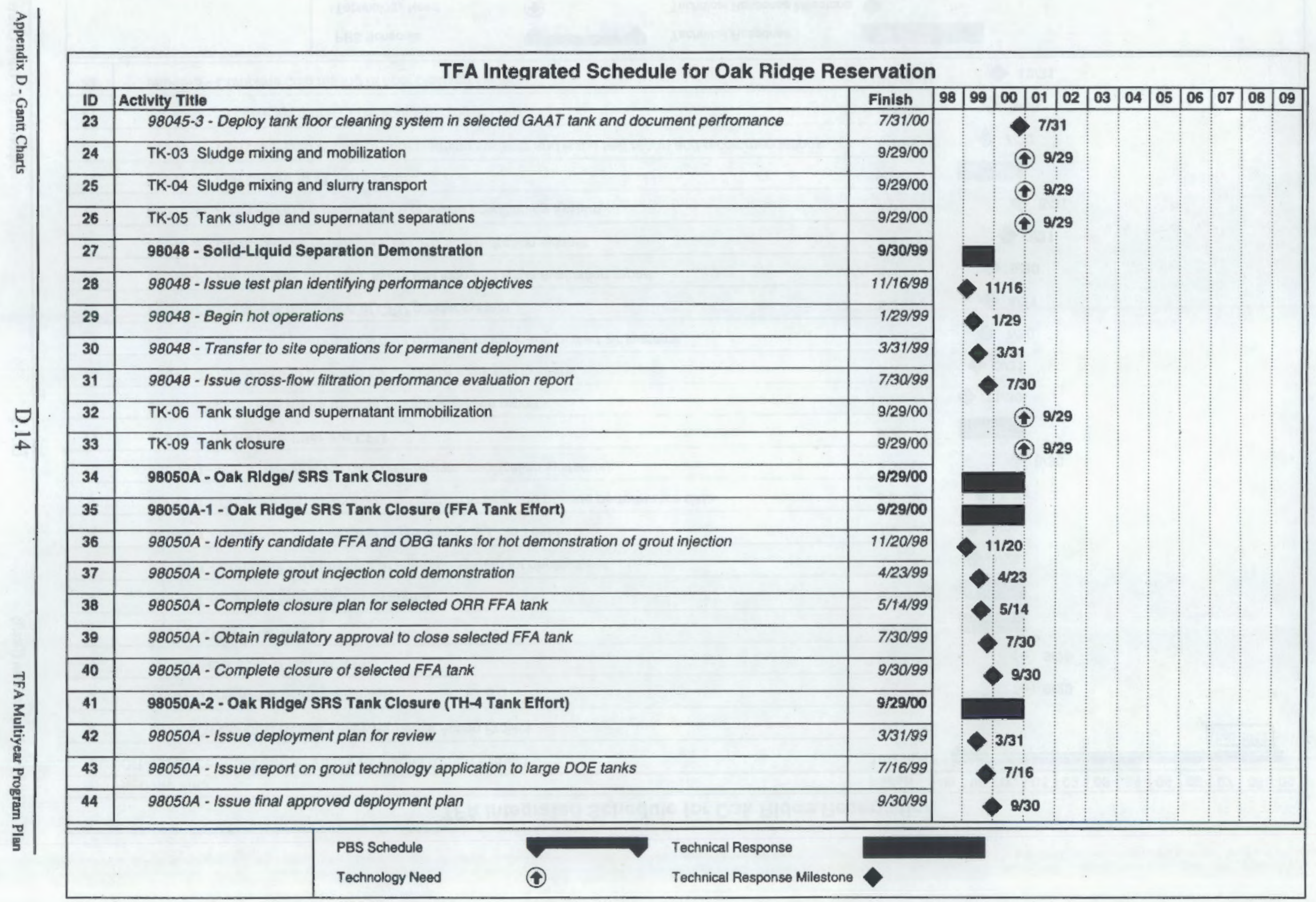




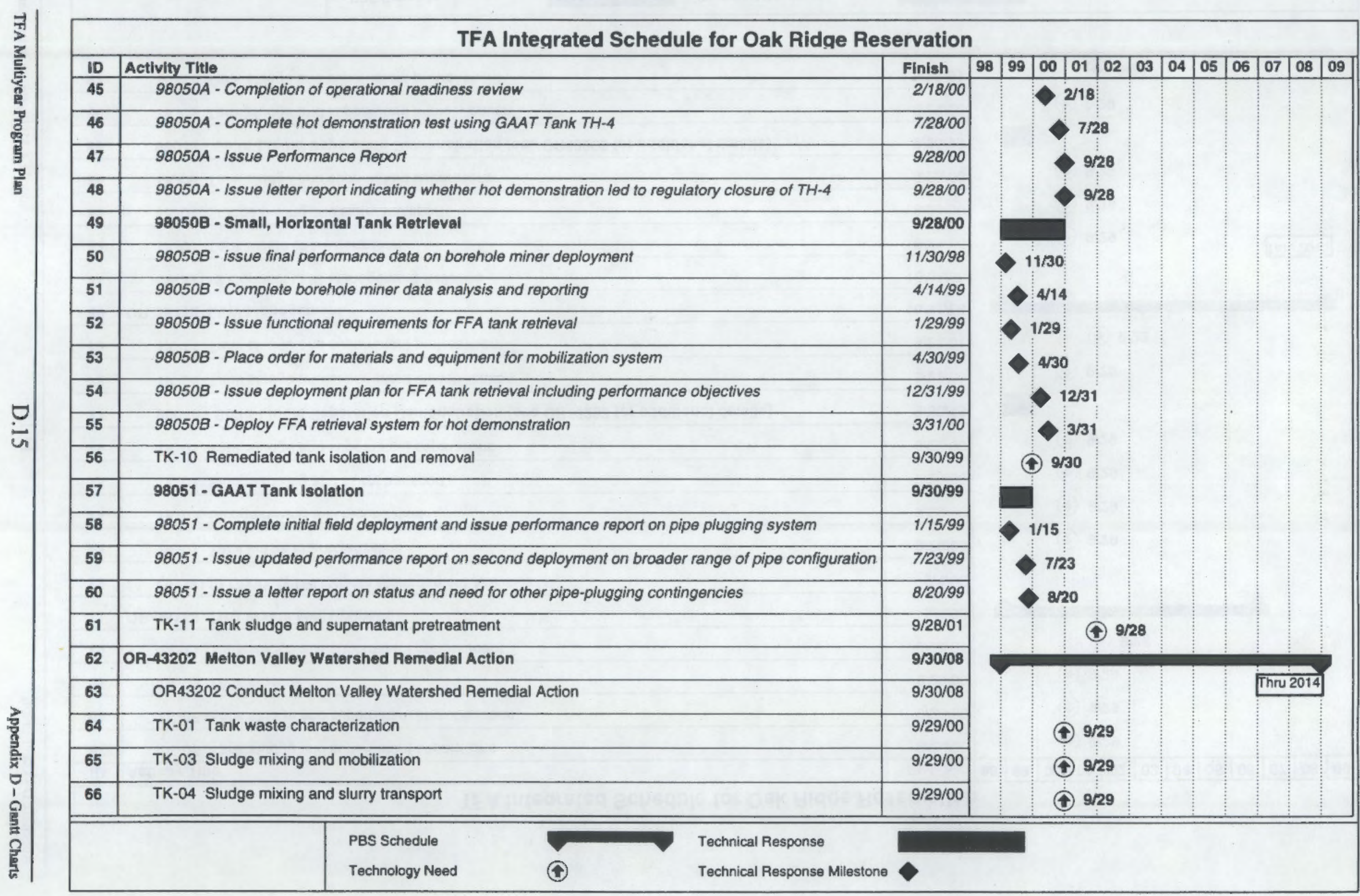




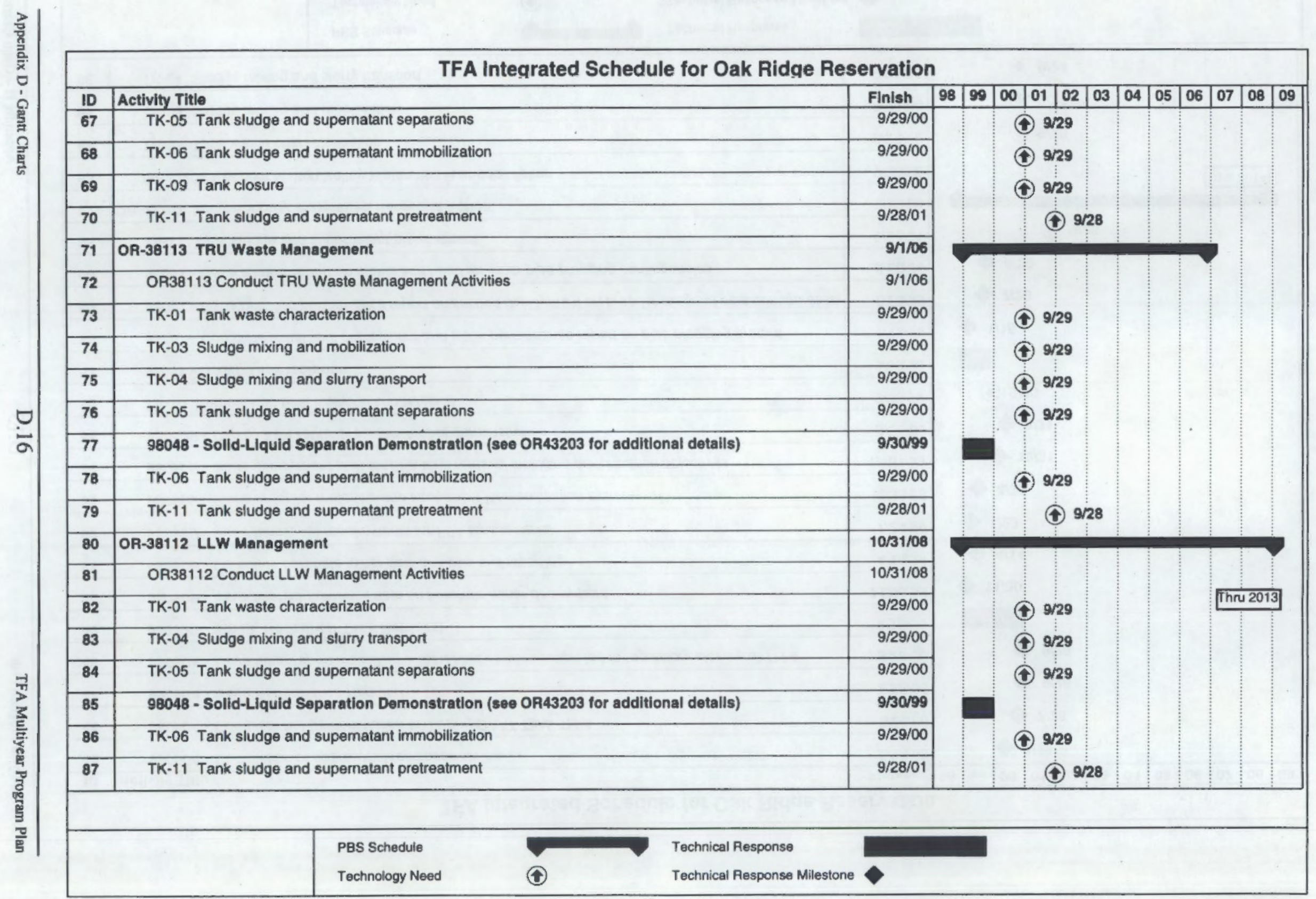




\section{Integrated Schedule for Savannah River Site}

\begin{tabular}{|c|c|c|c|c|c|c|c|c|c|c|c|c|c|c|c|c|}
\hline ID & Actlvity Titie & Finish & 98 & 99. & 00 & 01 & 02 & 03 & 04 & 05 & 06 & 07 & 08 & 09 & 10 & 11 \\
\hline 1 & SR-HLO1 H-Tank Farm & 9/30/24 & & & & & & & & & & & & & & \\
\hline 2 & SR-HL01 H-Tank Farm & $9 / 30 / 24$ & & & & & & & & & & & 20 & 24 & & \\
\hline 3 & SA-2901/2027 Demonstrate Altemative Filtration Technology to Peplace HEPA Filters & 10/1/99 & & & & & & & & & & & & & & \\
\hline 4 & 98061 - Metal Fliters for Waste Tank Ventilation & $9 / 28 / 01$ & & & & & & & & & & & & & & \\
\hline 5 & 98061 - Complete demonstration of metal filters for HLW & $7 / 23 / 99$ & & & & & & & & & & & & & & \\
\hline 6 & 98061 - Complete coordination meetings with INEEL & $8 / 30 / 99$ & & & & & & & & & & & & & & \\
\hline 7 & 98061 - Complete technical evaluation and needs for FETC call & $9 / 30 / 99$ & & & & & & & & & & & & & & \\
\hline 8 & 98061 - Complete testing of metal filters & $9 / 30 / 99$ & & & & & & & & & & & & & & \\
\hline 9 & 98061 - Initiate integration of metal filter system into a ventilation system & $9 / 29 / 00$ & & & & & & & & & & & & & & \\
\hline 10 . & 98061 - Demonstrate metal filters for HLW tanks . & $9 / 28 / 01$ & & & & & & & & & & & & . & & \\
\hline 11 & SR-2909/2035 Develop Advanced Technology For Life Extension Of Tanks/Piping & 9/28/01 & & & & & & & & & & & & & & \\
\hline 12 & SR-2913/2034 Methods to Unplug Waste Transfer Lines & $9 / 30 / 00$ & & & & & & & & & & & & & & \\
\hline 13 & 98056 - Methods to unplug waste transfer lines & 9/28/01 & & & & & & & & & & & & & & \\
\hline 14 & 98056-1 Slurry transportplugging phenomena & $9 / 28101$ & & & & & & & & & & & & & & \\
\hline 15 & 98056-1 - Issue ORR waste transfer recommendation report & $11 / 30 / 98$ & & & & & & & & & & & & & & \\
\hline 16 & 98056-1 - Issue test plan and transfer specification report companing SRS, ORR \& Hanford & $2 / 26 / 99$ & & & & & & & & & & & & & & \\
\hline 17 & 98056-1 - Complete slurny transport tests and issue test report & $4 / 30 / 99$ & & & $4 / 30$ & & & & & & & & & & & \\
\hline 18 & 98056-1 - Issue recommendation report on waste conditioning for transfer & 9/29/00 & & & & & & & & & & & & & & \\
\hline 19 & 98056-2 Pipeline unblocking and plug location tools/slurry transport/plugging phenomena & 9/2:/01 & & & & & & & & & & & & & & \\
\hline
\end{tabular}

PBS Schedule

Technology Need

(บ)

Technical Response

Technical Response Milestone 


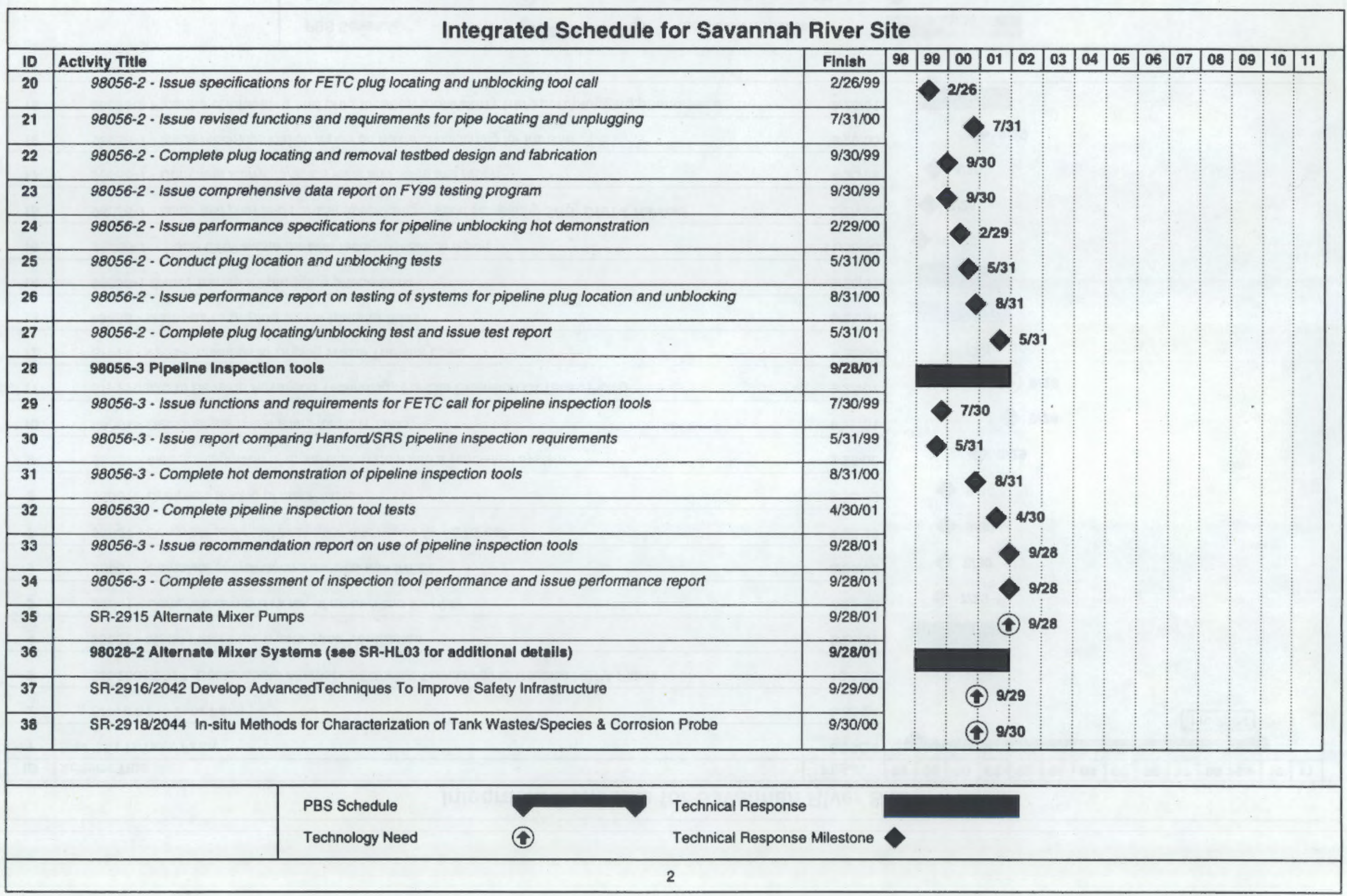




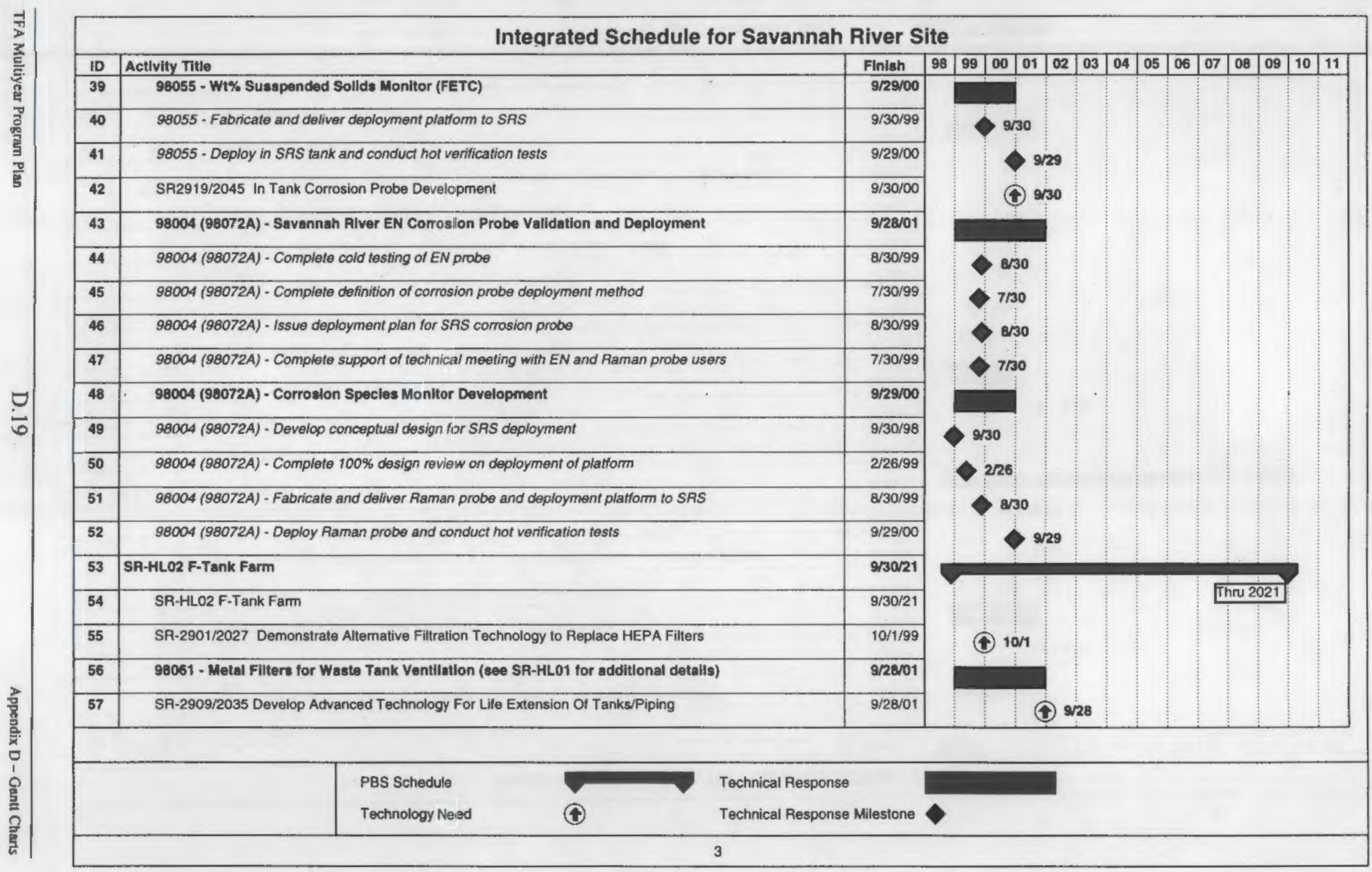




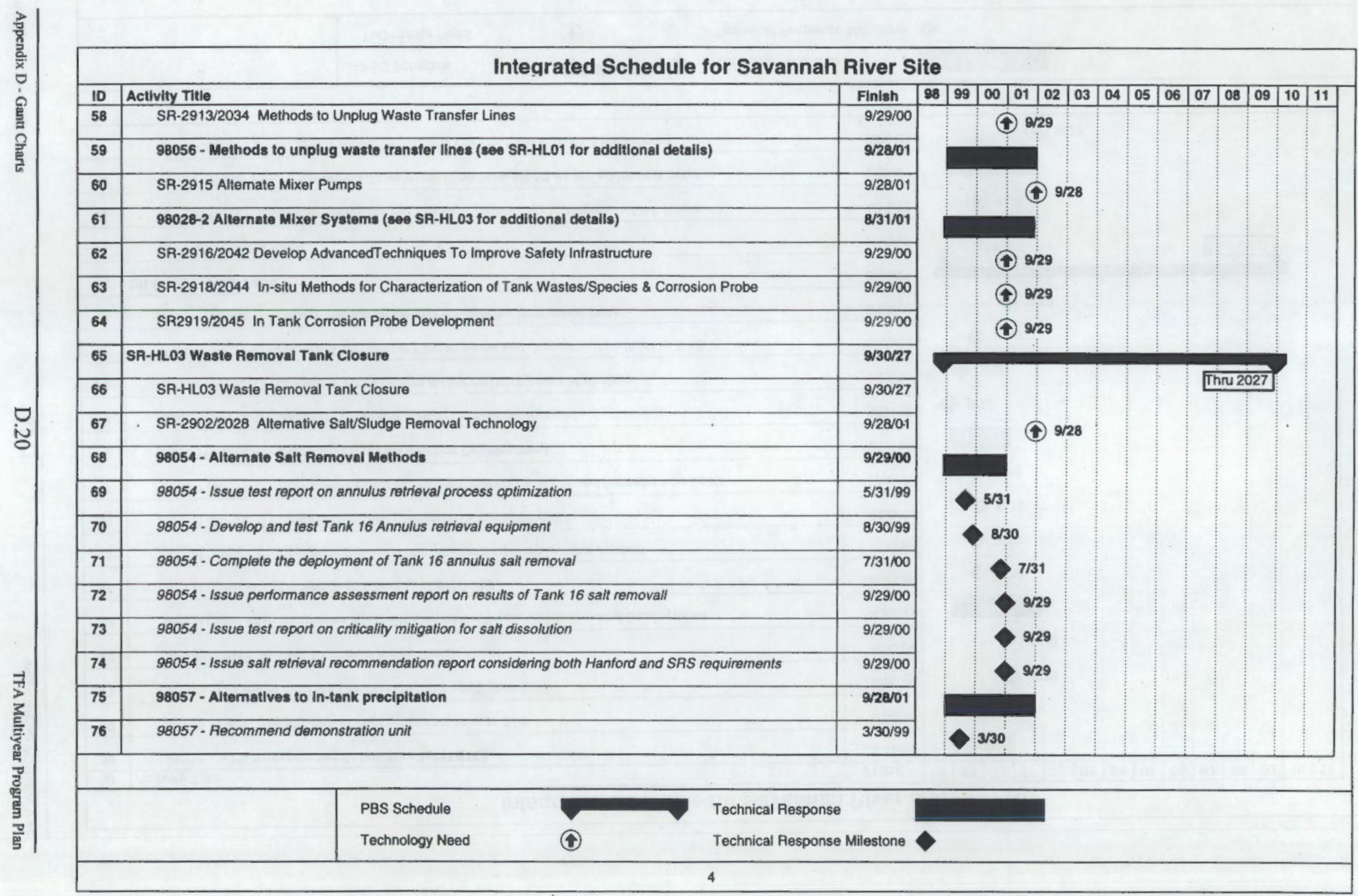




\section{Inteqrated Schedule for Savannah River Site}

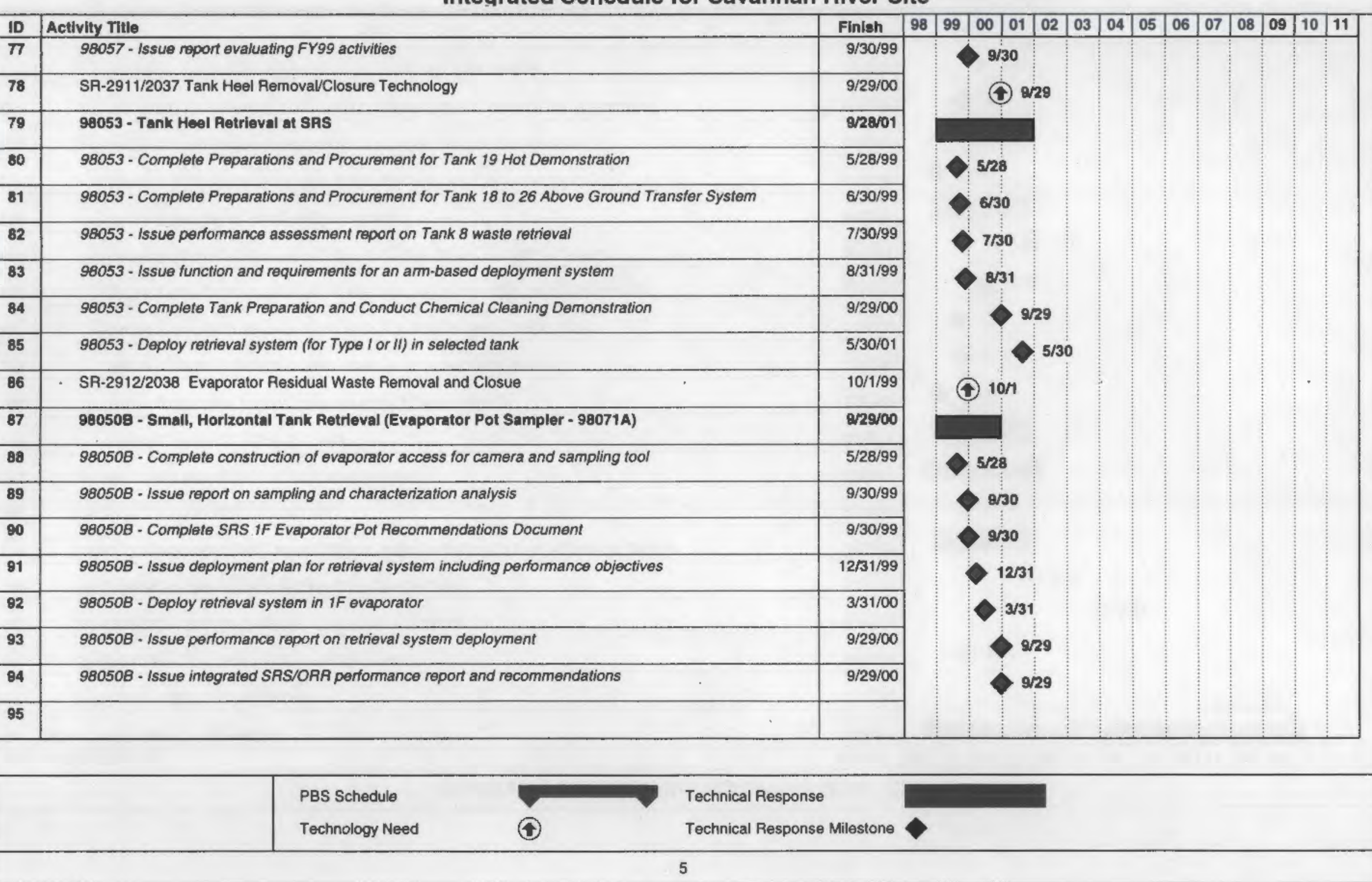


Integrated Schedule for Savannah River Site

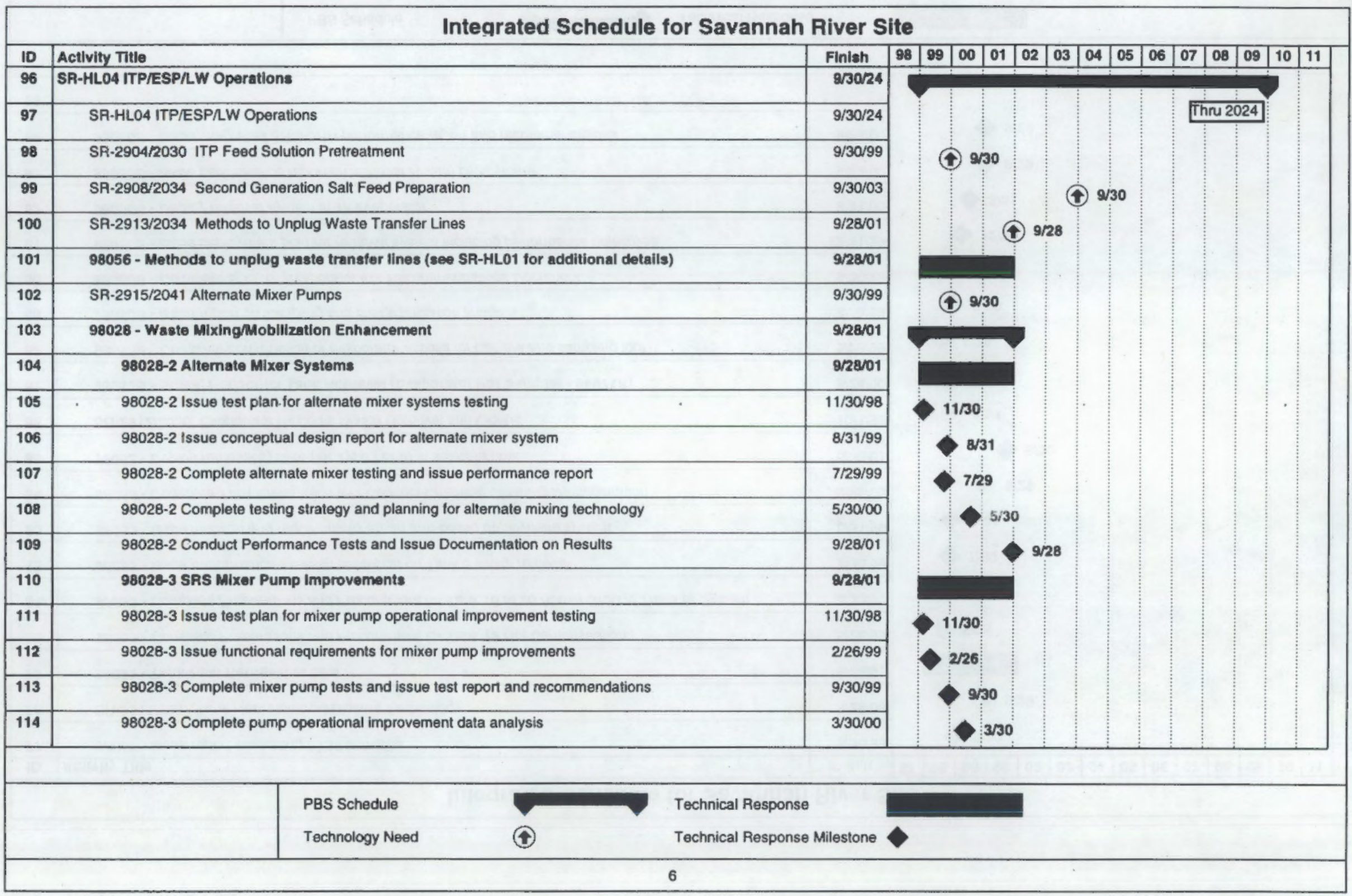




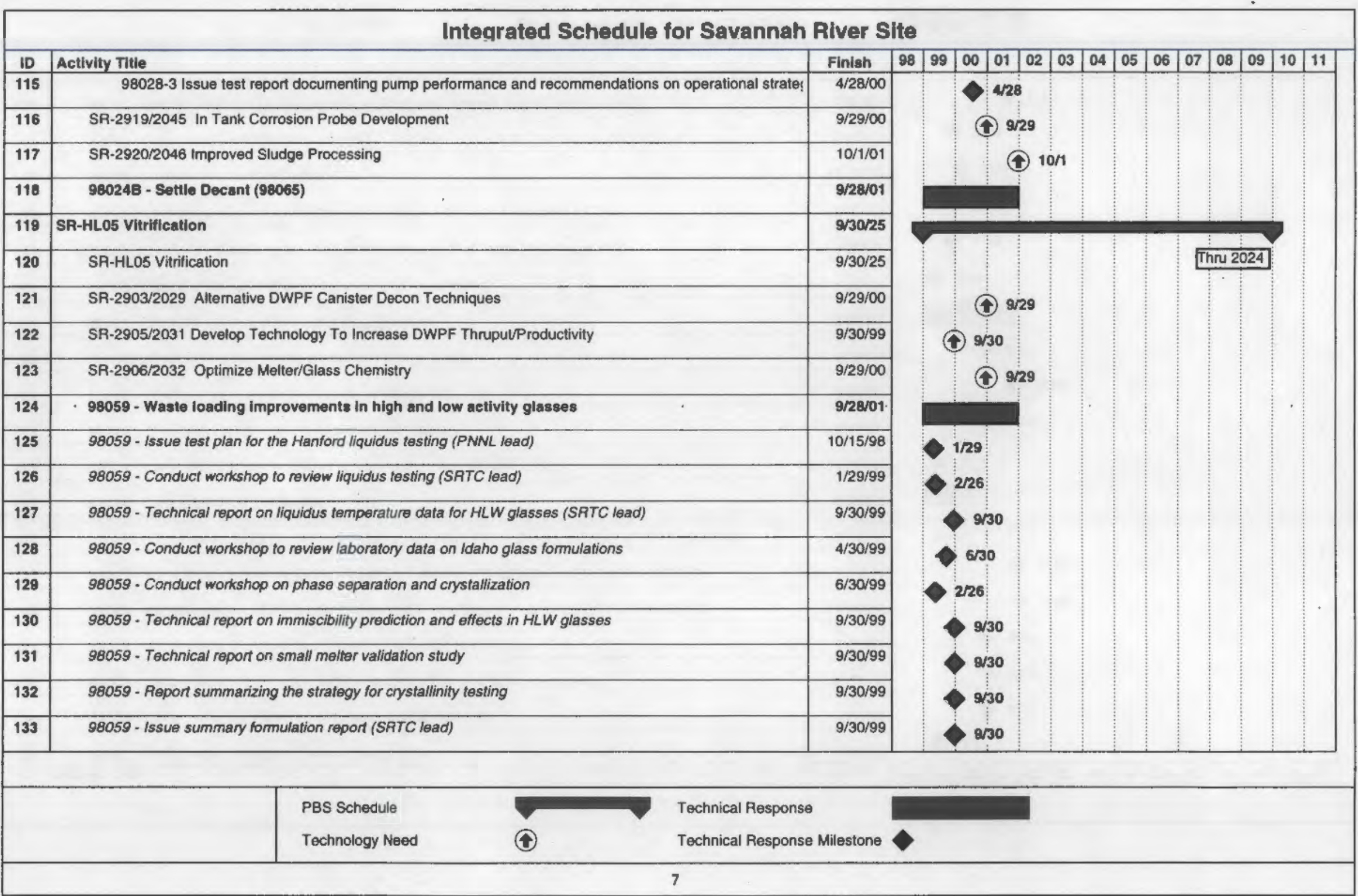




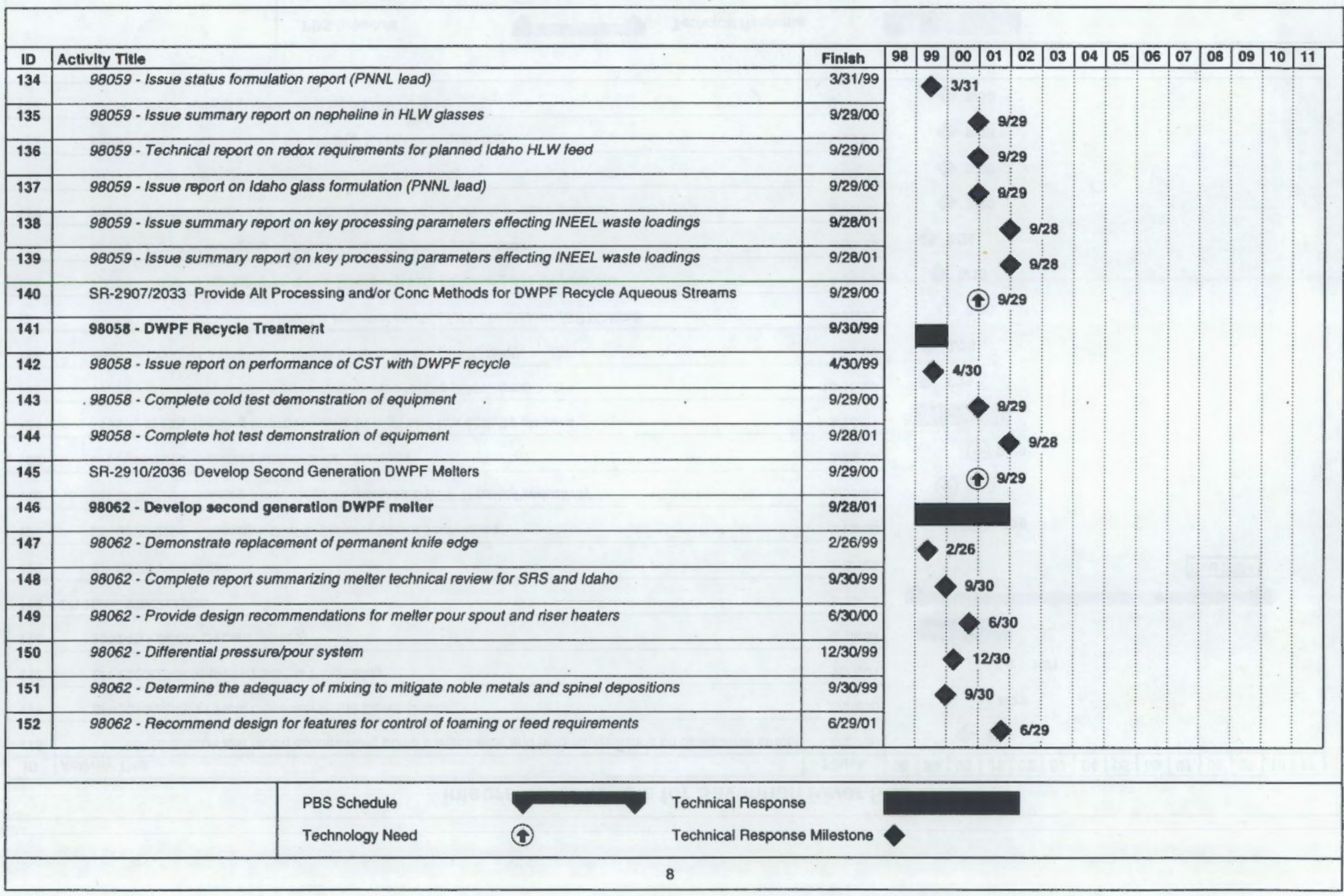




\section{Integrated Schedule for Savannah River Site}

\begin{tabular}{|c|c|c|c|c|c|c|c|c|c|c|c|c|c|c|c|}
\hline ID & Activity Titie & Finish & \begin{tabular}{l|l|l}
98 & 99 \\
\end{tabular} & 00 & 01 & 02 & 03 & 04 & 05 & 06 & 07 & 08 & 09 & 10 & 11 \\
\hline 153 & 98062 - Provide key design requirements for DWPF next generation meiter & 9/28/01 & & & & & 28 & & & & & & & & \\
\hline 154 & SR2914/2040 Demonstrate Remote Disassembly of HLW Melters and Other Processing Equipment & $6 / 29 / 01$ & & & & $6 / 2$ & & & & & & & & & \\
\hline 155 & SR-2917/2043 Develop Rernote Technology To Improve DWPF Operations & $9 / 29 / 99$ & & & & & & & & & & & & & \\
\hline 156 & SR-SW-01 Operate Consolidated Incineration Facillty & $9 / 30 / 30$ & & & & & & & & & & & & & \\
\hline 157 & SR-SW-01 Operate Consolidated Incineration Facility & $9 / 30 / 30$ & & & & & & & & & & 20 & & & \\
\hline 158 & SR2921 Volume Reduction for CIF Secondary Salt (NaCl) Liquid Waste & $9 / 29 / 00$ & & & & & & & & & & & & & \\
\hline 159 & 98073 - Consolldated Incinerator Facllity (CIF) evaporator & 9/30/99 & & & & & & & & & & & & & \\
\hline 160 & 98073 - Issue test plan for CIF evaporator corrosion and foaming tests & $11 / 30 / 98$ & & & & & & & & & & & & & \\
\hline 161 & 98073 - Complete corrosion tests and issue test report & $3 / 30 / 99$ & & & & & & & & & & & & & \\
\hline 162 & 98073 - Complete foaming evaluation tests and issue report . & $8 / 31 / 99$ & & & & & & . & & & & & & & \\
\hline 163 & 98073 - Issue interim operational status report of hot operations & $9 / 30 / 99$ & & & & & & & & & & & & & \\
\hline 164 & SR-HLO8 Operate Saltstone Facility & $9 / 30 / 09$ & & & & & & & & & & & & & \\
\hline 165 & SR-HL08 Operate Saltstone Facility & $9 / 30 / 09$ & & & & & & & & & & u & & & \\
\hline 166 & SR2923 Caustic Recovery and Pecycle & 9/29/00 & & & & & & & & & & & & & \\
\hline 167 & SR-ER-02 Four Mille Branch Project & 9/30/09 & & & & & & & & & & & & & \\
\hline 168 & SR-ER-02 Four Mile Branch Project & $9 / 30 / 09$ & & & & & & & & & & 220 & & & \\
\hline 169 & SR-3022 In-situ Grouting of Underground Tanks & $9 / 28 / 00$ & & & & & & & & & & & & & \\
\hline 170 & 98050A - Oak Rldge/ SAS Tank Closure & $9 / 29 / 00$ & & & & & & & & & & & & & \\
\hline 171 & $98050 A$ - Provide tank requirements information to ORNL (SRS) & $11 / 6 / 98$ & & & & & & & & & & & & & \\
\hline
\end{tabular}




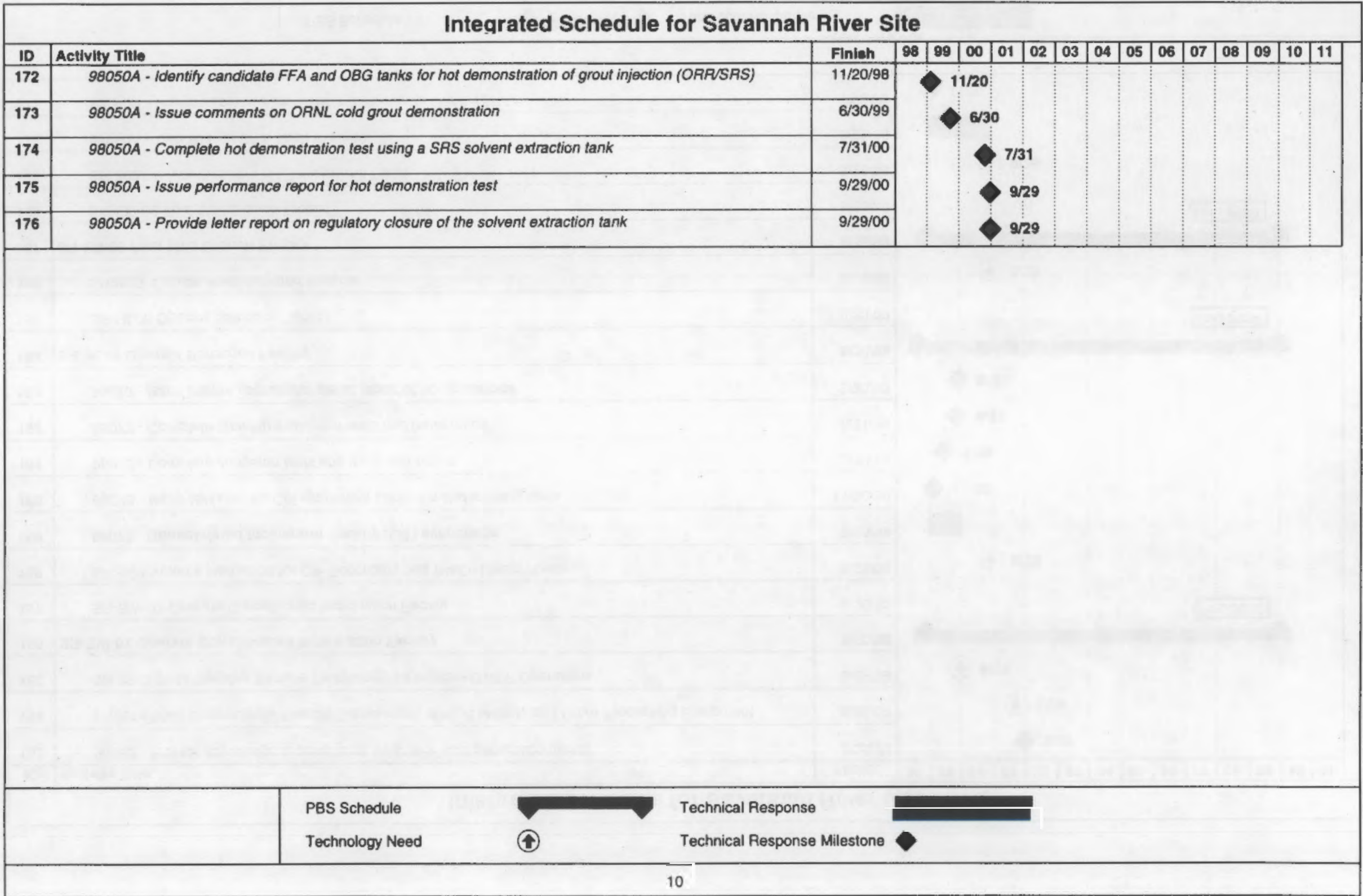




\section{Appendix E - Tanks Focus Area Organization}

This appendix provides the names of key Tanks Focus Area (TFA) team members. More TFA information may be found on the Internet:

- Office of Science and Technology Tanks Home Page at: http://em-52.em.doe.gov/ifd/tanks/tanks.htm

- TFA Technical Team Home Page at: http:/www.pnl.gov/tfa/. This home page also contains an extensive TFA contacts list.

\section{E.1 TFA Organization and Functions}

Before FY95, responsibility for remediating the U.S. Department of Energy's (DOE's) tanks and for developing supporting technologies was spread across multiple organizations and sites within the DOE complex. In January 1994, DOE issued an action plan establishing a new approach for solving complex remediation problems, including the high-level waste and transuranic waste tank problem. On April 1, 1994, DOE issued a call for proposals on approaches for transitioning tank technology development from a site-based effort to one with a national focus.

A team of seven contractors and national laboratories responded to the call for proposals and was awarded responsibility for implementing the new approach for tanks. In this effort, Pacific Northwest National Laboratory serves as the lead technical organization. Presently, this team is composed of Idaho National Engineering and Environmental Laboratory (INEEL), Los Alamos National Laboratory (LANL), Oak Ridge National Laboratory (ORNL), Sandia National Laboratories (SNL), Westinghouse Savannah River Company (WSRC), and Project Hanford Management Contractors (PHMC). The DOE's Richland Operations Office (DOE-RL) serves as the lead operations office and program manager of this team, coordinating the efforts of other site field activities through the TFA Management Team and Site Technology Coordination Groups (STCGs). See Figure E.1, Tanks Focus Area Organization.

The Technical Team is guided by the User Steering Group (USG) composed of senior managers from each of the Technical Team partners; there are user members from the four tank sites and three non-user members representing laboratories that participate on the team. The technical program is reviewed by the TFA Technical Advisory Group (TAG), which is composed of technical experts from across the country.

The RL leads the TFA Management Team, which prioritizes the techrical program and ensures TFA technical solutions are integrated into the site plans. The Management Team consists of DOE-Headquarters and Site Representatives from each of the user programs. 


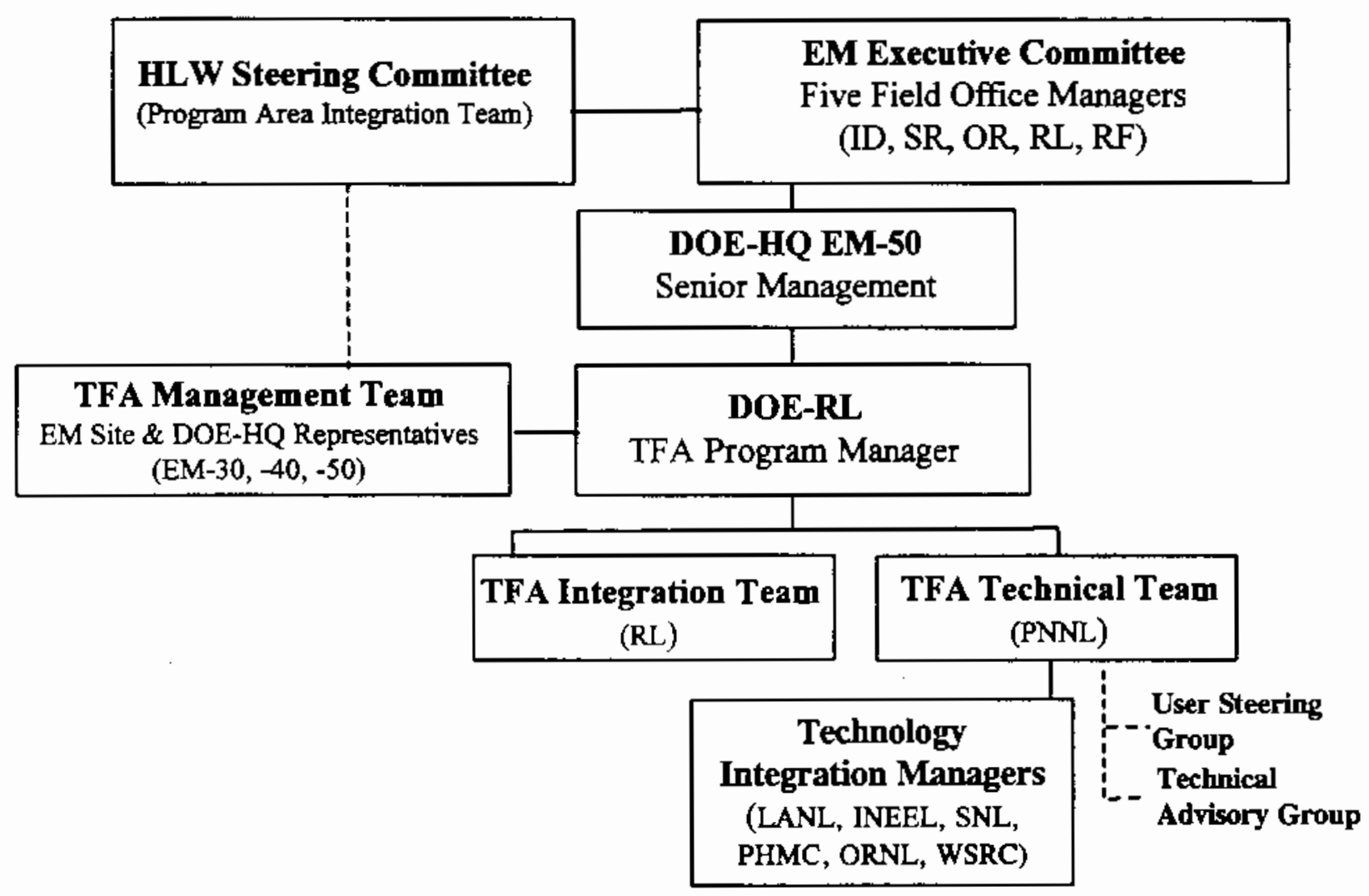

Figure E.1. Tanks Focus Area Organization

These representatives are also responsible for informing their line management of TFA activities and accomplishments, including members of the High-Level Waste Steering Committee.

The TFA began operations in October 1994. Its mission is to manage the development and demonstration of technologies using an integrated approach to safely and efficiently accomplish tank waste remediation across the DOE complex. Successful solutions will reduce technical, programmatic, or environmental, safety, and health risk and reduce the overall cost of tank remediation.

The TFA is responsible for technology development to support DOE's four major tank sites: Hanford Site, INEEL, Oak Ridge Reservation, and Savannah River Site. Its technical scope covers the major functions that comprise a complete tank remediation system: safety, characterization, retrieval, pretreatment, immobilization, and closure. The TFA integrates program tank-related activities across all organizations that fund tank technology development within DOE's Office of Environmental Restoration and Waste Management, comprising the Offices of Waste Management (EM-30), Environmental Restoration (EM-40), and Science and Technology (EM-50). In the future, the TFA will further integrate activities across and beyond the DOE complex as it strives to identify and leverage all available resources to address DOE's tank waste remediation needs. 
The following lists provide the names and positions of key TFA personnel.

\title{
TFA Management Team
}

Tom Gutmann, Site Representative, EM-30, DOE-SR, Aiken, SC

Cathy Louie, Site Representative, EM-30, DOE-RL, Richland, WA

Jacquie Noble-Dial, Site Representative, EM-50, DOE-OR, Oak Ridge, TN

Gene Woodall, Site Representative, EM-30, DOE-ID, Idaho Falls, ID

Dave Geiser, TFA DOE-HQ Program Manager, EM-50, DOE-HQ, Germantown, MD

Cavanaugh Mims, EM-40 Representative, DOE-OR, Oak Ridge, TN

Ken Picha, EM-30 Representative, DOE-HQ, Germantown, MD

\section{TFA Integration Team}

Jeff Frey, TFA PTogram Manager, DOE-RL, Richland, WA

Randy Brich, Program Execution Manager, DOE-RL, Richland, WA

Marcus Glasper, Program Integration Manager, DOE-RL, Richiand, WA

Lance Mamiya, Program Execution Manager, DOE-RL, Richland, WA

Billie Mauss, Program Development Manager, DOE-RL, Richland, WA

\section{TFA Technical Team}

Tom Brouns, Technical Team Manager, Pacific Northwest National Laboratory, Richland, WA

Bob Allen, Technical Program Integration Manager, Pacific Northwest National Laboratory, Richland, WA

Roger Gilchrist, Technical Integration Coordinator, Pacific Northwest National Laboratory, Ricbland, WA

Betty Carteret, Technology Delivery Managet, Pacific Northwest National Laboratory, Ricbland, WA

Bill Kuhn, EM Science Program, Pacific Northwest National Laboratory, Ricbland, WA

Kristin Manke, Communications, Pacific Northwest National Laboratory, Richland, WA

Steve Schlahta, Technical Operations Coordinator, Pacific Northwest National Laboratory, Richland, WA

Joe Westsik, Deputy Technical Integration Coordinator, Pacific Northwest National Laboratory, Richland, WA

\author{
Technology Integration Managers (TIM) \\ Larry Bustard, Closure TIM, Sandia National Laboratories, Albuquerque, NM \\ Pete Gibbons, Retrieval TIM, Numatec Hanford Corporation, Richland, WA \\ Bill Holtzscheiter, Immobilization TIM, Westinghouse Savannah River Company, Aiken, SC \\ Phil McGinnis, Pretreatment TIM, Oak Ridge National Laboratory, Oak Ridge, TN \\ Mike Terry, Safety TIM, Los Alamos National Laboratory, Richland, WA \\ Tom Thomas, Characterization TIM, Idaho National \\ Engineering and Environmental Laboratory, Idaho Falls, ID
}

\section{TFA User Steering Group}

Jim Honeyman, Lockheed Martin Hanford Corporation, Richland, WA

Arvid Jensen, Lockheed Martin Idaho Technologies Company, Idaho National Engineering and Environmental

Laboratory, Idaho Falls, ID

Jerry Morin, Westinghouse Savannah River Company, Aiken, SC

Tom Hirons, Los Alamos National Laboratory, Los Alamos, NM

Rod Quinn, Pacific Northwest National Laboratory, Richland, WA

Sharon Robinson, Martin Marietta Energy Systems, Inc., Oak Ridge National Laboratory, Oak Ridge, TN

Les Shephard, Sandia National Laboratories, Albuquerque, NM 


\section{TFA Technical Advisory Group}

Wally Schul, Group Chairman, W'2S Company, Inc., Albuquerque, NM

Jimmy Bell, Deputy Chairman, Bell Consultants, Inc., Kingston, TN

Pretreatment Subgroup

George Vandegrift, Subgroup Chairman, Argonne National Laboratory, Argonne, IL John Swanson, Private Consultant, Richland, WA

Major Thompson, Westinghouse Savannah River Company, Aiken, SC

\section{Characterization Subgroup}

Gary Eller, Subgroup Chaiman, Los Alamos National Laboratory, Los Alamos, NM

Dawn Kaback, Colorado Center for Environmental Management, Denver, CO

Bruce Kowalski, University of Washington, Seattle, WA

Immobilization Subgroup

Tom Weber, Subgroup Chairman, Private Consultant, Kennewick, WA

Joe Gentilucci, JAG Technical Services, Inc., Aiken, SC

William Prindle, Private Consultant, Santa Barbara, CA

\section{Retrieval Subgroup}

Paul Scott, Subgroup Chairman, Pacific Northwest National Laboratory, Richland, WA

Brenda Lewis, Westinghouse Savannah River Company, Aiken, SC

\section{Safety Subgroup}

Larry Tavlarides, Subgroup Chairman, Syracuse University, Syracuse, NY

\section{Closure Subgroup}

Robert Erdmann, Subgroup Chairman, Attomey, Grass Valley, CA

Jimmy Bell, Bell Consultants, Inc., Kingston, TN

\section{At-Large Members}

John Carberry, DuPont, Wilmington, DE

Greg Choppin, Florida State University, Tallahassee, FL

Larry Tavlarides, Syracuse University, Syracuse, NY 
믐 


\section{Appendix F - Crosswalk of Work Packages to Budget Formulation Product Lines}

Table F. 1 shows a crosswalk between the seven TFA work packages and its three budget formulation product lines.

Table F.1. Work Package Crosswalk to Product Lines

\begin{tabular}{|c|c|c|}
\hline Budget Formulation Product Line & TFA Work Package* & FY00 Funding (\$K) \\
\hline \multirow{4}{*}{ WT-01 Retrieval and Closure } & TFA-1 & $\$ 17,035$ \\
\hline & TFA-2 & 2,558 \\
\hline & TFA-7 & 50 \\
\hline & Total & 19,643 \\
\hline \multirow{6}{*}{ WT-02 Pretreatment and Immobilization } & TFA-2 & 6,937 \\
\hline & TFA-3 & 8,372 \\
\hline & TFA-4 & 6,080 \\
\hline & TFA-6 & 4,750 \\
\hline & TFA-7 & 2,375 \\
\hline & Total & 28,514 \\
\hline \multirow{3}{*}{ WT-03 Hanford Tanks Initiative } & TFA-5 & 8,900 \\
\hline & Total & 8,900 \\
\hline & Grand Total & $\$ 57,057$ \\
\hline \multicolumn{3}{|c|}{$\begin{array}{l}\text { *Work Packages } \\
\text { TFA-1: Technology Deveiopment to Support Closure } \\
\text { TFA-2: HLW Immobilization and Product Acceptance } \\
\text { TFA-3: Alternative Paths to Salt Waste Treatment at SRS } \\
\text { TFA-4: Slurry Preparation for Feed to HLW Vitrification } \\
\text { TFA-5: Hanford Tanks Initiative } \\
\text { TFA-6: Pretreatment to Reduce High- and Low-Level Waste Forms } \\
\text { TFA-7: INEEL and ORR Tank Waste Immobilization Cesium and Strontium }\end{array}$} \\
\hline
\end{tabular}





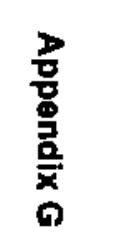




\section{Appendix G - Description of DOE's System for Remediating Tank Waste}

The U.S. Department of Energy (DOE) stores radioactive waste in tanks at Hanford Site, Washington; Idaho National Engineering and Environmental Laboratory (INEEL), Idaho; Oak Ridge Reservation (ORR), Tennessee; and Savannah River Site (SRS), South Carolina.

The Tanks Focus Area (TFA) selects user-driven solutions that reduce cost and risk and resolve regulatory and technical uncertainties. To support this goal, the technical program recommended in this multiyear program plan is based on assessment of the needs and qualitative judgments of the relative costs and risks of tank remediation at the four DOE sites. This appendix provides a brief summary of the sites, the wastes, the waste storage environments, regulatory drivers, and major site tank waste remediation milestones for these four DOE sites.

\section{G.1 Hanford Site}

The Hanford Site is a $560-\mathrm{mi}^{2}$ former plutonium production site in the southeastern part of Washington State just north of where the Snake and Yakima rivers meet with the Columbia River and about 25 mi north of the Oregon border. This area is dry, flat land surrounded by hills. In January 1943, Hanford was selected for the nation's first industrial-scale production site for plutonium.

For the first 45 years, the Site's primary mission was to produce plutonium for national defense and manage the resulting waste. In 1989, all production facilities were shut down and the mission diversified to include technology development, waste management, and environmental restoration. The Hanford Site was placed on the National Priorities List under the Comprehensive Environmental Response, Compensation, and Liability Act (CERCLA). There are several major facility areas requiring cleanup: 100 Areas, 200 Areas, 300 Area, 400 Area, 700 Area, 1100 Area, and 3000 Area (DOE 1995b). Hanford tank farms are located in the 200 East and 200 West Areas (see Figure G.1). In addition to cleaning up tanks, site problems include cleaning up or containing billions of liters of liquids discharged to the soil, decommissioning and decontaminating nine production reactors and hundreds of process-related facilities, disposing of stored solid wastes, and removing spent fuel from basins in the 100 Area (Gephart and Lundgren 1998, in press).

\section{G.1.1 Characteristics of Hanford Tank Waste}

The tank waste consists of high-level waste (HLW), transuranic (TRU) waste, and low-level waste $(\mathrm{LLW})$. The total activity of the waste stored is estimated to be about $128.3 \mathrm{MCi}$ in the tank solids and $70.1 \mathrm{MCi}$ in the tank liquids. The principal activity of the waste comes from cesium-137 and strontium-90 and their decay products (barium-137m and yttrium-90). 


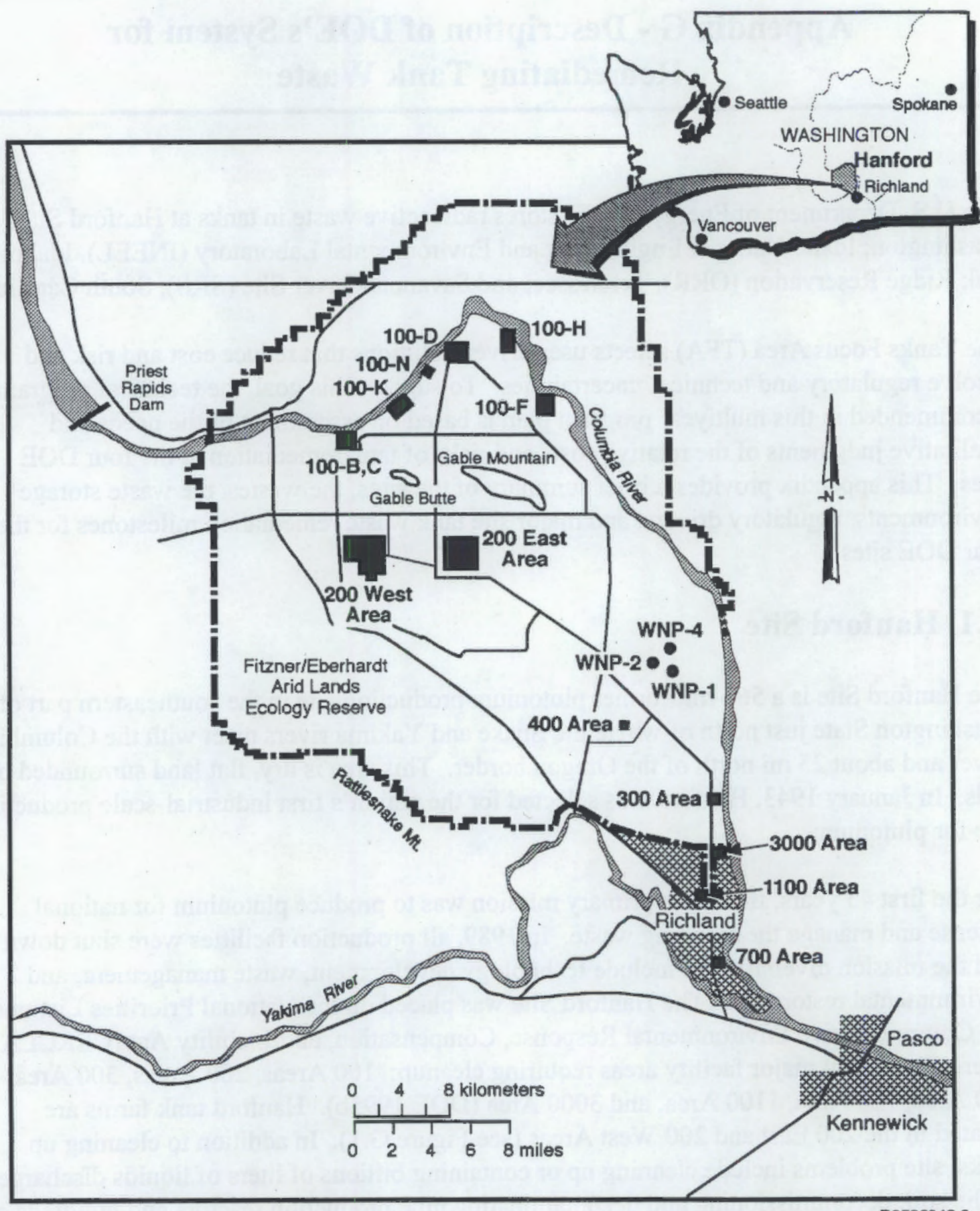

R9506042.6

Figure G.1. Hanford Site and Major Facilities 
Cesium- 137 is soluble and in the supernate, and strontium- 90 is largely contained in the sludge. The chemical constituents of the sludge are mostly precipitated sodium salts, heavy metals, and iron, aluminum, and other hydrated metal oxides. Saltcake is primarily sodium nitrate; and the supernate contains large amounts of dissolved sodium salts, especially nitrates and nitrites.

\section{G.1.2 Waste Generation at the Hanford Site}

The chemical and physical processes for separating plutonium from uranium and the rest of the chemical waste generated in Hanford plants changed over the years. Therefore, the composition of the waste piped to the tanks also varied.

First, uranium fuel in the form of uranium metal, which is surrounded by a thin-walled metal covering (called cladding) of aluminum and later Zircaloy (mostly zirconium) was placed in one of the nine nuclear reactors built between 1943 and 1963 along the Columbia River on the northern edge of the Site. The cladding surrounding the uranium fuel prevented chemical reactions between the uranium and cooling water, plus prevented radioactive fission products from getting into the reactor's cooling water.

The uranium fuel (uranium-238) was irradiated by being exposed to and capturing lowenergy neutrons emitted by uranium-235, as it underwent fission. Irradiating uranium-238 created more complex elements, such as plutonium-239. The fission of uranium-235 also created short-lived (less than a second) to long-lived (decades to millions of years) radioactive elements called fission products. The irradiated fuel was then transported in specially shielded rail cars to a reprocessing facility away from the Columbia River in the center of the Hanford Site.

From the 1940s to the mid-1950s, five of these reprocessing facilities were built: T Plant, B Plant, U Plant, the Reduction and Oxidation (REDOX) Plant, and the Plutonium and Uranium Extraction (PUREX) Plant. From 1944 to 1989, Hanford facilities reprocessed 110,000 ton of uranium fuel $-74 \%$ of this reprocessing took place at the PUREX Plant.

On average, approximately $1.5 \mathrm{lb}$ of plutonium-239 was chemically separated from each ton of reprocessed uranium fuel at a reprocessing plant. Over the years, several processes were used. Plutonium was recovered and purified from the dissolved uranium and fission products in the early Hanford plants by a bismuth phosphate $\left(\mathrm{BiPO}_{4}\right)$ chemical precipitation process and in later plants by two solvent extraction processes.

The first solvent extraction process used methyl isobutyl ketone (also known as hexone) $\left[\left(\mathrm{CH}_{3}\right)_{2} \mathrm{CHCH}_{2} \mathrm{COCH}_{3}\right]$ as the organic solvent with aluminum nitrate $\left[\mathrm{Al}\left(\mathrm{NO}_{3}\right)_{3}\right]$ added to improve uranium and plutonium separation from other radionuclides. This process was called the REDOX process. The first large-scale operation of the REDOX process began at 
Hanford in 1952 in the S Plant (also called the REDOX Plant). It offered several advantages over the bismuth phosphate process by 1 ) reducing waste volume, 2) recovering both uranium and plutonium, and 3) allowing continuous plant operations.

An improved solvent-extraction process called the PUREX process was subsequently developed. It differed from REDOX in the use of tributyl phosphate $\left[\left(\mathrm{C}_{4} \mathrm{H}_{9}\right)_{3} \mathrm{PO}_{4}\right]$ as the organic solvent and nitric acid as a salting agent. The PUREX process was first used at the site near Savannah River in 1954. In 1956, the process was used at Hanford in the A Plant (also called the PUREX Plant). It offered several advantages compared to the REDOX process including 1) increased reduction in waste volume, 2) greater flexibility in process control, 3) less fire hazard, and 4) decreased operation costs.

The solvent extraction processes created two liquid waste streams. The extractant contained plutonium and uranium. This stream then went through several chemical processing steps to separate the plutonium and uranium from each other, from other chemicals, and from other fission products. The second stream was called raffinate. This was considered waste and discharged to the tanks. It contained some $99 \%$ of all the fission products such as cesium and strontium. Some waste was also generated from the chemical separation processes undertaken in the extractant stream. That considered HLW was piped to the underground tanks. Less radioactive waste was discharged to the soil through cribs and trenches.

These processes generated liquid wastes containing large quantities of contaminated nitric acid, chemicals, fission products, and miscellaneous waste. Before being piped to a carbonsteel underground storage tank, these highly radioactive wastes were mixed with sodium hydroxide $(\mathrm{NaOH})$ to neutralize the acidic liquids by making the solutions strongly basic (pH 10-14).

Processes used to recover plutonium and uranium from irradiated fuel and to recover radionuclides from tank waste have resulted in a legacy of more than $54 \mathrm{Mgal}$ of wastes. Because of the various processes, the waste is found in a variety of layers. Some is an insoluble sludge with interstitial liquids, some is in the form of crystalline water-soluble solids (called saltcake), and some is in the form of supernatant liquids. Most of the pumpable liquids have been transferred from single- to double-shell tanks.

\section{G.1.3 Storage Tanks at the Hanford Site}

Hanford's tanks are cylindrical reinforced concrete structures with inner carbon steel liners. Tanks are split into two groups based on their design: 149 tanks have a single carbon steel liner and 28 tanks have two steel liners separated by a space called the annulus. The domes of the single-shell tanks are made of concrete without a steel inner liner. The double-shell tanks are completely enclosed by steel and reinforced by a concrete shell. Both single-shell tanks and double-shell tanks are covered with about $10 \mathrm{ft}$ of soil and gravel. 
These tanks contain about $200 \mathrm{MCi}$ of radioactivity.(mostly cesium-137 and strontium-90) and 240,000 ton of chemicals (mostly sodium nitrate). This is $50 \%$ of the radioactivity and $60 \%$ of the chemical waste at the Hanford Site.

In the 200 East and 200 West Areas of the Hanford Site, the tanks were built in 18 groups called tank farms. The farms contain from 2 to 16 tanks and hold different amounts of waste. The farms contain underground pipes so the waste can be pumped between tanks, between tank farms, from different facilities, and even between the 200 East and 200 West Areas. These farms also include equipment that is used to route the waste, such as diversion boxes and valve pits.

Because of the large volume of HLW produced, tank space was very limited. Various treatments were used to reduce the amount of liquid. One method involved waste evaporation. The first tank waste concentrators went into operation in 1951. They were steamheated pot-like evaporators operated at atmospheric pressure outside the tanks. Waste was piped from the single-shell tanks and into these concentrators to partially boil down the liquids.

The operation of the 242-S (located in 200 West Area near the REDOX Plant) and 242-A Evaporator-Crystallizers (located in 200 East Area near PUREX Plant) began in 1973 and 1977, respectively. These evaporators were used to boil off water from the tank liquids at a much larger scale than previous techniques. This was accomplished by pumping liquids from the tanks into the evaporator. Evaporation was carried out until a thick slurry was created containing about $30 \%$ by weight of solids. The slightly hot, concentrated slurry was then piped back into a tank where it cooled, crystallized, and/or settled to the tank's bottom. Between 1950 and 1995, approximately $200 \mathrm{Mgal}$ of liquids were evaporated from Hanford's tank waste.

Another early Hanford technique involved heating the tank's liquids from inside the tank. One approach used an electric heater inserted directly into the waste. The heated waste was then circulated into other tanks. A second approach involved circulating hot air in an individual tank through a perforated pipe.

Precipitating and settling otherwise soluble radioactive chemicals was another method; this made the tank's upper liquid layer less radioactive and less hazardous so it could be disposed of in the ground. From 1954 to 1957, radioactive cesium-137 was precipitated out of the solution by adding potassium ferrocyanide $\left[\mathrm{K}_{4} \mathrm{Fe}(\mathrm{CN})_{6}\right]$ and nickel sulfate $\left(\mathrm{Ni}_{2} \mathrm{SO}_{4}\right)$ to waste piped to the Uranium Recovery Plant. After the cesium settled out, the less radioactive liquid was sent to cribs. A crib is like a shallow buried tile field used to dispose of liquid wastes. With the tank liquids lowered, more plant reprocessing waste could be put in the tanks. Approximately 150 ton of ferrocyanide were added to some tanks in this process. 


\section{G.1.3.1 Single-Shell Tanks}

The single-shell tanks were built from 1943 to 1964 to hold the liquid radioactive waste created by the production and separation of plutonium. The 149 single-shell tanks were built at Hanford in four sizes:

- 16 have a capacity of $55,000 \mathrm{gal}$

- 60 have a capacity of 530,000 gal

- 48 have a capacity of $758,000 \mathrm{gal}$

- 25 have a capacity of $1 \mathrm{Mgal}$.

Over the years, the design of the single-shell tanks changed to better accommodate the waste being stored and to reduce the occurrence of metal corrosion and cracking. Alterations included adding equipment to handle self-boiling waste, increasing size, and changing the bottom to a flat surface instead of a bowl shape.

Another change was the addition of a grid of drain slots beneath the steel liner. The grids were designed to collect leakage and divert it to a leak detection well. Further, several 530,000-gal and 758,000-gal single-shell tanks were built in cascades of three or four tanks. These cascading tanks were connected with piping at different levels. Thus, when one tank filled to the level of the pipe, waste would flow through the pipe to the next tank. This allowed the solid contents of the tank waste to settle to the bottom. The liquid waste that went to the next tank had less solids and less radioactivity (mostly in the form of cesium; strontium had settled out in the solids).

\section{G.1.3.2 Double-Shell Tanks}

Double-shell tanks were built to provide more tank space. Liquid from the single-shell tanks was pumped into the newer, safer double-shell tanks. This left the single-shell tanks containing mostly saltcake and sludge, with some liquids. From then on, the double-shell tanks received supernatant liquids pumped directly from operating reprocessing plants such as the PUREX Plant and supernatant liquids pumped from single-shell tanks. The double-shell tanks were built from 1968 to 1986 (Figure G.2) and have two capacities:

- 4 tanks have a capacity of $1.0 \mathrm{Mgal}$

- 24 tanks have a capacity of $1.16 \mathrm{Mgal}$.

Generally, these tanks contain liquids and thicker slurries. Some tanks also contain a bottom layer of sludge. Approximately $75 \%$ of the double-shell tank waste consists of waste pumped from single-shell tanks to minimize the potential for leakage. 


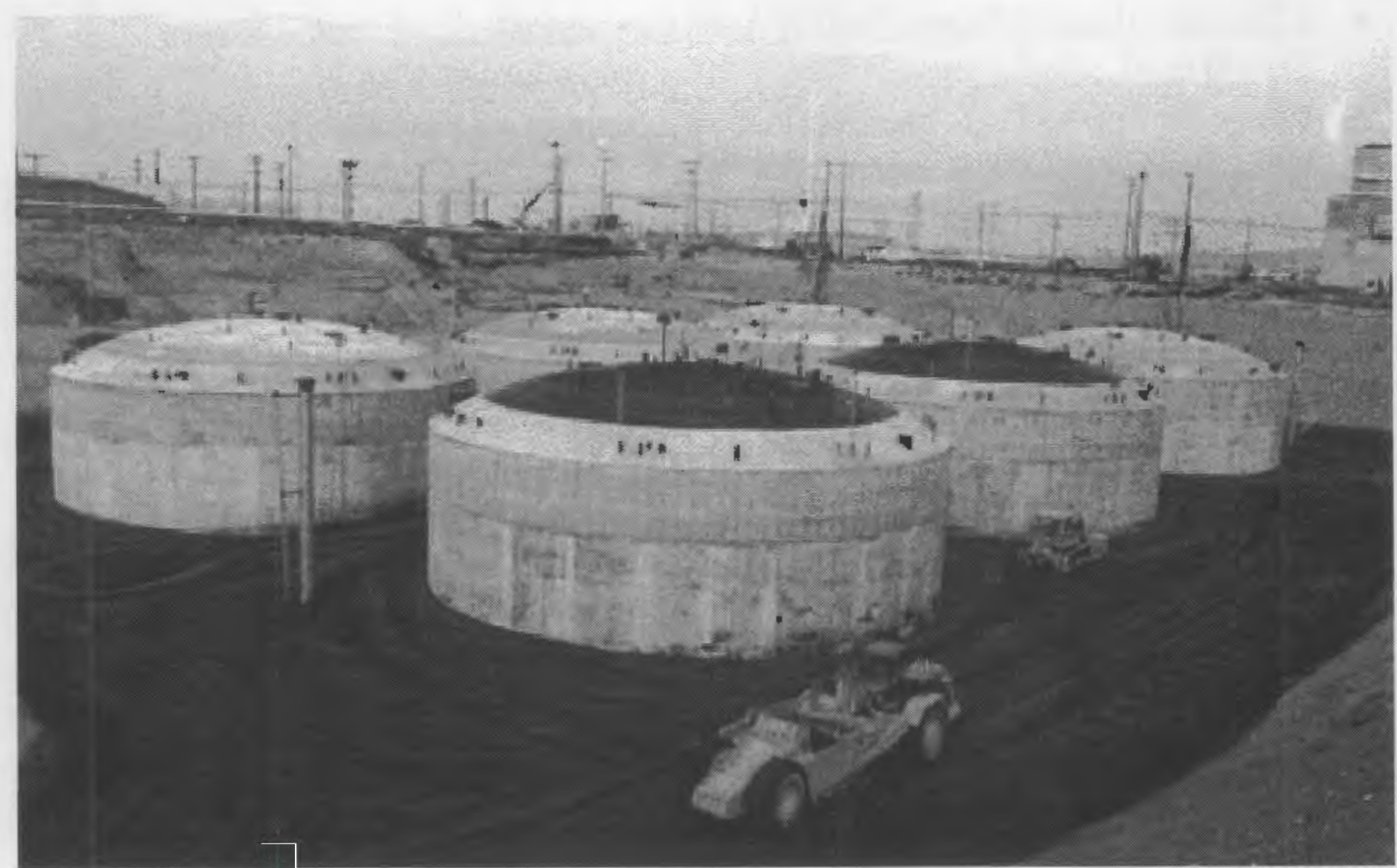

$7813231-26 \mathrm{CN}$

Figure G.2. Hanford Double-Shell Tanks Under Construction

\section{G.1.4 Regulatory Drivers for the Hanford Site}

Regulatory drivers for remediating tank wastes at Hanford are as follows:

- Hanford Federal Facility Agreement and Consent Order (Ecology et al. 1994). This agreement between the U.S. Environmental Protection Agency Region X, the DOE, and the Washington State Department of Ecology established the requirements for meeting federal and State Resource Conservation and Recovery Act regulations. The Hanford Federal Facility Agreement and Consent Order was originally signed in 1989 and then amended in 1994. The amended agreement committed Hanford to retrieval of waste from the single-shell tanks, vitrification of LLW, cessation of the grout program, and National Environmental Policy Act coverage of actions. This agreement serves as the site treatment plan required under the Federal Facility Compliance Act of 1992 (PL 102-386).

- Hanford Federal Facility Agreement and Consent Order 1996 Amendments (DOE-RL and Ecology 1996b). A Hanford Federal Facility Agreement and Consent Order change package was submitted that recognizes DOE's plans for private financing and operation of the tank waste treatment facilities (Tank Waste Remediation System Privatization Request for Proposal No. DE-RP06-96RL13308 [DOE-RL 1996c]). The change did not affect major milestones for the processing of tank waste, except that low-activity wastes will be treated by 2024 instead of 2028 . 
- Changes to Hanford Federal Facility Agreement and Consent Order Milestone M-44-00, Tank Waste Characterization. Submitted for public comment on July 15, 1997. This change package will eliminate requirements for sampling a predetermined number of tanks and instead base characterization on the needs identified by the programs.

- Draft Environmental Impact Statement (EIS) for the Tank Waste Remediation System (TWRS) (DOE-RL and Ecology 1996a). The EIS provides information that has the potential to rebaseline tank waste remediation. The environmental consequences of a number of alternatives for treating tank waste, including in situ treatment, are evaluated. A record of decision for the TWRS EIS, signed in February 1997, stated that the phased approach was the best path forward for treating tank wastes.

- Draft Hanford Remedial. Action Environmental Impact Statement and Comprehensive Land Use Plan (DOE-RL 1996). DOE has developed a land use plan for Hanford that is included in the EIS for Hanford remedial actions. The EIS was released in 1996. The plan and the record of decision for the EIS will identify land uses and accompanying restrictions for major site areas. The future land use currently assumed for the 200 Areas is industrial and/or commercial. This area will likely be held exclusively for disposal, containment, and management of waste, and other compatible uses. Access to the area and use of the groundwater is assumed to be restricted indefinitely.

- DOE/Ecology Retrieval Performance Objectives Memorandum of Understanding (MOU). The MOU specifies cost, risk and safety as some of the key parameters that must be evaluated in defining the tank waste end-state. The Hanford Tanks Initiative project is providing risk, cost, and performance data that will be necessary in establishing the retrieval performance objectives.

- Project Hanford Management Contract. Fluor Daniel Hanford, Inc., and its contractors manage and integrate remediation of the Hanford Site. The contract sets many near-term DOE-specified performance measures for tank waste disposal including designing a retrieval system by 2001 , providing feed material to the low-activity waste immobilization facility by 2002 , and constructing a low-activity waste interim storage facility by 2002. These performance objectives are not negotiable.

- Defense Nuclear Facilities Safety Board Recommendation 93-5 (DOE-RL 1994). The board issued recommendations to accelerate tank waste sampling at Hanford to ensure adequate protection of public health and safety. Safety-related sampling and analysis are to be completed by July 1995 and in other tanks by July 1996 . These deadlines have not been met.

- Integrated Vadose Zone Program. A program was established by TWRS to assess risk during waste retrieval, treatment, and closure from leaking tanks. A vadose zone program plan is under development. 
- Richland Accelerated Cleanup Plan (DOE-RL 1997). The plan describes how the site will meet existing cleanup agreements. Stakeholders have demanded that the goals of existing cleanup agreements not be compromised. Hanford completes vitrification of tank waste in 2028 .

\section{G.1.5 Milestones for the Hanford Site}

Selected Hanford Site milestones are shown in Table G.1.

Table G.1. Hanford Site Milestones

\begin{tabular}{|l|c|}
\hline \multicolumn{1}{|c|}{ Milestone Titie } & $\begin{array}{c}\text { Completion } \\
\text { Date }\end{array}$ \\
\hline \hline Construct initial low- and high-activity immobilization plants & 2002 \\
\hline Treat and immobilize 6 to 13\% of tank waste & 2011 \\
\hline Immobilize low-activity waste & 2024 \\
\hline Immobilize remaining tank waste & 2028 \\
\hline Close all tanks & 2032 \\
\hline
\end{tabular}

\section{G.2 Idaho National Engineering and Environmental Laboratory}

The $890-\mathrm{mi}^{2}$ Idaho National Engineering and Environmental Laboratory (INEEL) is located in eastern Idaho on a generally flat plain (see Figure G.3). The site was founded in 1949 as the National Reactor Testing Station. The first facilities, built in the early 1950s, supported the Experimental Breeder Reactor where the first usable amounts of nuclear-generated electricity were produced. Over time, a variety of other reactors were built here. A prototype for the reactor used in the first nuclear-powered submarine was developed. Also, three of the nation's commercial power reactor designs (the pressurized water reactor, the boiling water reactor, and the liquid metal cooled breeder reactor) were built and demonstrated. In total, 52 separate reactors have been built and operated at the site. All but one of these reactors has been decommissioned.

\section{G.2.1 Characteristics of INEEL Tank Waste}

As of August 1998, the total tank waste inventory stood at about 1.4 Mgal consisting of sodium-bearing waste generated from activities incidental to reprocessing, such as facility decontamination. In general, the tank waste at the Idaho Nuclear Technology and Engineering Center (INTEC, formerly the Idaho Chemical Processing Plant) is rather different from the waste at the other DOE tank sites. The INTEC waste is characterized by large concentrations of nitrates and dissolved metals such as aluminum, potassium, and sodium 


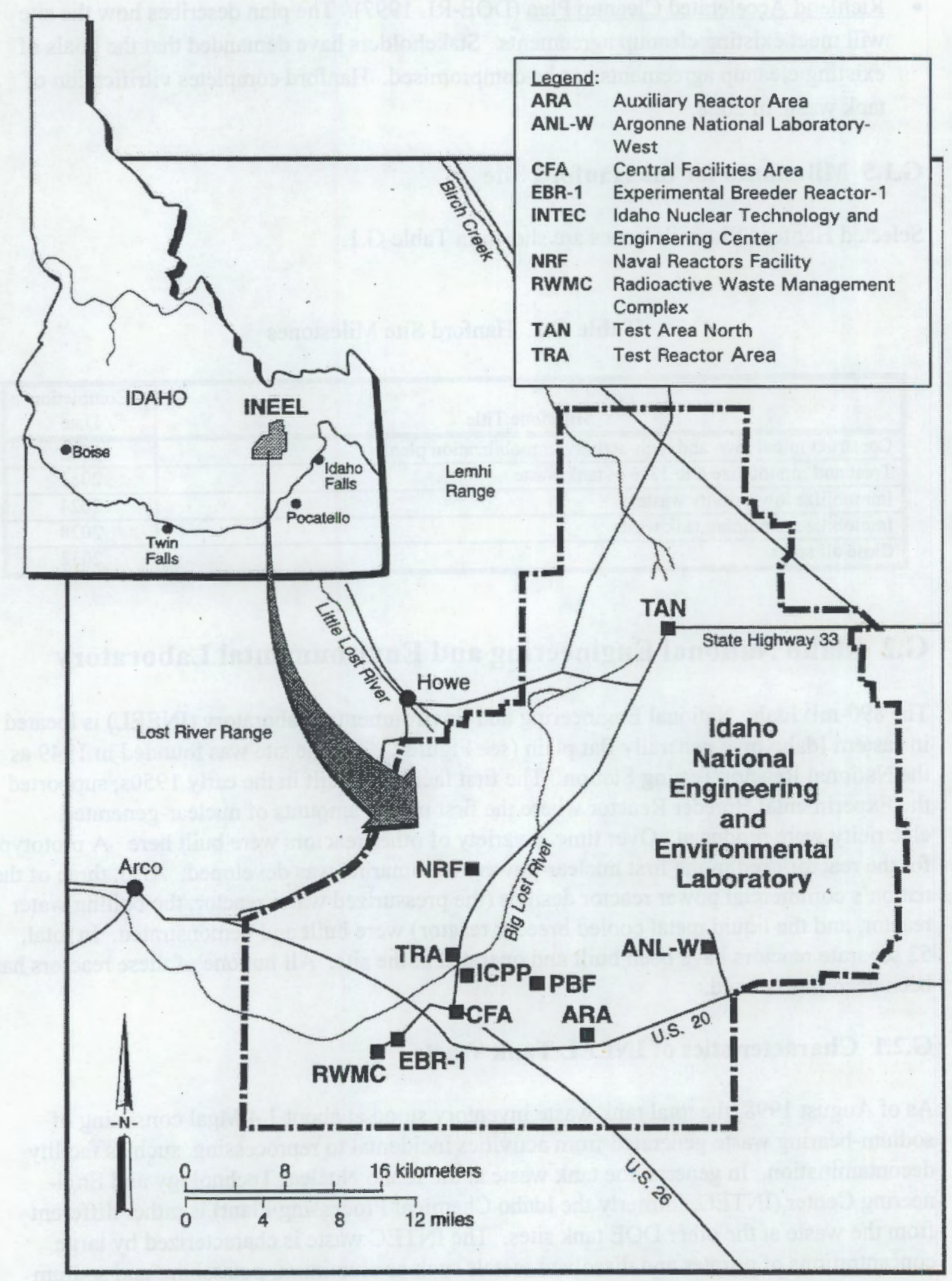

Figure G.3. Idaho National Engineering and Environmental Laboratory and Major Facilities 
with small concentrations of sulfates, chlorides, and heavy metals such as chromium and nickel (Rouse et al. 1993, p. 6-21). The tank waste is extremely acidic, with a pH of less than 1 (Rouse et al. 1993, p. 6-19). The liquid waste has a density of 1.1 to $1.3 \mathrm{~g} / \mathrm{cm}^{3}$ (Rouse et al. 1993, p. 6-19). The waste is composed predominantly of nitric acid $\left(\mathrm{HNO}_{3}\right)$ and sodium nitrate $\left(\mathrm{NaNO}_{3}\right)$. Small amounts of fission products and transuranic elements are also in the waste. Some of the major constituents of waste by molarity (nominal) are nitrate, 4.5 ; sodium, 1.5 ; acid, 1.3 ; aluminum, 0.57 , and potassium, 0.17 . The very basic (high $\mathrm{pH}$ ) waste in the other site's tanks caused many radioactive and nonradioactive metals to segregate into a complex chemical and physical mixture of liquids, slurries, and sludges. In contrast, the metals and other dissolved material in INTEC's acidic tank waste remain in solution. Other than a few inches of accumulated solids on the bottom of the tanks, the liquid is clear to the bottom of the tanks. This simplifies waste characterization and retrieval compared to other DOE tank sites.

INTEC's tank waste has been divided into two categories: high-level liquid waste and sodium-bearing waste. All of the high-level liquid waste resulting from the dissolution and processing of spent nuclear fuel has been calcined (see calcination description below) and only sodium-bearing waste remains in storage in the tank farm.

\section{G.2.2 Waste Generation at INEEL}

Several waste management facilities were built at INEEL. A key facility is INTEC. Building began on this facility in 1951, and it was operating by 1953 . This plant received, stored, and reprocessed spent nuclear fuel for the recovery of uranium-235. It is one of eight reprocessing facilities built in the DOE complex. The other seven were at Hanford (five plants) and SRS (two plants). Most reprocessing was performed on zirconium-clad uranium fuel used in the Navy's propulsion reactors. Significant quantities of fuel clad in aluminum, stainless steel, and graphite were also reprocessed. DOE terminated reprocessing activities in 1992.

Reprocessing began with the receipt of spent reactor fuel; it arrived in shielded casks via truck or rail. The spent fuel was removed from the casks and stored under water at the Fuel Receiving and Storage Building. If the fuel was not suitable for underwater storage due to corrosion or reactivity concerns, it was stored in dry storage facilities.

Next, the fuel was dissolved in either hydrofluoric acid for zirconium-clad fuel or nitric acid for aluminum- and stainless steel-clad fuel. An electrolytic process was employed to speed the dissolution of the stainless steel. The fluoride solutions were complexed with aluminum nitrate so the follow-on processing steps could be carried out with the same equipment used for the other fuel types. At this point the solution consisted of uranyl nitrate and nitrated fission products such as cesium-137, strontium- 90 , and transuranic elements. For graphite fuel, combustion preceded dissolution. Small quantities of other nuclear fuels were custom processed in specialized on-site hot cell laboratories. 
The solution was then treated using a modified PUREX process. This process produced a uranyl nitrate solution and waste solutions. The uranyl nitrate solution was evaporated and denitrated into uranium trioxide $\left(\mathrm{UO}_{3}\right)$ granules. These granules were shipped to the Y-12 Plant at the ORR in Tennessee to be processed into new reactor fuel (Rouse et al. 1993, p. 6-13).

The highly radioactive and chemically concentrated liquid (called raffinate) was collected and transferred to the tank farm, which consists of 11 underground storage tanks, to await further treatment. Low-level liquid wastes from incidental processes were collected and concentrated in an evaporator, which is still in operation. The concentrates from this evaporator are transferred to the tank farm and the evaporator overheads are superheated, filtered, and discharged to the atmosphere through the plant stack.

From FY98 through the year 2000, baseline waste generation modeling shows that site activities will generate about $515,000 \mathrm{gal}$ of sodium-bearing waste. Operation of the calciner will generate about 92,000 gal of calcined solids. About 15,000 gal of sodium-bearing waste are added to the tanks each month from facility decontamination and decommissioning, off-gas system operation, and spent nuclear fuel storage. No HLW has been added to the tanks since reprocessing was terminated in 1992 (TFA 1996, p. A.13). There is no projected generation of HLW at INTEC in the future; the projected generation of sodium-bearing waste through 2005 is $720,000 \mathrm{gal}$. An aggressive waste minimization program has been implemented at INTEC with the goal to reduce this waste generation by at least $35 \%$.

\section{G.2.3 Calcination}

Calcination of radioactive waste began in December 1963 at the Waste Calcining Facility, which operated until March 1981; the Waste Calcining Facility was replaced by a new facility. The New Waste Calcining Facility started operation in September 1982 and is still operational. Calcination converts liquid radioactive waste to a solid using a high-temperature (about $900^{\circ} \mathrm{F}$ ) drying process. The solid produced, called calcine, is dry with the consistency of granulated laundry detergent. Calcination is done because the calcined waste occupies approximately seven times less volume, is more chemically stable, and is safer to store than the liquid waste. Thus, the approximately $1 \mathrm{Mgal}$ of calcine produced at the site represents approximately $7 \mathrm{Mgal}$ of liquid waste calcined since 1963 .

To turn the liquid waste into calcine, waste from reprocessing activities is combined with chemical additives to minimize corrosion and produce calcine with the desired physical and chemical characteristics. Then, the mixture is sprayed into a heated fluidized bed of granular solids. (A fluidized bed uses a cushion of hot gas blown through a container to float a powered material as a means of drying.) This evaporates water, nitric acid, and other volatile species and chemically transforms the waste into a dry form consisting primarily of metallic oxides. The calcine is removed from the calciner vessel and pneumatically transported to aircooled storage bins. The main constituents in the calcined waste by weight percent for zirconium-clad fuel reprocessing waste are calcium fluoride $\left(\mathrm{CaF}_{2}\right)(\sim 54 \%)$, zirconium oxide 
$\left(\mathrm{ZrO}_{2}\right)(\sim 24 \%)$, aluminum oxide $\left(\mathrm{Al}_{2} \mathrm{O}_{3}\right),(\sim 15 \%)$, calcium oxide $(\mathrm{CaO})(\sim 3 \%)$, and boron oxide $\left(\mathrm{B}_{2} \mathrm{O}_{3}\right)(\sim 3 \%)$ with less than 1 weight percent fission product oxides. The main constituents in the calcined waste by weight percent for aluminum-clad fuel reprocessing waste are aluminum oxide $\left(\mathrm{Al}_{2} \mathrm{O}_{3}\right),(\sim 94 \%)$, sodium oxide $\left(\mathrm{Na}_{2} \mathrm{O}\right)(\sim 3 \%)$, and boron oxide $\left(\mathrm{B}_{2} \mathrm{O}_{3}\right)$ $(\sim 2 \%)$ with less than 1 weight percent fission product oxides (Childs et al. 1982, p. 57). The radioactivity in calcine is primarily from cesium-137, strontium-90, and their decay products. Sodium-bearing waste cannot be readily converted to calcine because it has a high sodium and potassium content. During the calcination process, the sodium and potassium form compounds that melt and agglomerate at calcination and bin storage temperatures. Calcination of sodium-bearing waste is achieved by blending with other wastes low in sodium and potassium content or by blending with nonradioactive additives.

\section{G.2.4 Storage Tanks and Calcine Bin Sets at INEEL}

Approximately $1.4 \mathrm{Mgal}$ of radioactive liquid waste contaiming $520,000 \mathrm{Ci}$ of radioactivity are stored as acidic solutions in INTEC's 11 tanks. The amount of waste is not spread evenly among the 11 tanks. Some tanks are close to capacity while others are not. One of the tanks is empty and has been declared a spare tank. The tanks are similar in design, constructed of stainless steel, and contained in underground concrete vaults. Each tank has four to five access risers. Steam jets are used to transport waste from tanks into the process system.

Eight of the 11 tanks can be cooled using cooling coils located along the tank floors and walls. These cooled tanks were used to contain the wastes and fission products (e.g., cesium-137 and strontium-90) from the thermally hottest first- and second-cycle extraction processes. Chemical raffinate from later extraction cycles and LLW evaporator concentrates were stored in the uncooled tanks. The wastes are stored in the tanks until ready for calcination.

To date, none of these tanks has leaked waste to the surrounding environment.

The 11 tanks have two different capacities and three different vault designs:

- 9 tanks have capacities of $300,000 \mathrm{gal}$

- 2 tanks have capacities of 318,000 gal (Rouse et al. 1993).

\section{G.2.4.1 Pillar and Panel Vault Tanks}

These five 300,000-gal-capacity tanks (WM-182 to WM-186) were built with a primary stainless steel liner. These tanks are in concrete octagonal pillar and panel concrete vaults. The vaults around Tanks WM-182 to WM-184 were built in 1954 with precast concrete components including a precast T-beam roof. The vaults around Tanks WM-185 and WM-186 were modified to increase their structural strength. The tanks have 50-ft diameters, with walls $21 \mathrm{ft}$ high. Except for Tanks WM-184 and WM-186, all of the tanks are equipped with cooling coils (Rouse et al. 1993, p. 6-17). The tanks were built from 1954 to 1957 . See Figure G.4. 


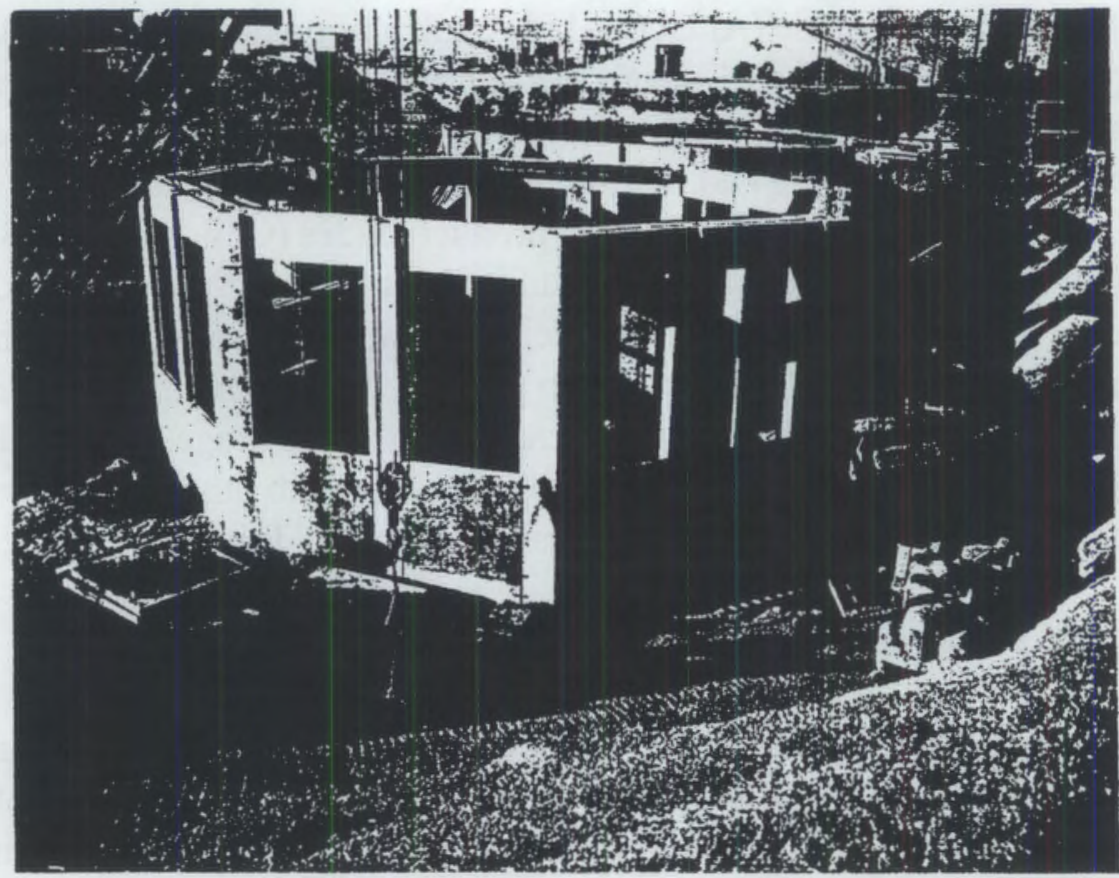

Figure G.4. Octagonal Pillar-and-Panel Vault

\section{G.2.4.2 Rectangular Vault Tanks}

These four 300,000-gal tanks (WM-187 to WM-190) were constructed with a primary stainless steel liner. They were built within rectangular, concrete cast-in-place vaults. Each vault contains two tanks and has a precast T-beam roof. The tanks have 50 -ft diameters, with walls $21 \mathrm{ft} \mathrm{high.} \mathrm{All} \mathrm{tanks} \mathrm{were} \mathrm{equipped} \mathrm{with} \mathrm{cooling} \mathrm{coils.} \mathrm{These} \mathrm{tanks} \mathrm{were} \mathrm{built} \mathrm{from}$ 1958 to 1964 (Rouse et al. 1993, p. 6-17). Tank WM-190 is empty and is maintained as a spare. See Figure G.5.

\section{G.2.4.3 Octagonal Concrete Vault Tanks}

The two 318,000-gal tanks (WM-180 and WM-181) were built with primary stainless steel liners and encased in cast-in-place octagonal concrete vaults. The tanks have 50 - $\mathrm{ft}$ diameters, with walls $23 \mathrm{ft}$ high. One of these tanks, WM-180, has cooling coils; the other does not. From 1951 to 1952, both tanks were built in the INTEC area. Tanks WM-180 and WM-181 entered service in 1954 and 1953, respectively, and are the oldest tanks on site (Rouse et al. 1993, p. 6-15, 6-16). See Figure G.6.

\section{G.2.4.4 Calcine Bin Sets}

Approximately $1 \mathrm{Mgal}$ of calcine containing $24 \mathrm{MCi}$ of radioactivity are stored in seven stainless steel bin sets enclosed in concrete vaults with walls up to $4 \mathrm{ft}$ thick. Thus, the calcine contains about $98 \%$ of the waste radioactivity at INTEC. The bin sets have a network 


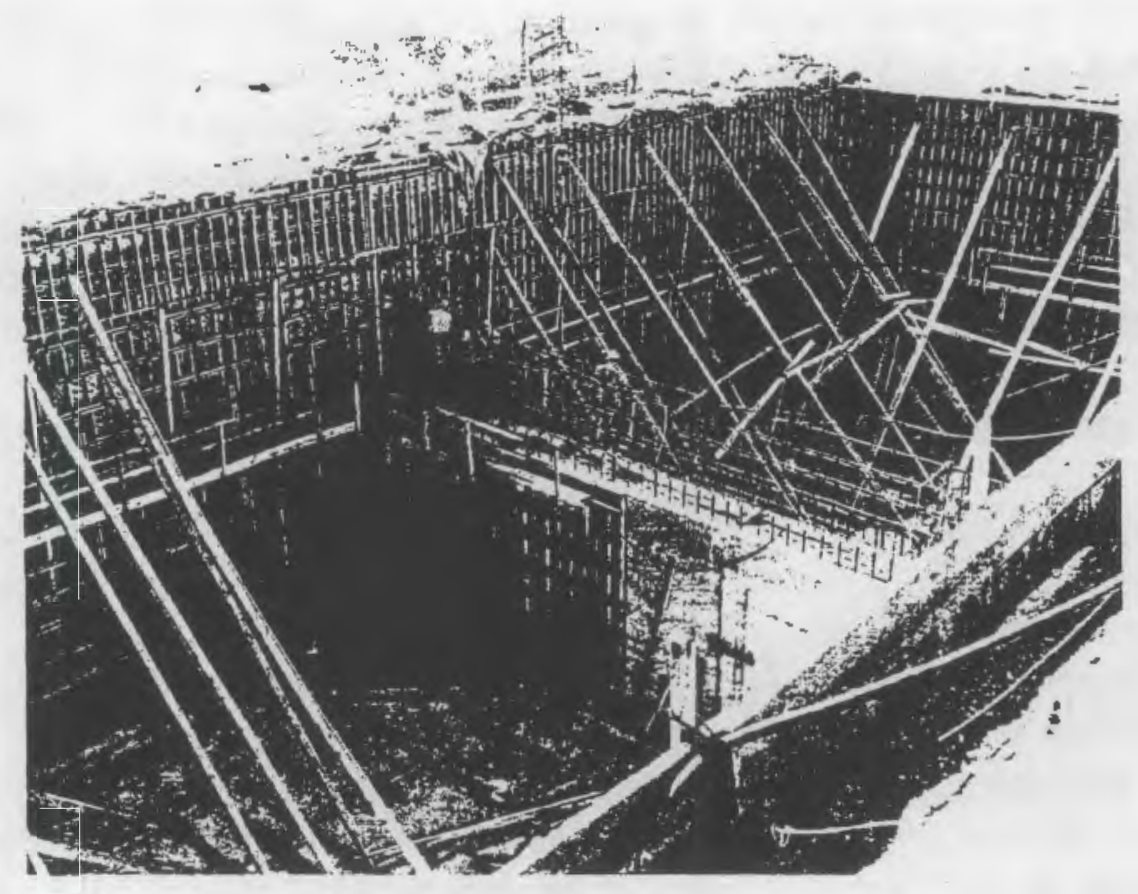

Figure G.5. Square Poured-In-Place Vault

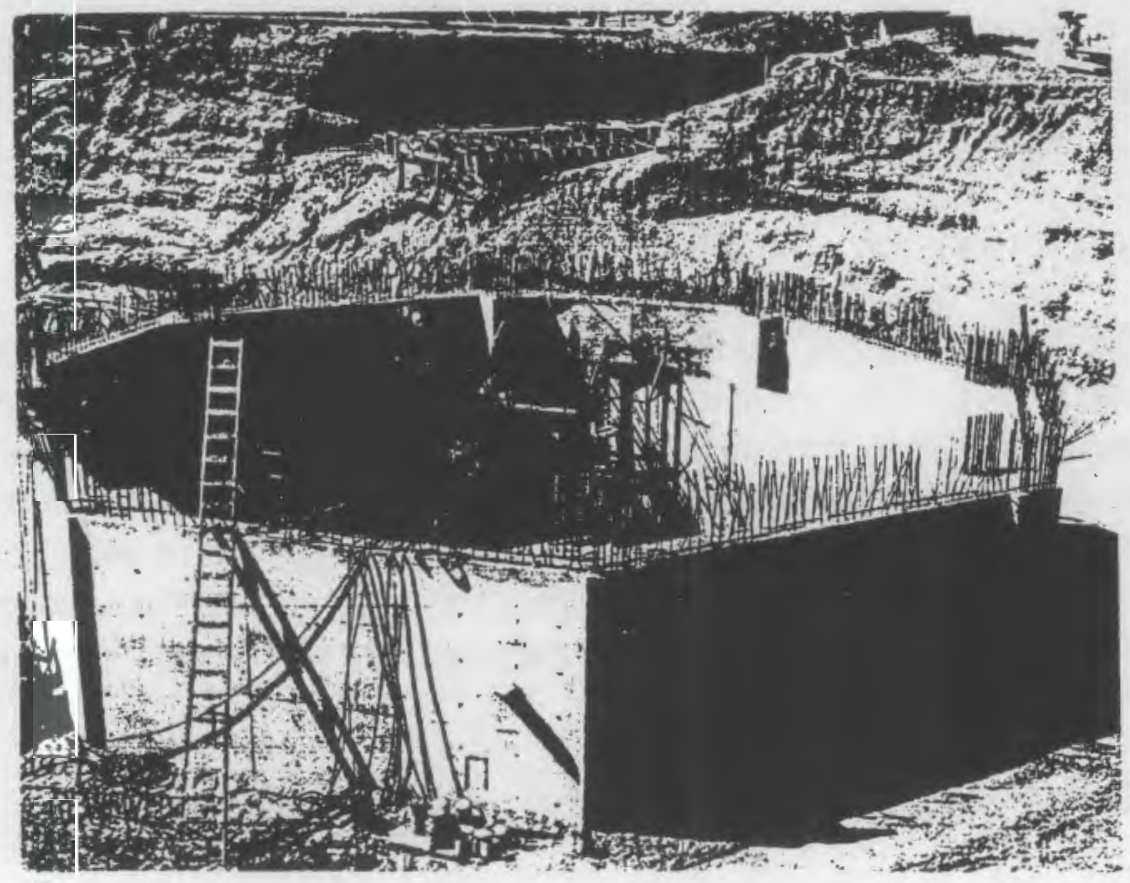

Figure G.6. Octagonal Poured-In-Place Vault 
of monitoring systems that include temperature, pressure, and radiation monitors (Rouse et al. 1993, p. 6-13 - 6-15). Five of the seven storage facilities are full, the sixth is being filled, and the seventh is empty. The bins have a life expectancy of 400 to 500 years. Radiation doses of $1,000 \mathrm{rem} / \mathrm{hr}$ have been measured in the annulus space of these bins (U.S. Congress 1991, p. 45). Calcined waste is not an acceptable form for permanent disposal because of concerns that the dry waste could be easily dispersed. Therefore, the calcined waste will be converted to an acceptable final form before disposal in a geologic repository.

\section{G.2.5 Regulatory Drivers for INEEL}

Idaho's major cleanup issues for INTEC are driven by two regulations: the Notice of Noncompliance Consent Order and the Idaho Settlement Agreement. Also, the accelerating cleanup plan plays a significant role.

- Idaho Accelerated Cleanup Plan (DOE-ID 1997). The plan describes how the site will meet certain existing cleanup agreements.

- Notice of Noncompliance Consent Order. The Consent Order, which was developed by the state, requires DOE's Idaho Operations Office to cease use of the five pillar and panel vault tanks by 2009 and to cease use of the remaining six tanks by 2015. An August 1998 modification to the Consent Order accelerated these cease use dates to 2003 and 2012 , respectively.

- Idaho Settlement Agreement (Public Service Co. of Colorado Batt). The Batt Settlement Agreement (formally known as the Settlement Agreement between the Governor of Idaho (Philip E. Batt), DOE, and the Navy) requires all high-level liquid waste to be calcined by June 1998, with the remaining sodium-bearing waste calcined by 2012. By 2009, a record of decision must be issued that establishes a date for completion of the calcine treatment. By 2035, DOE must remove all spent fuel from the site and have all the HLW road-ready for shipment and disposal at a repository.

To meet these last agreements, the following assumptions have been made. The bulk of the liquid tank waste will be retrieved and calcined, leaving liquid heels in the tanks that will be treated as part of tank closure. Calcine will then be retrieved from the bins and dissolved. After dissolution the resulting liquid will be separated into high- and low-activity fractions. High-activity waste, containing the cesium-137, strontium-90, and transuranic elements, will be vitrified for repository disposal. Low-activity waste, containing the radioactive chemicals, will be grouted and disposed. Currently, no agreements or plans have been finalized to close INTEC's tanks or calcine bins.

\section{G.2.6 Milestones for INEEL}

Selected milestones in the remediation of INEEL's radioactive waste are shown in Table G.2. 
Table G.2. Idaho National Engineering and Environmental Laboratory Milestones

\begin{tabular}{||l|c||}
\hline \multicolumn{1}{|c|}{ Milestone Title } & $\begin{array}{c}\text { Completion } \\
\text { Date }\end{array}$ \\
\hline \hline Commence negotiating a plan and schedule for calcined waste treatment & 1999 \\
\hline Commence calcination of sodium-bearing radioactive liquid waste & 2001 \\
\hline Cease use of waste tanks in pillar and panel vaults & 2003 \\
\hline Issue record of decision for calcined waste treatment & 2009 \\
\hline Complete calcination of sodium-bearing waste & 2012 \\
\hline Cease use of waste tanks contained in monolithic vaults & 2012 \\
\hline Complete treatment of all radioactive waste. Ready for offsite shipment to repository. & 2035 \\
\hline
\end{tabular}

\section{G.3 Oak Ridge Reservation}

The Oak Ridge Reservation (ORR), located $25 \mathrm{mi}$ west of Knoxville, Tennessee, was the Manhattan Project's first site for the production of nuclear material (see Figure G.7). This material included small quantities of plutonium-239 and large quantities of uranium-235. The $58-\mathrm{m}^{2}$ area was selected in September 1942 for several reasons, including abundant electric power, adequate surface water supply from the Clinch River, inexpensive land, and distance from U.S. population centers. Facility construction began in February 1943 with operations started by November of the same year.

Three of the site's major nuclear material production facilities were the $\mathrm{X}-10$ reactor, the $\mathrm{K}-25$ facility, and the Y-12 facility. The X-10 reactor, the world's first graphite-moderated reactor, was capable of producing small quantities (grams) of plutonium-239. This was an ' air-cooled reactor built between February and November of 1943 that was to have been the prototype for reactors at the Hanford Site in Washington State - the plutonium production site of the Manhattan Project. However, Hanford's reactor design was changed to a watercooled system. The K-25 facility, built between 1943 and 1946, used gaseous diffusion to separate uranium isotopes. This technology was based on the principle that when uranium is turned into uranium hexafluoride gas and passed through a porous barrier membrane, the heavier uranium-238 isotope moves more slowly than the lighter uranium-235 isotopes. Therefore, the two could be separated, and the uranium-235 isotopes collected and concentrated. In 1985, the K-25 facility was placed on standby and then shut down in 1987 . The Y-12 facility was built in 1943 and used an electromagnetic process to separate uranium isotopes by their atomic weight. Separation was accomplished using a cyclotron as a mass spectrometer to separate the desired uranium-235 isotope from the bulk of the uranium-238, which makes up naturally occurring uranium. The electromagnetic process was discontinued after World War II. 


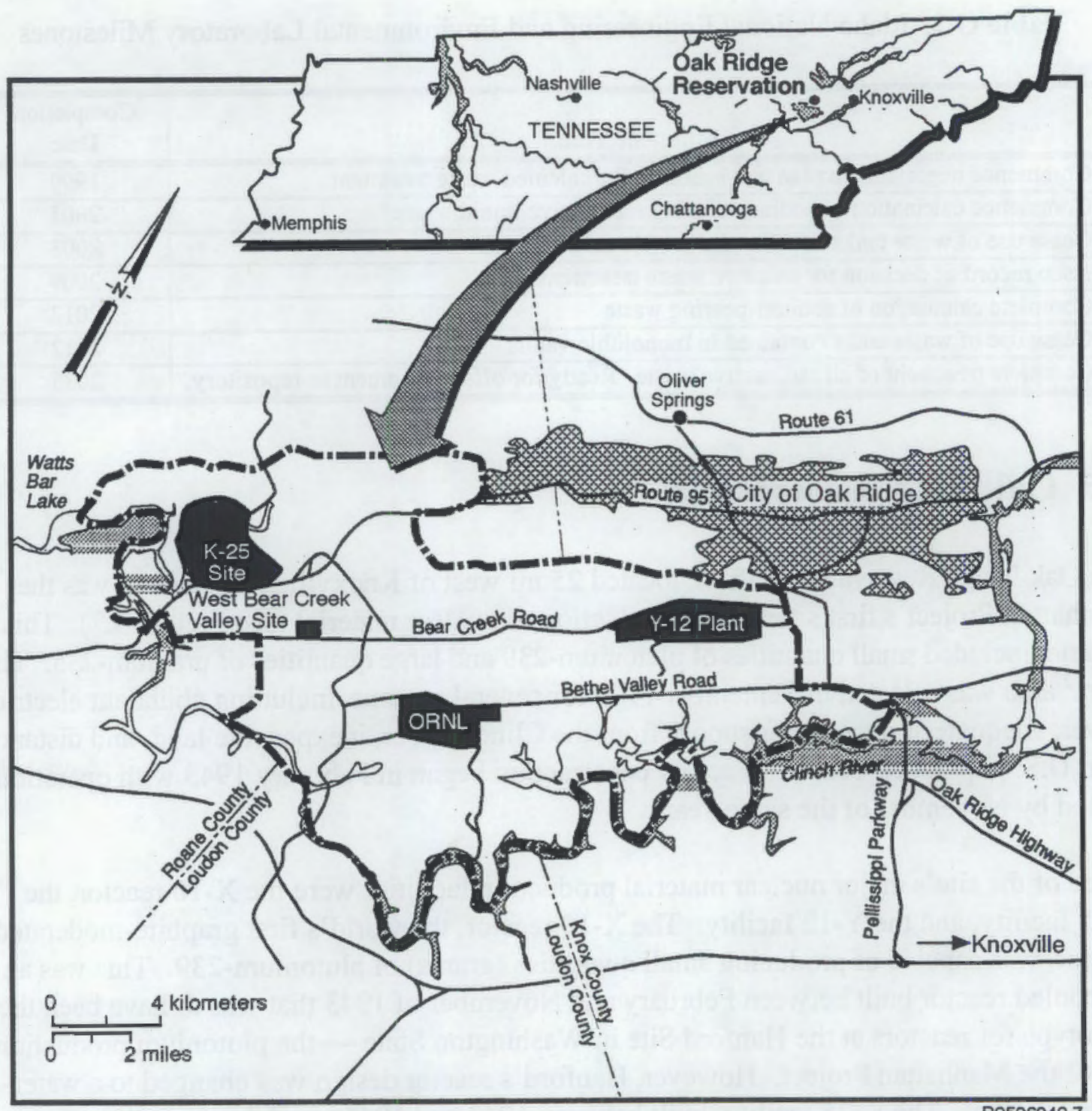

Figure G.7. Oak Ridge Reservation and Major Facilities

Over the years, X-10 site operations and research expanded. In 1948, it became known as the Oak Ridge National Laboratory (ORNL). One example of the site's expanding work is the world's first solvent extraction process (REDOX process) for chemically recovering uranium and plutonium from reprocessed spent fuel was pilot-tested at ORNL. Through 1964, the site's primary mission was to produce highly enriched uranium for nuclear weapons. From 1959 to 1969 , uranium production shifted to commercial-grade, low enrichment uranium-235 to support the nuclear power industry. The site also hosted gas centrifuge facilities that were used to develop and demonstrate uranium-enrichment technologies. These facilities have been shut down. 


\section{G.3.1 Characteristics of Oak Ridge Reservation Tank Waste}

Waste in the ORR's 34 main tanks is classified as either low-level or transuranic waste. This waste was created from several sources including reactor water cleanup, radiochemical process development and processing areas, facility decontamination, and laboratory operations.

Some ORR tank wastes have physical, chemical, and radiological characteristics similar to that of the HLW at other DOE sites, such as Hanford or SRS. Chemically, the waste is principally sodium nitrate $\left(\mathrm{NaNO}_{3}\right)$ as is the high-level tank waste generated from weapons production activities. However, because the U.S. definition of HLW is based on the waste's origin (waste from processing spent nuclear fuel is classified as HLW regardless of its radioactivity), the site's waste is not high level. Nonetheless, some of the transuranic waste in the sludge of some ORR tanks contain as much radioactivity as HLW at other DOE facilities (DOE 1996b).

In addition, because the ORR waste contains both radionuclides (e.g., cesium, strontium, plutonium, uranium, technetium, and ruthenium) and chemicals (e.g., lead, chromium, mercury, and some organic compounds), the waste is classified as mixed.

\section{G.3.1.1 Legacy Waste}

Approximately 436,000 gal of legacy waste containing $47,300 \mathrm{Ci}$ of radioactivity (mostly cesium-137 and strontium-90) exist at ORR (DOE 1996b). Ahout 87\% (381,000 gal) of this is liquid LLW. The remaining 55,000 gal is sludge containing the bulk of the transuranic radionuclides. This legacy waste is typically 10 to 100 times less radioactive than the tank waste at other DOE sites (DOE 1996h).

Legacy waste was originally acidic; it was made basic to avoid rapidly corroding the carbon steel and concrete tank containers. Sodium carbonate $\left(\mathrm{Na}_{2} \mathrm{CO}_{3}\right)$, sodium hydroxide $(\mathrm{NaOH})$, or lime $(\mathrm{CaO})$ was used to neutralize the waste. Neutralization caused the heavy metals and transuranic isotopes to precipitate, forming layers of sludge in the bottom of many of the tanks. Most of the transuranic elements and over $80 \%$ of the fission products are in the sludge (DOE 1996b). The later addition of calcium carbonate $\left(\mathrm{CaCO}_{3}\right)$ and waste evaporation enhanced the precipitation as well as sludge formation. Most of the legacy waste is in the 16 Gunite and Associated Tanks and the 5 Old Hydrofracture Tanks.

\section{G.3.1.2 Active Waste}

Waste is still being generated at ORR today. This waste is called "active waste" and results from decontamination activities and ongoing research projects. Annually, about 400,000 gal of liquid waste is generated (TFA 1996a, p. A.20). Through evaporation and other processes, this is concentrated to $15,000 \mathrm{gal}$ of waste containing $13,000 \mathrm{Ci}$ of radioactivity (DOE 1996b). Over $99 \%$ of the radioactivity (primarily cesium-137 and strontium-90) in this waste is from a single facility called the Radiochemical Engineering Development Center. This 
plant recovers a variety of radioisotopes produced by irradiation of other isotopes. The active waste is stored in thirteen 50,000-gal stainless steel tanks: the eight Melton Valley Storage Tanks and the five Bethel Valley Evaporator Service Tanks.

\section{G.3.2 Storage Tanks at Oak Ridge Reservation}

At ORR, 34 tanks hold the bulk of the site's past and current liquid waste (DOE 1996b). Most ORR tanks were constructed in the 1940s and 1950s and had a design life of 20 to 30 years. The tanks were built using a variety of materials; some were made of carbon steel, others were made of concrete reinforced with a steel frame, and still others from stainless steel. The first two building materials are characterized by susceptibility to corrosion from prolonged exposure to chemical waste. The ORR has 21 underground storage tanks that are classified as inactive and 13 large tanks classified as active. The inactive tanks are said to contain "legacy waste" from past waste generation and management practices. Because the 13 active tanks are nearly full, 6 new 100,000-gal tanks are being built (DOE 1996b). The 34 tanks are located in five tank farms.

\section{G.3.2.1 Gunite and Associated Tanks}

Radioactive and other hazardous chemical wastes have resulted from normal facility operations at ORR. To collect, neutralize, and store these wastes, 12 underground tanks were constructed of gunite (Figure G.8). Gunite is a mixture of cement, sand, and water sprayed through a nozzle over a steel reinforced framework (DOE 1996a, p. 1). Built between 1943 and 1951, these tanks were removed from service in the 1970s - as a result of their age and changes in onsite liquid waste system needs. These 12 tanks, along with 4 nearby stainless steel tanks, are known as the Gunite and Associated Tanks. The largest of the gunite tanks measures $50 \mathrm{ft}$ in diameter and $18 \mathrm{ft}$ in height (DOE 1996b). The $345,000 \mathrm{gal}$ of supernate in the 16 tanks is low-level radioactive waste while the $88,700 \mathrm{gal}$ of sludge is transuranic waste. Approximately $18,000 \mathrm{Ci}$ of radioactivity ( $75 \%$ in the waste sludge) exist in the tanks.

Four gunite and four stainless steel tanks and attached accessory equipment are in the North Tank Farm. Six gunite tanks and attached accessory equipment are in the South Tank Farm. Two separate gunite tanks also exist. Gunite and Associated Tank W-11 (a small tank reaching $8 \mathrm{ft}$ in diameter with 1,500 gal capacity) and Tank TH-4 (a larger tank with a $20 \mathrm{ft}$ diameter and a 17,900 gal capacity) are located in Bethel Valley, but outside the North and South Tank Farms.

None of the 16 Gunite and Associated Tanks are known to have leaked waste; however, groundwater has leaked into the tanks. From 1981 to 1983, most of the sludge was removed from the tanks using hydraulic sluicing and transferred to the operationally active Melton Valley Storage Tanks. Less than $1 \mathrm{ft}$ of sludge normally remains in each tank, although a few are reported to contain several feet of sludge (Falter et al. 1995, p. 2). Five of the gunite tanks contain about $99 \%$ (mostly strontium-90) of the radioactivity stored in all of the gunite 


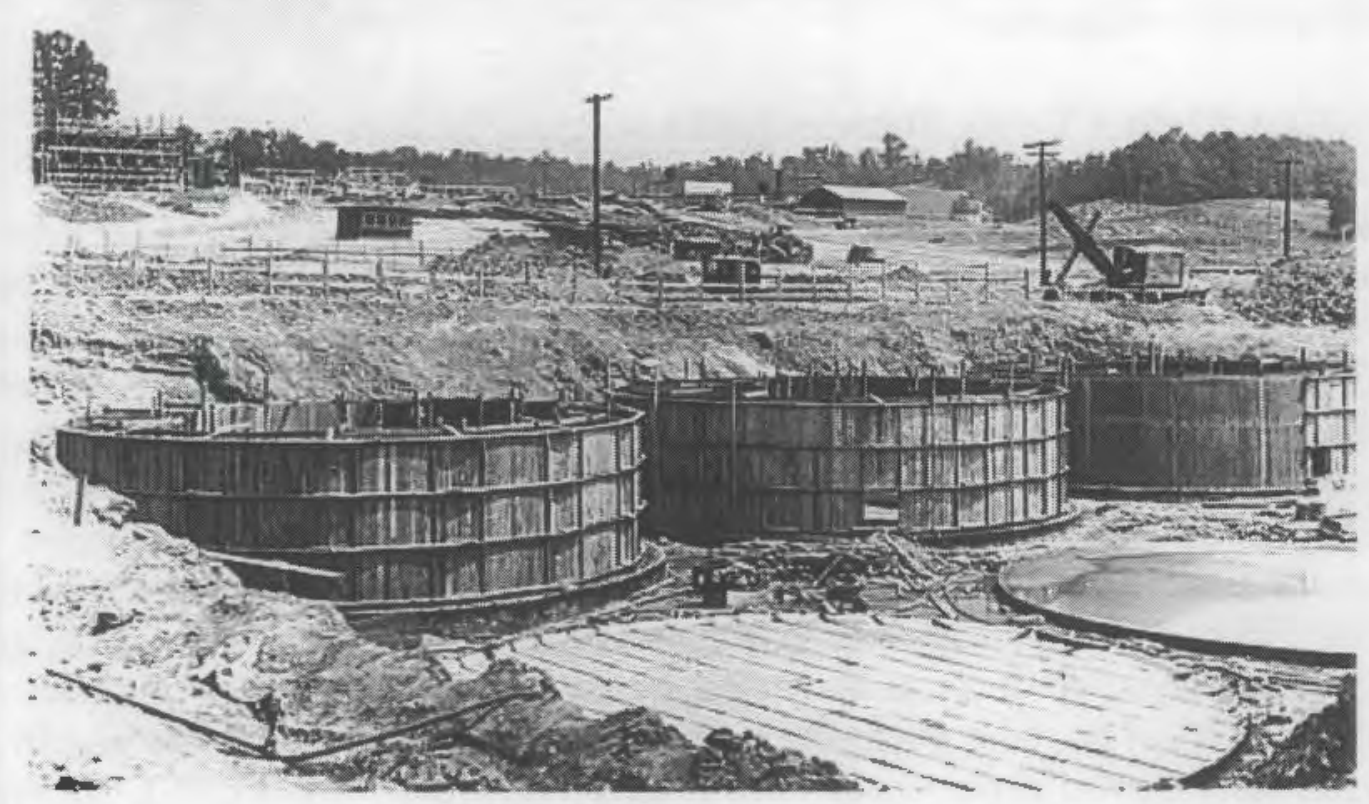

Figure G.8. Gunite Tanks Construction in 1943

tanks. Radiation levels are up to $100 \mathrm{Rad} / \mathrm{hr}$ at the waste surface (Falter et al. 1995, p. 1). In 1998 , the Gunite Tank Cleaning System was used to remove the bulk of the waste from several tanks.

\section{G.3.2.2 Old Hydrofracture Facility Tanks}

The Old Hydrofracture Facility was used from 1963 to 1980 for the subsurface disposal of radioactive waste. Intermediate-level radioactive waste was blended with cement and other additives to form a grout. This grout was injected underground into a shale layer (DOE 1996b). Within the fractures in the shale, the grout hardened into thin, horizontal sheets several hundred meters wide (DOE 1994). A "New" Hydrofracture Facility was built and was used from 1980 to 1983 . Hydrofracture disposal of waste ceased in 1984 and is no longer considered an acceptable disposal option in the United States.

The tanks that held waste to be processed and disposed of at the Old Hydrofracture Facility are made of carbon steel and contain about 42,000 gal of waste transferred from the gunite tanks. These five tanks vary in size from 13,000 to $25,000 \mathrm{gal}$. In 1997 , these tanks contained a total of 42,900 gal of liquids and 9,800 gal of sludge that was left in the tanks when the hydrofracture operations ceased. In 1998, the bulk of the waste was removed with the Borehole Miner and sent to the Melton Valley Storage Tanks.

The tank liquids contained about $800 \mathrm{Ci}$ of mostly cesium-137. The sludge contained $28,500 \mathrm{Ci}$ of strontium- 90 plus transuranics such as plutonium-238/239, americium-241, and 
uranium-233. The liquid and sludge in the Old Hydrofracture Tanks contained a variety of constituents; the liquid had mercury and chromium, and the sludge contained cadmium, chromium, lead, and mercury.

\section{G.3.2.3 Melton Valley Storage Tanks}

The eight Melton Valley Storage Tanks are cigar shaped; the tanks measure $12 \mathrm{ft}$ from floor to roof and $61.5 \mathrm{ft}$ from end to end. The tanks are contained in stainless steel vaults equipped with sumps and liquid level detectors. Each stainless steel tank has the capacity to hold $50,000 \mathrm{gal}$; as of 1997 , the tanks contained $309,000 \mathrm{gal}$ of waste and $126,500 \mathrm{Ci}$ of radioactivity. The waste is in the form of supernate and sludge. In the supernate, the major radioactive contaminants of concern are strontium-90, cesium-137, technetium-99, and ruthenium-106 (DOE 1996b, p. A.20). While the composition of the supernate varies, a typical chemical composition is a 4 to 5 molar sodium nitrate $\left(\mathrm{NaNO}_{3}\right)$ solution with large concentrations of soluble compounds such as potassium nitrate $\left(\mathrm{KNO}_{3}\right)$ and sodium chloride $(\mathrm{NaCl})$. The sludge, which contains transuranic elements, makes up $35 \%$ of the waste volume and $80 \%$ of the radioactivity in the Melton Valley Storage Tanks. Chemically, the sludge contains insoluble compounds, such as aluminum hydroxide $\left[\mathrm{Al}(\mathrm{OH})_{3}\right]$, calcium phosphate $\left[\mathrm{CaHPO}_{3}\right]$, and bentonite. The volume and composition of the waste in the Melton Valley Storage Tanks, which contain waste from current site activities, is changing as waste from other tanks is transferred to these tanks for final treatment.

\section{G.3.2.4 Bethel Valley Evaporator Service Tanks}

At the Bethel Valley Evaporator, five 50,000-gal stainless steel tanks were built in 1979 to hold waste before it was transferred into the evaporator. The cylindrical tanks are approximately $12 \mathrm{ft}$ high and $61.5 \mathrm{ft}$ long, which would cover roughly two-thirds the length of a basketball court. The tanks are filled with numerous pipes and other obstructions. As of 1997 , the tanks held about $135,000 \mathrm{gal}$ of waste: $96,000 \mathrm{gal}$ of supernate and $39,000 \mathrm{gal}$ of sludge. A total of $12,000 \mathrm{Ci}$ of radioactivity exist in these five tanks. Over the years, chemical reactions in the tanks have caused solids to precipitate.

In addition to waste destined for the evaporator, the tanks contain "evaporator bottoms." Evaporator bottoms are the residual wastes from the evaporator or, stated another way, the solids that do not evaporate. For years, the bottoms were pumped back into the tanks after each evaporator campaign and have formed a layer of sludge layer. In 1998, the sludge was removed from three tanks using the fluidic pulse jet mixer.

\section{G.3.3 Regulatory Drivers for ORR}

The regulatory drivers for remediating ORR tank wastes are as follows:

- Federal Facility Agreement for the Oak Ridge Reservation (DOE-OR et al. 1992). This is an interagency agreement between the U.S. Environmental Protection Agency, the DOE, and the Tennessee Department of Environment and Conservation. This agreement 
establishes requirements under CERCLA for the management of tanks. Per this agreement, DOE must remove all tanks from service that operate without secondary containment. Tanks with secondary containment may continue to operate.

- Tennessee Department of Environment and Conservation Commissioner's Order for ORR Site Treatment Plan. This requires that Resource Conservation and Recovery Act (RCRA) land disposal restricted waste must be treated for disposal per the agreed upon schedule.

- Oak Ridge Accelerated Cleanup Plan (DOE-OR 1997). The plan accelerates cleanup of the site by 50 years. The high funding case will treat and disposition all transuranic legacy waste by 2006 ( 2010 in the low funding case). Privatization will be an integral part of achieving clean-up goals.

\section{G.3.4 Milestones for ORR}

Selected ORR milestones are shown in Table G.3.

Table G.3. Oak Ridge Reservation Milestones

\begin{tabular}{||l|c|}
\hline \multicolumn{1}{|c|}{ Milestone Title } & $\begin{array}{c}\text { Completion } \\
\text { Date }\end{array}$ \\
\hline \hline Complete Bethel Valley Remedial Action & 2006 \\
\hline Complete White Oak Creek Remedial Action & 2006 \\
\hline Complete legacy transuranic waste treatment & 2006 \\
\hline Complete legacy mixed and low-level waste treatment & 2006 \\
\hline
\end{tabular}

\section{G.4 Savannah River Site}

Construction of the 310- $\mathrm{m}^{2}$ Savannah River Site (SRS), in South Carolina, began in 1951. The site is located approximately $12 \mathrm{mi}$ south of Aiken, South Carolina, and $13 \mathrm{mi}$ southeast of Augusta, Georgia (see Figure G.9). The site borders the Savannah River and has several streams running through it. The primary missions were to produce tritium and plutonium239 for nuclear weapons, plutonium-238 to support the space program, and special medical isotopes. At the site, 36.1 metric tons of weapons-grade plutonium were produced, roughly one-third of the total 104 metric tons produced in U.S. government reactors (Usdin 1996). The rest came from Hanford. In 1991, SRS stopped producing nuclear materials for weapons. However, the spent nuclear fuel reprocessing facilities still operate on a low-activity basis as required to supply, for example, plutonium-238 to the National Aeronautics and Space Administration for powering deep space probes. Today, the site's primary mission is to manage and clean up the nuclear wastes that resulted from its production mission. 


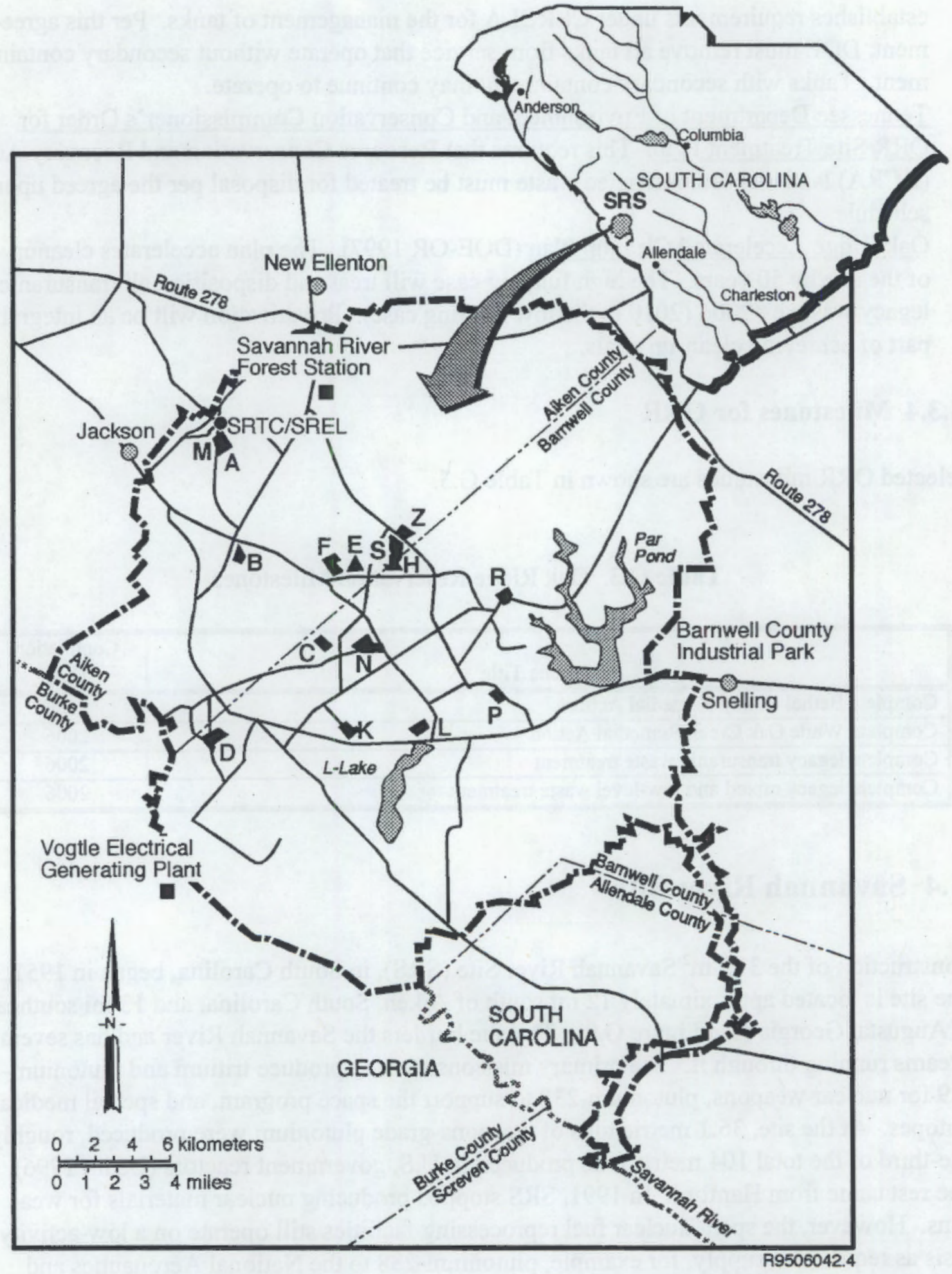

Figure G.9. Savannah River Site and Major Facilities 
Because of its nuclear production work, SRS contains numerous facilities - from office buildings to nuclear reactors. Five heavy-water-moderated reactors, which produced plutonium and tritium, and a heavy-water production plant are on the site. Two reprocessing facilities, or chemical extraction facilities, called the F Canyon and the $\mathrm{H}$ Canyon were built, along with supporting structures, to extract plutonium and uranium from irradiated nuclear fuel.

\section{G.4.1 Characteristics of Savannah River Site Tank Waste}

Soluble chemical constituents are primarily sodium salts such as sodium nitrate (49 wt\%), sodium nitrite (12 wt\%), sodium hydroxide (13wt\%), sodium-aluminum tetrahydroxide (11 wt \%), sodium sulfate ( $6 \mathrm{wt} \%$ ), and sodium carbonate ( $5 \mathrm{wt} \%)$. The chemical composition of the insoluble sludges are primarily aluminum oxide (33 wt\%), iron oxide (30 wt\%), silicon oxide (6 wt\%), sodium nitrate/nitrite salts (6 wt\%), and zeolite (4 wt\%) (WSRC 1995).

About $10 \%$ ( $3.5 \mathrm{Mgal}$ ) of the tank waste volume is sludge. The rest is supernate ( $49 \%$ or $16.5 \mathrm{Mgal})$ and saltcake ( $41 \%$ or $14 \mathrm{Mgal})$. All of the sludge and about $27 \%$ of the salt and supernate will go to the Defense Waste Processing Facility where it will be converted to glass. The remainder of the waste will go to the Effluent Treatment Facility for release into the environment after treatment or to the Saltstone Facility for conversion into grout. A discussion of the major facilities at SRS is helpful in understanding the characteristics of the wastes.

\section{G.4.2 Waste Generation at SRS}

The $\mathrm{F}$ and $\mathrm{H}$ reprocessing plants started operation in 1954 and 1955, respectively. They have not been officially shut down, as have the five Hanford reprocessing plants. Both reprocessing plants used the PUREX process and variations of that process to remove fission products from aluminum-clad spent fuel. The F Canyon reprocessed natural uranium $(99.3 \%$ by weight uranium- 238 and $0.7 \%$ uranium- 235 ) while the $\mathrm{H}$ Canyon reprocessed more enriched uranium (higher uranium-235 content). Uranyl nitrate $\left[\mathrm{UO}_{2}\left(\mathrm{NO}_{3}\right)_{2} 6 \mathrm{H}_{2} \mathrm{O}\right]$ and two forms of plutonium nitrate (uranium and plutonium in nitric acid solutions) left each canyon. Further processing was required to convert the plutonium nitrate into plutonium metal. Four evaporators (two in the $\mathrm{F}$ Area and two in the $\mathrm{H}$ Area located near the respective tank farms) were used to evaporate liquids from the tank waste into a chemically concentrated slurry. After evaporation, the slurry was returned to the tanks. In 1997, two evaporators were in operation (one each in the $\mathrm{F}$ and $\mathrm{H}$ areas). Each evaporator processes between 3 and $3.75 \mathrm{Mgal}$ of supernate per year. A new evaporator began operation in 1998. This new evaporator can process about $9.7 \mathrm{Mgal}$ of supernate per year. Some $82 \mathrm{Mgal}$ of tank waste have been generated at SRS since the $1950 \mathrm{~s}$. Evaporation has reduced this volume by $60 \%$ - to about $34 \mathrm{Mgal}$. 
Beginning in 1955 and 1957, tritium, a form of hydrogen gas, was separated and processed in the site's F and $\mathrm{H}$ areas, respectively. Tritium is released into the center of a nuclear weapon's plutonium core just before detonation. It supplies a pulse of extra neutrons for boosting the weapon's explosive power. The result is a thermonuclear explosion. Essentially all the tritium in the U.S. military arsenal was produced at SRS, which produced an estimated $500 \mathrm{lbs}$ of tritium (International Physicians 1995, p. 249).

Tritium in the nation's weapon stockpile must be replenished continually because it has a half-life of only 12.3 years. In the past, irradiated lithium-aluminum targets were processed to separate tritium from other materials; this tritium was then purified. Today, tritium is recycled from existing weapons. All DOE tritium recycling work is conducted at SRS.

\section{G.4.2.1 Defense Waste Processing Facility}

The Defense Waste Processing Facility contains the vitrification processing equipment to convert the highly radioactive sludge and saltcake precipitate into glass (see Figure G.10). These waste materials are mixed with sand-like borosilicate glass (called frit) and are sent to the plant's 65-ton steel and ceramic melter. Following 13 years (1983-1996) of construction and testing, the Defense Waste Processing Facility began processing HLW in March 1996.

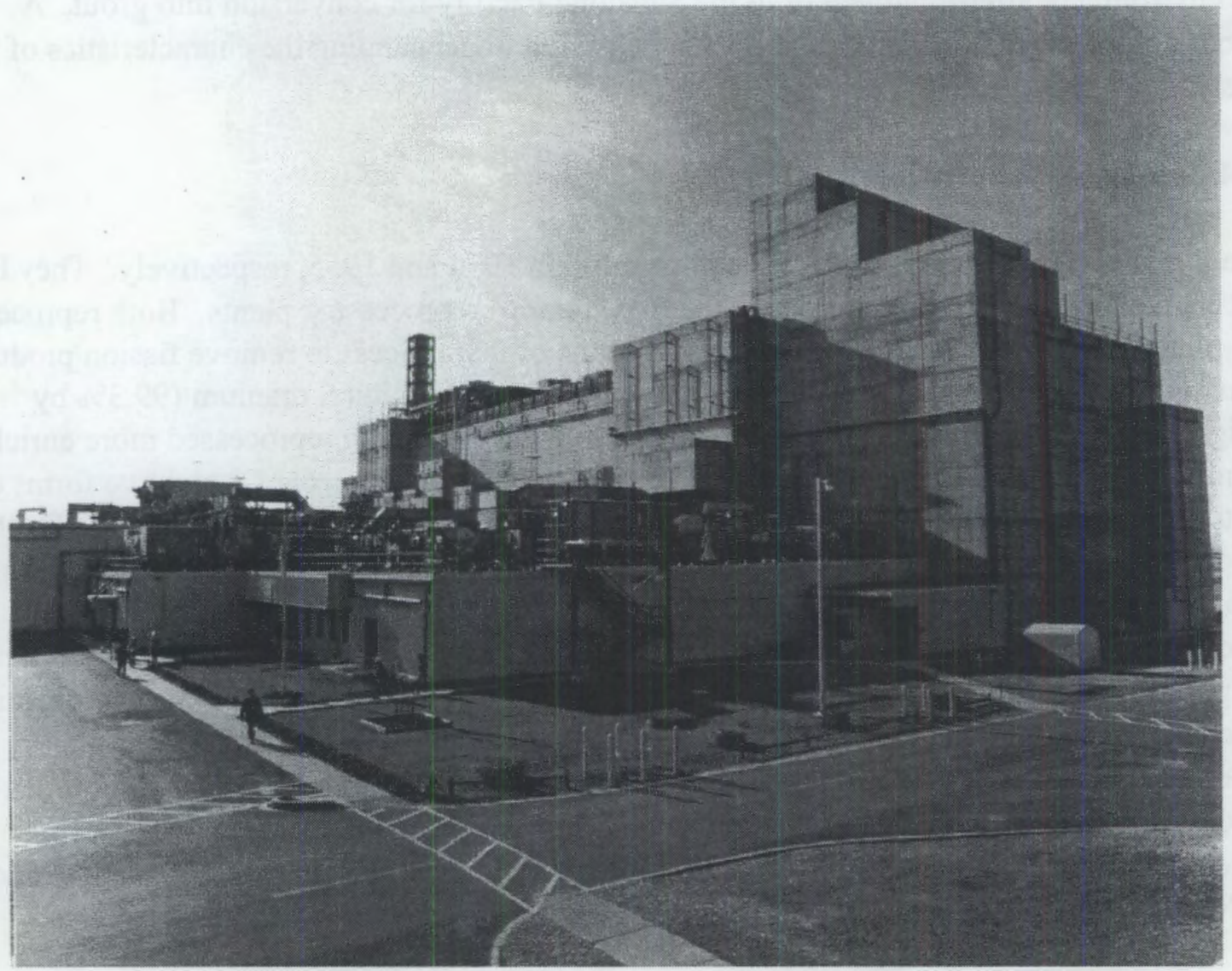

Figure G.10. Defense Waste Processing Facility 
In the melter, electricity is used to heat the waste and frit mixture to $2100^{\circ} \mathrm{F}$. At this point, the mixture is molten. The molten mixture is poured in a pencil-thin stream into a stainless steel canister to cool and harden. It takes about 24 hours to fill one canister. Each canister is $2 \mathrm{ft}$ wide by $10 \mathrm{ft}$ long and weighs about 2.5 ton when full. The exterior of each canister is blasted with frit to remove any contamination, then welded shut. The canister is then taken to a storage facility and lowered into an underground concrete vault. As of July 1998, 433 canisters of radioactive glass have been produced.

It will take approximately 25 years (until the year 2023) to vitrify all of the HLW currently in SRS's tanks. The canisters will remain onsite until a geologic repository opens.

\section{G.4.2.2 Saltstone Facility}

The Saltstone Facility has been operating since 1990, the facility processes and disposes of the chemical salt solution (which contains low levels of contamination) coming from the pretreatment of tank waste. This salt solution is blended with cement (10\%), furnace slag $(54 \%)$, and flyash (45\%). After these materials are mixed with water, the grout mixture, with a consistency resembling latex paint, is pumped to a large concrete vault to harden (or cure). Once hardened, it's called saltstone. Approximately $200 \mathrm{Mgal}$ of solidified saltstone will be produced. All of SRS's saltstone will contain less than one-hundredth of $1 \%$ (about $20,000 \mathrm{Ci}$ of mostly technetium-99) of the original tank waste radioactivity.

The soluble salts mixed with the grout are mostly sodium nitrate. These salts make up about $93 \%$ of the $34 \mathrm{Mgal}$ of HLW stored at SRS. Tank waste pretreatment separates soluble salts from the insoluble sludge to create $100-120 \mathrm{Mgal}$ of salt solution. This salt solution is then sent to the In-Tank Waste Processing Facility for further removal of any cesium and strontium. Sludge and these additionally extracted radionuclides are sent to the Defense Waste Processing Facility for vitrification.

Plans are being made to build 15 vaults, each covering about 2.7 acres. Fourteen vaults are designed with 12 cells inside, and one is designed with six cells. Each cell is $24 \mathrm{ft}$ deep, $100 \mathrm{ft}$ long, and $100 \mathrm{ft}$ wide. After filling, each vault will be capped with concrete overlain by an engineered barrier of earth, clay, and a commercially available polymer roofing material. Construction of the Saltstone Facility and the first two vaults was completed in 1988 at a cost of $\$ 45,000,000$ (1986 dollar value) (see Figure G.11.).

\section{G.4.3 Storage Tanks at Savannah River Site}

The 51 underground tanks at SRS contaim about $34 \mathrm{Mgal}$ of liquid HLW. An estimated $470 \mathrm{MCi}$ of radioactivity exist in this waste. Some $99.4 \%$ of this radioactivity is from approximately even contributions of cesium-137 and strontium-90, plus their decay products. 


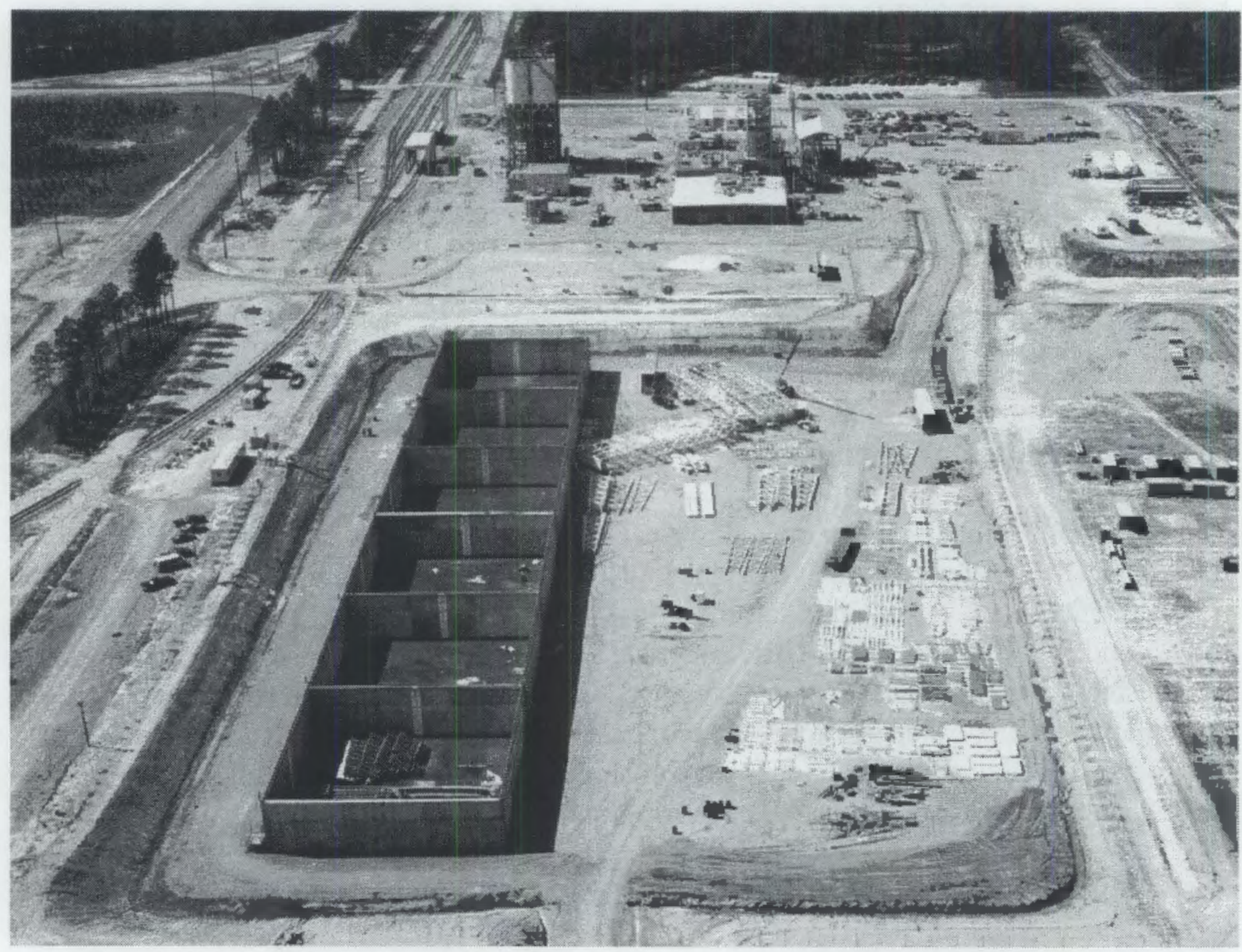

Figure G.11. Saltstone Vaults Under Construction

The tanks were built from 1951 to 1981 . They are located in the F Area ( 22 tanks) and H Area (29 tanks) tank farms. The tanks were built with three different capacities and four designs:

- 12 have capacities of $750,000 \mathrm{gal}$

- 4 have capacities of $1.03 \mathrm{Mgal}$

- 35 have capacities of $1.3 \mathrm{Mgal}$.

Depending on location, some tanks were built below ground level and others above. The 22 tanks in the $\mathrm{H}$ Area were built above the natural grade and then surrounded with mounded earth. A brick encasement with an asphalt inner liner was used in the $\mathrm{H}$ Area because the water table sometimes rises above the tank bottoms. This was done to avoid burying the tanks within the shallow groundwater. The deeper water table in the F Area allowed burying those 29 tanks so that their tops are nearly flush with the ground surface. A waterproofing material was applied to the exterior of the F Area tank concrete shells to provide additional waterproofing to the concrete. Although tank designs are labeled Types I through IV at the site, the labeling system does not denote the chronological order in which the tanks were built. 


\section{G.4.3.1 Type I Tanks}

These twelve 750,000-gal tanks were built from 1951 to 1953 in the H and F Area farms. They were placed in service in 1954 . These tanks have a $1 / 2$-in-thick primary steel liner that covers the top of the tank and a partially enclosed secondary outer carbon-steel liner called a "pan" that extends $5 \mathrm{ft}$ up the walls. The tanks have a diameter of $75 \mathrm{ft}$ and an external height of $29 \mathrm{ft}$ (this includes the thickness of an outer concrete shell). Twelve concrete columns encased in carbon steel were installed within the primary liner to support the flat concrete roof. The tanks are encased in a rectangular-shaped concrete shell and buried about $9 \mathrm{ft}$ underground. Each tank is equipped with 36 parallel cooling water coils suspended from the ceiling inside the primary liner (Rouse et al. 1993). Five of these tanks have leaked waste into the secondary steel liner. An estimated 27\% (127 MCi) of the site's tank waste radioactivity and $12 \% 4 \mathrm{Mgal}$ of the site's tank waste volume is contained in these 12 tanks.

\section{G.4.3.2 Type II Tanks}

These four 1.03-Mgal tanks were built in the H Area between 1955 and 1966. The first Type II tank was placed in service in 1956. These tanks have a primary steel liner that covers the top of the tank and a secondary carbon-steel liner ("pan") that extends $5 \mathrm{ft}$ up the walls. The tanks have a diameter of $85 \mathrm{ft}$ and an external height of about $34 \mathrm{ft}$. The primary and secondary steel liners are enclosed in concrete. A single central column is used to support a flat roof. Each tank is equipped with 44 parallel cooling water coils suspended from the roof. All four Type II tanks are known to have leaked waste. An estimated 8\% (38 MCi) of the site's tank waste radioactivity is in these tanks. About $4 \%(1.4 \mathrm{Mgal})$ of the site's tank waste volume is in these tanks.

\section{G.4.3.3 Type III Tanks}

These 27 tanks hold the majority of the waste at SRS. The tanks have a primary steel liner that covers the top of the tank and a secondary carbon-steel liner that extends part way up the tank's outer wall. These liners are enclosed in a concrete shell and covered by a flat roof. The concrete is grooved so that circulating air can flow at the outer annulus. Any waste that leaked would move along the grooves and could be detected at the outer annulus. Tank diameters are $85 \mathrm{ft}$ with an external height of $41 \mathrm{ft}$. Six of these tanks have cooling coil bundles that are suspended from the concrete roof. All 27 tanks were built in the $\mathrm{H}$ and F Areas from 1967 to 1982 with the first tank placed in operation in 1969 (Rouse et al. 1993) (see Figure G.12). Though none of these tanks are known to have leaked, there has been minor water leakage into two tanks. Most of the site's tank waste radioactivity ( $64 \%$ or $300 \mathrm{MCi}$ ) and tank waste volume ( $77 \%$ or $26.2 \mathrm{Mgal})$ is contained in these 27 tanks.

The Type III tanks still receive small amounts of HLW from the site's limited production activities. Two types of waste are being sent: high-heat waste, which contains most of the radionuclides and must be aged in a high-heat waste tank before evaporation, and low-heat waste. After the waste is put in the Type III tanks, it separates into a bottom sludge layer and 


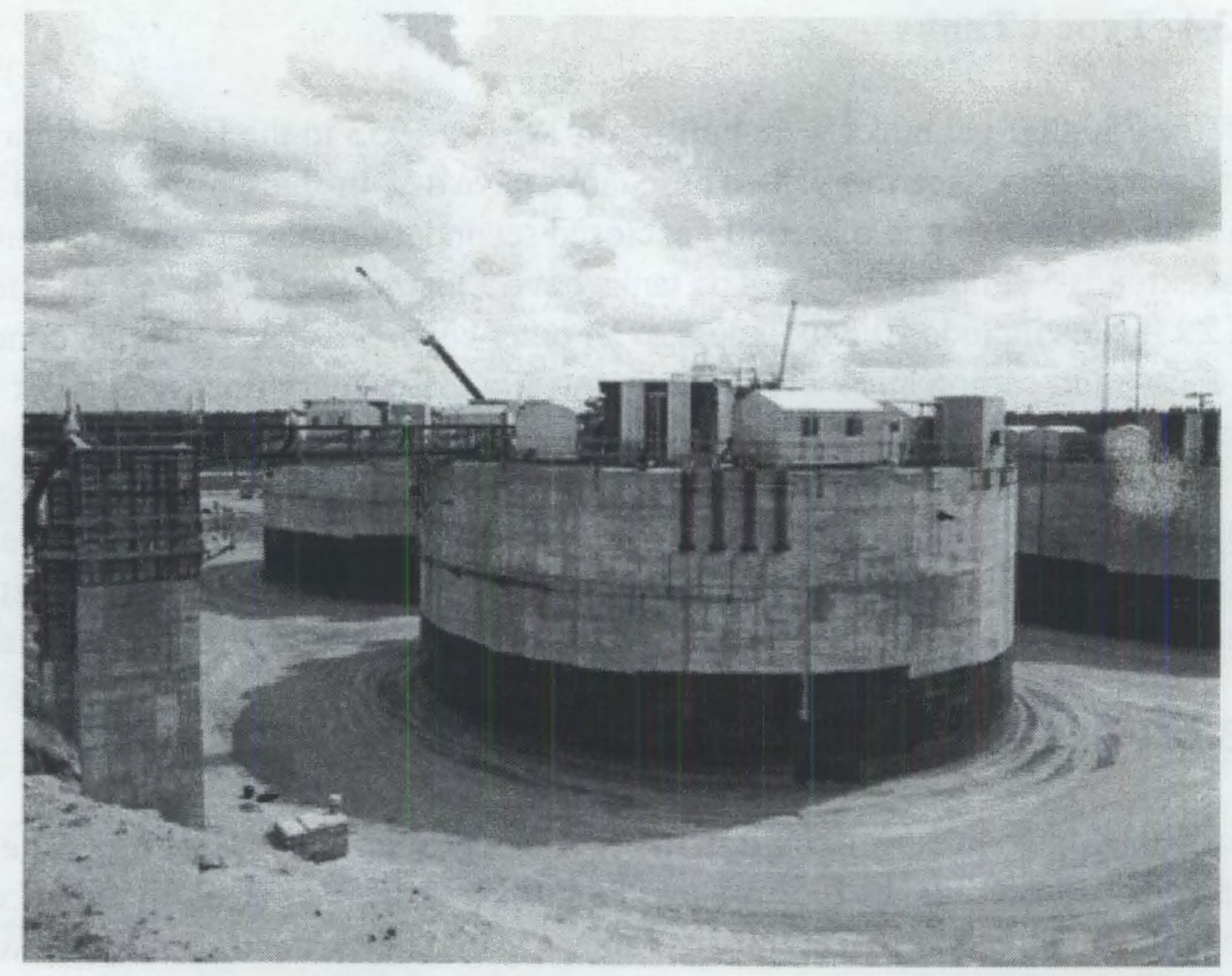

Figure G.12. Type III Tank Construction in 1980

an upper layer of salts dissolved in water (supernate and saltcake). Seven of the Type III tanks are used for waste processing or feed supply (TFA 1996a, pp. A.24, A.25).

\section{G.4.3.4 Type IV Tanks}

These eight 1.3-Mgal-capacity tanks are domed with a single carbon-steel liner. The tanks have a diameter of $85 \mathrm{ft}$ and the walls are $34 \mathrm{ft}$ high. These tanks do not contain cooling coils as do the other three designs. Four Type IV tanks were build in the F Area in 1958, and from 1959 to 1961 four additional tanks were built in the H Area. Type IV tanks were first placed into service in 1959. Less than $1 \%(<5 \mathrm{MCi})$ of the site's tank waste radioactivity and $7 \%$ (2.4 Mgal) of site's tank waste volume is contained in these tanks. Monitoring records suggest that a small amount of water has leaked into these tanks. Waste was removed from one Type IV tank because of a leak that developed in its primary steel liner.

\section{G.4.4 Regulatory Drivers for Savannah River Site}

The regulatory drivers for remediating tank wastes at SRS are as follows:

- $\quad$ Final EIS Defense Waste Processing Facility and Supplemental EIS (DOE SRS 1982; DOE-SRS 1994). The record of decision from the EIS (47 FR 23801) documents the decision to construct and operate the Defense Waste Processing Facility. Since then, DOE has prepared a supplementary EIS that addresses in-tank precipitation, saltstone 
processing and disposal, a late wash facility addition, and a number of other modifications to the Defense Waste Processing Facility. The record of decision (60 FR 18589) was issued in April 1995 to complete startup testing and begin operation of the Defense Waste Processing Facility.

- Savannah River Federal Facility Consent Agreement (EPA 1993). This is an agreement between the U.S. Environmental Protection Agency Region IV, the DOE, and the South Carolina Department of Health and Environmental Control. This agreement establishes requirements for remediation of SRS. Tanks must meet structural integrity requirements or be removed from service.

- Savannah River Waste Management EIS (DOE-SRS 1995). This sitewide EIS provides the basis to select processes to manage wastes generated from ongoing operations and the operation of the Consolidated Incineration Facility. The record of decision from this EIS (60 FR 26845) documents the decision to construct and operate the HLW evaporator and to transfer waste from the storage tanks to the Defense Waste Processing Facility when it becomes operational.

- Site Treatment Plan (WSRC 1995). The Federal Facility Compliance Act requires a site treatment plan for treating and disposing of mixed wastes. The SRS Site Treatment Plan identifies the Defense Waste Processing Facility as the preferred treatment option for treating liquid HLW.

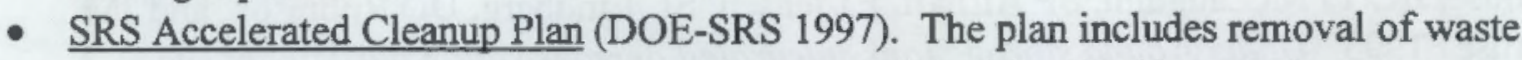
from 14 of the 24 highest risk tanks and closure of the 14 tanks (these tanks store over $111 \mathrm{MCi}$ of $\mathrm{HLW}$ ). At the end of 2006 , over $37 \%$ of the HLW in tanks will be immobilized to a safe final form.

\section{G.4.5 Milestones for Savannah River Site}

Selected SRS milestones are shown in Table G.4.

Table G.4. Savannah River Site Milestones

\begin{tabular}{||l|c|}
\hline \multicolumn{1}{|c|}{ Milestone Title } & $\begin{array}{c}\text { Completion } \\
\text { Date }\end{array}$ \\
\hline \hline Initiate DWPF Coupled Operations & 2000 \\
\hline Complete Closure of 20 Old-Style Tanks & 2006 \\
\hline Start Shipping Canisters to the Federal Repository & 2015 \\
\hline Waste Removal Complete from All Tanks & 2020 \\
\hline Complete DWPF Activities & 2022 \\
\hline Complete Saltstone Vault High-Level Waste Activities & 2024 \\
\hline Complete Shipping Canisters to the Federal Repository & 2026 \\
\hline Complete High-Level Waste Management Activities & 2026 \\
\hline
\end{tabular}




\section{G.5 References}

Childs, KF, RI Donovan, and MC Swenson. 1982. The ninth processing campaign in the Waste Calcining Facility. ENICO-1100, Exxon Nuclear Idaho Company, Idaho Falls, Idaho.

Falter, DD, SM Babcock, BL Burks, PD Lloyd, JD Randolph, JE Rutenber, and SD Van Hoesen. 1995. Remote systems for waste retrieval from the Oak Ridge National Laboratory gunite tanks. Presented at the American Nuclear Society 1995 Winter Meeting, October 29-November 2, 1995, San Francisco, California.

Gephart, RE and RE Lundgren. 1998. Hanford tank cleanup: A guide to the technical issues. Battelle Press, Columbus, Ohio, in press.

International Physicians for the Prevention of Nuclear War and the Institute for Energy and Environmental Research. 1995. Nuclear wastelands: A global guide to nuclear weapons production and its health and environmental effects, The MIT Press, Cambridge, Massachusetts.

Rouse, JK, TJ McLaughlin, SP Airhart, EJ Jensen, SL Lindberg, DD Robinson, and JM Cruse. 1993. Underground storage tank-integrated demonstration participant site characteristic summary. WHC-EP-0566, Westinghouse Hanford Company, Richland, Washington.

Tanks Focus Area (TFA). 1996. Multiyear Program Plan, FY97-FY99. PNNL-11272, Pacific Northwest National Laboratory, Richland, Washington.

U.S. Congress. 1991. Long-lived legacy: managing high-level and transuranic waste at the DOE Nuclear Weapons Complex. IOTA-BP-O-83, Office of Technology Assessment, U.S. Government Printing Office, Washington, D.C.

U.S. Department of Energy (DOE). 1994. Integrated data base (IDB) for 1993: U.S. spent fuel and radioactive waste inventories, projections, and characteristics [Internet]. Available: http://www.em.doe.gov/idb/glossary.html

U.S. Department of Energy (DOE). 1995. Estimating the Cold War mortgage: 1995 baseline environmental management report. DOE/EM-0232, Vol. I and II. National Technical Information Service, Springfield, Virginia.

U.S. Department of Energy (DOE). 1996a. Gunite and associated ranks operable unit at Waste Area Grouping 1 at Oak Ridge National Laboratory: fact sheet. U.S. Department of Energy, Oak Ridge Operations Office, Oak Ridge, Tennessee. 
U.S. Department of Energy (DOE). 1996b. Oak Ridge National Laboratory tank cleanup: A guide to understanding the issues. U.S. Department of Energy, Office of Environmental Management, Washington, D.C. December.

U.S. Department of Energy Idaho Operations Office (DOE-ID). 1997. The INEEL environmental management accelerating cleanup: focus on 2006, discussion draft. U.S. Department of Energy, Idaho Operations Office, Idaho Falls, Idaho.

U.S. Department of Energy Oak Ridge Operations Office (DOE-OR). 1997. Accelerating cleanup: focus on 2006, discussion draft. U.S. Department of Energy Oak Ridge Operations Office, Oak Ridge, Tennessee.

U.S. Department of Energy Oak Ridge Operations Office (DOE-OR), Environmental Protection Agency (EPA), and the Tennessee Department of Environmental and Conservation. 1992. Federal facility agreement for the Oak Ridge Reservation. DOE/OR-1014, U.S. Department of Energy Oak Ridge Operations Office, Oak Ridge, Tennessee.

U.S. Department of Energy Richland Operations Office (DOE-RL). 1994. Recommendation 93-5 implementation plan. DOE-RL-94-0001, U.S. Department of Energy Richland Operations Office, Richland, Washington.

U.S. Department of Energy Richland Operations Office (DOE-RL). 1996. Draft Hanford remedial action environmental impact statement and comprehensive land use plan. U.S. Department of Energy Richland Operations Office, Richland, Washington.

U.S. Department of Energy Richland Operations Office (DOE-RL). 1997. Accelerating cleanup: focus on 2006, discussion draft. U.S. Department of Energy Richland Operations Office, Richland, Washington.

U.S. Department of Energy Richland Operations Office and Washington State Department of Ecology. 1996a. Draft environmental impact statement for the Tank Waste Remediation System. U.S. Department of Energy Richland Operations Office, Richland, Washington.

U.S. Department of Energy Richland Operations Office and Washington State Department of Ecology. 1996b. Tentative agreement on Tank Waste Remediation System privatization. U.S. Department of Energy Richland Operations Office, Richland, Washington.

U.S. Department of Energy Savannah River Site Operations Office (DOE-SRS). 1982. Final environmental impact statement Defense Waste Processing Facility. DOE/EIS-0082, U.S. Department of Energy Savannah River Operations Office, Aiken, South Carolina.

U.S. Department of Energy Savannah River Site Operations Office (DOE-SRS). 1994. Final environmental impact statement - Defense Waste Processing Facility. DOE/EIS0082S, U.S. Department of Energy Savannah River Operations Office, Aiken, South Carolina. 
U.S. Department of Energy Savannah River Site Operations Office (DOE-SRS). 1995.

Savannah River Site, waste management, final environmental impact statement. DOE/EIS0217, 2 volumes, U.S. Department of Energy Savannah River Operations Office, Aiken, South Carolina.

U.S. Department of Energy Savannah River Site Operations Office (DOE-SRS). 1997. Accelerating cleanup: focus on 2006, discussion draft. U.S. Department of Energy Savannah River Operations Office, Aiken, South Carolina.

U.S. Environmental Protection Agency (EPA). 1993. Federal facility consent agreement between the U.S. Environmental Protection Agency, Region IV, the U.S. Department of Energy, and the South Carolina Department of Health and Environmental Control. Docket No. 89-05-FF, U.S. Environmental Protection Agency, Washington, D.C.

Usdin, S. 1996. "DOE lifts the plutonium veil," Nuclear Remediation Week, January 9, 1996, Vol. 3, Number 7, King Publishing Group, Washington, D.C.

Washington State Department of Ecology, U.S. Environmental Protection Agency, and U.S. Department of Energy. 1994. Hanford federal facility agreement and consent order fourth amendment. Ecology Docket No. 89-10, Rev. 3, Washington State Department of Ecology, U.S. Environmental Protection Agency, Region X, and U.S. Department of Energy Richland Operations Office, Richland, Washington.

Westinghouse Savannah River Company (WSRC). 1995. FY-96 High-level waste management technology program plan. HLW-TEC-950027, Westinghouse Savannah River Company, Aiken, South Carolina (December). 


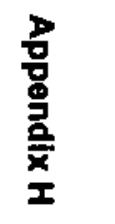




\section{Appendix H - Leveraged Programs}

This appendix summarizes in tabular form (Table H.1) the TFA's known or expected support from other U.S. Department of Energy Office of Science and Technology development prorams for FY99 and FY00. Program management support costs are not considered.

Table H.1. TFA Leveraged Program Content $(\$ \times 1,000)$

\begin{tabular}{|c|c|c|c|}
\hline $\begin{array}{c}\text { TFA } \\
\text { Response \# }\end{array}$ & Project Name & $\begin{array}{c}\text { FY99 } \\
\text { Funding }\end{array}$ & $\begin{array}{c}\text { FY00 } \\
\text { Funding }\end{array}$ \\
\hline \multicolumn{4}{|c|}{ CROSSCUTTING PROGRAMS } \\
\hline \multicolumn{4}{|c|}{ Characterization, Monitoring, and Sensor Technology (CMST) Crosscutting Program } \\
\hline 98004 & Raman pOH Sensor (EIC) & 120 & 400 \\
\hline 98009 & Nested At-Tank Analysis System & 500 & 150 \\
\hline 98010 & Waste Form Product Acceptance Testing & 0 & 400 \\
\hline 98023 & Sludge Washing Monitors & 469 & 350 \\
\hline 98045 & Pipeline Slurry Monitors & 50 & 0 \\
\hline 98055 & Fluid Level and Density Monitor (SEA) & 197 & 250 \\
\hline $98067 \mathrm{~A}$ & Tank Inspection Techniques & 0 & 300 \\
\hline TOTALS & & 1336 & 1850 \\
\hline \multicolumn{4}{|c|}{ Efficient Separations and Processing (ESP) Crosscutting Program } \\
\hline 98008 & Salt Splitting of Radioactive Wastes & 0 & 300 \\
\hline 98035 & Russian Support & 230 & 250 \\
\hline 98035 & Integrated Pilot Testing of TRU Removal Flowsheet & 100 & 250 \\
\hline 98035 & Spheroidal Inorganic Sorbents & 50 & 400 \\
\hline 98035 & Russian Liaison & 50 & 50 \\
\hline 98057 & Fission Product Solvent Extraction & 275 & 550 \\
\hline 98058 & Advanced Chemical Separations at SRS & 420 & 633 \\
\hline TOTALS & & 1125 & 2433 \\
\hline \multicolumn{4}{|c|}{ Robotics Crosscutting Program } \\
\hline$\overline{98009}$ & Nested At-Tank Analysis System (Automation Analysis) & 150 & $\overline{150}$ \\
\hline 98021 & Valve Box/Pump Pit Decontamination & 600 & 1000 \\
\hline 98045 & Compact Processing Unit & 350 & 0 \\
\hline $98050 \mathrm{~B}$ & Scarab & 150 & 0 \\
\hline $98050 \mathrm{~B}$ & Houdini II & 100 & $\overline{0}$ \\
\hline \multirow[t]{2}{*}{98053} & Heel Floor Cleaning & 300 & 600 \\
\hline & Tarzan & 150 & 0 \\
\hline TOTALS & & 1800 & 1750 \\
\hline
\end{tabular}


Table H.1. (contd)

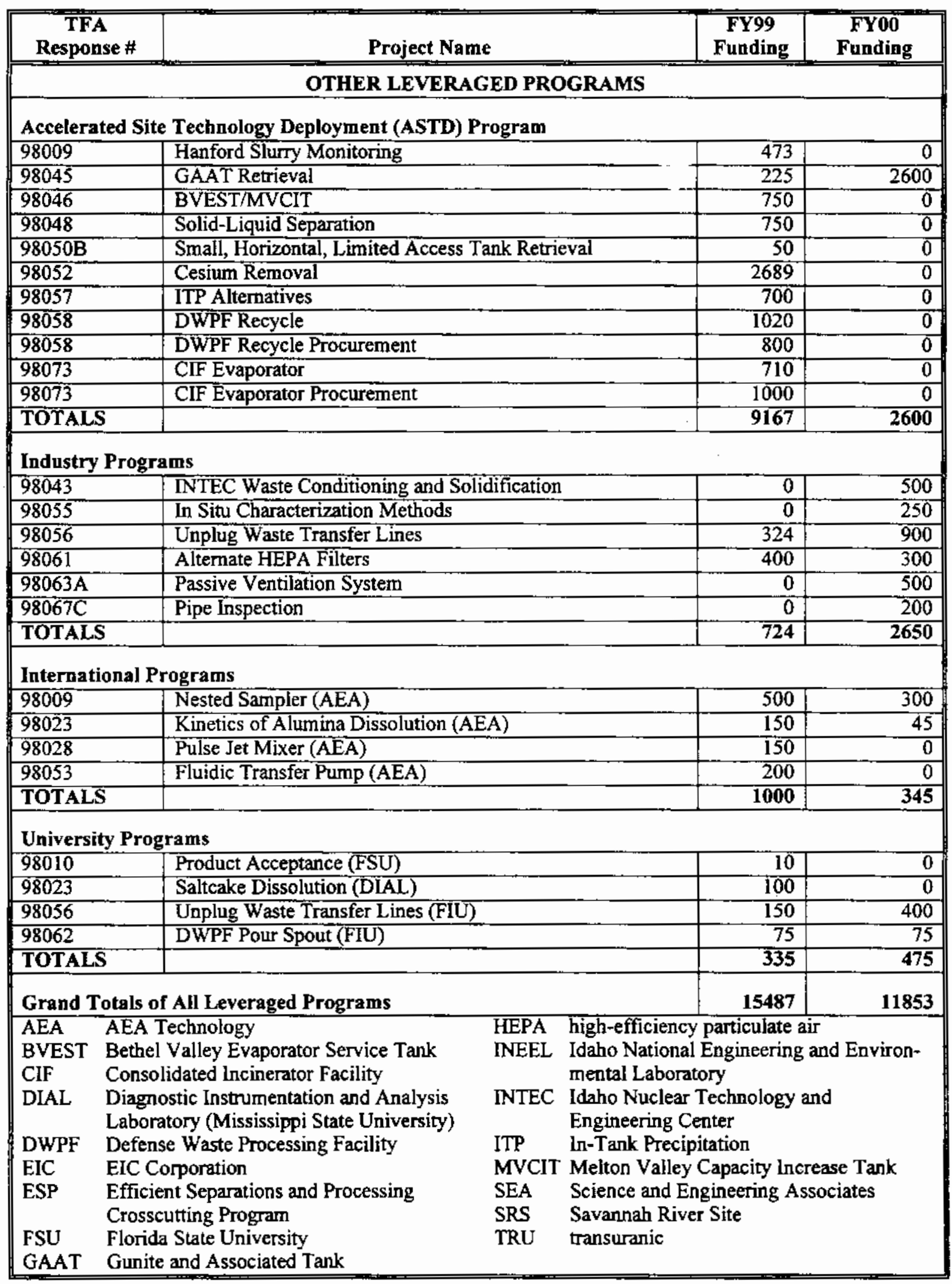


At publication of this multiyear program plan, Environmental Management Science Program (EMSP) research grants for initial funding in FY99 have not been announced. The U.S. Department of Energy (DOE) awarded 66 EMSP research grants in FY97. Twenty-three of them relate primarily to the Tanks Focus Area. These are listed below:

- Chemical Speciation of Inorganic Compounds Under Hydrothermal Conditions University of Washington

- Development of Advanced Electrochemical Emission Spectroscopy for Monitoring Corrosion in Simulated DOE Liquid Waste - Pennsylvania State University

- Dynamic Effects of Tank Waste Aging on Radionuclide-Complexant Interactions - Los Alamos National Laboratory

- Foaming in Radioactive Waste Treatment and Immobilization Processes - Illinois Institute of Technology

- Fundamental Chemistry, Characterization, and Separation of Technetium Complexes in Hanford Waste - Los Alamos National Laboratory

- High Temperature Condensed Phase Mass Spectrometric Analysis - Idaho National Engineering and Environmental Laboratory

- Ion-Exchange Processes and Mechanisms in Glasses - Pacific Northwest National Laboratory

- Mechanics of Bubbles in Sludges and Slurries - Pacific Northwest National Laboratory

- Mechanism of Pitting Corrosion Prevention by Nitrite in Carbon Steel Exposed to Dilute Salt Solutions - Westinghouse Savannah River Company

- Mineral Surface Processes Responsible for the Decreased Retardation (or Enhanced Mobilization) of ${ }^{137} \mathrm{Cs}$ from HLW Tank Discharges - Pacific Northwest National Laboratory

- New Silicotitanate Waste Forms: Development and Characterization - Pacific Northwest National Laboratory

- Optically-Based Array Sensors for Selective In Situ Analysis of Tank Waste - Oak Ridge National Laboratory

- Particle Generation by Laser Ablation in Support of Chemical Analysis of High Level Mixed Waste from Plutonium Production Operations - Washington State University

- Phase Chemistry of Tank Sludge Residual Components - Sandia National Laboratories

- Potential-Modulated Intercalation of Alkali Cations into Metal Hexacyanoferrate Coated Electrodes - University of Washington

- Radiation Effects on Transport and Bubble Formation in Silicate Glasses - Argonne National Laboratory

- Reactivity of Peroxynitrite: Implications for Hanford Waste Management and Remediation - Brookhaven National Laboratory

- Removal of Technetium, Carbon Tetrachloride, and Metals from DOE Properties Pennsylvania State University

- Research Program to Investigate the Fundamental Chemistry of Technetium - Lawrence Berkeley Laboratory

- Stability of High-Level Waste Forms - Oak Ridge National Laboratory

- Synthesis and Characterization of Templated Ion Exchange Resins for the Selective Complexation of Actinide Ions - Johns Hopkins University Applied Physics Laboratory 
- The Influence of Radiation and Multivalent Cation Additions on Phase Separation and Crystallization of Glass - University of Arizona

- Thermospray Mass Spectrometry Ionization Processes Fundamental Mechanisms for Speciation and Characterization of Organic Complexants in DOE Wastes - Oak Ridge National Laboratory

The following 30 TFA-related tasks were approved by DOE in FY96:

- Acid-Base Behavior in Hydrothermal Processing of Wastes - University of Texas at Austin

- Acoustic Probe for Solid-Gas-Liquid Suspensions - Syracuse University

- Analysis of Surface Leaching Processes in Vitrified High-Level Nuclear Wastes Using In-Situ Raman Imaging and Atomistic Modeling - University of Florida

- Architectural Design Criteria for F-Block Metal Ion Sequestering Agents - Pacific Northwest National Laboratory

- Chemical Decomposition of High-Level Nuclear Waste Storage/Disposal Glasses Under Irradiation - Naval Research Laboratory

- Chemical Speciation of Strontium, Americium, and Curium in High Level Waste: Predictive Modeling of Phase Partitioning During Tank Processing - Pacific Northwest National Laboratory

- Collodial Agglomerates in Tank Sludge: Impact on Waste Processing - Pacific Northwest National Laboratory

- Design and Development of a New Hybrid Spectroelectrochemical Sensor - University of Cincinnati

- Design and Synthesis of the Next Generation of Crown Ethers for Waste Separations: An Inter-Laboratory Comprehensive Proposal - Oak Ridge National Laboratory

- Determination of Transmutation Effects in Crystalline Waste Forms - Argonne National Laboratory (two tasks)

- Enhanced Sludge Processing of HLW: Hydrothermal Oxidation of Chromium, Technetium, and Complexants by Nitrate - Los Alamos National Laboratory

- f-Element Ion Chelation in Highly Basic Media - University of New Mexico

- High Fluence Neutron Source for Nondestructive Characterization of Nuclear Waste Los Alamos National Laboratory

- Ionizing Radiation Induced Catalysis on Metal Oxide Particles - Pacific Northwest National Laboratory

- Imaging and Characterizing the Waste Materials Inside an Underground Storage Tank Using Seismic Normal Modes - Massachusetts Institute of Technology

- Improved Analytical Characterization of Solid Waste-Forms by Fundamental Development of Laser Ablation Technology - Lawrence Livermore National Laboratory

- Interfacial Radiolysis Effects in Tank Waste Speciation - Pacific Northwest National Laboratory

- Investigation of Microscopic Radiation Damage in Waste Forms Using ODNMR and AEM Techniques - Argonne National Laboratory 
- Investigation of Novel Electrode Materials for Electrochemically-Based Remediation of High-and Low-Level Mixed Wastes in the DOE Complex - Califomia Institute of Technology

- Microstructural Properties of High Level Waste Concentrates and Gels with Raman and Infrared Spectroscopies - Los Alamos National Laboratory

- Mixing Processes in High-Level Waste Tanks - University of California at Berkeley

- On-Line Slurry Viscosity and Concentration Measurement as a Real-Time Waste Stream Characterization Tool - University of California at Davis

- Polyoxometalates for Radioactive Waste Treatment - Georgetown University

- Processing of High Level Waste: Spectroscopic Characterization of Redox Reactions in Supercritical Water - Furman University

- Quantifying Silica Reactivity in Subsurface Environments: Controls of Reaction Affinity and Solute Matrix on Quartz and $\mathrm{SiO}_{2}$ Glass Dissolution Kinetics - Georgia Institute of Technology

- Radiation Effects in Nuclear Waste Materials - Pacific Northwest National Laboratory

- Radiation Effects on Materials in the Near-Field of Nuclear Waste Repository University of New Mexico

- Studies Related to Chemical Mechanisms of Gas Formation in Hanford High-Level Nuclear Wastes - Georgia Institute of Technology

- Superconducting Open-Gradient Magnetic Separation for the Pretreatment of Radioactive or Mixed Waste Vitrification Feeds - Argonne National Laboratory

- The NOx System in Nuclear Waste - Argonne National Laboratory 



\section{Distribution}

No. of

Copies

\section{OFFSITE}

2 Office of Scientific and

Technical Information

J. Bell

Bell Consultants, Inc.

137 Bowsprit Lane

Kingston, TN 37763

L. D. Bustard

Sandia National Laboratories

P.O. Box 5800, MS: 0734

Albuquerque, NM 87185-5800

J. Carberry

DuPont

Experimental Station

Building 249/119

P.O. Box 80249

Wilmington, DE 19880-0249

G. A. Choppin

Chemistry Department

Florida State University

$600 \mathrm{~W}$. College Ave

Tallahasee, FL 32306-3006

P. G. Eller

Los Alamos National Laboratory

NMT-6 Advanced Technology Group

MS: E5-10

Nuclear Material Technology Division

Los Alamos, NM 87544

R. C. Erdmann

P.O. Box 922

Grass Valley, CA 95945
No. of

Copies

1 D. W. Geiser, EM-50

U.S. Department of Energy

19901 Germantown Road

Germantown, MD 20874-1298

J. A. Gentilucci

JAG Technical Services, Inc.

127 Savannah Drive

Aiken, SC 29803

12 K. D. Gerdes

U.S. Department of Energy

Office of Science and Technology

19901 Gemantown Rd.

11861 Cloverleaf Bldg.

Germantown, MD 20874-1290

T. S. Gutmann

U.S. Department of Energy

Savannah River Operations Office

P.O. Box A

Aiken, SC 29802

T. J. Hirons

Los Alamos DOE-FP

Los Alamos National Laboratory

P.O. Box 1663 MS J591

Los Alamos, NM 87545

E. W. Holtzscheiter

Westinghouse Savannah River Company

Savannah River Technology Center

Aiken, SC 29802

A. M. Jensen

Lockheed Martin Idaho Technologies

Company

P.O. Box 1625

Idaho Falls, ID 83415-5219

Distr. 1 
No. of

Copies

D. S. Kaback

Colorado Center for Environmental Management

999 18th St, Ste 2750

Denver, CO 80202

B. R. Kowalski

Chemistry Department, BG-10

University of Washington

Seattle, WA 98195

B. Lewis

Westinghouse Savannah River Company

Building 703-8C, Room 7

P.O. Box 616

Aiken, SC 29802

P. W. Lurk, EM-542

U.S. Department of Energy

19901 Germantown Road

Germantown, MD 20874-1298

C. P. McGinnis

Oak Ridge National Laboratory

P.O. Box 2008

Oak Ridge, TN 37821-6273

C. S. Mims

U.S. Department of Energy

Oak Ridge Operations Office

P.O. Box 2001

Oak Ridge, TN $37830-8620$

J. P. Morin

Westinghouse Savannah River Company

P.O. Box 616

Aiken, SC 29802

J. R. Noble-Dial

U.S. Department of Energy

Oak Ridge Operations Office

P.O. Box 2001

Oak Ridge, TN $37830-8620$
No. of

Copies

K. G. Picha

U.S. Department of Energy EM-32

Office of Eastern Operations

19901 Germantown Road

343/TREV

Germantown, MD 20874-1290

W. Prindle

1556 Crestline Drive

Santa Barbara, CA 93105

S. M. Robinson

Oak Ridge National Laboratory

P.O. Box 2088, MS: 6044

Oak Ridge, TN 37831-6044

W. W. Schulz

5314 Arbustos Court, NE

Albuquerque, NM 87111

L. E. Shephard

Sandia National Laboratories

P.O. Box 30307

N. Las Vegas, NV 89036-0307

J. L. Swanson

1318 Cottonwood

Richland, WA 99352

L. L. Talvarides

Syracuse University

334 Hinds Hall

Syracuse, NY 13244

T. R. Thomas

Lockheed Martin Idaho Technologies

Company

P.O. Box 1625 MSIN 3458

Idaho Falls, ID 83415-3423

M. C. Thompson

Westinghouse Savannah River Company

Building 773-A, C140

P.O. Box 616

Aiken, SC 29802 
PNNL-1 1938

UC -600

No of

Copies

J. H. Valentine

Lockheed Martin Idaho

Technologies Company

P.O. Box 1625

Idaho Falls, ID 83415-3100

G. Vandegrift

Argonne National Laboratory

Building 205

9700 South Cass Avenue

Argonne, IL 60439

T. E. Weber

6622 West Victoria

Kennewick, WA 99336

T. D. Welch

Oak Ridge National Laboratory

P.O. Box 2008, MS: 6273

Oak Ridge, TN 37831-6273

M. Winokur

Waste Policy Institute

12850 Middlebrook Road

Suite 250

Germantown, MD 20874

P. E. Woodall

U.S. Department of Energy

Idaho Operations Office

750 Doe Place, MS: 1145

Idaho Falls, ID 83402

\section{ONSITE}

\section{DOE-RL}
R. F. Brich
M. J. Glasper
C. S. Louie
L. S. Mamiya
B. M. Mauss

No of

Copies

Los Alamos National Laboratory

M. T. Terry

K9-91

Lockheed Martin Hanford Corporation

J. O. Honeyman

G3-21

Numatec Hanford Corporation

P. W. Gibbons

H5-61

Waste Policy Institute

P. A. Hummer

K8-50

35 Pacific Northwest National Laboratory

J. F. Adams

K9-26

R. W. Allen

K9-69

T. M. Brouns

K9-08

J. L. Buelt

P7-41

B. A. Carteret

K9-91

S. H. Chin

K1-39

R. M. Ecker

K6-91

R. L. Gilchrist

K9-91

M. S. Hanson

K9-02

S. W. Heaberlin

K8-31

W. L. Kuhn

K8-93

R. E. Lundgren

K9-69

K. L. Manke

K9-69

T. L. Page

K9-18

R. K. Quinn

K9-69

S. N. Schlahta

K9-69

P. A. Scott

K9-46

T. L. Stewart

K9-69

W. C. Weimer

P7-27

J. H. Westsik

K9-91

S. J. Widener

K9-77

TFA Library (8)

K9-69

Information Release Office (5)

K1-06 
